\title{
Tracking and treating COPD in primary care : an integrated approach to diagnosis and therapy
}

Citation for published version (APA):

Chavannes, N. H. (2005). Tracking and treating COPD in primary care : an integrated approach to diagnosis and therapy. [Doctoral Thesis, Maastricht University]. Universitaire Pers Maastricht. https://doi.org/10.26481/dis.20051206nc

Document status and date:

Published: 01/01/2005

DOI:

10.26481/dis.20051206nc

Document Version:

Publisher's PDF, also known as Version of record

\section{Please check the document version of this publication:}

- A submitted manuscript is the version of the article upon submission and before peer-review. There can be important differences between the submitted version and the official published version of record. People interested in the research are advised to contact the author for the final version of the publication, or visit the DOI to the publisher's website.

- The final author version and the galley proof are versions of the publication after peer review.

- The final published version features the final layout of the paper including the volume, issue and page numbers.

Link to publication

\footnotetext{
General rights rights.

- You may freely distribute the URL identifying the publication in the public portal. please follow below link for the End User Agreement:

www.umlib.nl/taverne-license

Take down policy

If you believe that this document breaches copyright please contact us at:

repository@maastrichtuniversity.nl

providing details and we will investigate your claim.
}

Copyright and moral rights for the publications made accessible in the public portal are retained by the authors and/or other copyright owners and it is a condition of accessing publications that users recognise and abide by the legal requirements associated with these

- Users may download and print one copy of any publication from the public portal for the purpose of private study or research.

- You may not further distribute the material or use it for any profit-making activity or commercial gain

If the publication is distributed under the terms of Article $25 \mathrm{fa}$ of the Dutch Copyright Act, indicated by the "Taverne" license above, 
TRACKING AND TREATING COPD IN PRIMARY CARE:

AN INTEGRATED APPROACH TO DIAGNOSIS AND THERAPY 
The studies presented in this thesis were performed at the Care and Public Health Research Institute (CAPHRI), which participates in the Netherlands School of Primary Care Research (CaRe), accredited in 1995 by the Royal Netherlands Academy of Arrs and Sciences (K NAw).

The COOPT Study is a joint project of the Departments of General Practice of Maastricht University and the University Medical Centre Nijmegen St. Radboud, The Netherlands.

The studies contained within this thesis have financially been enabled by grants from the Dutch Asthma Foundation and the Durch Council of Health Insurances. Medication for the COOPT Study was supplied by GlaxoSmithKline and Zambon. Health Center Zuiderkroon Rotterdam, Zilveren Kruis Achmea, Dutch Asthma Foundation, Maastricht University, Boehringer Ingelheim/Pfizer, Zambon and GlaxoSmithKline financially supported publication of this thesis.

ISAN 9052784868

(1) Copyright Niels Chavannes, Rotterdam

All rights reserved. No part of this book may be reproduced or ransmitued, in any form or by any means, without written permission from the author.

Designed and typeser by Saskia van Rheeden

Cover and illustrations by Miriam Reeders

Printed by Datawyse/Universitaire Pers Maastricht 
TRACKING AND TREATING COPD IN PRIMARY CARE:

AN INTEGRATED APPROACH TO DIAGNOSIS AND THERAPY

Een wetenchappelijke proewe op bet gebied wan de

Medische Wetenschappen

\section{PROEFSCHRIFT}

Ter werkrijging van de graad van doctor aan de Universiteit Maastricht, op gezag van de Rector Magnificus Prof.mr. G.P.M.F. Mols, volgens her besluit van her College van Decanen, in het openbaar te verdedigen op

dinsdag 6 december 2005 om $12.00 \mathrm{mur}$

door

Niels Henrik Chavannes

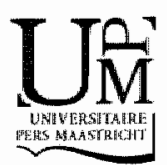




\section{Promotores}

Prof. Dr. C.P. $\operatorname{van}$ Schayck

Prof. Dr. E.F.M. Wouters

\section{Co-promotor}

Dr. J.W.M. Muris

\section{Beoordelingscommissie}

Prof. dr. G.J. Dinant (voorzitter)

Prof. dr. M. Decramer (Universiteits Hospitaal Leuven, Belgie)

Prof. dr. J.F.M. Mersemakers

Prof. dr. J.A. Wedzicha (St. Bartholomews Hospital, London, U K)

Dr. G.J. Wesseling 
Fortitudo in dualitate 
TA BL OF CONTENTS

Preface 9

Chapter I Introduction 16

Chapter 2 Impact of spirometry on GPs' diagnostic differentiation and decision-making 26

Chapter 3 The necessity for spirometry versus peak expiratory flow in the primary care management of COPD: a pro-con sertes 40

Chapter 4 Patterns of inflammation and the use of reversibility testing in smokers with airway complaints 60

Chapters Predictive value and utility of oral steroid testing for treament of COPD in primary care: The coop $\mathrm{T}$ Study 74

Chapter 6 Associations of depressive symptoms with gender, body-mass index and dyspnea in primary care CopD-patients 86

Chapter 7 Effects of physical activity in mild to moderate COPD:

a systematic review 96

Chapter 8 Randomised, double blind, placebo controlled trial of $N$-acerylcysreine and Auticasone propionate in general practice patients with chronic bronchiris or chronic obstructive pulmonary disease (COPD):

The coopt Study uro

Chapter 9 Clinical and demographic determinants of response to $\mathrm{N}$-acetylcysteine and fluticasone propionate in primary care COPD: "The COOPT Suldy 138

Chapter ro General Discussion 154

Summary 175

Samenvatring 185

Dankwoord 197

Publications 203

About the author 207 


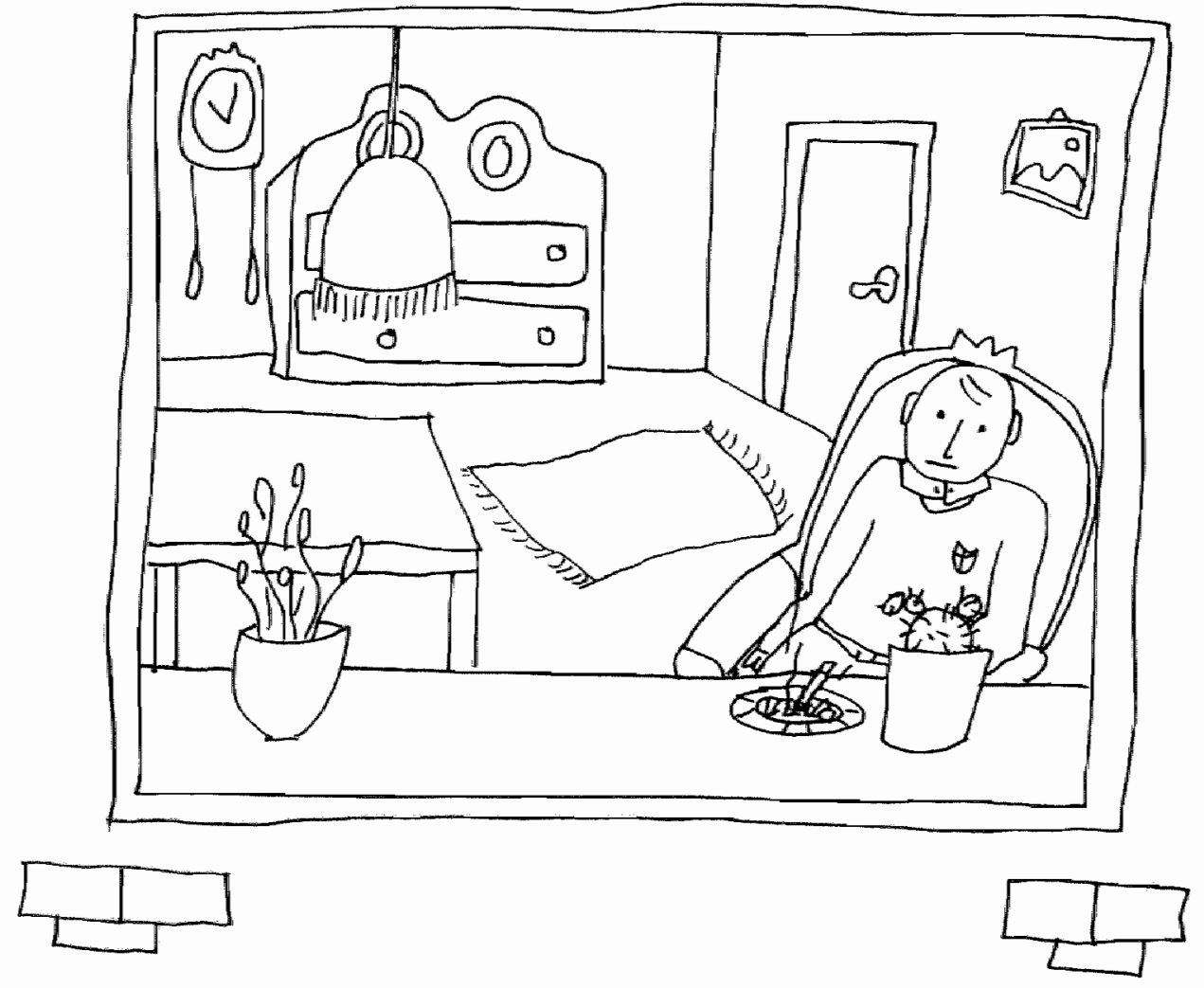


Preface 
Recognising COPD has been a challenge for clinicians and researchers for many years, but also for parients themselves. In parcicular, the slowly progressive narure of COPD appears to lead to diminished awareness of signs of disease. For instance, a smokers' cough each morning or worsening exercise tolerance in daily activities are both perceived as normal phenomena, accepted during the accumulating years of gradual deterioration. As a result, patients remain unknown to their general practitioner (GP). In addition, the subjects who do present with respiratory problems and have a reduced lung function are not always recognised. In addition, therapies aimed at reducing the progressive loss of lung function, traditionally regarded as its most prominent clinical feature, disappointingly seem not to fulfil expectations. As a consequence, many clinicians found themselves in a relatively helpless situation when confronted with this disease ${ }^{2}$. The current state of diagnosis and treatment of COPD in primary care now seems to be shifting away from this somewhat passive attitude towards an active, more integrated approach. This is an important psychological change, since being aware of the huge problem of the growing prevalence of COPD will probably lead to more effective solutions than shying away from it. This active approach has led to the integration of new insights, summarised in Chapter I: Introduction, based on Integrated Disease Management of COPD in Primary Care, a secrion of the ATS/ERS Standards for Diagnosis and Therapy of Patients with COPD3. For the first time, the organisation of COPD care outside the hospital has been part of a major international guideline. The key aspects of disease management in COPD are described, providing a framework for further talloring to local circumstances. These continuously updated Standards are freely accessible at: www.thoracic.org/COPD or www.ersnet.org/guiclelines.

The first part of this thesis deals with diagnostic considerations in COPD care: after identifying potential patients through practice records screening or case-finding strategies, the GP is supposed to be able to use the right tools to establish a specific diagnosis. This entails the proper use of spirometry and it's sometimes difficult interpretation in primary care, including the role of bronchodilator reversibility, the possibility of a diagnostic prednisolone test and looking further than lung function, by carefully assessing complaints, wellbeing, risk factors and life-style factors of individual COPD-patients. 
Confidence in one's own abilities is then needed however and in which respect this holds true for the interpretation of spirometric measurements in primary care is investigated in Chapter 2: Impact of spirometry on GPS diagnosric differentation and decision-making. How able are GPs actually in recognising spirometric patterns, and how may this influence their clinical behaviour? Which categories of respiratory disease can reliably be diagnosed in primary care?

The international discussion on the role of spirometry in primary care has been lively in the past few years, between pulmonary physicians and $\mathrm{GP}^{4}{ }^{4}$, but also between supporters of peak expiratory flow measurement versus those in favour of spirometry. This is touched upon in a pro-con series, presented in Chapter 3: The necessity for spirometry versus peak expiratory flow in the primary care management of $\mathrm{COPD}^{6-9}$. It is argued that a complete flow-volume loop is an important diagnostic element in the diagnosis of COPD, since incipient obstruction is primarily localised in the small airways and does not markedly affect the peak expiratory flow rate.

Besides spirometry $y_{n}$ clinicians establish diagnosis by careful history taking and considering risk factors. There has been some uncertainty on how well this clinical practice correlates with underlying inflammatory patterns, which have been shown to cause different respiratory diseases ${ }^{\text {to }}$. Especially when risk factors like smoking are present, the differential diagnosis can be broad, and this situation is explored in Chapter 4: Patterns of inflammation and the use of reversibility testing in smokers with airway complaints ${ }^{11}{ }_{n}$ In what respecr do clinical diagnoses correlate with sputum inflammatory patterns of primary care patients with respiratory complaints? Which inflammatory markers are linked to clinical disease caregories in primary care, and what is the role of measuring bronchodilator reversibility?

After initial spirometry, many clinicians perform an oral steroid test to optimise lung function, but also to assess the response in $\mathrm{FEV}$, before and after two weeks of oral prednisolone. According to several international guidelines this test is supposed to predict treatment response to inhaled steroids, but the literature is still inconclusive on the utility of this test in primary care ${ }^{\mathrm{i} 2}$. This long-standing issue is therefore investigated in Chapter 5: Predictive value and utility of oral steroid testing for trearment of COPD in primary care: the COOP'T Study ${ }^{13}$. Does the oral prednisolone-test distinguish long-term responders on inhaled corticosteroids from non-responders? What long-term outcomes are related to a response and which (inter) national guidelines predict best?

In past years, increasing attention has been paid to the occurrence of depressive symptoms in COP D-patients, but most reports have focussed on severe COPD. In primary care, with its' wide range of mild to moderately 
severe patients, it is still unknown what factors may be connected to depressive symproms in COPD-patients. In Chapter 6: Associations of depressive symptoms with gender, body-mass index and dyspnea in primary care COPD-patients ${ }^{34}$ it is explored whether depressive symptoms in mild to moderate COPD are related to clinical or demographic chatacteristics, and which risk factors can be distinguished in primary care.

The second part of this thesis deals with the utility of some common therapeutic options: the use of inhaled corricosteroids and oral anti-oxidants, but also the role of reactivation in primary care COPD-pacients. Medical interventions may only be successful in sharply defined groups within the COPD-population, which provides furcher rationale for employing careful diagnostic procedures. While medical treatment is usually prescribed first, a non-medical intervention such as reacrivation deserves more emphasis, since it may cause a relatively swift and noticeable effect for patienrs, which in turn can act as a crowbat for compliance with further intervencions such as smoking cessation. For which clinical outcomes evidence is available for reacrivation of COPD patients, is investigated in Chapter 7 : Effects of physical activity in mild to moderare COPD: a systematic review ${ }^{15}$. In what respect has reactivation of COPD-patients been proven to be efficacious in primary care?

High-dose inhaled steroids have been shown to affect health status and exacerbations to a certain degree in severe $C O P D$, while oral anti-oxidants like $N$-acetylcysteine seem to cause similar effects on the short term. It is therefore worthwhile to investigate these two agents head-to-head versus placebo in a double-dummy, double blind, randomised clinical trial with three year's follow-up in primary care COPD-patients. The results of this trial are reported in Chapter 8: Randomised, double blind, placebo controlled trial of $\mathrm{N}$-acetylcysteine and futicasone propionate in general practice patients with chronic bronchitis or chronic obstructive pulmonary disease (COPD) ${ }^{16}$. In this study the long-term clinical effectiveness of inhaled fluticasone versus oral $N$-acetylcysteine in mild to moderate COPD is assessed in terms of exacerbations, health status and lung function.

Since COPD in practice represents a wide group of mild to moderately severe obstructed patients with quite differing degrees of disease burden and clinical characteristics, it is clinically relevant to explore the determinants related to treatment response in the three-year primary care trial mentioned above. The results are reported in Chapter 9: Clinical and Demographic determinants of response to $N$-acetylcysteine versus futicasone in mild to moderate COPD in primary care ${ }^{17}$. What are the factors that derermine treatment success or failure? Is it possible to identify subgroups in the heterogeneous primary care population that determine clinicall outcomes? 
In Chapter 10: General Discussion, a picture is drawn of the implications for diagnosis and treatment of COPD in primary care, based on the thesis chapters and following publications ${ }^{18-21}$. It is also artempted to give a broader view on epidemiological shifts, as described earlier ${ }^{2}$, since COPD is rapidly transforming into a global threat in the developing world as well, which deserves targeted strategies tailored to local circumstances ${ }^{22}$.

\section{References}

1 Schayck van CP. Chavannes $\mathrm{NH}$. Detection of asthma and COPD in primary care. Eur Rexp/2003: $39: 16 s-22 s$.

2 Chavannes NH, Schayrtk van CP. Developments in the treatment of chronic obstrucrive pulmonary discase (COp D): The clinica picture. Curp Opir Ynvest Drag zooo: (1) (1): $75-78$

3 ATS/ERS TASK FORCE REPORT: BR Cell, W MacNee, A Agusti, A Anzueto, B Berg, AS Buist PMA Calverley, N Chavannes, T Dillard, B Fahy, A Fein, I Heffuer, 5 Larcau, P Meck, F Martinew, W McNicholas, J Muris, E Austegard, R Pauwels, SRennard, A Rossi, NSiafakas, B Iliep, J Vestbo, E Wouters, and R ZuWallack. Standards for the diagno:sis and treatment of pattents with COFD: a summary of the ATS/ERS position paper. Exr Respir / 2004; 23:932-946.

* Schermer TRJ, Jacobs A; Chavannes MH; Hartman J; Folgering H; Botrema B; van Weel C. Validity of spirometry in a general practice popularion of parients with chronic obstructive pulmonaty disease (COPD). Thonax 2003:58:861-866.

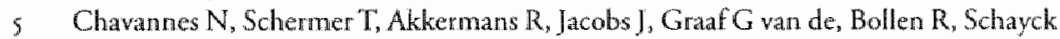
$O$ wan Botrama B. Impact of spiromerry on GPs diagnostic differeratiation and decision-making, Resp Med 2004: 98: 1124-1130.

6 Chavannes $\mathbb{N}$. The necessity for spirometry in the primary care management of COPD. Prim Care Resp / 2004; 13: II-14.

7 White P. Reply to: The necessity for spirometry in the primary care management of COPD. Prim Care Resp J 2004; 13: 15-16.

8 White P. Spiromerty and peak axpinatory flow in the primary care namagement of COPD Prim Care Resp/2004; $13 \% 5.8$.

9 Chavanes N. Reply to: Spirometry and peak explatory flow in the primary care management of COPD by Patrick White. Prim Cart Resp / 2004 ; 1 ; $9-10$.

10 Vernooy IH, Kucukayan M, Jacobs $/ A$, Chavannes NH, Bumman WA, Dentener MA, Wouters EF Local and Systemic Inftammation in Patients with Chronic Obstructive Pulmonary Disease: Soluble Tumor Necrosis Factor Receptors Are Increased in Sputum. Am/Respir Crir Cark Med 2002;166: 1218-1224.

II Chavannes $\mathrm{NH}_{n}$ JH Venooy, TRJ Schermer, JA Jacobs, M Dentener, C van Weel, CP wan Schayck. EFM Wouters. Paterns of inflammation and the he of reversibility resting in smokers with airway complaints. The COOPT sputarm induction study. Eut Rep/2003; 22: 69s.

12 Chavannes $N$, Schermer TRJ, on behalf of the coO "r Study Group. Long-term inhaled steroid response testing should be done in theterogeneous cop D-popultation llet[rir]. Thom 2003: $58: 647$. 
13. Chawanes NH, Schermer TRJ, Woukers EFM, Akkermans R, Dekhuijwen R, Muris JWM, van Weel C, wan Schayck CP. Predicrive value and utility of oral steroid testing for treatment of COPD in primary care: The COOP'T Study. Presented at ERS zoos.

I4 Chavannes $N$ H, MJH Huibers, IRJ Schermer, A Hendriks, C van Weel, EFM Wouters, CP van Schayck. Associations of depressive symptoms with gender, body mass-index and dyspnea in primary care Cop Dupatients. Fom Poractice 2005; July 15 Adwance Access.

15 Chavannes NH, Vollenberg JJH, Schayek van CP, Wourers EFM. Effects of physical activicy in mild to moderate COPD: a systematic newiew. $B r f$ Gen Prac 2002; 52:574578 .

16 Schemer TRJ, Chavannes NH, Dekhuijzen R, Wouters EFM, Muris JWM, Akkermans $\mathrm{R}$, van Schayck $\mathrm{CP}$, van Weel C. Randomised, double blind, placebo controlled trial of $\mathrm{N}$-acerylcysteine and Auticasone propionate in general practice parients with chronic bronchitis or chronic obstructive pulmonary disease (COPD). Presented at ERS 2005.

17 Chavannes NH, Schermer TRU, Wonters EFM, Folgering H, Akkermans R, Muris JWM, van Weel $\mathrm{C}_{\text {, van }} \mathrm{Schayck}$ CP. Demographic and dinieal determinants of response to $N$-acerylcysteine and Auticasone propionate in mild to moderate $C O P D$ in primary care: The COOPT Study. Presented at ERS zoos.

18 Chavannes NH. A palliarive approach for COPD and heart failure? Eum J Pald Cow 2001; $8(6): 225-227$.

19 Adams R, Chavannes N, Jones K. Qstergaard MS, Price D. Exacerbations of chronic obstructive pulmonary disease - A parienrs" perspective. Ear Resp J 2003; 22: 69s.

2o Huibers MJH, Chavannes NH, Wagena EJ, Schayck van CP. Antidepressancs for smoking cessation: â promising new approach? Eut Resp / 2000; 16:379-380.

21 Chavannes N. Pulse oximetry and respiratory disease in primary care. Prim Core Resp. I $2003 ; 12(1): 2-3$.

22 Hamers RL, Bontemps ST, Akker M van den, Souza RG, Penaforte JC, Chavannes NH. Diagnostic achievement and case finding of chronic obstructive pulmonary disease in Brazilian primary care. Trop Med Int Heath zoos; $10(2)$ : A5. 
Chapter I

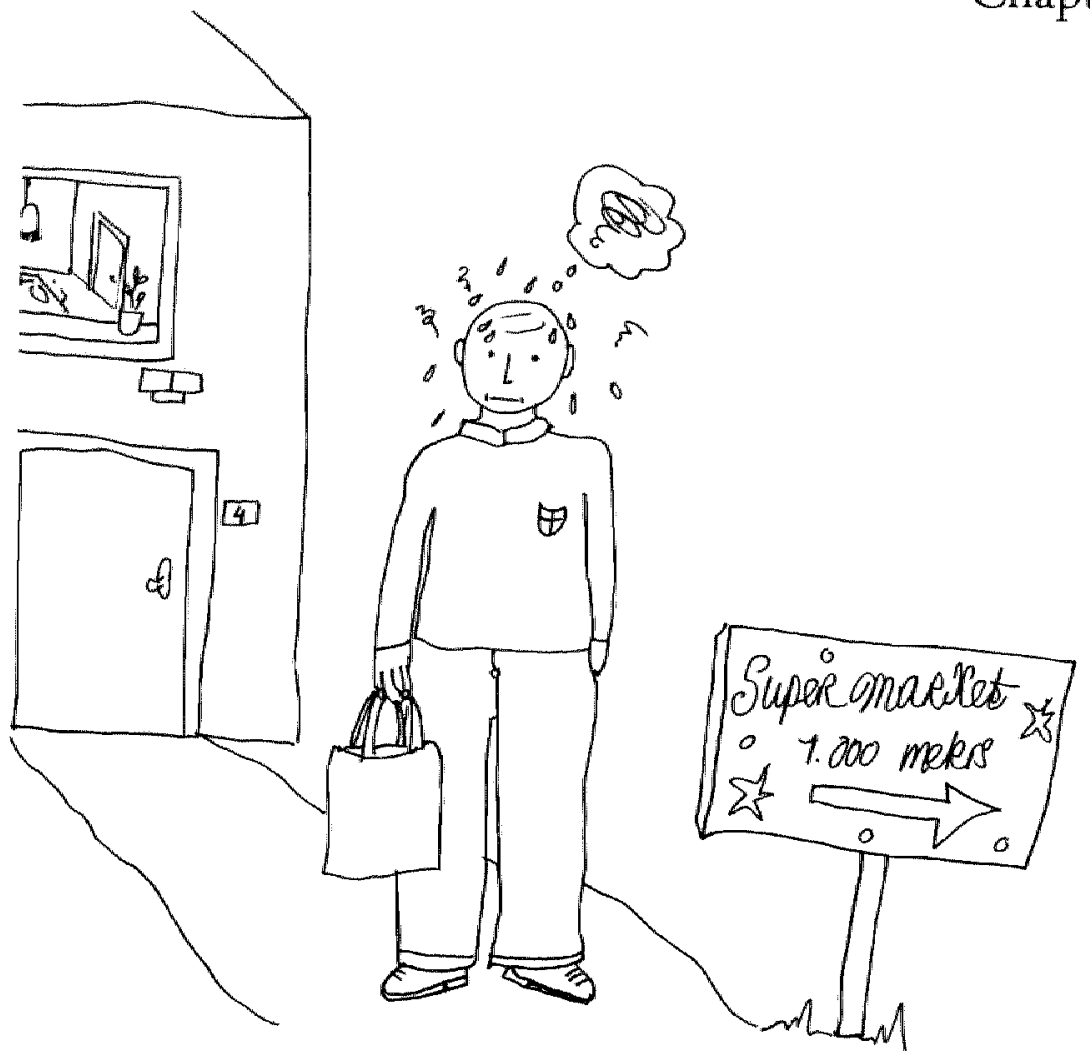




\section{Introduction}

\section{Integrated Disease Management for Primary Care}

NH Chavannes, SC Lareau, BL Tiep, JWM Muris

Published electronically in September 2004 as part of:

American Thoracic Society and European Respiratory Society Standards for the Diagnosis and Treatment of Patients with Chronic Obstructive Pulmonary Disease

Continuously updated and electronically available at:

www.thoracic.org/COPD or www.ersnet.org/guidelines

Summary of the ATS/ERS position paper:

ATS/ERS task force report: BR Celli, W MacNee, A Agusti, A Anzueto, B Berg, AS Buist, PMA Calverley, N Chavannes, T Dillard, B Fahy, A Fein, J Heffner, S Lareau, P Meek, F Martinez, W McNicholas, J Muris, E Austegard, R Pauwels, S Rennard, A Rossi, N Siafakas, B Tiep, J Vestbo, E Wouters, and R ZuWallack. Standards for the diagnosis and treatment of patients with COPD: a summary of the ATS/ERS position paper. Eur Respir J 2004; 23: 932-946. 


\section{Key points}

- Integrated care for chronic obstrucrive pulmonary disease (COPD) involves the patient and a team of clinical professionalls cooperating with secondary care and rehabilitation services.

- Optimal disease management involves redesigning standard medical care to integrate rehabilitative elements into a system of patient selfmanagement and regular exercise.

- Case finding is a simple and effective means of enhancing the diagnosis of COPD in primary care. Use of spirometry by primary care providers is recommended to detect airways obstruction and facilitate smoking cessation.

- A diagnosis of COPD is confirmed by spirometry, which can be performed in a primary care setting if personnel are specifically trained and quality assurance is maintained.

- COPD is ofren accompanied by deconditioning, comorbid illnesses and symptoms of depression. Even in patients with mild disease, health status can be substantially compromised.

- The majority of COPD exacerbations are managed at home by the patient or the primary care team. Approximately $50 \%$ of exacerbations are not reported to clinicians.

- Patients with COPD should be made more aware of the symptoms of an exacerbation and be encouraged to report these early to clinicians.

Conversely, physicians should make use of the experience of the individutal patient and ask for early signs of an exacerbation.

- In most cases, short courses of oral corticosteroids should be initiated at first signs of an exacerbation.

- Most of the professional care provided to patients reaching end of life is given by primary care teams.

- A disease management flow diagram for integrated care of COPD is introduced. 


\section{Background}

Disease management can be regarded as an integrated and systematic approach in which healthcare providers work rogether in a coordinated and cooperative manner to produce an optimal outcome for a particular patient with COPD throughout the entire continuum of care'.

COPD is a progressive chronic disease with an increasing prevalence ${ }^{2}$ (see Definition, diagnosis and staging). In recent years, the most substantial increase in prevalence has been in females, who now surpass the number of males dying of the disease in the USA ${ }^{3}$ (see Epidemiology, risk factors and natural history).

Integrated care for COPD involves the patient and a team of clinical professionals working in primary care, cooperating with secondary and rehabilitation services.

In this section an integrated care flow diagram for the disease management of COPD will be introduced (Fig. I).

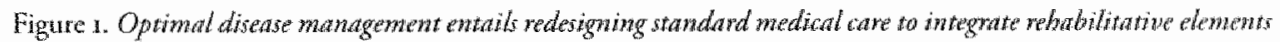
into a system of parient" self-phandagewent and regular exercise ${ }^{r}$.

Siandards for the Diagnosis and Management of Patients with co P D
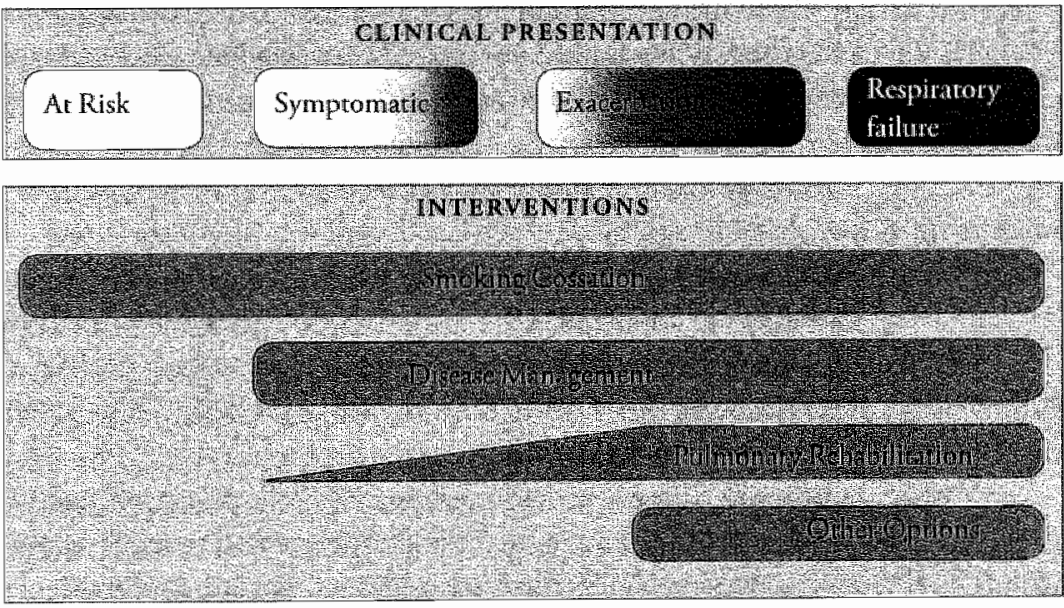

B: EV 


\section{Prevention}

Cigarette smoking is by far the most important risk factor for COPD in the Western world (see Management of stable COPD: smoking).

Patients with COPD need to be vaccinated against influenza annually. Pneunococal vaccination is recommended according to national guidelines (see Management of stable COP D: pharmacological therapy).

Use of office spirometry by primary care providers is recommended to detect airways obstruction and facilitate smoking cessation ${ }^{4}$.

\section{Diagnosis}

A diagnosis of COP $D$ is confirmed by spirometry, which can be performed in a primary care setting if personmel are specifically trained and qualicy assurance is main tained 5,6 .

Case-finding is a simple and effecrive means of enhancing the diagnosis of COPD in primary care. Preselecting smoking patients on the basis of chronic cough and age $>60$ years increases the chance of finding airways obstruction from 18 to $48 \%$.

In primary care there is a need to consider a diagnosis of COPD in smokers currently diagnosed and treated as having respiratory tract infections or asthma.

When diagnostic problems arise, or the quality of measurements cannot be assured, patients should be referred to specialised diagnostic centres in hospitals or clinics (see Clinical assessment, testing and differential diagnosis).

\section{Management of stable disease}

Every patient should have access to a smoking cessation programme. Cessation of smoking is the only proven way to slow the decline in lung function $^{8}$. COPD patients who receive repeated counseling and spirometry stop smoking more easily than smoking controls without COPD (40 versws $22 \%$ ) after 3 yrs follow-up?.

Bronchodilators provide symptom relief and, combined with inhalled corticosteroids, may reduce the frequency and severity of exacerbations in severe COPD. Neither bronchodilators, nor inhaled corticosteroids have any effect on lung function decline ${ }^{\text {to }}$ [see Management of stable COPD: pharmacological therapy]. The inhalation technique should be regularly checked since many patients need feedback on how to use devices effectiwely. Especially in patients with severe COPD, the use of spacer devices should be reinforced [see Patients: medication].

It is important to recognise that even in parients with mild disease, health status can be substantially compromised ${ }^{\mathbb{}}$. There is evidence that 
directing patients to engage in relatively simple programmes of physical acrivity can improve exercise tolerance in mild- to moderate $C O \mathrm{PD}^{12}$.

Comorbidity is a frequent problem in COPD. Other illnesses, such as bronchiectasis, lung cancer, hearr failure, osteoporosis and malnutrition are frequenc in patients with COPD.

Depressive symptoms are also common, especially in patients with severe disease, who are at a 2.5 -times greater risk ${ }^{13}$. It is important to search for symptoms of depression and treat appropriately.

COPD is ofren accompanied by deconditioning and a low level of social activity. Pulmonary rehabilitation improves exercise capacity, relieves dyspnoea and farigue, reduces length of stay in hospital, and enhances patients' sense of control over their condition ${ }^{14-16}$ [see Management of stable COPD: pulmonary rehabilitation]. Currently, rehabilitation is available to a small percentage of those who could benefit. Optimal disease management entails redesigning standard medical care to integrate rehabilitative elements into a system of parient self-management and regular exercise ${ }^{17}$ (Fig. 1).

Long-term oxygen therapy ( $>$ I5 h-day-I) for patients with chronic hypoxaemia has been shown to prolong life ${ }^{18}$ [see Management of stable COPD: long-term oxygen therapy].

\section{Management of exacerbations}

The majority of exacerbations are handled at home by the patient or the primary care team, with $-50 \%$ of exacerbations unreported to clinicians ${ }^{1 \%}$. Moderate-to-severe COPD patients with frequent exacerbations have a faster decline in lung function and are more often admitted to hospital with longer lengths of stay ${ }^{20}$.

Symptoms and not lung function worsen significantly before an exacerbation, with dyspnoea or colds characterising the more severe [see Exacerbation: definition evaluation and treatment].

Therefore, patients with COPD should be made more aware of the symptoms of an exacerbation and encouraged to report these early to clinicians $^{21}$. Conversely, physicians should make use of the experience of the individual patient and ask for early signs of an exacerbation and initiate a plan of care.

Since oral steroids seem especially useful for the first $72 \mathrm{~h}^{22}$, these should be initiated at first signs of an exacerbation. If corticosteroids are initiated, short courses ${ }^{23}$ are recommended (Fig. 1). Antibiotics may be initiated in patients with altered sputum characteristics, but level I patients with in creased quantities of nonpurulent spurum improve without antibiotic therapy ${ }^{24}$ [see Exacerbation secrions].

Programmes that include social and medical support for early planned discharge may reduce hospital stay and do not result in an increased re- 
admission rate $25-27$. Patients are more likely to prefer domiciliary care to inpatient care ${ }^{28}$, leading to greater patient satisfaction ${ }^{29}$.

Planned monitoring of the patient after discharge is an integral component to the rehabilitation approach and promotes the ability of the patient and family to move toward self-management ${ }^{30}$.

It is important that long-term care for chronic relapsing diseases be delivered by a team of professionals with the "expert patient" at the centre; such an approach is likely to maintain the patient's quality of life ${ }^{31}$.

\section{Referral indications}

Referral to specialist care generally has the purpose to confirm diagnosis, perform additional investigations, optimise and initiate treatment, or exclude other illnesses. This is indicated for COPD patients with:

- disease onset at age < 40 yrs;

- frequent exacerbations (two or more per year) despire adequate treatment;

- rapidly progressive course of disease (decline in forced expiratory volume in one second ( $\left.F E V_{\mathrm{r}}\right)$, progressive dyspnoea, decreased exercise tolerance, unintentional weight loss);

- severe COPD ( $\mathrm{FEV}_{1}<50 \%$ predicted) despite optimal treatment;

- need for oxygen therapy (see Management of stable COPD: long-term oxygen therapy);

- onset of comorbid illness (osteoporosis, heart failure, bronchiectasis, lung cancer);

- possible indication for surgery (see Management of stable COPD: surgery in and for COPD).

\section{Follow-up/monitoring}

Patients with COPD need to be followed and actively managed. The frequency and intensity of follow-up depend on the individual patient's disease status and course, as well as the local healthcare system. Tasks of all professionals caring for COPD patients should be clear ${ }^{32}$ in order to reach local agreement on the organisation of:

- symptoms registration, signs of comorbidity, health status, exercise rolerance, nutritional condition and lung function dara;

- a call/recal] system that generates appointments for education, inhalation technique check, vaccinations;

- regular multidisciplinary meetings of healthcare professionals aimed at difficult cases. 


\section{End-stage disease management}

Patients with end-stage COPD have physical and psychosocial needs at least as severe as lung cancer patients ${ }^{33}$. But their significantly impaired quality of life and emotional well-being may not be met as well as those of parients with lung cancer ${ }^{34}$.

Patients with severe COPD are ofren disabled longer by their disease than those with lung cancer, yet COPD patients have a mortality rate comparable to that of many cancers ${ }^{35}$.

In practice, it seems difficult to recognise when chronic care becomes palliative care ${ }^{36}$.

Uncertainty among primary care physicians as to how patients view the discussion of prognosis and inadequate preparation may pose potential barriers $^{37}$.

Most of the professional care received by people reaching the end of life is provided by primary care teams. Further training to incorporate the principles of palliative care explicitly into the planning and provision of care is essential ${ }^{38}$.

Discussions about the end of life should take place when the patient is stable. Enquires should be made about their preference for end-of-life support, including ventilatory support (see Ethical and palliative care issues).

The task is complex, requiring long-term surveillance of patients who are likely to become housebound. Respiratory nurse speciallists can play an important role in coordinating care of COPD at the end of life $e^{39}$.

\section{References}

r. Epstein RS, Sherwood LM. Fron ontcomes research to disease nanagement: á guide for the perplexed. Am Interm Med 1996;124: 8,2-837.

2. Murray CJL, Lopez AD. Mortality by cause for eight regions of the world global bulden of disease study. Lawcet 1997: 349: 1269-1276.

3 Mannino DM, Homa DM, Akinbami LJ, Ford ES, Redd SC. Chronic obsuructive Pulmonary discase surveillance - United Stares, n971-2000. Centers for Discase Control and Mrevention, Surveillance Sunmaries. Morb Mortal Wkly Rep zooz: 51 : I-16.

4 Ferguson GT, Enright PL, Buist A,S. Higgins MW. Office spitomerry for lung heath assessment in adults. A consensus statement from the National Lung Health lichation Program. Chest 2000:177: 1146-1161.

5 Schermer TR, Jacobs JE, Chavanes NH, Hartman J, Folgering HT, Botrema BJ, Wed van C. Validity of spirometric testing in a general practice population of patients with chronic obstructiwe pulmonary disease (COPD). Thorax 2003:58:861-86.

6 Chawannes N, Schermer T, Akkemans R, Jacobs J, Grat G van de, Bollen R, Schayck $O$ van, Botrema B. Impact of spiromery on GPS diagnostic differentiation and decision-making. Resp Med 2004; $98: 1124$-1130. 
7 Schayck CP van, Loozen JMC, Wagena E, Akkemans RP, Wesseling GI. Detecting patients at a high risk of developing chronic obstructive pulmonary disease in general practice: cross sectional case finding study. BMJ 2002; 324: 1370 .

8 Anthonisen NR, Connett JE, Kiley JP, et al. Effects of smoking intervemtion and the use of an inhaled anticholinergic bronchodilator on the rate of decline of $\mathrm{FEV}_{1}$. The Lung Health Study. JAMA r994; 272: 1497 -1505.

9 Czajkowska-Malinowska M. Gorecka $D$, Zelinski J. Effeces of repeared spirometries and antismoking counselling on smoking cessation rate. Eur Resp J 2002; 20: Suppl 38, 13.4s.

ro Calverley PMA. Modern treatment of chronic obstructive pulmonary disease. Eur Resp J2001; 18: Suppl. 34, 605-66s.

II Ferrer M. Alonso J, Morcra J, et al. Chronic obstructive I'ulmonary disease stage and healith-related quality of life. Amn Intern Med 1997; 127: 1072-1079.

12 Chavanies NH, Vollenberg JJH, Srchayck CP van, Wouters EFM. Effects of physical activity in mild to moderate COPD: a systematic review. Br J Gen Prac 2002:52: 574578.

13 Maanen JG van, Bindels PJE, Dekker FW, IJzermans CJ, Zee JS van der, 5 chade E. Risk of depression in parienss wich chronic obstructive pulmonary diseasc and its determinants. Thorax 2002; 57: 412-416.

14 Lareau SC, Zuwallack R, Carlin B, et al. Pulmonary rehabilitation. Official Statement of the American Thoracic Society. AJRCCM 1999; 159: 1666-1682.

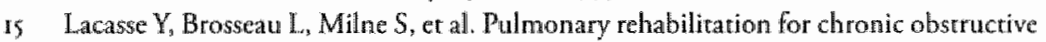
pulmonary disease (Cochrane Review). In: The Cochrane Library, Issue 3. Oxford, Update Software, 2002 .

16 Griffiths TL, Burr ML, Campbell LA, et al. Resulss at year of outparient multidisciplinary pulmonary rehabilitation: a randomised controlled trial. Lancet 2000; 355: 362368.

17 Tiep BL. Disease management of COPD with pulmonary rehabilitation. Chest 1997; II2: $1630-1656$.

18 Nocturnal Oxygen Therapy Trial Group. Continuous or nocturnal oxygen therapy in hypoxemic chronic obstructive lung disease: a clinical trial. Ann Intern Med 1980; 93: 391-

19) Seemungal TAR, Donaldson GC, Baul EA, Bestall JC, Jeffries DJ, Wedzicha JA. Effecr of exacerbarion on quality of life in patients with chronic obstructive pulmonary dis. case. Am J Respir Crit Care Med 1998; 157: 1418-1422.

20 Donaldson GC, Seemungal TA, Bhowmik A, Wedzicha IA. Relationship between exacerbation frequency and lung function decline in chronic obstructiwe pulmonary disease. Thordex 2002; 57:847-852.

21. Seemungal TA, Donaldson GC, Bhowmik A, Jeffries DJ, Wedzicha JA. Time course and recovery of exacerbations in parients with chronic obstructive pullmonary clisease. Am J Respir Crit Care Med 2000; 161: 1608-161:.

22 Wood-Balker $R$, Walters $\mathrm{EH}$, Gibson $\mathbb{P}$. Oral corticosteroids for acure exacerbations of chronic abstrucrive pulmonary disease (Cochrane Review). In: The Cochrane Library, Issue 4. Oxford, Updare Software, 2002.

23 Snow $V_{0}$ Lascher S, Mottur-Pilson $C$. The evidence base for management of acure exacerbations of COPD; clinical practice guideline, part 1. Chest 2001; 119 : 118 s-1189.

24 Stockley RA, O'Brien C, Pye A, Hill SL. Relationship of sputum color to nature and outparient management of acute exacerbations of COPD. Chest 2000; 117: 1638-1645. 
Skwarska E, Cohen $G_{\text {, Skwarski } K M}$, at al. Randomized controlled trial of supported discharge in parients with exacerbations of chronic obstructire puimonary disease.

Tharax 2000; 55: 907-912.

26 Corton MM, Bucknall CE, Dagg KD, en al. Early discharge for patients with exacetbations of chronic obstructive pulmonary disease: a randomized controlled trial. Thorax 2000; $55: 902-906$.

27 Sala E, Alegre L, Carrera M, et al. Supported discharge shortens hospital stay in patients hospitalized because of an exacerbation of COPD. Eur Respur / 2001; 17: 1138II.42.

28 Ojoo JC, Moon T, MoGlone S, al. Patients' and carers' preferences in rwo models of care for acure exacertations of COPD: results of a randomised controlled trial. Tharax 2002;57: 167-1609.

29 Wilson A, Wynn A, Parker H. Patient and carer sarisfaction with "hospital ar home": quantitative and qualitarive resulrs from a randomised controlled trial. $\mathrm{Br} / \mathrm{Gen}$ Prat 2002:52:913.

30 Bernier M], Leonard B. Pulmonary rehabilitation after acuse COPD exacerbation. Crit Care Nurs Clim North Am 2001; 13: 375-387.

31 Rafferty S, Elborn JS. Do nurses do ir betrer? (edirorial) Thorax 2002; 57: 659-660.

32 Vijhoef HJM, Bergh JHAM van den, Spreeuwerberg C, Diederiks JPM. The nurse specialise as central care-provider to patients with stable COPD: a justified alternative for usual outpatient care by the pulmonologist. Eur Respir J 2001; 18: Suppl 33, 2065.

33 Edmonds $\mathbb{P}$, Karlsen $S$, Khan S, Addingron-Hall J. A comparison of the palliative care needs of parients dying from chronic respiratory diseases and lung cancer. Patliat Med 2001;15: 287-295.

34 Gore JM, Brophy Cl, Greenstone MA. How wetl do we care for patients with end stage chronic obscructive pulmonary disease (COPD)? A comparison of palliatiwe care and qualizy of life in COPD and lung cancer. Thorax 2000; $55: 1000-1006$.

35. Shee C. Palliation in chronic respiratory disease. Palliat Med 1995; 9:3-12.

36 Hill KM, Muers MF Palliatixe care for parients with non-malignant end stage respiratory disease. Thora $2000 ; 55: 979-981$.

37 Elkington $\mathrm{H}$, White $\mathrm{P}$ Higgs $\mathrm{R}$, Pertinari Cl. GPs views of discussions of prognosis in severe COPD. Fam Pract 20or; $18: 440-444$.

38 Chawannes NH. A palliative approach for COPD and hear failure? Eur / Wa/ Cam 2001; 8: 225-227.

39 Elkington $\mathrm{H}$, White $\mathrm{P}$. Chronic obstructive pulmonary disease and primary care. Br J Gen Prac 2002; 52: 532-534. 
Chapter 2

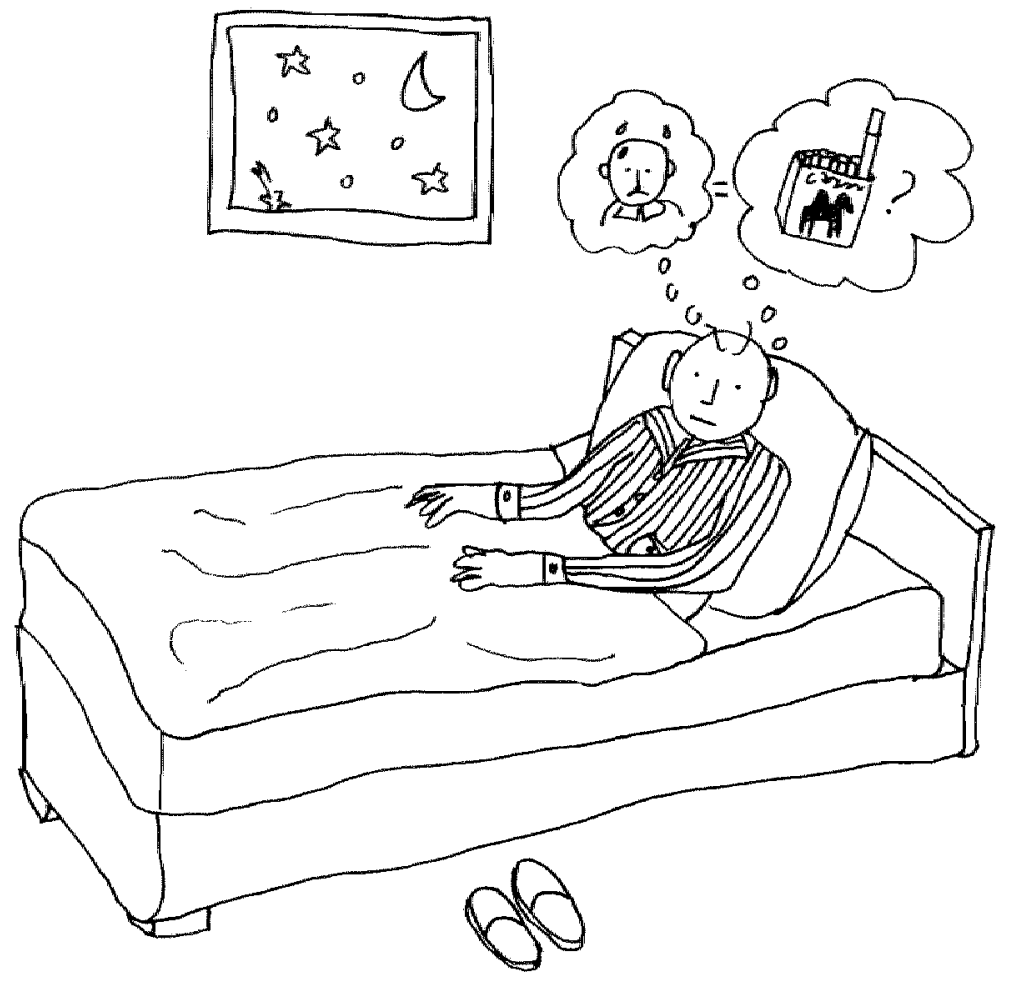




\section{Impact of Spirometry on GPs' Diagnostic Differentiation and Decision-Making}

Niels Chavannes, Tjard Schermer, Reinier Akkermans, J.E. Jacobs, Gabrielle van de Graaf, Ralf Bollen, Onno van Schayck, Ben Bottema

Published in Respiratory Medicine 2004; 98: 1I24-II30 Abstract published in European Respiratory Journal 2002; suppl 38: 4145 


\begin{abstract}
Background

Spiromery is increasingly implemented in general practice, while the ability of general practitioners (GPS) to interpret flow-volume curves (F-V curves) has been questioned. Furthermore, the role of spirometry in the $G$ P's decision-making process has barely been studied.
\end{abstract}

Aim

To compare the achievements of trained GPs in spirometric diagnosis with an expert consensus panel ( 1 ) and to assess the influence of spirometry on the GPS decision-making (2).

\title{
Method
}

39 GP's as well as the expert panel interpreted twelwe cases including a wide range of F-V curves. Diagnostic test characteristics were calculated using multi-level analysis and summarised by diagnostic odds rarios (DOR). Differences in decision-making indicators were expressed as odds ratios and $95 \%$ confidence intervals.

\section{Results}

Normal F-V curves (DOR 65.0) and obstructive F-V curves (DOR 48.9) were reasonably well diagnosed, while rare and mixed pathological parterns achieved considerably lower scores (DOR 3.8). Intermediate scores were obtained in the recognition of incorrect test manoeuvres (DOR 24.4). Spirometry influenced the GPS decision-making in reducing the number of alternative diagnoses ( $O \mathbb{R} 0.266[0.200,0.353]$ ), but also increased referral rates $(7.26[4.7$ r, rr.2]) and the use of diagnostic prednisolone courses $(4.55[3.12,6.64])$ substantially.

\section{Conctusion}

Trained GPs were able to differentiate berween normal and obstructive disease patterns, while F-V curves suggestive of rare and mixed pathology were often missed. Spirometry seems to infuence the decisionmaking process of the GP; whether this represents an initial or a more sustained effect remains to be evaluated in studies of daily primary care practice. 


\section{Introduction}

In general practice, medical history taking and physical examination are the most important instruments to establish diagnosis and initiate treatment. Diagnostic cools originating from secondary care serrings such as electrocardiography ${ }^{1,2}$ and spirometry ${ }^{3-5}$ are increasingly used in primary care and the results are being interpreted by general practitioners ( $\mathrm{GPs}$ ). Access to spirometry in primary care has increased rapidly in the past years, surveys ranging from $21 \%{ }^{10}$ (1998) to $77^{\%}$ (200r) in the UK ${ }^{11}$. By contrast, insufficient training hampers spirometer utilisation: less than half are used to diagnose COPD ${ }^{\mathrm{II}}$. Several national and international guidelines consider formal spirometric testing essential to establish a diagnosis of $\mathrm{COPD}^{4: 12,14}$, while education in its use has been identified as a major goal for primary care physicians ${ }^{4,13,15}$.

However, the value of spirometry in differentiating between specific respiratory disease patterns still needs to be assessed in general practice. Most authors focus on the quality of spirometry test performances-7, while studies investigating the interpretative skills of physicians report rather disappointing results, both in primary ${ }^{5}$ and secondary care ${ }^{8,9}$ setting.

A number of studies in COPD and asthma suggest that spirometry could reduce both under- and overdiagnosis of obstructive airway disease in general practice ${ }^{\mathrm{r} 6-18}$, which might influence disease management. Adjustment of treatment afrer spirometry has been reported in $4-25 \%$ of patients with mostly asthmatic complaints ${ }^{1 \%, 20}$. However, the direct influence of spirometry on the decision-making process of GPs has not been assessed. Therefore, the aim of the current study was to determine the achievements of GPs in differentiating between various chronic respiratory diseases when spirometry is provided as a supplementary diagnostic tool. In addition, we investigated the impact of the flow-yolume curve on the GPs decisionmaking process.

\section{Methods}

\section{Participants and spirometry training}

GPS with an interest in spirometry were recruited from the general practice networks of the Nijmegen and Maastricht Universities in the Netherlands. Most of these GPs already used spiromerry in daily practice, had received previous training and were motivated to assess their skills. Additionally, GPs involved in the vocational training in the Nijmegen and Maastricht regions were invited by postal mailing to participate in the study.

Participating GPs received a standardised postgraduate spirometry-training course (rwo three-hours sessions with an interval of one month), and 
could bring their newly acquired spiromerric knowledge and skills into practice for a period of six to nine months before the study started. The spirometry course was based on a format widely used in the Netherlands. During the first session the focus was mainly on the pathogenesis and clinical characteristics of asthma, COPD and other chronic respiratory diseases; theoretical concepts of lung function testing; execution of spirometry tests; and practical guidelines and strategies for spirometry interpretation. The second session was manly used to discuss actual case descriptions submitred by either the participants or course leaders. Training was provided by a pulmonologist and an experienced lung function technician. Interactive education and feedback on the spot were emphasized throughout the course.

\section{Standardised case descriptions}

A set of twelve standardised case descriptions was constructed, based on actual patients from two general practices from our academic networks. "The cases were designed in cooperation with a pulmonologist and a $G P$ with ample experience in the field of chronic respiratory diseases. The case set included a range of typical How-volume curves suggesting mild obstruction $(n=1)$; moderate obstruction $(n=1)$; severe obstruction $(n=2)$; rare pattern of restriction $(n=1)$; fixed upper airways obstruction $(n=1)$; mixed pattern of both obstruction and restriction $(n=1)$; incorrect test manoeuwres $(n=2)$; and normal curves $(n=3)$. The participating GPS worked through two sets of six cases each, which were assessed in random order within a period of one year. Randomisation codes were prepared by a fellow-researcher who was not involved in the study and stored in sealed envelopes until use. Data were collected in the period July 1999 through April 200r.

A research assistant visited the GPs in their practice. For each case, a concise medical history and results of the physical examination were presented to the GP first. Subsequently, absolute and predicted postbronchodilator spirometry rest results (including $\mathrm{FEV}_{\mathrm{r}}, \mathrm{FEV}_{1} / \mathrm{FVC}$ and flow-wolume curves) were provided. After having assessed a case, G Ps had to select one spiromerric diagnosis from a preformulated list. An example of the case structure is depicted in figure $x$.

Before the study, the rwelve paper cases had been judged by an independent expert panel consisting of two pulmonologists, a pulmonary physiologist and a GP with specific expertise in the pulmonary field. The panel reached consensus on the spirometric and clinical diagnoses of the paper cases during a panel discussion meeting, while no cases were excluded. "The panel meeting was audiotaped and independently scored by two of the authors (NC and TS) in order to establish the panels' final diagnosis and - when applicable - alternative diagnoses for each case. There was 
I00\% agreement between the two observers with respect to the panels' final and alrernative diagnoses. The panel consensus diagnoses served as the Gold standard' in the subsequent evaluation of the GPs' diagnostic achievements.

\section{Outcome measures}

To assess the diagnostic achievements of GPS with regard to interpretation of spirometry, the following four outcome categories were considered most relevant and contrasting from a clinical point of view: ( 1 ) bronchial obstruction (from mild to severe); (2) rare respiratory pathology (i.e., restriction, fixed upper airways obstruction, mixed partern); (3) normal lung function; (4) incorrect test manoeuvre.

In addition, the impact of spirometry on the GPs decision-making process was assessed using four indicators: (r) diagnostic uncertainty (size of differential diagnosis, i.e. the number of alternative diagnoses considered by the GPs while assessing a case); (2) probability of prescribing respiratory medicarion; (3) probabiliry of initiating a diagnostic prednisolone course, a commonly used test (albeit its' value is uncertain); and (4) probability of referral to a pulmonologist and/or cardiologist. These process indicators of GP decision-making were assessed before and after the results of spirometry were shown to the GPS (figure 1 ).

Figute 1 . Schewatic representation of case structure 'mild to moderate COPD'

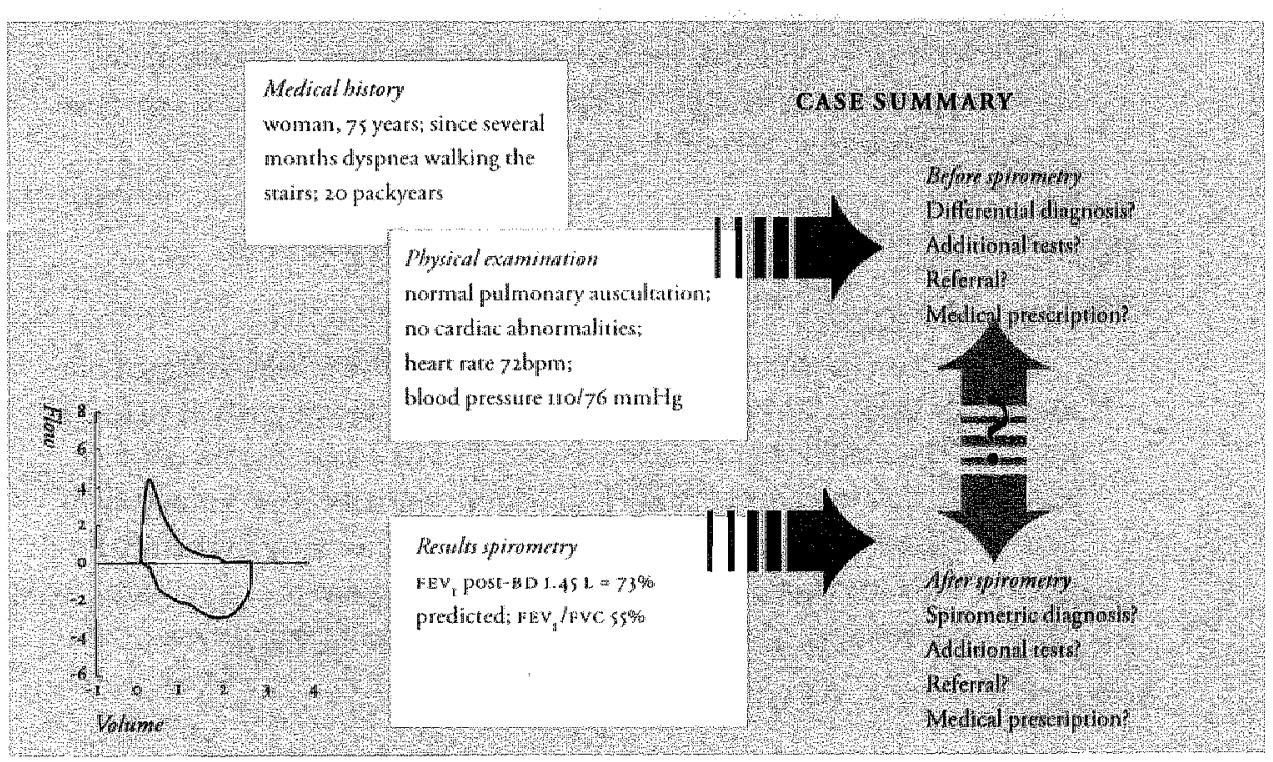




\section{Statistical analyses}

First, the agreement between the GPs' interpretations and the expert panels 'Gold standard' diagnoses was investigated univariately using the SPSS software package (Version 9.0 for Windows). Subsequently, multilevel linear and logistic modelling was used to account for the intra-cluster correlation induced by the fact that each $G_{P} P$ assessed more than one case.

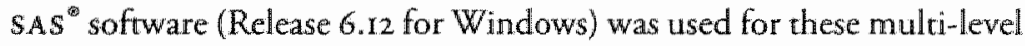
anallyses.

The following diagnostic test characteristics were calculated for each outcome measure ${ }^{2 x}$ : positive and negative predictive values (further referred to as PPV and NPV, respectively), positive and negative likelihood ratios (LR+ and LR-, respectively) and the diagnostic odds ratio (DOR). PPV Expresses the probability of disease in subjects with a positive test result, N PV the probability of absence of disease in subjects with a negative test result. LR + is the ratio of the probability of a positive test in subjects with disease and the probability of a positive test in subjects without disease.

Conwersely, LR-is the ratio of the probability of a negative test in subjects with disease and the probability of a negative test in subjects without disease. A diagnostic test is better the more LR differs from $I_{n}$ that is, greater than $\mathrm{I}$ for LR+ and lower than I for LR-. Finally, the DoR summarises the overall discrimination of a diagnostic test with a dichotomous outcome. In fact, it is the ratio of LR+ and LR-. Therefore, a diagnostic test is useless if DOR $=I^{21}$.

After the four indicators of decision-making were dichotomised ( $\mathrm{I}$ vs. >r diagnosis; o vs. I diagnostic prednisolone course; o vs. x or more referrals; a vs. $x$ or more prescriptions), the before-after spirometry measurements were compared using multilevel logistic regression analysis and expressed as odds ratios with $95 \%$ confidence intervals $(95 \% \mathrm{CI}$ ).

\section{Results}

\section{Genenal practitioners}

Thircy-nine (39) GPs participated in the study. Three GPS dropped out during the study, one because of early retirement, the others due to loss of interest. These three GPs completed one set of six cases, instead of both sets. Table I shows that the study population consisted predominantly of middle-aged male doctors who had been using spirometry in their daily practice for a mean of 4.3 ( SD 3.7) years, having received $4.2\left(\begin{array}{ll}S \mathrm{D} & 4.9\end{array}\right)$ hours of spirometry training in the year preceding the experiment. 


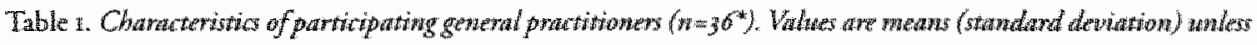
stated otherwise.

$\begin{array}{ll}\text { Male/female } & 33 / 3 \\ \text { Age, years } & 48(5.1) \\ \text { Pacients enlisted per GP, number } & 2086(712) \\ \text { Surgery hours per week, hours } & 43.6(12.7) \\ \text { Use of spirometer in daily patient care, yes/no } & 35 / 1 \\ \text { Duration of spirometry ucilisation, years } & 4.3(0.7) \\ \text { Spirometry training in previous year, hours } & 4.2(4.9)\end{array}$

*dara missing ond 3 . 6 ns who dropped out during the study

\section{Diagnostic achiovements by $G P_{s}$}

Altogether, the GPs assessed 444 cases. Table 2 shows the agreement between GP judgements and expert panel for each of the diagnostic outcome categories. Concordance with the expert panel regarding obstruction was present in $94.3 \%[95 \%$ CI $86.8,95.8]$ of cases, followed by normal spirometry obtaining $77.9 \%[95 \% \mathrm{Cr} 70.2,85.6]$ correct answers, while incorrect manoeuvres reached a score of $64.9 \%[95 \%$ CI $54.0,75.8]$, and rare parhological curves were recognised in $41.3 \%$ [95\% CI $32.1,50.5]$ of cases.

Table 2. Agreetnent between expert panel and $G P$ judgement for the presence (or absence) of obstwictive distense (A),

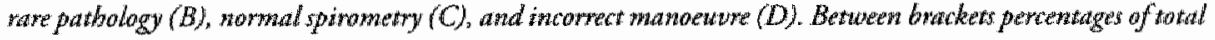
number of cases.

\begin{tabular}{|c|c|c|c|c|}
\hline \multirow[t]{2}{*}{ (A) } & & \multicolumn{3}{|c|}{ Expert pinel judgmens } \\
\hline & & Obstruction & No obstruction* & \\
\hline \multirow[t]{3}{*}{ GP judgment. } & Obstruction & $136(31)$ & $52(12)$ & $188(42)$ \\
\hline & No abstruction ${ }^{*}$ & $3(3)$ & $243(55)$ & $256(58)$ \\
\hline & & $149(34)$ & $295(66)$ & $444(100)$ \\
\hline
\end{tabular}

(B)

Expert panel judgmeont

$\begin{array}{lllll} & & \text { Rare Pathology } & \text { No rare pathology* } \\ \text { Gpjudgment } & \text { Rare Pathology } & 45(10) & 52(12) & 97(22) \\ & \text { No rare parholo- } & 64(14) & 283(64) & 347(78) \\ & & 109(25) & 335(75) & 444(100)\end{array}$

-either obstruction, normal spirometry, or incorrect manoeswre 


\begin{tabular}{|c|c|c|c|c|}
\hline (c) & & Expers panel judgraen & & \\
\hline \multirow[t]{4}{*}{$C^{\prime}$ judgment } & & Normal Spiromery & Not normal spiromerry & \\
\hline & Normal Spirometry & $88(20)$ & $17(4)$ & $\operatorname{tos}(24)$ \\
\hline & Not normal spirometry & $25(6)$ & $314(71)$ & $339(76)$ \\
\hline & & $13(25)$ & $331(75)$ & $444(100)$ \\
\hline
\end{tabular}

\begin{tabular}{|c|c|c|c|c|}
\hline \multirow[t]{2}{*}{ (D) } & & \multicolumn{3}{|l|}{ Expert panel judgment } \\
\hline & & Incorrect Manoetswre & Nor incorrect manoeu- & \\
\hline \multirow[t]{5}{*}{ G"judgment } & Incorrect Manoeuvre & $48(11)$ & $26(6)$ & $74(17)$ \\
\hline & Not incorfect manocurre ${ }^{*}$ & $26(6)$ & $344(77)$ & $370(83)$ \\
\hline & & $74(17)$ & $370\left(8_{3}\right)$ & $444(100)$ \\
\hline & "either obscruction, rare partholo & $y$, or normal spiromerry & & \\
\hline & \multicolumn{4}{|c|}{$\begin{array}{l}\text { Table } 3 \text { shows that normal and obstructive curves were characterised by } \\
\text { high diagnostic odds ratios: } 65.0 \text { and } 48.9 \text {, respectively. By contrast, rare } \\
\text { pathological curves obtained a low diagnostic odds ratio of } 3.8 \text {. Scoring of } \\
\text { an incorrect test manoeuvre generated an intermediate diagnostic odds ra- } \\
\text { tio of } 24.4 \text {. The negative predictive values (probability of righteously ruling } \\
\text { out disease) varied between } 0.93 \text { and } 0.96 \text {, except for rare pathology, which } \\
\text { reached } 0.82 \text {. Posirive predictive values (probability of righteously labelling } \\
\text { disease) however, revealed a range of values between } 0.87 \text { (normal curves) } \\
\text { and } 0.49 \text { (rare pathology). }\end{array}$} \\
\hline
\end{tabular}

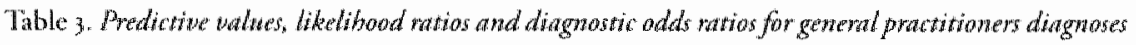

\begin{tabular}{|c|c|c|c|c|c|}
\hline & PPV & $N P^{P}$ & LR+ & $\mathbb{L} \mathbf{R}-$ & DOR \\
\hline Normal Spirometry & 0.87 & 0.93 & 15.16 & 0.23 & 65.0 \\
\hline Obstruktive Disease & 0.75 & 0.96 & $5+18$ & 0.11 & 48.9 \\
\hline Incotrect Manoenve & 0.68 & 0.93 & 9.23 & 0.38 & 24.4 \\
\hline Rare Parhology & 0.49 & 0.82 & 2.66 & 0.70 & $3: 8$ \\
\hline
\end{tabular}

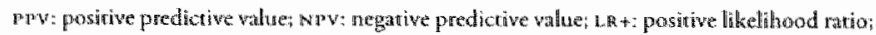

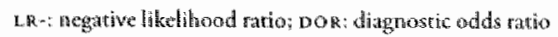




\section{Indicators of $G P^{\prime} s^{\prime}$ decision-making}

Before spirometry, GPs considered an average of 2.05 diagnoses per case, with a maximum of eight, while after spirometry this was reduced to a mean of $\mathrm{I} .35$, with a maximum of six. Table 4 quantifies this significant reduction of diagnostic uncertainry: $>$ I diagnosis is considered in $59.6 \%$ [55.I, 64.II] of cases before spirometry, while after spirometry $>\mathrm{I}$ diagnosis is considered in $31.2 \%[26.9,35.5]$ of cases (OR $0.266[0.200,0.353]$. Conversely, spirometry significantly increases the number of diagnostic prednisolone courses and the referral rare, whille the proportion of cases where medication is prescribed increases, bur nor significantly. The probability of diagnostic prednisolone testing rises threefold, from $8.0 \%[5.5$, I0.5] to $27.6 \%[23.5,31.7]$ per case (OR $4.55[3.12,6.64]$ ) as a result of spirometry. The probability of referral changes from $6.0 \%[3.8,8.2]$ to $31.7 \%$ $[27.4,36.0]$ as a result of spirometry (OR 7.26 [4.71, 11.2]).

Table 4. Impact of fowenwolume curve on ind dicators of the decion-making process in gremeral practitioners. Numbers an percentages with $95 \%$ confidence interuals.

$\begin{array}{llll}\text { Process indicators } & \text { Before F/V-curve } & \text { After F/V-curve } & \text { OR }(95 \% \text { CI }) \\ \text { Diagnostic uncertanty* } & 59.6 \%(55.1,64.1) & 31.2 \%(26.9,35.5) & 0.266(0.200,353) \\ \text { Prednisolone course } & 8.0 \%(5.5,10.5) & 27.6 \%(23.5,31.7) & 4.55(3.12,6.64) \\ \text { Referral rate } & 6.0 \%(3.8,8.2) & 31.7 \%(2.7 .4,36.0) & 7.26(4.71,11.2) \\ \text { Medication prescription } & 36.5 \%(32.0,41.0) & 39.4 \%(3.4 .9,43.9) & 1.1 .4(0.87,1.50) \\ & & \end{array}$

\section{Discussion}

The present study demonstrates for the first time the reasonable diagnostic achievements of trained GPS with regard to commonly encountered spirometric patterns. Curves of obstructive airways disease as well as the physiological can be considered the more prevalent conditions, as opposed to parterns suggestive of restriction or fixed upper airways obstruction, which GPs can be expected to be less familiar with. On the whole, the positive predictive values are lower than the negative predictive values. This reflects the fact that in primary care it remains more difficult to label a disease than to exclude it, due to the lower a priori probability. The relatively low positive predictive value of an incorrect test manoeuvre illustrates the need to emphasise the importance of quality assessment of the flow-volume curve, which should precede interpretation. The low diagnostic achievements in the less prevalent caregories points out the paradoxical necessity of recog- 
nising parterns one doesn't understand. Another explanation might be that dynamic spirometry is of limited use in differentiating between normal and restrictive disease, thus contributing to the low diagnostic yield. These elements should receive considerable artention in future spirometry courses, professional supervision or automated supportive software.

The significant influence of the flow-volume curve on the trained GPs' decision-making is expressed in a reduction of the number of alternative diagnoses but an increase in referral rates and diagnostic prednisolone courses. Thus, the flow-volume curve seems to support establishing a diagnosis in patients with respiratory morbidity, but probably leads to an increased use of additional diagnostic procedures or specialist care, at least initially. "This could partially reflect the relatively high prevalence of pathology in this specific case-set, warranting further work-up. Another explanation could be that the number of options was limited; for example an option to repeat spirometry to verify correctness of the manoeuvre was missing, possibly leading to increased prednisolone testing or referral instead. The current design does not allow us to deduct if this initial increase would be sustained in time, nor does it predict the exact effect size in daily practice.

Spirometers are increasingly available but seem underused ${ }^{\mathrm{x}}$, while doctors have been observed to overestimate their actual interpretative skills in spirometry ${ }^{22}$, as well as in ECGs ${ }^{23}$. This underlines that training is a prerequisite for meaningful implementation of advanced diagnostic tools in primary care. Both quality assessment and pattern recognition have been part of our standardised spirometry training course, which took place 6 to 9 months preceding the measurements, allowing the primary care physicians to integrate skills in daily practice. The format and duration of the training were directly derived from a common postgraduate spirometry course, which has been attended by large numbers of Dutch primary care physicians in the past few years.

The results of the present study reflect the ability of trained general practitioners to diagnose this specific case-set. Therefore, we do not pretend to reflect actual prevalences of the disease patterns within the constitution of the cases. By analysing spirometric patterns separately this over-representation is corrected for. Consequently, the multilevel analysis was performed to account for intra-cluster correlation within the GPS. However, it remains to be investigated what the results will be in a real-life setting, with actual patients and less or even untrained GPs. The case-set structure allowed us to compare the level of pattern recognition quite precisely with an expert panel, which was confronted with the identical set of cases. Moreover, the expert panel scored cases preceding the study, independent 
of the results of the primary care physicians, thereby eliminating a potential bias, which might have been overlooked in previous studies $5.8,9$.

In this study we demonstrated that the novel method of combining standardised case material with techniques of multilevel analysis might be useful to evaluate complex diagnostic tools, like spirometry. We conclude that trained GPs were able to differentiate between normal and obstructive disease patterns, while F-V curves suggestive of rare and mixed pathology were often missed. Spirometry seems to infuence the decision-making process of the $\mathrm{GP}$ by reducing diagnostic uncertainty but increasing use of additional diagnostics and referral to specialist care. Whether this represents an initial or a more sustained effect remains to be evaluated in studies of daily primary care practice.

\section{Acknowledgements}

The authors are grateful to dr. JWM Muris, GP, and dr. GJ Wesseling, pulmonologist, who kindly assisted the preparation of the cases used in this study.

\section{References}

I Davie AP, Francis CM, Love MP et al. Value of the electrocardiogram in identifying. heart failure due to left ventricular systolic dysfunction. BMJ x996: $32: 222$.

2 Macallan DC, Bell JA, Brassick M, Endersby K, Rizzo-Naudi J. The electrocardiogram in general practice: its use and its interpretation. J R Soc Med 1990; 83: 559-62.

3 Den Otter J, Knitel M, Akkermans RPM, Schayck CP van, Folgering HTM, Weel C van. Spirometry in general practice: the performance of practice assistants scored by lung funcrion technicians. Br / Gen Pract 1997; 47: 41-42.

4 Geijer RMM, Van Schayck CP, Van Weel C, Sachs APE, Bottema BIAM, Smeele IJM, Thiadent HA, Van hensbergen W, Rosmalen CFH. Dutch College of General Practirioners Guideline on COPD: Treatment. Huisarts Wet 200r; 44(5): 207-19.

5 Eaton T, Whithy S, Gartett JE, Mercer J, Whitlock RML, Rea HH. Spirometry in primary care practice. The importance of quality assurance and the impact of spirometry workshops. Chest 1999; 116: 416-23.

6 White PT, Nolan D. Spirometry in primary care. [letter] Thorax 2000; 55: 439-440.

7 Ferguson GI, Enright $\mathbb{P L}$, Buist AS, Higgins MW. Office spirometry for lung health assessment in adults. A consensus statement from the national health education program. Chest 2000; 117 : 1146-116.

8. Hnatiuk O, Moores L, Loughney T, Torrington $\mathrm{K}$. Evaluation of internists' spirometric interpretations. J Gen Intern Med sog6; In: 204-8.

9 Quadrelli SA. Roncoroni AJ, Porcel G. Analysis of variabillity in interpretation of spirometric tests. Respiration 1996; 63: 131-6.

no Dowson LJ, Yeung A, Allen MB. Most practices would use open access spirometry in hospitals. [letter]. $B M J 1998 ; 317 ; 209$. 
I. Booker R, Weller $\mathrm{T}$. Use of spirometry in the diagnosis of chronic obstructive pulmonary disease. Prim Care Respir J 2001; 10(3): 81 .

12 Pauwels RA, Buist AS, Calverley PMA, Jenkins CR, Hurd SS, on betall of the GOLD Scientific Commintee. Global strategy for the diagnosis, management, and prevencion of chronic obstruictime pulmonary disease: NHLB I Global Iniriarve for Chronic Obstructive Lung Digease (GoLD) Workshop Summary. Am J Respin Crit Care Med. $2001 ; 63: 1256-1276$.

13 Van Sehayck CP, Primary and Sccondary Care Respiratory Specialists Working Group. Diagnosis of asthma and chronic obstructive pulmonary disease in general practice. Brf Gen Pract 1996*46:193-197.

If British. Thoracic Sociery. Guidelines on the management of chromic obstructive pulmomary disease. Thorat $1997 ; 52$ (Suppl 5): Si-24.

15 Voelkel NE. Raising awareness of COPD in primary care. Chest 2000; 117: 3725-5s.

r.6 Pinnock H, Carleh-Smith J, Kalideen D. Spirometry in primary care: an anatysis of the frrst noo patients referred in one general practice. Astbyna Gen Pract 1999; 7: 23-4.

17 Boom G van den, Schayk CP van, Möken MP van, Tirimanna IR, Otter J] den, Grunswen PM van, et al. Active detection of chronic obstructive pulmonary disease. and asthma in the general population. Results and conomic consequences of the DIMCA program. Am / Respir Crit Case Med 1998; 158: 1730-8.

I8 Den Otter J], Van Dijk B, Van Schayk CP, Mollema J, Van Weel C. How to avoid underdiagnosed astama/chronic obstructive pulmonary disease? /. Asthwa 1998; 35: $381-7$.

19. Jones $\mathbb{K}$ ?. "The role of measuring fored expirarory volume in one second in derermining therapeutic changes made in an asthma dinic in general practice. Respir Med 1995: $89: 171-4$.

20 Spann SJ. Impact of spiromery on the management of chenic obstructive airway discasc. J Fan Iract 1983; 16: 271-5.

21 Knotmerus JA, Van Weel C, Muris JWM. Ewidence base of clinical diagnosis. Evaluation of diagnostic procedunes. BMJ 2002;324:477-480.

2.2 Stephenson N, Morgan R, Abdel-Rahman-Abdel-WahabE, Turnbull CJ. Hospital doctors" assessment of baseline spirometry. Postgrad Med/J 1998; 74:537-40.

23 Khunt K, Mckinley. Courses on interpreting ECGs would improve general practitioners $^{3}$ skills [letrer]. BMJ $1996 ; 312:$ :161. 
V.

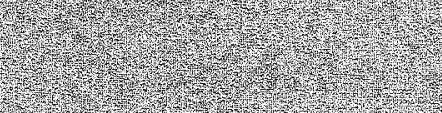

.

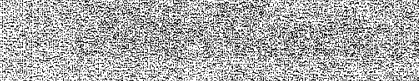

\begin{tabular}{ll}
1 \\
\hline
\end{tabular}

13
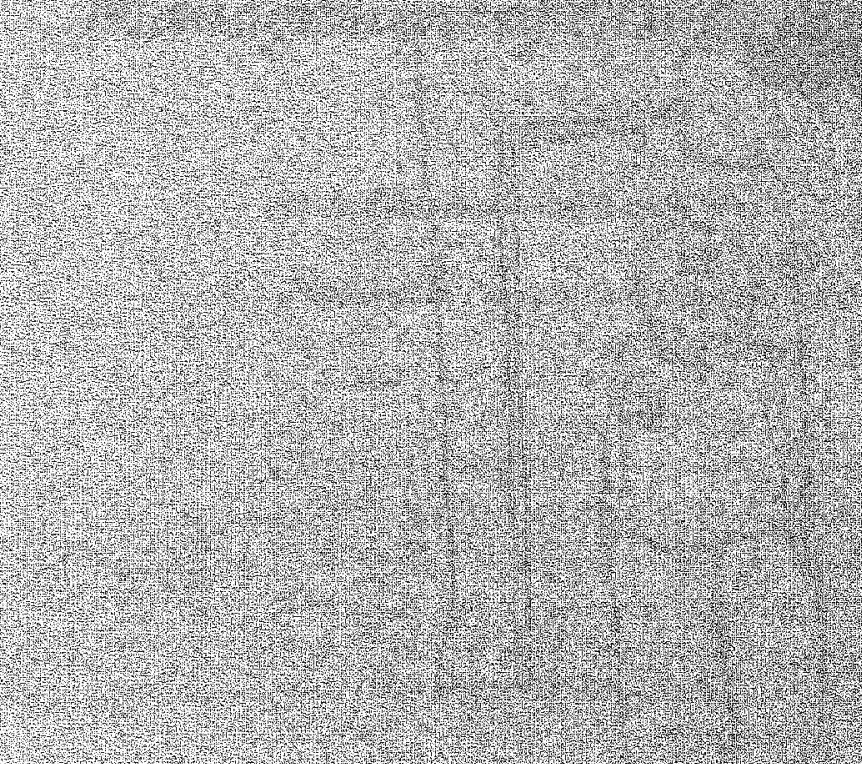
Chapter 3

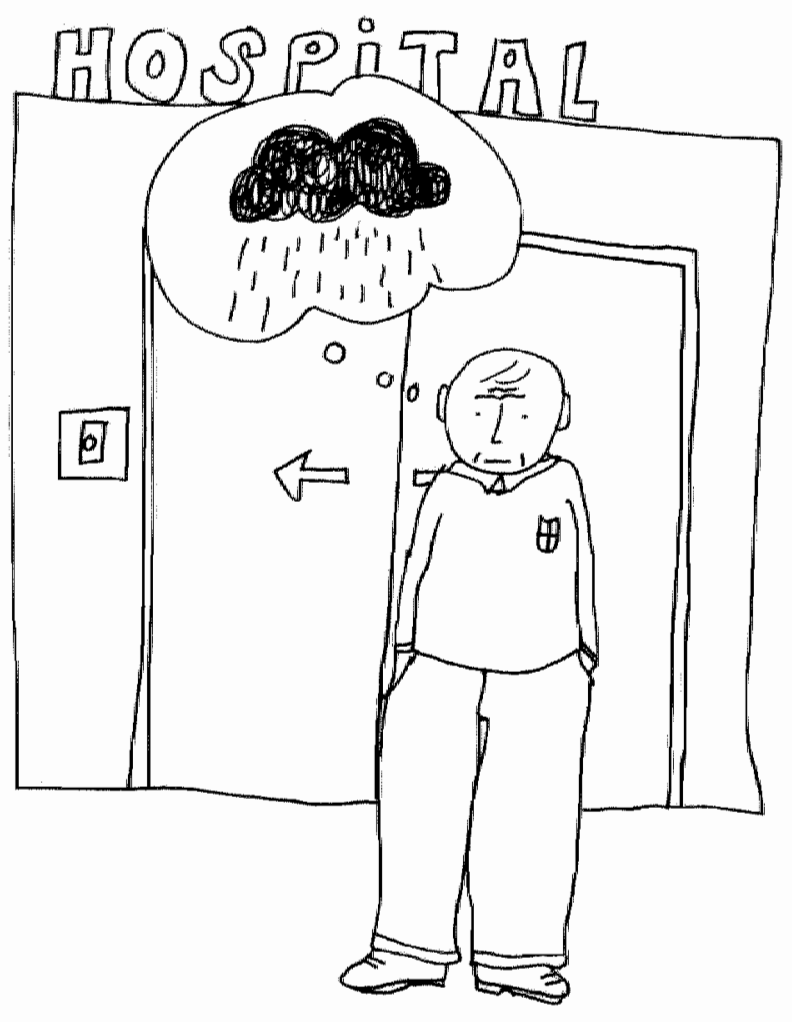




\section{The Necessity for Spirometry versus Peak Expiratory Flow in the Primary Care Management of COPD: a pro-con series}

Niels Chavannes and Patrick White

Published in Primary Care Respiratory Journal 2004; 13:5-16 


\title{
The Necessity for Spirometry in the Primary Care Management of COPD
}

\author{
Niels Chavannes \\ Department of General Practice, CAPHRI Research Institute, Maastricht \\ University, 6229 HA, Maastricht. The Netherlands
}

\begin{abstract}
Implementation of spirometry in the primary care setting is controversial. Spirometry allows a unique non-invasive look into the functioning of the lungs, which can be both medically informative and of practical value. Respiratory complaints are among the most prevalent in primary care, whille smoking rates remain globally high, illustrating the need for proper tools to investigate the possible causes of chronic pulmonary symptoms. Smoking cessation programs and disease management programs are the preferred trearment strategies for $\mathrm{COPD}$; these rely on a valid spirometric diagnosis, as promoted by international COPD guidelines. In addirion, involving the patient in treatment plans and explaining the detrimental effects of smoking can be greatly facilitated by the visual impact of a flowvolume curve. Evidence suggests that spirometry is a valid, feasible and interpretable diagnostic tool in a primary care setting, provided that quality standards of performance and training are sufficiently met. COPD is a growing problem for society, which should not be underestimated. Provided sufficient funding, adequate training and motivated healthcare workers are available, there is no good reason why spirometric testing cannot be widely implemented.
\end{abstract}


Over the past few years, increasing atrention has been paid to the detection and treatment of chronic obstructive pulmonary disease (COPD) in primary care, in part caused by the worldwide increase in burden and mortaliry. In contrast with other major diseases, the prevalence of COPD will continue to rise, predominanty caused by an increase in the numbers of female patients with COPD ${ }^{2}$. Early diagnosis of COPD is important, since smoking cessation can reduce the rate of progression to severe disease, which benefits each patient and every practice. There are, however, both patient-and healthcare provider-related factors that hamper this early detection ${ }^{4}$, in particular underreporting of complaints and lack of active detection.

Spirometry is being increasingly implemented throughout primary care in Western Europe, and in some countries is now being used in the majority of practices 5.6 . GPs seem to appreciate this relatively new rool highly7, as it generates diagnostic information previously unattainable in primary care. It provides a comprehensive overview of airflow and lung capacity, and if performed well, permits an accurate and reliable diagnosis of obstructive airways disease and the degree of reversibility. A recent study has shown for the first time that performing simple spirometric tests in the primary care setting produces results at least as good as those of pulmonary function laboratories ${ }^{8}$. Recognizing patterns of obstruction and physiological curves, and being able to assess the quality of the spirometric procedure, is feasible and adds ro the quality of general practice". Most importantly, it has proved to be a helpful tool in convincing patients to stop smoking ${ }^{n 0}$, with the spirometric diagnosis providing the motivation to quit in the long-term ${ }^{\mathrm{II}}$.

A few How-volume curves from patients in my own practice illustrate the abowe issues. Figure I illustrates the flow-volume curve from a patient who 'tongued' the mouthpiece whilst performing the spirometric manoeuvre, causing an indented pattern easily recognized on the flow-volume curve. If one were relying only on peak expiratory flow (PEF) measurement, this poor quality manoeuvre would have suggested PEF-rewersibility. Figure 2 represents a typical flow-volume loop from a patient with moderately severe COPD, but with a relatively preserved $\mathrm{PEF}$ measurement as is often the case. If relying on PEF measurement alone, the severity of disease would have been grossly underestimated. Figure 3 is a flow-volume loop suggestive of restrictive lung disease; this 52 -year-old patient complained of progressively decreased exercise tolerance without ever smoking. The forced vital capacity (FVC) and forced expiratory volume in $1 \mathrm{~s}\left(\mathrm{FEV}_{\mathrm{I}}\right.$ ) are both reduced at 62.8 and $67.3 \%$ predicted, respectively, but the $\mathrm{FEV}_{\mathrm{a}} / \mathrm{FVC}$ ratio is normal (greater than 0.7 ) showing that this is not an obstructive curve. PEF is normal and would not have contributed a great deal to the diagnosis. The differential diagnosis includes sarcoidosis and lung fibrosis, 
both serious conditions, and this patient is curtently under investigation at the pulmonary department.

Figure r. A typhal tongue-indentation in the pre-bronchodilator carve

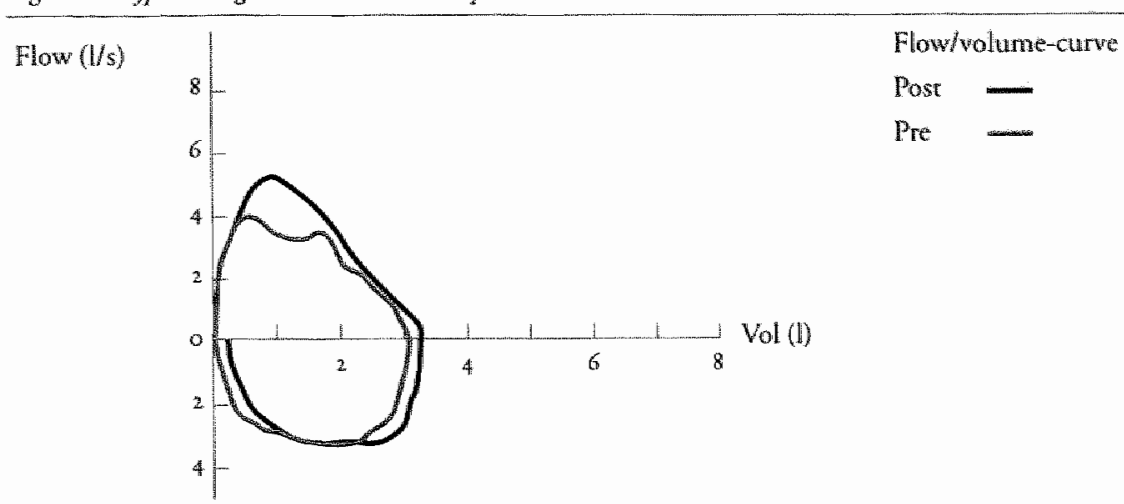

Figure 2. Obsmanive pattern with peak expinatory flow relatively preserved

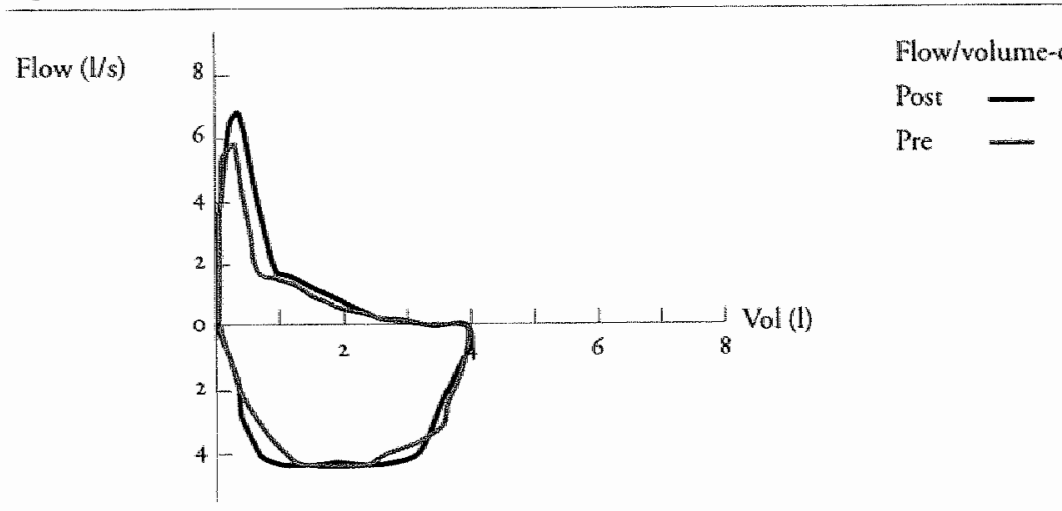

Figure 3. A restrictive pattern with normal peakflowe

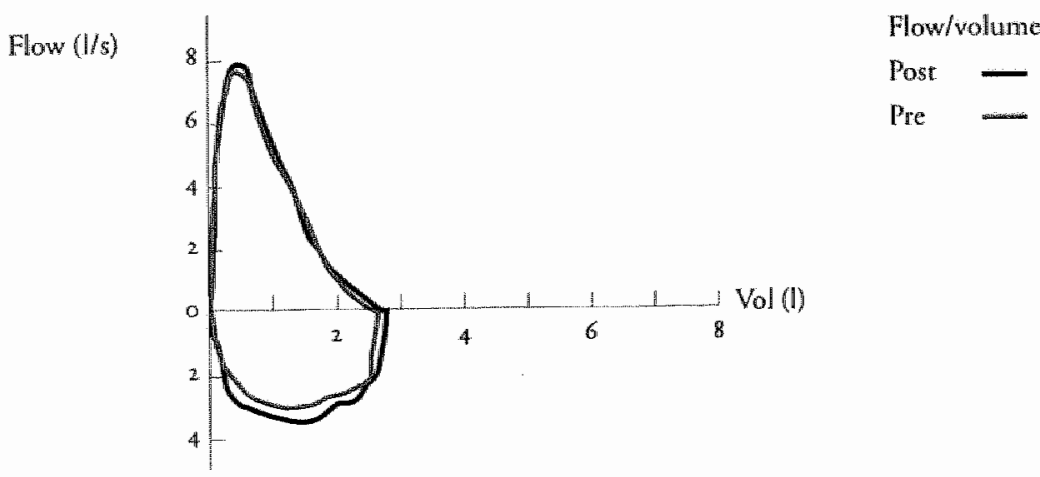


In disease management programs for $C O P D$, spirometry plays a central role in re-confirming the diagnosis (providing further argument for smoking cessation), and in monitoring disease progression. An annual rewiew for a COPD parient who is still smoking, would include assessment of medication adherence, body mass index (BMI), exercise tolerance and social functioning, and would incorporate self-management measures agreed upon during more frequent contacts with the respiratory nurse over the previous year. This generates crucial information for smoking cessation purposes, which can be directly enforced by using the results of spirometry. All these assets are potentially available within the daily practice setting, provided that adequate spirometric training and quality control are maintained ${ }^{8}$. In several countries, reimbursement policies for performing spirometry have improved, so that it can be an economically sound part of primary care business as well.

A majority of parients prefer domiciliary over hospital care ${ }^{\mathrm{r} 2}$, leading to greater patient satisfaction ${ }^{13}$. Thus, spirometry in the primary care setring can be an important example of this demand-driven care.

The proportion of parients eligible for spirometry is considerable in the primary care population, since smoking rates have remained at high levels and respiratory symptoms are among the most frequently presented. It is possible to perform screening of all smokers ${ }^{10}$, but this is likely to present a large burden on practice time and resources. Therefore, it seems more practical to use case-finding strategies to detect high-risk patients, which has been shown to increase detection rates of COPD from I 8 to $48 \%$ by selecting patients on the basis of age, symptoms and smoking ${ }^{\mathrm{I}}$. Recently, it has been proposed that PEF measurement instead of spiromerry tesring should be used to detect obstructive airways disease ${ }^{\text {Is }}$, based on secondary analyses of a large American database. In this study, although PEF testing didn't seem to miss many cases of COPD, it did lead to a positive predictive value of just $30 \%$. The question this short paper fails to answer is: what should be done with the resulting crude selection in practice? - that is, how many of these detected cases are actually asthmatic patients who may need inhaled corticosteroids?, and which ones have more advanced COPD and. should be referred because of an $\mathrm{FEV}$, less than $50 \%$ of predicted?

Previously, it has been demonstrared that PEFs' correlation with FEV diminishes as obstructive disease becomes more severe ${ }^{\mathrm{IC}}$, illustrating the necessity for spirometry to distinguish berween parients who are in need of referral and those who can be treated in primary care. In addition, using spirometry for COPD case-finding has been shown to produce a significant number of patients with restrictive lung disease, cases which would have been missed using PEF measurement alone ${ }^{77}$. Probably, all these patients still need spirometry testing, be it at a local diagnostic center or a hospital. 
In conclusion, provided sufficient funding, adequate training and motivated healthcare workers are awailable, there is no good reason why spirometric testing cannot be widely implemented. COPD is a growing problem for society, which should not be underestimated. It was once thought appropriate to measure blood pressure by the physician only using his fingertips, while the establishment of a detailed diagnosis in terms of milimetres of mercury used to be the elaborate task of a specialist. To measure is to know; primary care physicians should strive to be the first to know about their patients' airways disease, and not shy away from it.

\section{References}

I Pawwels RA, Buist AS, Calverley PM, Jenkins CR and Hurd SS, GOLD Scientific Committee. Global strategy for the diagnosis, managenent, and prevention of chronic obstructive pulmonary disease. NHLBI/WHO Globall Initiative for Chronic Obstrucrive Lung Disease (GOLD) Workshop Summary Am / Repon Crit Cani Med 163; 200r; pp. 12,56-1276

2 Mannino DM, Homa DM, Akinbami LJ, Ford ES and Redd SC. Chronic obstructive pulmonaty disease surveillance-United States, 197-2000. Centers for Disease Control and Prevention, Sarveillance Summaries. Morb Mortal Whly Rep 51; 2002, pp. I-15.

3 Anthonisen NR, Connetr JE, Kiley JP, Altose MD, Bailey WC, Buist AS et al. Efeets of smoking intervention and the use of an inhaled anticholinergic bronchodilation on the rate of decline of $\mathrm{FEV}_{\mathrm{I}}$. The Lung Health Study. IAMA 272; 1994x pp. 1497-1505.

4 Schayck van CP and Chavannes NH. Detection of asthma and chronic obstructiwe pulmonary disease in primary care. Eur Respor / 21 Suppl 39 (2003), pp. 16s-225.

5 Arne M, Spirometry in primary carew a meed for standardization. Ewr Respir J 20 Suppl 38;2002, p. 414s.

6 Bashord S. Chadwick S, Ward J, McIntyre P, Dent R and Williams I. Identifying chronic obstructive pulmonary disease un the conmunt Eur Respir/20 Suppl 38; 2002, p. 413s.

7 Donner E, Lusuardi M, De Benedetro F, Paggiaro L, Sanguinetri M, Poll A er al. Office spirometry in asthma and $C O P D$ : role and feasibilicy in standard practice. Prellminary data of the "SPACE' Italian study. Ever Respir/2.2 Suppl 45; 2003, p. 439.

8 Schermer TR, Jacobs JE, Chawannes NH., Hartman J, Folgering HT, Bottema BJ ct al. Validity of spirometric testing in a genetral practice population of patients with clyonic obstructive pulmonary disease (COPD). Thorax $\$ 8 ; 2003, \mathrm{pp} .86 \mathrm{r}-886$.

9 Chavannes $N$, Schermer T; Akkermans R, Jacobs J, Graat G van de. Bollen R, Schayck van $\mathrm{O}$, Bottena B. Impact of spiromery on GPS diagnostic differentiation and decision-making. Resp Med 2004; 98: 1124-1130.

10 Gorecka D, Bednarek M, Nowinsky A, Puscinska E, Goljan-Geremelk A and Zidinsky 1. Diagnosis of airtow limitarion combined with snoking cessation advice increases stop-smoking tate. Chert 123; 2003, pp. 1916-1923.

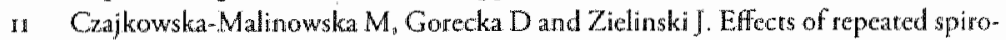
metries and anti-smoking counselling on smoking cessation tatu. Eur Reppir / 20 Suppl 38:2002, p. 1945. 
Ojoo JC, Moon T, MeGlone S, Martin K, Gardiner ED, Greenstone MA ex al. Patients" and carers' preferences in two models of care for acute exacerbations of COPD: results of a randomised controlled trial. Thorax $57 ; 2002, \mathrm{Pp}$. 167-169.

13 Wilson $A$, Whn $A$ and Parker $H$. Parient and carer sarisfaction with "hospital ar home": quantitative and qualitative results from a randomised controlled trial.

Brf Gens Pract 52; 2002, pp. 9-13

14 Schayck van $\mathrm{CP}$, Loozen JMC, W/agena E, Akkermans RP and Wesseling GI. Detecting parients at a high risk of developing chronic obstructive pulmonary disease in general practice: cross sectional case finding study. $B M J 324 ; 2002$, p. 1370.

15 Jackson $H$ and Hubbard $R$. Detecting chronic obstructive pulmonary disease using peak flow rate: cross sectional survey. BMJ $327 ; 2003, \mathrm{Pp}, 693-694$.

I6 White PT, Cajear E, Fleming T, Nolan D and Gray B. The relationship berween peak expiratory How rate (PERR) and forced expiratory volume in the first second ( $F E V_{R}$ ) at low levels of $\mathrm{FEV}_{\mathrm{A}}$. Implications for the assessment of COPD (chronic obstructiwe pulmonary disease) in primary care. Eur Respir/20 Suppl 38; 2002, p. 397s.

17 Mannino DM, Ford ES and Redd SC. Obstructive and restrictive lung disease and markers of inflammation: data from the Third National Health and Nutrition Examination. AmJ Med 144; 2003, pp. 758-762.

\section{Reply}

\section{Response to: the Necessity for Spirometry in the Primary Care Management of COPD}

\section{Patrick White}

The case for the widespread adoption of spirometry in primary care put by Niels Chavannes is based almost solely on the role of spirometry in the detection of COPD at an early stage in the disease. Early detection of COPD should lead to the possibility of promoting smoking cessation in smokers with COPD. Smoking cessation is the great challenge in COPD. Anything that increases smoking cessation rates is to be recommended. This is essentially an argument for the role of screening with spirometry in the secondary prevention of $\mathrm{COPD}$.

The case for screening for $C O P D$ in primary care should be determined ultimately by the advantage offered to patients who are identified from the screening process ${ }^{2}$. It requires an analysis of the number of cases detected by screening in whom the development of COPD can be arrested by a smoking cessation intervention. It demands a clear plan on how a screening programme in primary care can be implemented. Evidence to enable all of these conditions to be addressed is not yet available, but the argument is compelling for those primary care teams which are motivated to use spirometry as a screening tool now. Interestingly, the paper quoted by Chavannes to support his statement that spirometry is "proven to be a 
helpful tool in convincing patients to stop smoking" shows that there is no difference in the cessation rate of subjects with normal lung function compared to those with abnormal lung function and suggests the opposite of his conclusion ${ }^{3}$.

Chavannes argues that primary care has the capacity to do spiromerry as well as it is done in hospital. This is not surprising particularly with modern hand-held electronic spirometers which can be set to accept spirometric readings only if the subject achieves the ATs criteria of three readings with an $\mathbb{F E V}{ }_{\mathrm{x}}$ within 0.21 of each other ${ }^{4}$ Spirometry is a relatively simple test. It requires careful instruction of the patient, three acceptable tests, regular calibration of the instrument, and regular in-service training of the operator. Its principal drawback is that it is time consuming to conduct reliably. In addition, it requires rechnical expertise to interpret and it is unlikely to be needed often enough in day-to-day consulting to justify every $\mathrm{GP}^{\mathrm{P}}$ and practice nurse becoming proficient in its use. It is likely to remain a test that is done outside the routine consultation.

The role of lung function in the primary care management of COPD is complex at every stage of the disease, and not just in screening. The approach to lung function in COPD management is demanding whether it is in the diagnosis of the disease, the treatment of the symptoms, the management of exacerbations, or the interventions that are made to prevent or shorten the length of hospital admissions. None of these issues is addressed by Chavannes although he mentions in passing the role of spirometry in diagnosis and monitoring.

The management of COPD is undergoing a radical shift. From a relatively nihilistic position in the late 1990 s when the only invention thought likely to influence the outcome of the disease was smoking cessation, the approach of clinicians and researchers in COPD is changing. In the early stages of the disease asthma and COPD may co-exist and the airways obstruction may have a significant reversible component. Later in the disease when reversibility appears to have been all but lost clinical improvement can still be gained with long acting inhaled anti-cholinergics (tiotropium), with long acting beta-agonists (salmeterol and formoterol) and with oral steroids $s^{5-7}$. The impact of these changes though small is significant and worth seeking. The effects of the drugs are subtle. They infuence the frequency of exacerbations as well as symptoms. They also improve lung function. Lung function also deteriorates in acute exacerbations and improves with recovery.

There are advantages to measuring lung function in severe COPD. The measurement gives doctor and patient an objective view of what is happening, which they can share. Small changes encourage patient and doctor to continue with their strategy. The absence of change after a new treatment may convince patients and doctors that the intervention has little to 
offer. These measurements should form part of the routine dialogue around the disease upon which the treatment (including smoking cessation) is set. Spirometry is useful for this purpose every $\mathrm{I}-2$ years. It will only be used within the consultation by en thusiasts who are happy to borrow the time from other consultations. When it comes to the annual or biennial test, where it is done and how is less important than that it is done well. In the meantime, the less complete measure of lung function, peak expiratory flow (PEF), should help to fill the gap. PEF measures airway calibre which is the element of lung function which the drugs are designed to improve, and which gets worse during exacerbations. It tells us little about the underlying structural damage caused by the disease but that detail can be provided every $\mathrm{I}-2$ years by spirometry. Lung function measurement is not a substitute for the detailed clinical assessment and advice needed by COPD sufferers but it provides a useful backdrop to the consultation and helps to anchor it in the underlying process of the disease.

\section{References}

1 N. Chavannes, The necessity for spirometry in the primary care management of COPD. Rrim Care Respir / 13 1; 2004, pp. II-14.

2 J.M. Wilson, Principles of screening for disease. Proc R Soc Med 64 12; 1971 , pp. 1255 1256

3 D. Gorecka, M. Bednarek, A. Nowinski, E. Puscinska, A. Goljan-Geremek and I. Zielinski, Diagnosis of airflow limitation combined wirh smoking cessation advice increases stop-smoking rate. Chest 1236; 2003, pp. 1916-1923.

4. Committee on Proficiency Standards for Clinical Pulmonary Function Laboratories, American Thoracic Society. Standardization of Spirometry. Am J Respir Crit Care Med $1995 ; 152: 1107-36$.

5 R. Casaburi, D.A. Mather, P.W. Jones, A. Wanner, P.G. San, R. L, ZuWallack et al., A long-term evaluation of once-daly inhaled tiotropum iri chronic obstructive pulmomary disease. Eur Respir / 19 2; 2002, Pp. 217-2244.

6 P. Calverley, R. Pauwels, J. Vestbo. P. Jones, N. Pride, A. Gulsviket al, Combined saj.meterol and futicasone in the treatment of chronic obstructive pulmonary disease: a rundomised controlled trial. Lawnet 36r 9356;2003, pp. 449-456.

7 R.S. Lrwin and J.M. Madison, Systemic corticostaroids for acute exacerbations of chronic obstructive pul monary disease. N Engl/ Med 348 26:2003, pp. 2679-2681 


\title{
Spirometry and Peak Expiratory Flow in the Primary Care Management of COPD
}

\author{
Patrick White
}

Department of General Practice of Primary Care, Guy's, King's o St Thomas'School of Medicine, King's College London and Genenal Practitioner, Croundale Medical Centre, London SErg $3 N Y$ UK

\begin{abstract}
Spirometry is essential for the diagnosis of chronic obstructive pulmonary disease (COPD). In patients with COPD the decline in lung function is usually so slow that spirometry is unlikely to provide significantly new information more than every $1-2$ years. However, it is useful to have an objective measure of lung function in the assessment of acute exacerbations of COPD and in the assessment of treatments.

Peak expiratory flow (PEF) has been dismissed by national and international guidelines as an inappropriate test for the assessment of the impact of COPD, but with poor evidence in support of this position. This seems short-sighted since PEF is a reliable and reproducible test and could contribute to the management of COPD in the short term and in support of spirometry. As a result of infection or in response to treatment there may be changes in airway calibre in COPD which could be captured in the consultation by $\mathrm{PEF}$. In a primary care setting spirometry is too time consuming and complex to be provided in the context of normal acute consulting. Furthermore there is no evidence that spirometry provides more information than PEF in the day-to-day management of a patient already diagnosed with COPD using forced expiratory volume in the first second/ forced vital capacity (FEV/FWC).

Primary care teams should ensure that their patients have adequate access to high quality spirometry. This can be provided in primary care or in local centres or in hospitals depending on the interest, motivation and resources of primary care teams. In support of spirometry general practitioners ( $G P$ s) should then consider using PEF in the day-to-day management of COPD.
\end{abstract}




\section{Introduction}

International guidelines for the management of chronic obstructive pulmonary disease (COPD) have declared that spirometry is the only acceptable objective measure of the impact of COPD both in the diagnosis and in the continuing management of the disease ${ }^{1,2}$. This has presented primary care teams with a difficult choice. Should they invest in spirometry as a routine disease management tool in primary care? Or should primary care teams rely on hospital laboratory services for the diagnosis of COPD, and use history and examination alone for its day-to-day clinical assessment? Or is there another way in the primary care management of COPD? Many general practirioners (GPs) have opted for practice-based spirometry as the only credible approach to good clinical care of COPD. This option is supported by a growing literature on the use of spirometry in the primary care management of $\mathrm{COPD}^{3}$. Most recently the new contract for GPs in the UK has specifically named the annual measurement of forced expiratory volume in the first second ( $\left.F E V_{1}\right)$ in COPD as a quality measure which will earn a financial reward4. In addition to the use of spirometry in the diagnosis of suspected COPD and in its day-to-day management, spirometry has recently been promoted as a screening tool for the early derection of $\mathrm{COPD}^{5,6}$. These proposed roles for spirometry in primary care COPD management are based on two assumptions. The first assumption is that peak expiratory flow (PEF) should have no role in the management of COPD. The second assumption is that spirometry is a suitable deskrop tool for use in standard general practitioner consultations. Neither of these assumptions is well supported by evidence. In this paper the evidence for the unsuitability of PEF in the day-to-day management of COPD is questioned. The factors which limit the use of spirometry in routine primary care consultations are considered and a proposal is made for the integration of PEF and spirometry in the objective assessment of COPD outcome.

\section{Peak expiratory flow in COPD}

British Thoracic Society Guidelines, and later the Global Initiative for Chronic Obstructive Lung Disease (GOLD) have both based their rejection of peak expiratory How as a useful clinical test in COPD on research which actually proposed the opposite, the superiority of PEF over forced expiratory volume in the first second $\left(\mathrm{FEV}_{1}\right)^{x, 2,7}$. Concerns about the limitations of PEF have been about the reliability and reproducibility of the test itself, and about the capaciry of the test to give an adequate assessment of the loss of lung function in COPD. There is good evidence that PEF, measured with a hand-held peak flow meter, is both reliable and reproduc- 
ible ${ }^{8-12}$. A recent report suggests that PEF may be more reproducible than FEV $_{1}{ }^{12}$.

The status of PEF has been undermined by the persistent use of inaccurate reference equations for predicted normal values. In the UK, for example, the Association for Respiratory Technology and Physiology has conrinued to enDORse the predicted values for PEF derived from the European Coal and Steel Community survey ${ }^{13 \times 14}$. The equations from which their values are derived significantly underestimate predicted values in adults compared to the equations of Nunn and Gregg which are now preferred by the European Respiratory Society ${ }^{1 I_{5} 15}$. They have led to PEF being presented in report outputs from lung funcrion laboratories as equal to or greater than the predicted values for age sex and height in patients in whom the $\mathrm{FEV}_{\mathrm{T}}$ is less then predicted. They undermine clinicians' confidence in PEF as a measure. Although the problem of inaccuracies with predicted values is not unique to PEF and is also seen in $\mathrm{FEV}_{\mathrm{I}}$, as Roca er al. have demonstrated, the observation is damaging to the perception of PEF because FEV ${ }_{1}$ is referred to as the GOLD standard ${ }^{16}$.

A second but less obvious problem has been the inaccuracy of the scale of measurement used on European peak flow metres ${ }^{17}$. Miller et al. have shown that peak flow meters have characteristic error profiles which under-read peak flow at lower and higher flow rates and over-read How in the middle range ${ }^{8,18}$. These errors are easily correctable mathematically and more accurate scales approved by the American Thoracic Society are provided for peak flow meters in North America ${ }^{\mathrm{I}}$. The failure to correct the scales of peak flow meters in Europe reflects difficulty in agreeing a policy on standards for peak flow meters in the European Union.

The most important reason to doubt the usefulness of PEF compared to spirometry (and $\mathrm{FEV}$ in parricular) in COPD lies in the difference in the information each provides. PEF is tecorded in the first tenth of a second of forced expiration. FEV, continues to record forced expiration for a further $0.9 \mathrm{~s}$. As expiration progresses the volume of expired air falls as the flow rate falls. FEV, records what happens to expired air after peak flow is reached. It is in this component of forced expiration that the changes characteristic of $C O P D$ are observed. Instead of the steady proportional decline of expiratory flow which is seen in normal subjects afrer peak flow is reached (Figure ra), the flow rate collapses in parients with severe COPD (Figure ib). The sudden fall in expiratory flow is due to the structural damage caused by COPD. Loss of the parenchymal architecture of the lung through the chronic inflammatory processes of COPD removes the elastic support of the small airways. The rise in incra-thoracic pressure during expiration causes some small airways to collapse, trapping air in the alveoli and preventing its expiration, leading to a sudden drop in expiratory flow. This damage in COPD is permanent and progressive, and cannot be re- 
versed by treatment. It is this pathological process which is measured by spirometry and which cannot be assessed by PEF. This is why $\mathrm{FEV}_{\mathrm{I}} / \mathrm{FVC}$ is the diagnositic test of choice for COPD.

Figure 1 . Fou wotume loops from a person with normal long function (a) and a person with aduanced COPD (b)

(a)

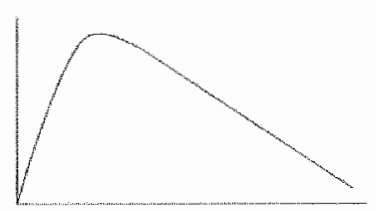

(b)

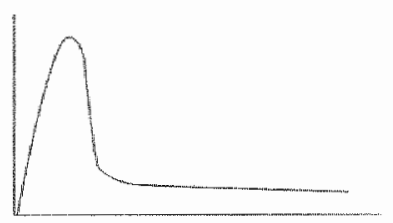

The decline in lung function in COPD is slowly progressive ${ }^{2}$. There is no point in assessing the decline in $\mathrm{FEV}_{1} / \mathrm{FEC}$ more than every $\mathrm{I}-2$ years. In the meantime important short-term changes occur in airway callibre in response to acute exacerbations and in response to treatment ${ }^{20-22}$. Acute exacerbations lead to narrowing of the bronchi and bronchioles with increasing mucous, inflammatory exudate, and muscle spasm. There are other elements of lung function which are increasingly tecognised as important in COPD such as the inspiratory reserve capacity and relaxed vital capacity, but the immediate changes which result from infection or which improve with treatment of exacerbations are those of airway calibre ${ }^{23}$. Allhough the pathological basis of the reversible elements of COPD is different to that of asthma, the effect is similar in that the key dynamic element is airway calibre. Why should PEF be less useful in measuring changes in airway calibre in COPD than it is in asthma? According to this reasoning PEF should be as useful in the short term evaluation of COPD as it is in asthma.

If there is no advantage in spirometry compared to PEF in measuring the short term changes in COPD should primary care teams not continue to use PEF in the day-to-day management of COPD? Since there is no dispute about the pre-eminence of spirometry in the diagnosis of $C O P D$ the challenge for primary care should be to consider how best to acquire high quality access to spirometry to add to existing provision of PEF.

\section{Access to spirometry in primary care}

Spirometry is relatively easy to perform with appropriate training and adequate facilities. It should be possible to provide high quality spirometry in primary care if staff are motivated and well supported. There are many reports of primary care teams integrating spirometry into their care of patients with respiratory disease which have demonstrated that it is feasible 
and acceptable ${ }^{3,5}$. The British Thoracic Society Guidelines for the management of COPD outlined three possible options for primary care teams: spirometry provided by the primary care team, a mobile visiting spirometry service, or open access to hospital laboratory spirometry ${ }^{\mathrm{I}}$. To these may be added the option of primary care based recording of spirometry with a local respiratory specialist or general practirioner with a special interest providing reporring of the results electronically, "down the line". The advantages and disadvantages of these methods have been described in detail by Schermer et al. in this journal in $2000^{3}$.

However, spirometry is time consuming and cannor be performed easily in the course of a normal consultation. It is considerably more time consuming and complex than PEF recording ${ }^{13,19}$. Patients should be at rest for at least $5 \mathrm{~min}$ before the test. They require instruction in carrying out the test especially if they nave not done it previously. Experienced technicians allow at least to min per test. Van Schayck's and Loozen's report that it takes about $4 \mathrm{~min}$ to carry out spirometry in primary care seems overopt:mistic, especially in patients with reduced lung capacity and limited cxercise tolerance ${ }^{6}$. This is not a desktop test which can be easily administered without warning in the course of a GP's or practice nurse's consulting session.

When patients attend acutely with exacerbations of COPD spiromerry has to be arranged at a later appointment unless the clinician has unexpectedly the time and opportunity there and then, or unless there is another colleague free to do the test. Realistically the choice facing the clinician is either to settle for PEF during the consultarion and to arrange to have spirometry done later, or to continue the clinical assessment without any form of lung function measurement. PEF may add useful information about airway calibre at the time of presentation which can be re-measured at review on recovery or after treatment.

Despite enthusiasm and commirment spirometry may be done unacceptably badly in primary care ${ }^{24}$. The decision to provide spiromerry in primary care must therefore be determined by the capacity and motivation of the primary care team to provide a reliable and high quality service to the patient.

\section{Conclusion}

Spirometry is essential for the diagnosis of COPD. In patients with COPD the decline in lung function is usually so slow that spitometry is unlikely to provide significantly new information more than every $\mathrm{I}-2$ years. In a primary care setting spirometry is too time consuming and complex to be provided in the context of normal acure consulting. Furthermore there is no evidence that in a patient already diagnosed with COP D spiromerry pro- 
vides more informarion than PEF in the day-to-day management of the condition. Primary care teams should therefore ensure firstly that their patients have adequate access to high quality spirometry. This can be provided in primary care or in local centres or in hospitals. In support of spiromerry GPS should consider using PEF in the day-to-day management of COPD.

\section{References}

1 BTS guidelines for the management of chronic obstructive pulmonary disease. The COPD Guidtelines Group of the Standards of Care Comminte of the BTS. Thonox $1997 ; 52($ Suppl 5): SI-28.

2. Pauwels RA, Buist AS, Ma P Jenkins CR and Hurd SS. Global strategy for the diagnosis, management, and prevention of chronic obstructive pulmonary disease: National Heart, Lung, and Blood Instinte and World Health Organization Global Initiative for Chronic Obstructive Lung Disease (GOLD): executive summary. Am / Respir Crit Care Med 468;2001, pp. 798-825.

3 Schermer TR], Folgering HTM, Botrema BJM, Jacobs JE, Schayck CP van and Weel $C$ van. The value of spirometry for primary care: asthma and COPD. Prim Care Respirl 93: 2000, pp. 51-55.

4 General Practitioners Committee, The NHS Confederation. New GMS Contract 2003. Investing in general practice. London: British Medical Associarion; 2003.

5. Schayck $\mathrm{CP}$ and Chavannes NH. Detection of asthma and chronic obstructive pulmonary disease in primary care. Eur Respir/ Suppl 39:2003, pp. 16s-22s.

6 Schayck CP van, Loozen JM, Wagena $\mathrm{E}_{y}$ Akkermans RP and Wesselling GJ. Detecring patients at a high risk of developing chronic obstructive pulmonary disease in general practice: cross sectional case finding study. BMJ 32.47350; 2002, p. 1370

7 Kelly CA and Gibson G]. Relation berween FEV and peak expiratory flow in patients witly chronic airflow obstruction. Thorax 43; 1988 , pp. 335-336.

8 Miller MR, Dickinson SA and Hitchings DJ, The accuracy of portable peak flow meters. Thorax 47 (1992), pp. $904-909$

9 Miller MR and Ouanjer PH. Peak flow meters: a problem of scale. $B M / 3086928$; $1994, \mathrm{PP}, 548-549$

10 Pedersen OF, Miller MR and Mark "TW van der. Performance testing new peak flow meters. Ene Respir/ n2; 1998, pp. $261-262$.

i1 Quanjer PH, Lebowitz MD, Gregg I, Miller MR and Pedersen OF Peak expirarory flow: conclusions and recommendations of a Working Party of the European Respiratory Society. Eur Respü J 24 Suppl; 1997, pp. 2 S-85.

:2. White PT, Cajeat E, Fleming T, Gray B and Nolan. D. The relationship berween peak expiratory fow rate (PEFR) and forced expiratory volume in the first second (FEV). Inplications for the als sessment of $C O P D$ (chronic obstruccive pulmonary disease) in primary care. Eur Respirf zo Suppl. 38; 2002, p. 397s.

13 Bush $A$ and Cramer D. Guidelines for the measurement of respiratory function. Respir Med 88 10; 1994: D. 798

14 Quanjer PH, Tamneling G], Cotes JE, Pedersen OF, Peslin R and Yernauk JC. Lungvollumes and forced ventilatory fows - Report Working Parry Standardization of Lung-Function Tests European-Community for Steel and Coal-Official Starement of the European Respiracory Society. Eur Respir J 6; 1993. Pp. 5-40 
15 Nunn AJ and Gregg 1. New regression equations for predicting peak expiratory flow in adults. $B M / 298$ (1989), pp. $1068-1070$

16. J. Roca, F. Burgos, ]. Sunyer, M. Saez, S. Chinn, J.M. Anto et al, References values for forced spiromery. Eur Respin/ In 6:1998, pp. 1354 -136:.

n7 Miller MR and Quanjer PH. Peak flow meters - a problem of sale. BMJ 3086928 (I994), PP. $548-549$.

18 Pedersen OF and Miller MR. The Peak Flow Working Group: rest of portable peak How meters by explosive decompression. Eut Respir / 24 Suppl. (1997), PP. 235-25S

19 Commirree on Proficiency Standards for Clinical Punonary Function Laboratories, American Thoracic Society. Standardization of Spirometry. Am / Respir Crir Care Med 1995; 15: $: 1107-36$.

20 Ram FS and Sestini P. Regular inhalled short acting beraz agonists for the management of stable chronic obstructike pulmonary disease: cochrane systematic review and netaanalysis. Thorax $587 ; 2003$, pp. 580-584.

21 Irwin RS and Madison IM. Systemic corricosrerouds for acute exacerbations of chronic obstructive pulmonary disease. N Engl / Med 348 26; 2003, pp. 2679-2681

22. Donohue JF, Noord JA van, Bateman ED, Langley S1, Lee A, Witek TJ at al. A 6month, placebo-controlled scudy comparing lung function and health status changes in COPD patients treated with tiorropium or salmeterol. Chest 1221 (2002), pp. 47-55

23 O'Donnell DE, Lam M and Webb KA, Spironertic correlates of improvement in exercise performance after anticholinergic therapy in chronic obstructive pulmonary disease. Am J Respir Crit Care Med 160 2; 1999, pp. 542 549.

24. Eaton T, Withy S, Garrett JE, Mercer J, Whitlock RM and Rea HH, Spirometry in primary care practice: the importance of quality assurance and the impact of spirometry workshops. Chest 116 2; 1999, Pp. 416-423.

\section{Reply}

\section{Response to: Spirometry and Peak Expiratory Flow in the Primary Care Management of COPD}

\section{Niels Chavannes}

Basically, Dr. White argues that we do need spirometry to establish a diagnosis of chronic obstructive pulmonary disease (COPD), but that subsequently we should use peak expiratory flow (PEF) measurement to assess airway calibre during 'normal acure consulring' and 'day-to-day management of COPD'. It is interesting that so much emphasis is laid on the repeated measurement of millilitres under all circumstances by a $\mathrm{GP}$ who wants to represent the average colleague dealing with time restrictions in daily practice. A COPD patient presenting to me with an acute exacerbation is not required to do any lung function; rather l'd look at him (how ill does he look?, does he use accessory muscles?) and listen to his speech (will. he complete sentences?) and naturally listen to the lungs. Most importantly I will ask how sick he feels, how many steps he is able to take and what is 
the time course and progression of symptoms in relation to his earlier experiences. PEF measurement (or for that matter spirometry) does not add much in that situation; it rather wears the patient out further. If $\mathbb{I}$ were to do a diagnostic test it would be an oxygen saturation measurement $\left(\mathrm{SpO}_{2}\right)$, which is non-invasive and does not pose a burden to the patient. This could provide important additional information for referral. if one suspects respiratory failure ${ }^{\pi}$.

Using PEF measurement in day-to-day management is a possibility, but again one really wonders why? Asthma certainly is a variable disease state that needs monitoring when unstable, or when the (mostly adolescent) patient needs to gain insight in the fluctuating nature of airway obstruction and how to control it by medication. COPD is entirely different. Mostly elderly patients need to learn about the self-enforcing negative spiral of physical inactivity and social deprivation. They need to recognize the danger of weight loss and the importance of nutrition plus exercise. Most importantly, they need to srop smoking and continue abstinence over the years to come. The tools to reach these goals are education, self-management, regular physical activity, dietary intervention and smoking cessation programs. All these elements should ideally be integrated in a disease management program, and this could in turn be coupled to an annual office visit, which usually includes a lung function measurement. I always use this moment to stress the importance of all elements mentioned above and feel greatly supported by the visual explanation the flow-volume curve provides. Also, I am happy to assess any degree of reversibility (which is quite variable in time) because it might justify the use of inhaled corticosteroid therapy; I am relieved when obstruction has not accelerared in the past year, and always point out the clear mid-expiratory loss of airway funcrion as the main reason for all the hard work and effort put into the program. Without spirometry, I would find it much harder to keep the patient and primary care team motivated. Moreover, without the How-volume curve, I wouldn't know if I were missing a patient with some restrictive airways disease (Figure I), which may justify an entirely different interwention.

Regular PEF measurement would probably be much betrer than no measurement at all, but in a patient with moderate COPD, one would still want regular spiromerry to check for referral indications, such as an $\mathrm{FEV}_{\mathrm{I}}$ of less than $50 \%$ predicted, at which point mortality begins to increase 3 . Furthermore, many practices are already equipped with a spirometer, and it simply does not make sense to use both test modalities. Zielinski has described how in Poland spiromerry has been the key to his successful national smoking cessation program 4 . In the Netherlands, several pragmatic primary care studies have shown that spirometry is feasible, valid and interpreta- 


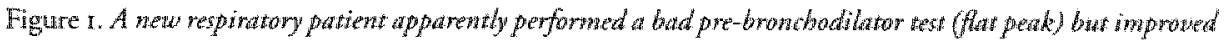

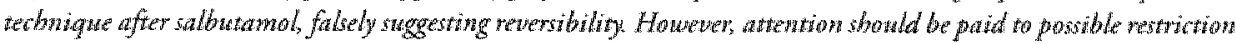

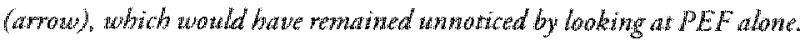

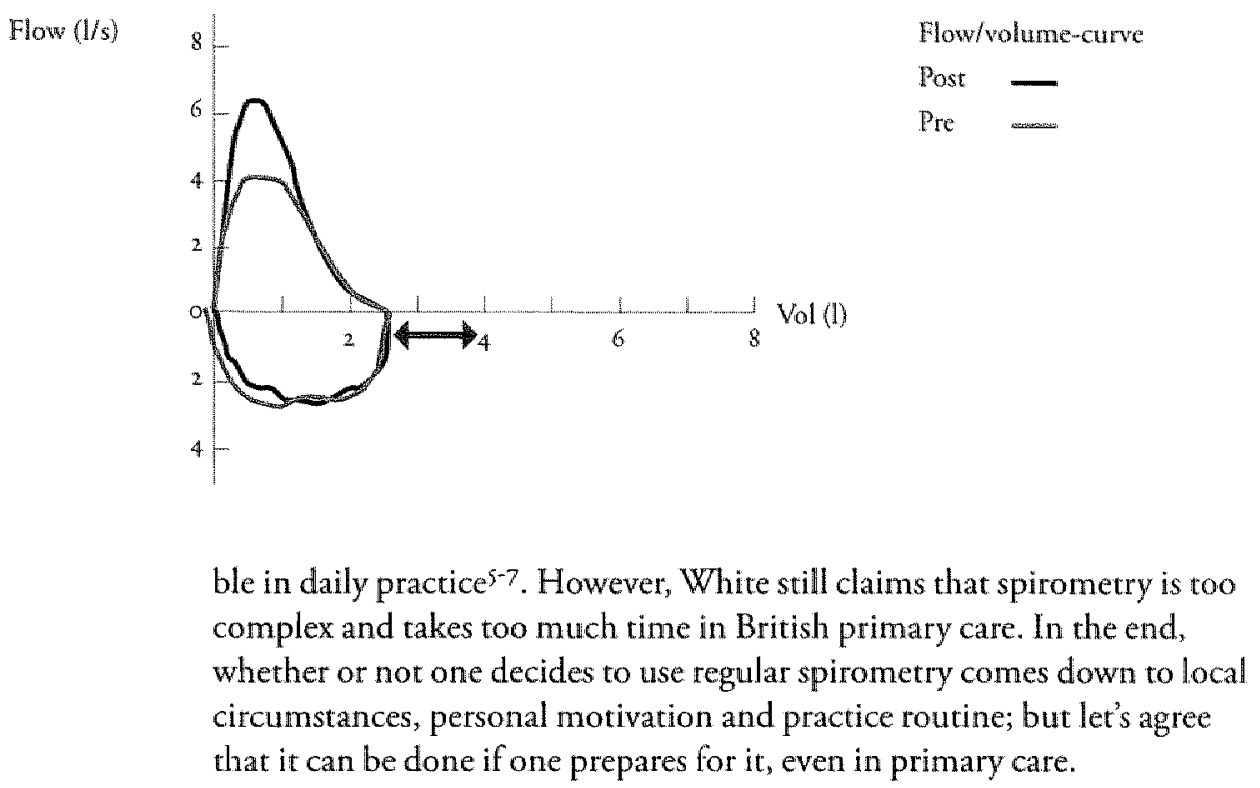

\section{References}

I White P. Spirometry and peak expiratory How in the primary cate management of COPD. Prim. Catre Resp.J. 13 I; 2004, Pp. 5.8.

2 Chavannes N. Pulse oximetry and respiratory disease in primary care [editorial]. Prim Care Resp / 12; 2003, pp. 2-3.

3. Cell B. The impontance of spirometry in COPD and asthmen. Weffer on approach to mamagement. Chest $117 ; 2000, p p .159-19 S$.

4 Zielinski ], Bednarek M. Know the Age of Your Lung Study Group. Early detection of COPD in a high-risk population using spurometric screening. Chest 2001; 119: 731-36.

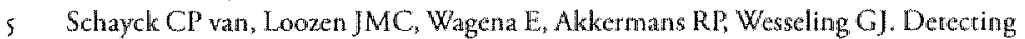
patients at a high risk of developing chronic obstructive pulmonary disease in general pracice: cross-secrional case finding study. BM/2002; $324: 1370$.

6 Schermer TR, Jacobs. E, Chavanes NH, Hartman I, Folgering HT, Botrema BJ and Weel $C$ wan. Validity of spitometric testing in a general pracrico population of parients with chronic obstructive pulmonary disease (COPD). Thora 58 ; 2003. Pp. 861-886.

7 Chavanes N, Schermer T, Akkermans R, Jacobs J, Graf G vandd, Bollen R, Schayck $O$ van, Botrema B. Impact of spirometry on GPS diagnostic differentiation and decision-making. Resp Med 2004; 98: 1124-1130. 
Chapter 4

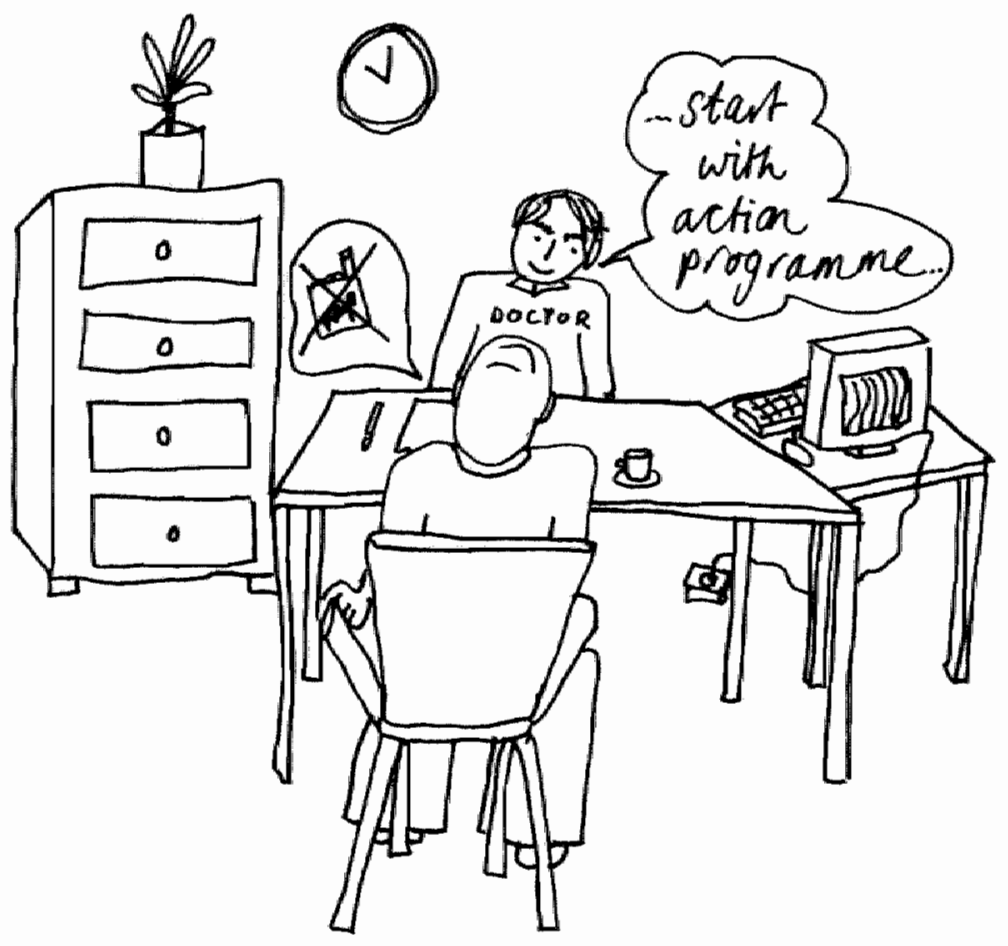




\section{Patterns of Inflammation and the Use of Reversibility Testing in Smokers with Airway Complaints}

Niels H Chavannes, Juanita HJ Vernooy, Tjard RJ Schermer,

Jan A Jacobs, Mieke A Dentener, Chris van Weel, Onno CP van Schayck, Emiel FM Wouters

Submitted for publication

Abstract published in European Respinatory Journal 2003; 22 (suppl 45): 69s 


\section{Abstract}

Aim

Although both smoking and respiratory complaints are very common, tools to improve diagnostic accuracy are scarce in primary care. This study aimed to reveal what inflammatory patterns prevail in clinically established diagnosis groups, and what factors are associated with eosinophilia, the most probable target for treatment.

\section{Method}

Induced sputum and blood plasma of 59 primary care patients with COPD $(n=17)$, asthma $(n=11)$, chronic bronchitis $(C B, n=14)$ and smokers with no respiratory complaints ('healthy smokers', $n=I 7$ ) were collected, as well as lung function, smoking history and clinical work-up. Patterns of inflammatory markers per clinical diagnosis and factors associated with eosinophilia were analyzed by multiple regression analyses; the differences expressed in odds ratios (OR) with $95 \%$ confidence intervals.

\section{Results}

Univariately, COPD was associated with sputum neutrophilia, raised levels of IL-8, STNF-R55 and STNF-R75 in sputum and plasma, while LBP was only raised in plasma. Healthy smokers showed a relatively lowered LBP in plasma, but no other significant relations. Asthmatics showed a positive association with sputum eosinophilia, and inversely with neutrophils in sputum, while patients with chronic bronchitis showed raised levels of sputum lymphocytes and lower levels of STNFR55 and STNF-R75 in plasma. Multivariately, COPD remained signifcantly associated with raised plasma-LBP (OR $1.2[$ r.04-r.37]) and STNFR55 in sputum (OR I.OI [r.OOI-I.OI]), while HS expressed significantly lowered plasma-LBP (OR 0.8 [0.72-0.95]). Asthma was characterized by higher sputum eosinophilic counts (OR I.3 [1.05-1.54]); whille CB showed significantly higher lymphocytic sputum counts (OR $1.5[1.12-$ I.9]). Clinically, sputum eosinophilia was significantly associated with reversibility after adjusting for smoking, lung function, age, gender and allergy.

\section{Conclusion}

Clinical diagnoses were largely distinguishable on the basis of a panel of inflammatory markers in sputurm and blood plasma. Multivariately, a smaller set of potential biomarkers remained significantly associated, which opens the possibiliry to test predictive values of these markers in larger prospective populations. Sputum eosinophilia remained significantly associated with reversibility across the spectrum of respiratory disease, while other dinical characteristics were not. 


\section{Background}

Smoking causes chronic airway complaints in a significant proportion of the population ${ }^{1}$. The primary care physician and respiratory nurse specialist are generally the first to assess patients with a chronic cough, complaints of dyspnea or sputum production ${ }^{2}$. Ideally, common causes like CoPD and asthma are differentiated by spirometry with reversibility testing, performed and interpreted by sufficienty trained staf $\$, 4$. However, this differentiation is especially difficult in chronic respiratory patients with a smoking history, where symptoms often overlap and even lungfunction does not always seem to offer a clear distinction.

Sputum induction is a valid and noninvasive method to assess airway inHammation, which is useful in both asthma and COPD ${ }^{7,8}$. There is evidence of different cellular and cytokine activation in induced sputum from smoking compared with nonsmoking asthmatics; a relationship is apparent between smoking history, airway inflammation and lung function in smoking asthmatics ${ }^{21}$. Patients with COPD show significantly higher percentages of neutrophils and levels of soluble TNF receptor P5S ( $5 T$ N F-R 55 ) and the chemokine interteukin $1 L-8$ in sputum as compared with control subjects 5 . Both neutrophils and easinophils seem to be activated by IL $-8^{19}$. ${ }^{26}$, which seems to be closely related with the degree of airflow obstruction $^{20}$. In the circulation, increased levels of inflammatory markers such as lipopolysaccharide binding protein (LBP) and STNF-R.55 have been reported $^{27}$. In mild asthmatics, but also in other respiratory patients, sputum, bronchoalveolar lavage and blood measure different compartments of inflammation ${ }^{18}$. The proportion of eosinophils in sputum is a more accurate marker of asthmatic airway inflammation than the proportions of blood eosinophils ${ }^{\text {to }}$, suggesting a local inflammatory process of lung tissue.

In daily primary care practice, however, diagnosis is established on the basis of symptoms, risk factors and if available, lungfunction measurement. We therefore studied the relation between patterns of inflammation and clinical diagnosis in primary care parients. By careful history taking and measuring lungfunction including reversibility in smoking patients with respiratory complaints, we distinguished four clinical diagnosis groups: COPD (according to GOLD I), asthma, chronic bronchitis (GOLD O) and a control group of 'healthy smokers' (no respiratory symptoms, no obstruction). Aim of the study was to reveal any specific inflammatory patterns underlying these diagnosis groups, which were clinically established according to the points mentioned above. We also tested what factors were associated with eosinophilia, the most probable target for treatment in asthmatics, but also likely in other respiratory patients when present. 


\section{Methods}

\section{Patient selection}

The COOPT-study ${ }^{25}$ recruited a heterogeneous group of (current or past) smokers with chronic airway complaints from general practice. Reversibility was not an exclusion criterion, but asthma history was. Patients between $40-88 \%$ of predicted values were included, mean post-BD PEV ${ }_{1}$ was $66 \%$ of predicted value (GOLD 2). A subgroup of the COOPTpopulation underwent sputum induction at the lung function laboratory. Additionally, control smoking parients with asthma features (atopy), patients with symptoms of chronic bronchitis (GOLD O), and smokers without respiratory complaints ('healthy smokers') were recruited in general practice. Respiratory symptoms, risk factors, careful clinical history taking and lungfunction measurements inclucling reversibility determined the diagnostic category into which subjects were divided, analogue to earlier studies ${ }^{53}$. During the recruiting phase, considerable effort was put into age-matching, since this has been shown to affect sputum induction results ${ }^{36}$. A smoking history of ar least 15 pack-years was used as criterion for inclusion. Exclusion criterion was any current inhaled or oral corricosteroid use, since this is known to possibly influence sputum induction results and underlying systemic inflammatory patterns ${ }^{28,34}$. Furthermore, a history of increased respiratory complaints or respiratory tract infection during 4 weeks preceding the study was considered a criterion for exclusion. The control subjects lived in the same geographical area as the patient population. The study was approved by the Medical Ethics Committee of the University Hospital Maastricht, and writren informed consent was obtained from all subjects.

\section{Pulmonary function testing and blood and sputum sampling}

Trained lung function technicians measured FEV, using a spirometer (Masterlab; Jaeger, Würburg, Germany) before and is minutes after inhalation of $B$-agonist via a metered-dose inhaler. Before sputum induction (8: oo to 10: 0o A.M.) took place, blood samples were collected in evacuated blood collecting tubes containing ethylenediaminetetraacetic acid (EDTA; Sherwood Medical, St. Louis, MO). Plasma samples were stored at $-80^{\circ} \mathrm{C}$ until analyzed. Sputum was induced after a procedure as reported elsewhere ${ }^{26}$. Briefly, subjects inhaled $3 \%$ hypertonic saline, nebulized via an ultrasonic nebulizer (NEB2000; TEFA-Portanje, Woerden, The Netherlands) during three 7 -minute periods. To minimize saliva contamination, subjects were instructed to mouthwash thoroughly with saline solution before expectoration. The collected sputum was pooled and kept at $4^{\circ} \mathrm{C}$ for not more than 2 hours prior to further processing. The volume of the pooled sputum (without selection of sputum plugs) was recorded, and an equal volume of $0.2 \%$ dithiothreitol (DTT; Sputolysin; Calbiochem, La Jolla, 
CA) was added. The samples were then mixed genty by a wortex mixer and incubated for 20 minutes at room temperature to ensure complete homogenization. Cell-free supernatants were frozen as $-80^{\circ} \mathrm{C}$ until subsequent analysis. The toral cell count and cell viability were assessed using a standard haemocytometer (Coulter Zr; Coulter Electronics, Mijdrecht, The Netherlands) and by trypan blue exclusion, respectively. Cytospins were stained according to the May-Grünwald-Giemsa method. An observer who was blinded to the clinical characteristics carried out the differential cell counts, counting 500 nucleated cells. The numbers of squamous cells: were subtracted, and the differential cell counts were expressed as corrected percentages. A sample was considered adequate if the slides contained $15 \%$ or less squamous epithelial cells.

\section{Measurements of inflammatory mediators in sputwm and plama}

sTNF-R were measured in sputum supernatant and plasma using specific sandwich enzyme-linked immunosorbent assay (ELISA) as described earli$\mathrm{er}^{29,30}$, which were not affected by presence of $\mathrm{TNF}-\mu^{31}$, indicating measurement of total amounts of STNF-RS5 and STNF-R75 (free and bound to TNF- $\mu$ ). Total TNF- $\mu$ (free TNF- $\mu$ and TNF- $\mu$ bound to STNF-R) was determined using a commercially available ELISA (HyCult Biotechnology BV, Uden, The Nerherlands). IL-8 and LBP levels were determined using specific sandwich ELISA as described previously ${ }^{32-34}$ "The lower detection limit was $60 \mathrm{pg} / \mathrm{ml}$ for sTNF-R55, 30pg/ml for STNF-R75, $20 \mathrm{pg} / \mathrm{ml}$ for total TNF- $\mu, 8 \mathrm{pg} / \mathrm{ml}$ for $\mathrm{LL}-8$ and $\mathrm{ng} / \mathrm{ml}$ for $L B P$. The presence of $D T T$ resulted in less than $5 \%$ inhibition of the detection of STNF-R $55, \mathbf{L}-8$ and LBP and less than 10\% inhibition in case of STNF-R75 and total TNF- $\mu$ fraction, indicating that DTT has little or no effect on the assays used in this study (data not shown).

\section{Statistical Analysis}

Results are presented as mean $\pm \mathrm{SD}$ for normally distributed variables and median (range) otherwise. Cross-sectional data analysis was performed, with degree of obstruction, complaines, riskfactors and reversibility determining the diagnostic category (COPD, asthma, chronic bronchitis and 'healthy smokers'). Cell patterns and inflammatory mediators in induced sputum were analysed, and compared with inflammatory mediators in blood samples. Cut-off point for sputum eosinophilia was $\geq 3 \%{ }^{15}$ " Patterns of inflammatory markers per diagnosis and clinical factors associated with eosinophilia were analyzed in an adjusted backward regression model, the differences expressed in odds ratios (OR) with $95 \%$ confidence intervals. A p value of less than 0.0 s denotes the presence of a significant statistical difference. (Statistical Package for the Social Sciences, version rr.o for Windows; spSs Inc., Chicago, IL). 


\section{Results}

Table I shows the population characteristics are shown, indicating moderate obstruction (average $\mathrm{FEV}$, post BD $59 \%$ predicted; GOLD 2 ) and highest level of packyears in parients with COPD, while asthmatics have fewer packyears and clinically relevant reversibility. Healthy smokers and chronic bronchitis (GOLD o) patients express normal lung function despite considerable packyears, while females are overrepresented among healthy smokers, especially compared to COPD.

Table I. Popularion chamacteriotics. Figures are means (SD) wndes stated ot herwise.

\begin{tabular}{|c|c|c|c|c|c|}
\hline & $\operatorname{COPD} n=17$ & Asthma $n=1:$ & $\mathrm{CB} n=14$ & $\mathrm{HS} \mathrm{n}=17$ & Toral $n=59$ \\
\hline Age (range) & $6.4(41-74)$ & $\$ 7.6(36-73)$ & $53.9(34-72)$ & $54.6(42.64)$ & $57.0(34-74)$ \\
\hline Giender $(\mathrm{f} / \mathrm{m})$ & $2 / 15^{* *}$ & 3,8 & $5 / 9$ & $11 / 6^{*}$ & $21 / 38$ \\
\hline P & $55.5^{*}(14)$ & $70.0(22)$ & $96.2^{*}(16)$ & $97.9^{*}(16)$ & $80 \times(25)$ \\
\hline FEV ${ }_{1}$ post BD (\%pred) & $59.0 *(\mathrm{nt})$ & $82.1(n)$ & $100.7^{116}(17)$ & $103.9^{*}(19)$ & $83.4(25)$ \\
\hline FVC preBD (opred) & $76.7^{*}(23)$ & $89.6(22)$ & $109.8 *(18)$ & $\operatorname{m11.6*}(29)$ & $94.4(27)$ \\
\hline FVC postBD (opped) & $88.7^{* \pi}(20)$ & $97.7(17)$ & $11 \% \cdot 3^{*}(20)$ & $112.4(24)$ & $104.9(23)$ \\
\hline $\begin{array}{l}\text { Smoking status } \\
\text { (formerfourrent) }\end{array}$ & 6rin & $s 16$ & $4 / 10$ & $7 / 10$ & $22 / 37$ \\
\hline Packyenrs & $48.4^{4}(29)$ & $23.1^{*}(20)$ & $33.5(18)$ & $32.3(13)$ & $35.5(2 y)$ \\
\hline $\begin{array}{l}\text { BD-Reversibility } \\
\text { (AFEV \%pred) }\end{array}$ & $3.5(9)$ & $12, x^{*}(7)$ & $4.5(5)$ & $4.9(4)$ & $5.9(8)$ \\
\hline
\end{tabular}

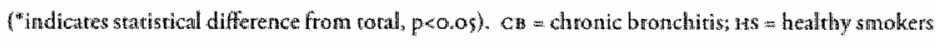

In table 2 the inflammatory patterns in different diagnosis groups are presented. Univariately, COPD was associated with sputum neutrophilia (OR I.09 [I.04-1.15]), elevated IL-8 (OR I.4 [I.I - I.7]), sTNF-R55 (OR I.005 [1.0 -1.OI]) and STNF-R75 (OR. 1.005 [1.0-I.OI]) in sputum, and raised levels of IL-8 (OR 2.5 [1.OI - 6.01), STNF-R55 (OR 7.6 [I.6-35.1]), sTNF-R75 (OR $10.2[2.2-47.8])$ and LBP (OR I.I [I.04-1.25]) in plasma,. Asthma patients showed a positive association with sputum eosinophils (OR 1.3 [1.05- 1.5]), and inversely with sputum neutrophils or $0.96[0.9-0.99])$, while patients with chronic bronchitis (GOLD o) showed raised levels of lymphocytes (OR I.5 [I.I - I.9]) in spurum, and significantly lower levels of STN F-R 55 (OR 0.1 [0.02-0.7]) and sTNF-R-75 in plasma (OR 0.I [0.2$0.81)$. Healthy smokers showed a lowered LBP (OR $0.8[0.7 \cdot 0.95])$ in plasma, but no other significant relations. In table 3 these (positive or negative) univariate patterns of inflammation are indicated by + and -, while ++ and -- indicate multivariate patterns of (positive or negative) significant relations. 


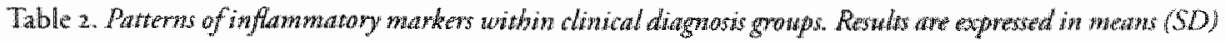
tanless atured othertirse.

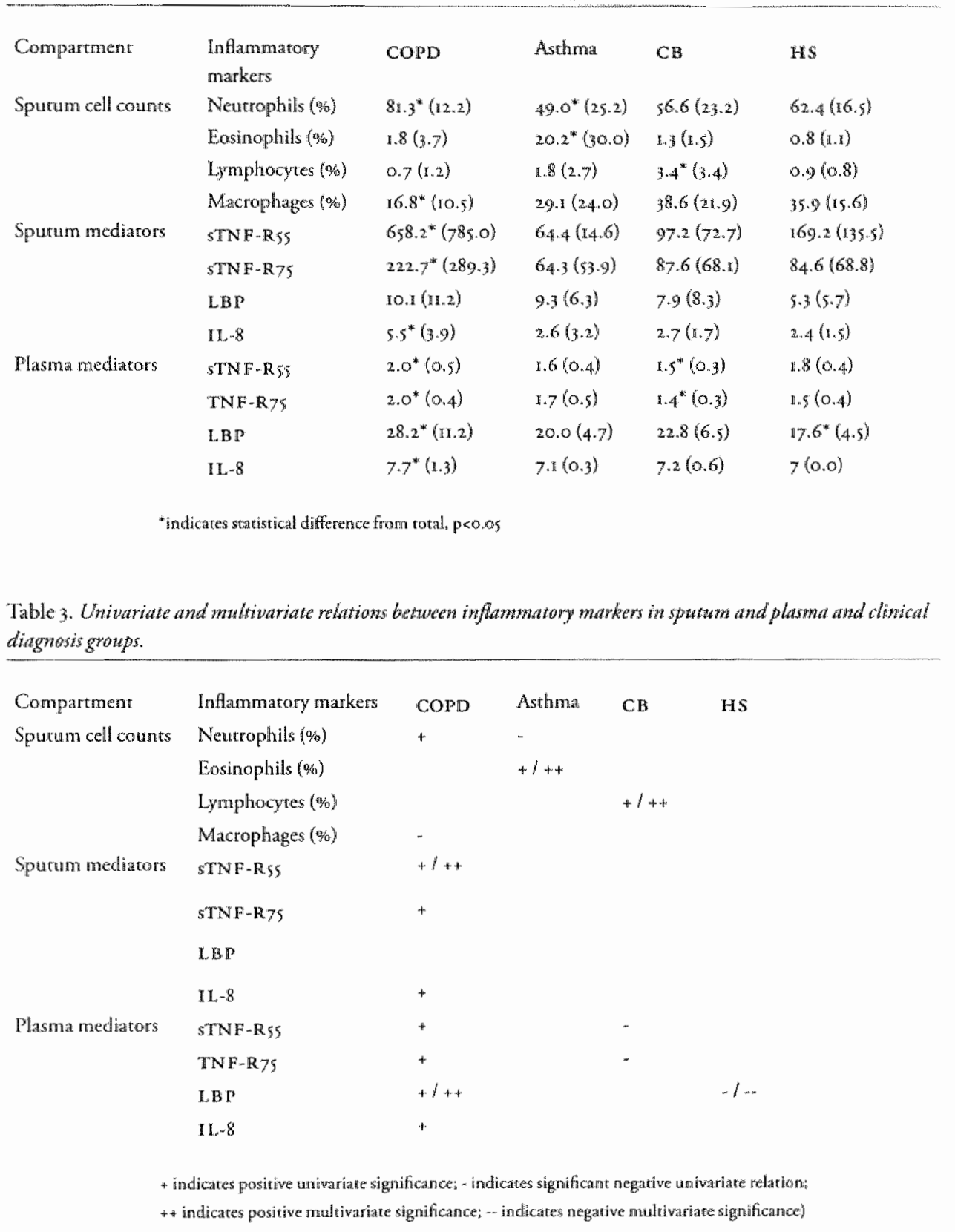




\section{Multivariate associations}

Multivariately, COPD remained significandy associated with STNF-R55 in sputum (OR I.Or [1.0Or-r.or]) and raised plasma-LB P (OR 1.2 [1.04r.37]), while HS expressed significantly lowered plasma-LBP (OR 0.8 $[0.72-0.95]$ ) by contrast (indicated by ++ and - - in Table 3 ). Asthma was characterized by higher sputum eosinophilic counts (OR 1.3 [1.05-I.54]), while CB (GOLD o) showed significantly higher lymphocytic counts in sputum (OR 1.5[1.12-1.9]).

Clinically, sputum esinophilia $(\geq 3 \%)^{\mathrm{H} y}$ was the only variable significantly associated with reversibility (OR 1.2 [1.04-1.36]) after adjusting for smoking, lung function, age, gender and allergy in the backward regression model. Figure I illustrates that sputum eosinophilia occurs across the spectrum of respiratory disease, independent from degree of obstruction; postbronchodilator FEV $s$ are between $40-110 \%$ of predicted. The independent relationship between reversibility and sputum eosinophilia was somewhat stronger when choosing the more recently proposed higher cut-off point of $4.6 \%{ }^{32}$ : OR $1.3[1.08-1.53]$.

Figure . Spurwm esinophilia ( $23 \%$ ) occurs in respinatowy patients with a wide range of airway obstruction (left) and is associated with browchodilator reversibility (right)
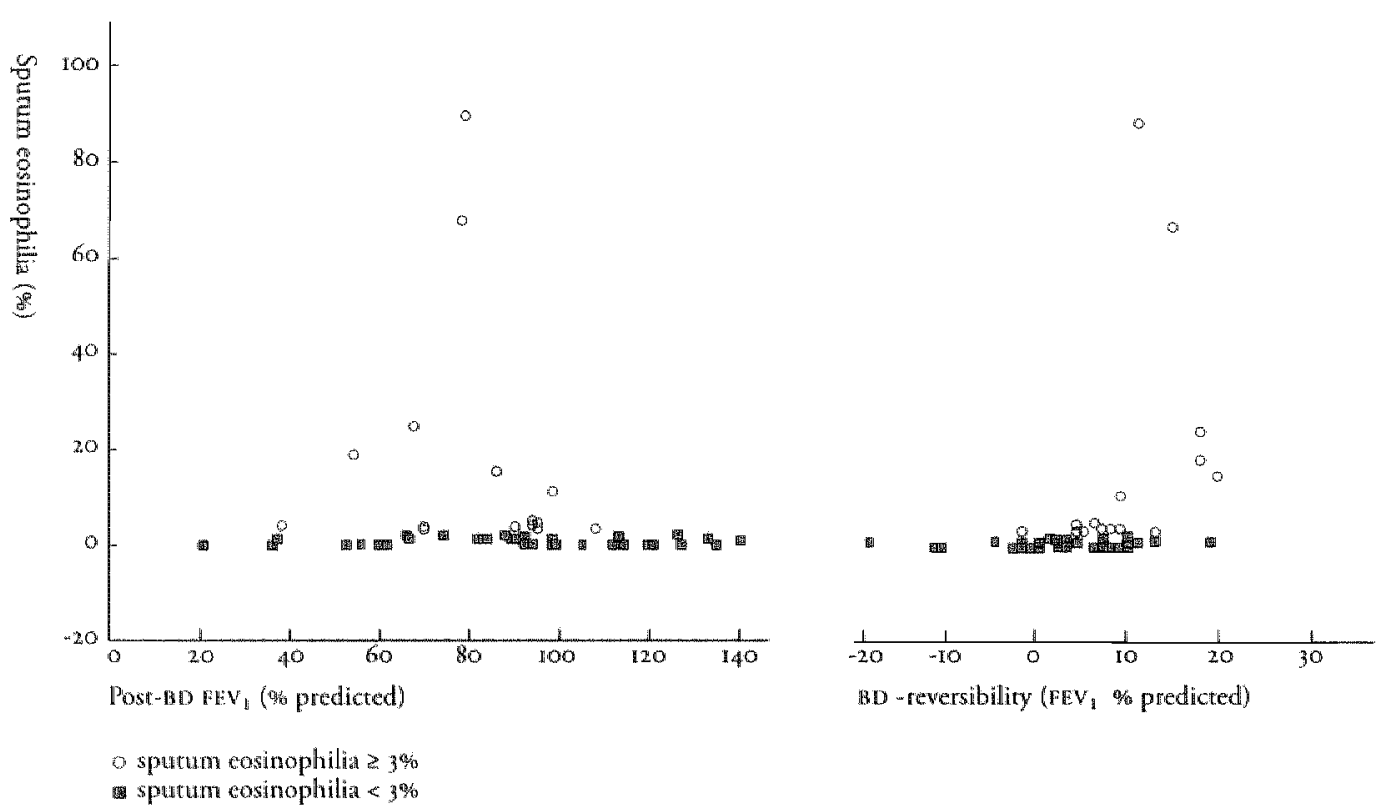

spucum cosinophilia $23 \%$

sputum cosinophilia \& $3 \%$ 


\section{Discussion}

In this study we demonstrate that distinct inflammatory mechanisms in sputum and blood underlie clinical diagnoses, which largelly support valid. disease entities, distinguishable on the basis of careful history-taking and lung function. Univariately, COPD was associated with sputum neutrophilia, and raised levels of IL-8, STNF R5S and STNF R75 in both sputum and plasma, and plasma LBP. By contrast, chronic bronchitics (GOLD O) were associated with raised lymphocytes and lowered STNF R5F and STNF R75 plasma-levels. Healthy smokers showed a lowered plasmaLBP level, while asthma patients showed a pattern of lowered neutrophils but high eosinophils. Multiwariately, COPD remained associated with raised sputum-STNF R55 and plasma-LBP, in contrast with a significantly and independently lowered plasma-LBP in healthy smokers. In asthma patients, only eosinophilic inflammation remained independently associated. Chronic bronchitics (GOLD o) retained a relative predominance of lymphocytic inflammation compared to the other clinical diagnosis groups. The clear difference in inflammatory patterns between GOLD $O$ and COPD patients is an intriguing finding, which provides support for earlier findings from the longitudinal Copenhagen Ciry Heart Study, in which a gradual development from GOLD o to GOLD r or higher levels of obstructive disease could not be demonstrated ${ }^{37}$.

Through multivariate analysis confounding differences in baseline were corrected for, and insight was achieved into the relative importance of each variable; most previous diagnostic studies have not used such statistical techniques. Furthermore, careful age-marching during the recruitment phase resulted in sufficiently comparable diagnosis groups, since age is known to affect spurum inducrion results, especially neutrophilia ${ }^{36}$. Based on the same reasoning, we excluded the use of inhaled or systemic steroids, since this would likely affect levels of inflammatory cells and mediators in sputum and plasma ${ }^{28}$.

Furthermore, eosinophilia occurs across the spectrum of clinical diagnosis groups, remaining associated with reversibility, in contrast with all oner clinical variables. It seems that the recent ATS/ERS Standards for the diagnosis and treatment of COPD recommendation to treat patients showing a clinically relevant reversibility as asthmatics' is in line with these findings ${ }^{2}$. Fabbri and coworkers ${ }^{35}$ found that despite fixed airflow obstruction similar to COPD, a history of asthmatic symptoms remains closely related to eosinophilic inflammation. Indeed, they concluded that different inflammatory pathways do exist in patients with fixed airway obstruction. We may add that in smoking patients without a history of asthmatic symptoms but with reversibility we should be aware of possible eosinophilic inflammarion. 
Previously, it was shown that a response to prednisolone occurred in 12 out of $25(48 \%)$ unselected COP D patients and was associated with eosinophilic inflammation 6 . In more severe obstruction $\left(\mathrm{FEV}_{\mathrm{I}} / \mathrm{VC}<60 \%\right) 8$ out of $18(40 \%)$ had sputum eosinophilia and similar clinical and physiologic characteristics to those without sputum eosinophilia. Only in those 8 did prednisolone produce a clinically important effect on effort dyspnea and quality of life, associated with a small but significant improvement in $\mathrm{FEV}_{\mathrm{x}}$, indicating that in smokers with severe airflow limitation, sputum eosinophilia predicts a beneficial effect of prednisolone treatment ${ }^{9}$. In a randomised controlled trial of the short-term response to prednisolone treatment in moderate to severe COPD patients, greater improvements were seen in patients with higher baseline sputum eosinophil counts $(43 \%)$ than for those with lower counts, while cell and molecular markers of neutrophilic inflammation were not affected ${ }^{15}$. Airway inflammation with eosinophils has been reported to occur not only in asthma but also in other airway diseases such as chronic cough, allergic rhinitus and $C O P D^{13}$. Induced sputum analysis allows detection of sputum eosinophilia in clinical practice" which is clinically important since it may respond to treatment with corticosteroids. By contrast, there is increasing evidence that an absence of sputum eosinophilia is associated with steroid resistance ${ }^{17}$. Spurum eosinophilia has been associated with an accelerated decline in $\mathrm{FEV}_{\text {, }}$ and the development of COPD ${ }^{12}$. A recent study proposes that responders to steroids have both eosinophil- and mast cell-driven disease regardless of whether they have asthma or COPD, although the magnitude of the response may be different ${ }^{14}$. Whilst many clinicians and researchers recognise that there is significant overlap between what is clinically defined as asthma and COPD, in the absence of clear-cut differences, some management guidelines continue to treat these two conditions as distinct entities ${ }^{14}$. Therefore, there is a great need for a reliable predictor of benefit from corticosteroid treatment in patients with chronic aitflow limitation". The decision to prescribe lifelong inhaled corticosteroids should not be taken easily, however, and should be based on the type of inflammatory patterns involved. Reversibility could now be considered as an indirect physiological measure of sputum eosinophilia in smokers with airway complaints. On the basis of this study, the number of eosinophilics seems to be limited, but possibly clinically relevant: 4 out of $17(24 \%)$ COPD-diagnoses when using the $\geq 3 \%$ cut-off for sputum eosinophilia, but only I out of $17(6 \%)$ when using the more recently proposed cut-off of $4.6 \%$, which is in line with literatures'. 


\section{Conclusion}

Clinical diagnoses were largely distinguishable on the basis of inflammatory markers in blood plasma and sputum. Multivariately, a smaller set of variables remained significantly associated, which opens the possibility to test predictive values of these variables in larger populations. COPD (GOLD 2) and so-called healthy smokers showed consistent opposite associations with plasma LBP, while chronic bronchirics (GOLD O) showed relatively predominant lymphocytic inflammation compared to other diagnosis groups. Eosinophilia remained significantly associated with reversibility across the spectrum of respiratory disease, while other clinical chatacteristics were not.

\section{Acknowledgements}

We would like to express our gratitude to all patients, physicians and coworkers involved in this study, who made it possible to increase our knowledge of the different inflammatory patterns underlying respiratory disease.

\section{References}

I Pauwels RA, Buist AS, Calverley PM, Jenkins CR, Hurd SS. Global stmagy for the diagnosis, management, and prevention of chronic obstructive pulmonary disease. NHLBI/WHO Global Initiative for Chronic Obstructive Lung Disease (GOLD) Worksthop summary. Am J Respir Crit Care Med 2001; 163: 1256-76.

2 Celli BR, MacNee W, Agusti A, Anzueto A, Berg B, Buist AS, Calverley PMAn Chavames N, Dillard T, Fahy B, Fein A, Heffner J, Lareau $S$, Meek P, Martinez F, MoNicholas W, Muris J, Austegard E, Pauwels R, Rennard S, Rossi A, Sirafakas N, "Tiep B. Vestbo I. Wouters E, ZuWallack R. Standards for the diagnosim and treament of palcients wirh COPD: a summary of the ATS/ERS position paper. EM Respir/. 200 an: $23(6) \div 932-46$

3 Schermer TR, Jacobs JE Chavannes NH, Marman J, Folgering HT, Bottema BJ, Weol var $\mathrm{C}$. Validity of spiromente testing in a general practice population of parients with chronic obstructiwe pulmonary disease (COP D). Thorax 2003: 58:861-86.

4 Chavanes $\mathbb{N}$, Schemer T, Aktermans R, Jacobs J. Grafaf G wan de, Bollen R, Schayck O van, Botema B. Impacr of spirometry on $G$ Ps diagnostic differentiation and deci. slion-making. Rexp Med 2004; 98:124-1830.

5 Vernooy JH, Kücrukaycan M, Jacobs JA, Chavamnes NH, Buurman WA, Dentener MA, Wourers EF. Local and Systemic Inflammarion in Patients with Chronic Obstructive Pulmonary Disease: Soluble Tumor Necrosis Factor Receptors Are Increased in Spurum. Am / Respir Crit Care Med 2002; 166(9): 1218-24.

6 Chanez P, Vignola AM, $O^{*}$ Shaugnessy T, Enander I, Li D, Jeffery PK, Bousquet . Corticosteroid reversibility in $\mathrm{COF}^{\mathrm{D}} \mathrm{D}$ is related to features of asthma. Am J Res Crit Cans Med 1997: 155:1529-1534. 
7 Kips JC, Fahy JV, Hargreave FE, et al. Methods for sputum induction and analysis of induced spurum: a method for assessing airway inflammation in asthma. Eat Resp $f$ 1998; 11: 9 S-12S.

8 Peleman RA, Rytila PH, Kips JC, er al. The cellital composition of induced sputum in chronic obstructiwe pulmonary disease. Eut Resp J1999; 13: 839-843.

9 Pizzichini E, Pizzichini M, Gibson P, Paramewaran K, Gleich GJ, Berman L, Dolowich 1. Hargreave FE. Sputum easinophilia predicts benefit from prednisone in smokers with chronic obstructive bronchitis. An I Resp Crit Care Med 1998; 158: 1511 -1517. Pizzichini E, Pizzichini MM, Efthimiadis A, Dolovich J, Hargreave FE. Measuring airway inflammation in asthma: eosinophils and eosinophilic cationic protein in induced sputum compared with peripheral bilood. J'Allergy Clin Immunol 1997;99:539-44:

11 Gibson PG, Dolowich J, Denburg J, Ramsdalle EH, Hargreave FE. Chronic cough: cosinophilic bronchitis without asthma. Lancet 1989 ; $1: 1346-1348$. Brightling CE, Ward R, Goh KL., Wardlaw AJ, Pavord ID. Eosinophilic bronchitis is an important cause of chronic cough. Am / Resp Crit Care Med 1999; 160: 406-410.

i) Sibel Oktem Ayik, Ozen Kacmaz Basoghu, Munewver Erdinc. Eosinophilic bronchitis as a cause of clyronic cough. A systemic diagnostic evaluation. Eur Resp J 2002; 20: 4515.

I4 Louis RE, Cataldo D, Buckley MG, Sele J, Henket M, Lau LC, Bartsch P, Walls AF, Djukanowic R. Evidence of mast-cell activation in a subset of patients with cosinophilic chronic obstructive pulmonary disease. Eur Resp I 2002,; 20:325-331.

15 Brightling CE, Monteiro W, Ward R, Parker D, Morgan MDL, Wardlaw AJ, Pavord ID. Spurum eosinophilia and short-rerm response to prednisolone in chronic obstructive pulmonary disease: a randomised controlled trial. Lancet 2000; 20: $1480-1485$.

16 Saetta M, DiStefano A, Maestrelli P, Turato G, Ruggieri MP, Roggeri A, Calcagni P, Mapp CE, Ciaccia A, Fabbri LM. Airway eosinophilia in chronic bronchitis during exacerbarions. Ams J Respo Crit Cave Med 1994; 150: 1646-1652.

17 Hargreave FE, Leigh R. Induced sputum, eosinophilic bronchitis, and chronic obstructive pulmonary disease. Am J Resp Crit Care Med 1999: 160: $S_{53}-S_{57}$.

18 Pizzichini E, Pizzichini MMM, Kidney JC, Efthimiadis A, Hussack P, Popov T, Cox G, Dolovich J, O'Byrne P, Hargreave FE. Induced spurum, bronchoalveolar lavage and blood from mild asthmatics: inflammatory cells, lymphocyte cells, lymphocyte subsets and soluble markers connpared. Eur Resp J1998; 11: 828-834.

19 Yamamoro $C_{n}$ Yoneda T, Yoshikawa M, Fu A, Tokuyama T, Tsukaguchi K, Narita N. Airway inflammation in COPD assessed by sputum levels of interleukin-8. Chest 1997 ; 112: 505-510.

20 Keatings VM, Jarakanon A, Worsdell YM, Barnes PJ. Effects of inhaled and oral glucocorticoids on inflammatory indices in asthma and COPD.Am J Resp Grit Care Med $1997: 155: 542-548$.

21 Chalmers GW, Macleod KJ, "Thomson L, Litule SA, MeSharry C, "Thomson NC. Smoking and airways inflammation in patients with mild asthma. Chest 200r; 120: I917-1922.

22 Barnes PJ. Molecular genetics of chronic obstructive pulmonary disease. Thorax 1999; $54: 245-252$.

23 Silverman EK, Chapman HLA, Drazen IM, et al. Genetic epidemiology of severe, early onset chronic obstructive pulmonary disease. Risk to relatives for airflow obstruction and chronic bronchitis. Am J Respir Crit Carte Med 1998;157: 1770-1778.

24 Barnes PJ. Chronic obstructive pulmonary disease: new opportunities for drug development. Trend Phamacol Sici 1998; 19:415-423. 
25 Chavannes NH, Schermer TR, Wouters EFM, Weel C van, Schayck CP van. Treatment of COPD in general pracrice: the COOPT study. Eur Repp / 2001; Suppl 33:348s.

26 Keatings VM, Collins PD, Scotr DM, Barnes PJ. Differences in interleukin-8 and utmor necrosis factor-alpha in induced sputum from patients wirth chronic obstructive pulmonary disease or asthma. Am J Respir Crit Catr Med 1996: 153: 530-534.

27 Schols AM, Buurman WA, Sraal van den Brekel AJ, er al. Evidencefor a relation between merabolic derangements and increased levels of inflanmtory mediators in a subgroup of parienrs with chronic obstructive pulmonary disease. Thorax 1996; 51: 819-24.

28 Dentener MA, Creutzberg EC, Schols AMWJ, Manrovani A, Veer $C$ van it, Buurman WA, Wouters EFM. Systemic anti-inflammatory mediators in COPD: increase in soluble interleukin I receptor II during treatment of exacerbation. Thowax zoof; $56: 721-726$

29 Leeuwenberg JF, Dentener MA, Buturman WA. Lipopolysacharide LPS-mediared soluble TNF recepror release and TNF receptor expression by monocytes: role of $\mathrm{CD}_{4}$, LPS binding protein, and bactericidal/permeability-increasing protein.//mmnnol 1994; 152: 5070-5076

30 Leeuwenberg JF, Jeunhomme TM, Buurman WA. Slow release of soluble TNF receptors by monocytes in witro. J Immunol $1994 ;$ 152: 4036-40.43.

3I Engelberts I, Stephens S, Francor G), var der Linden CI, Bunurman WA. Evidence for different effects of soluble TNF-receptors on various TNF measurements in lauman biological fuids. Lancet 1991; 338: $515-516$.

32 Engelberts I, Moller A, Schoen GJ, van der Linden CJ, Buturman WA. Evaluation of measurement of human TNF in plasma by ELISA. Lymphokine Cytokine Res 19g1;10: $69-76$.

33 Bouma MG, Stad RK, wan den Wildenberg FA, Bumrman W/A. Differential regulatory effects of adenosine on cytokine release by activated human monocytes. / Immurol 1994; 153: 4159-4168.

3.4 Froon AH, Dentener MA, Greve JW, et al, Lipopolysaccharide toxicity-regularing proteins in bacteremia. J Infect Dis 1995; 171: 1250-1257.

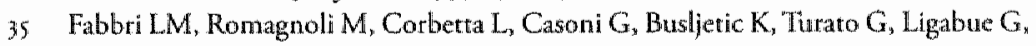
Ciaccia A, Saetta M, Papi A. Differences in airway inflammation in parients with fixed aurflow obstrucrion due to asthma or chronic obstructive pulmonary disease. A $4 m$ I Respir Crit Care Med 2003; 167(3): 4:8-24.

36 Thomas RA, Green RH, Brighrling CE, Birring SS, Parker D, Wardlaw AJ, Paword ID. The influence of age on induced spurum differential cell counts in normal subjects. Chest 2004, 126: 1811-13.

37 Vestbo J, Lange P. Can GOLD stage o provide information of prognostic value in chronic obstructive pulmonary disease’ Am / Respir Crit Cowe Med 2002; 166: 329-332. 
Chapter 5

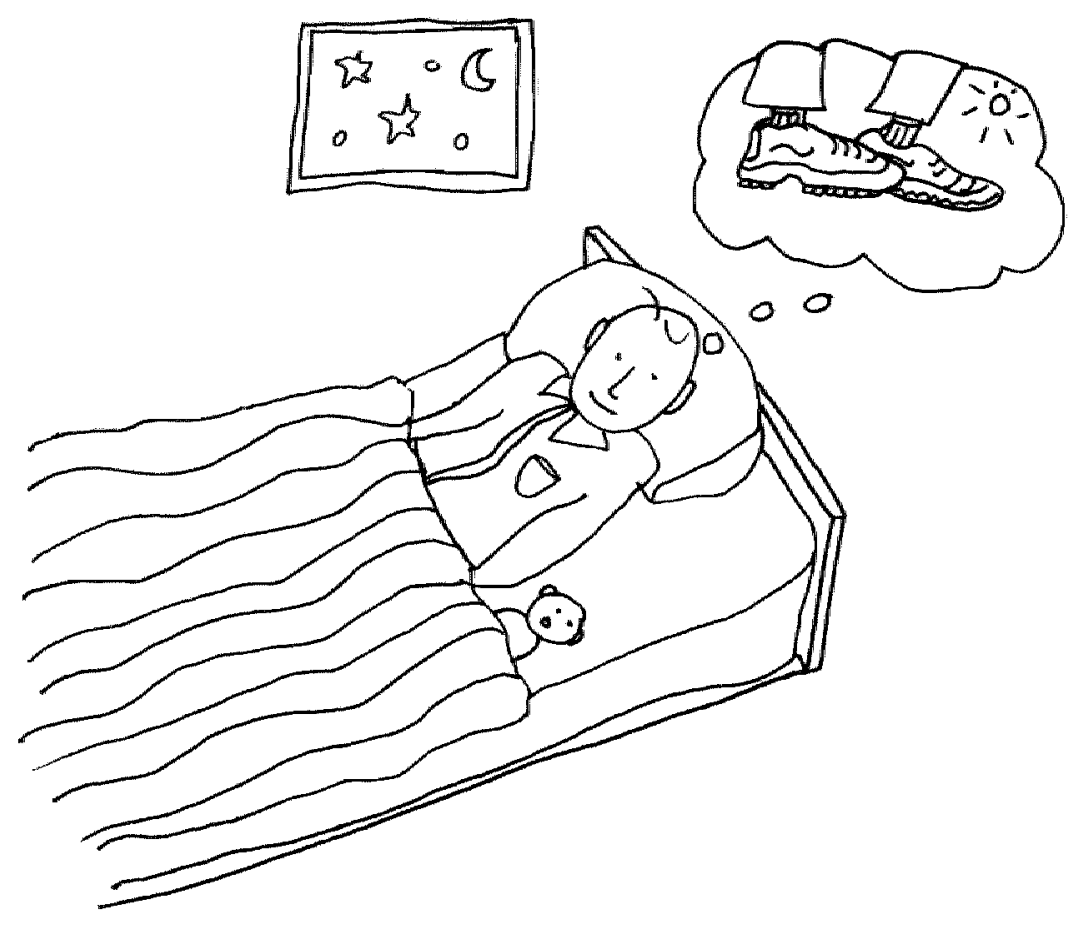




\section{Predictive Value and Utility of Oral Steroid Testing for Treatment of COPD in Primary Care: the COOPT Study}

Chavannes NH, Schermer TR, Wouters EFM, Akkermans RP,

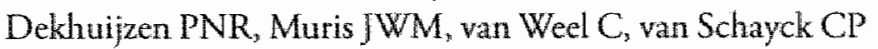

Submitted for publication

Presented at ERS 2005 Copenhagen

Abstract published in Hussars en Wetenschap 2005; $48(7):$ AI 


\begin{abstract}
Background

The oral prednisolone test is widely used to distinguish COPD-patients who might benefit from inhaled steroid treatment. Previous studies used selected patient groups not representing the large COPD-population in primary care.
\end{abstract}

\title{
Methods
}

The study included 286 primary care COPD-patients who underwent prednisolone testing ( 14 days $30 \mathrm{mg}$ ) before randomisation in a 3-year follow-up RCT (COOPT-Study). Spirometry was performed before and after the test; responders and non-responders were classified according to international criteria. Effectiveness of inhaled Auticasone relative to placebo was compared in terms of exacerbations, health status (CRQ) and post-BD $\mathrm{FEV}_{\mathrm{T}}$, using repeated measurements analysis.

\section{Reswlts}

9 to $16 \%$ of the COPD-population was classified as responder, depending on criteria used. Responders experienced a significant effect of inhaled fluticasone on health status $(0.29$ points $/ y t, p=0.05)$. Possible clinically relevant reductions in exacerbation rate (rate-ratio 0.67 ) and $F E V_{1}$ decline $(39 \mathrm{ml} / \mathrm{yr})$ occurred in responders, but did not reach statistical significance.

\section{Conclusions}

Prednisolone testing may distinguish COPD patients that benefit from inhaled steroid treatment in terms of health status. Test responders may also exhibit possible relevant effects on exacerbation rate and lung function decline. 


\section{Background}

In COPD, many different patient groups are represented: from bronchitic to emphysematous, with overweight or with nutritional depletion, and from irreversible obstruction to having a reversible component besides persistent obstruction. By GOLD definition, and in daily practice, all these groups are termed COPD. In most recent (therapeutic) COPD-tri$\mathrm{als}^{2,33}$ however, a strong entry selection occurred to ensure population homogeneity, thereby diminishing external validity'. From large prospective studies ${ }^{2,3,5,6}$ it has become clear that the progressive lung function loss in COPD cannot be altered by inhaled corticosteroid therapy. However, these randomised clinical trials strictly excluded patients with any form of reversibility for methodological reasons ${ }^{7}$. In practice, the diagnostic prednisolone test is used widely, to identify the parients responding to oral steroids, thus foreboding presumable efficacy of inhaled corticosteroid therapy. It is disputed what proportion of COPD-patients suffer from persistent obstruction with a reversible component, but esrimates differ from $10 \%$ to $30 \%$, depending on clinical setring ${ }^{7-9}$. It is estimated that $20-30 \%$ of patients with COPD may experience a significant improvement in FEV, from short-term corticasteroid use t, $^{\text {,O-12 }}$.

In case of persistent obstruction with a significant reversible component, a diagnostic prednisolone test is recommended, although the validity of this test is questioned and different cut-off points for 'response' are advised according to several international guidelines ${ }^{1,13-15}$. As a consequence, the utility and predictive value of responders within the COPD population is debated with vigour 7.9 . Small, short-term studies in selected patient groups have described different regimes of prednisolone resting, and as a result the more or less accepted current form ( 14 days of $30 \mathrm{mg}$ prednisolone) has been part of the diagnostic work-up of CoPD-patients ${ }^{17-20}$. However, the prednisolone test was never validated prospectively in a primary care population ${ }^{21}$. In severe disease without reversibility it has recently been shown not to be useful, using the American Thoracic Society (ATs)-criteria ${ }^{22}$. As a result, it was concluded that a short course of oral glucocorticoids is a poor predictor of the long-term response to inhaled glucocorticostroids in COPD. The aim of this study was therefore to determine the predictive value and usefulness of the prednisolone test; to what extent is the clinical efficacy of inhaled corticasteroids (Aluticasone $500 \mathrm{ug}$ bid) versus placebo related to a positive test response in a primary care population during three years follow-up. 


\section{Methods}

The coopr-trial ${ }^{23}$ is a double-blind, double-dummy, randomised placebo-controlled clinical trial with three year follow-up, which was undertaken in The Netherlands between 1998-2004. GP-diagnosed patients with chronic bronchitis and COPD from 44 general practices participated in the study, when postbronchodilator FEV, was between 40-90\% predicted, and $\mathrm{FEV}_{1} / \mathrm{FVC}$ was below $88 \%$ (males) or $89 \%$ (females). A clear history of asthma, allergic rhinitis or atopic eczema was an exclusion criterion, while reversibility to bronchodilators was not. Outcome measures were health status, as measured with the Chronic Respiratory Disease Questionnaire $(\mathrm{CRQ})^{24}$, exacerbation frequency and postbronchodilator forced expiratory volume in one second $\left(\mathrm{FEV}_{\mathrm{I}}\right)$. In this randomised clinical trial a threeleg design was used, with fluticasone propionate and $N$-acetylcysteine being intervention groups, the third leg being placebo. In this analysis we compared the fluticasone versus placebo legs. A wash-out period of three months preceded the study, allowing any effects of stopping inhaled steroids or $N$-acetylcysteine to subside. Before randomisation took place, all patients underwent the prednisolone test, before and after which lung function measurements were taken.

The diagnostic prednisolone test is generally defined as FEV measurement $_{1}$ before and after $\mathrm{I}_{4}$ dlays of $30 \mathrm{mg}$ prednisolone, but cut-off points for a response differ among the various international guidelines. The American Thoracic Sociery (ATS) ${ }^{14}$ considered an increase of $>1.2 \%$ and $200 \mathrm{ml}$ of baseline FEV as a response, while the British Thoracic Sociery (BTS) ${ }^{\text {Is }}$ stated an increase of $>15 \%$ of baseline $\mathrm{FEV}_{\mathrm{I}}$. By contrast, the European Respiratory Society (ERS) ${ }^{\mathrm{H} 3}$ used to recommend a $10 \%$ increase of FEV predicted in her guidelines, but this recommendation thas been left out in the 2004 ERS/ATSS Guidelines ${ }^{16}$. Specific criteria for response have also been delered from the British N ICE Guidelines ${ }^{29}$ and the 2004 updates of GOLD'.

Differences in longitudinal scores on health status, exacerbation frequency, and postbronchodilator $\mathrm{FEV}_{\mathrm{I}}$ were tested, by using statistical techniques for repeated measurements. The placebo group has been taken as representing the natural course, relative to the intervention groups. For statistical resting of differences in exacerbation frequency between placebo and intervention groups during the study period we used a correlated timeevent model 25 (GENMOD-procedure in SAS; Poisson distribution, compound symmetry correlation structure). In analysing the effects on health status a longitudinal analysis was performed on the CRQ-totalscore, while for the statistical testing of differences in annual lungfunction decline 
analyses for repeated $\mathrm{FEV}_{\mathrm{I}}$ measurements were used. The regression model for these outcomes accounted for correlation between repeated measurements ${ }^{26}$ (PROC MIXED in SAS, compound symmetry correlation structure).

\section{Results}

In Table 1 the study population is described. The number of responders differs from $25(9 \%$, ERS) to 44 (16\%, ATS) depending on guideline used. Responders show a significant higher proportion of females, almost equalling men, in comparison with non-responders across all guidelines. Age, smoking behaviour, packyears, degree of obstruction and reversibility to bronchodillator do not differ significantly.

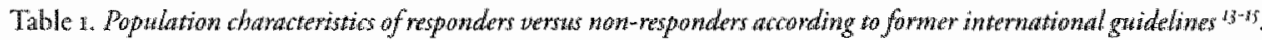

\begin{tabular}{|c|c|c|c|c|c|c|c|}
\hline & Total group & ERS & & ATS & & BTS & \\
\hline & & resp & non & resp & non & resp & non \\
\hline $\begin{array}{l}\text { Number } \\
\text { (9of of toul) }\end{array}$ & 286 & $\begin{array}{l}25 \\
(9 \%)\end{array}$ & $\begin{array}{l}261 \\
(9 r \%)\end{array}$ & $\begin{array}{l}44 \\
(16 \%)\end{array}$ & $\begin{array}{l}242 \\
(84 \%)\end{array}$ & $\begin{array}{l}35 \\
(12 \%)\end{array}$ & $\begin{array}{l}251 \\
(8848 \%)\end{array}$ \\
\hline Age (cange) & $59.1(34-76)$ & 59 & 59 & 59 & 59 & 59 & sid \\
\hline Gender $(f / m)$ & $77 / 209$ & $12 / 13^{*}$ & $65 / 196$ & $18 / 26^{\text {क }}$ & $59 / 193$ & $16 / 19^{*}$ & $61 / 190$ \\
\hline$(\%$ female) & $(27 \%)$ & $(48 \%)$ & $(25 \%)$ & $(4 \mid \%)$ & $(24 \%)$ & $(46 \%)$ & $(24 \%)$ \\
\hline Smoking (curr/form) & $125 / 16 \mathrm{r}$ & $9 / 16$ & $116 / 145$ & $14 / 30$ & $\mathrm{nu} / \mathrm{s} ; \mathrm{i}, \mathrm{I}$ & $11 / 24$ & $114 \sqrt{137}$ \\
\hline (bo curent) & $(44 \%)$ & $(36 \%)$ & $(44 \%)$ & $(32 \%)$ & $(46 \%)$ & $(31 \%)$ & $(45 \%)$ \\
\hline Packyears (SD) & $28.2(0.5)$ & 29 & 28 & 29 & 28 & $3 \mathrm{~L}$ & 28 \\
\hline FEV , postBD (\%pred) & $69.4(15.6)$ & 69 & 69 & 68 & 70 & 65 & 70 \\
\hline FVC postB D (moped) & $89.9(17.7)$ & 94 & 89 & $9 x$ & 90 & 9 & 90 \\
\hline $\mathrm{FEV}_{i} / \mathrm{FVG}_{i}(\mathrm{SD})$ & $62.6(11.8)$ & 60 & 63 & 61 & 63 & 58 & 63 \\
\hline BD-Rewersibilicy (\%) & $6.2(5.1)$ & 6 & 6 & 6 & 6 & 6 & 6 \\
\hline $\mathrm{BMI}(\mathrm{kg} / \mathrm{mz})$ & $26.3(4.4)$ & 26 & 26 & 25 & 27 & 25 & 27 \\
\hline
\end{tabular}

In Table 2 the long-term effectiveness of Huticason propionate relative to placebo in responders versus non-responders is shown, according to different guideline criteria. Outcome variables are exacerbation rate, health status and post-BD FEV . Responders according to ERs experienced a significant effect of inhaled fluticason on health status ( 0.29 points/yr, $\mathrm{p}=0.05$ ), and to a lesser extent in BTS-responders $(0.26$ points/yr, $\mathrm{p}=0.06)$. ATS-responders did not experience any significant benefit from longterm fluticason. Possible dinically relevant reductions in exacerbation rate (Rate Ratio 
$0.67)$ and $\mathrm{FEV}$, decline ( $39 \mathrm{ml} / \mathrm{yr}$ ) occurred in BTS-responders, but did not reacla statistical significance. These effects were similar (Rate Ratio 0.68 , FEV ${ }_{1}$ decline $30 \mathrm{ml} / \mathrm{yr}$ ) in ERS-responders, while much smaller in ATS-responders (Rate Ratio 0.78, FEV,-decline $8 \mathrm{ml} / \mathrm{yr}$ ).

Table 2. Longterm effectiwewess of futicasone proponate versus placebo in responders and non-respondas on exacer-

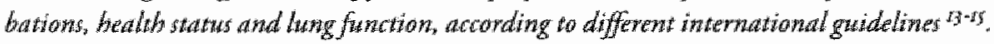

\begin{tabular}{|c|c|c|c|c|c|c|c|c|}
\hline \multirow[t]{2}{*}{ Variables } & \multicolumn{2}{|c|}{ Total group } & \multicolumn{2}{|l|}{ ERS } & \multicolumn{2}{|l|}{ ATS } & \multicolumn{2}{|l|}{$\mathrm{BTS}$} \\
\hline & & & Resp & Non-resp & Rexp & Non-resp & Resp & Non-resp \\
\hline \multirow[t]{2}{*}{ Exacurbations (number/yr) } & ELU & 0.98 & 0.74 & 0.93 & 0.56 & 0.96 & 0.63 & 0.95 \\
\hline & Pla & 0.73 & 1.04 & 0.70 & 0.73 & 0.73 & 0.94 & 0.70 \\
\hline Rate ratio & & 1. 30 & 0.68 & 1.33 & 0.77 & 1.32 & 0.67 & 1.36 \\
\hline \multirow[t]{2}{*}{ Health status (poinrs/yr) } & LU & +0.15 & +0.30 & +0.14 & 20.29 & 40.14 & +0.29 & 40.14 \\
\hline & Pla & +0.13 & , 0.01 & +0.13 & +0.09 & +0.13 & $+0,03$ & $+\infty .13$ \\
\hline Annual difference (points) & & +0.02 & $+0.29^{*}$ & $+\mathrm{O}_{n} \mathrm{OL}$ & +0.20 & +0.01 & +0.26 & $+0.0 \mathrm{r}$ \\
\hline \multirow[t]{2}{*}{ FEV ${ }_{1}$ change $(\mathrm{m} l / y r)$} & FLU & -59 & -67 & -58 & -61 & -59 & -60 & -59 \\
\hline & Pla & -60 & -97 & -56 & -69 & -58 & -99 & -55 \\
\hline Annual difference $(\mathrm{ml})$ & & +1 & +30 & -2 & 48 & -1 & +39 & -4 \\
\hline
\end{tabular}

"staristical difference berween responders and non-responders p<o.os

\section{Discussion}

To our knowledge, this study for the first time prospectively relates the responses to longterm inhaled corticosteroid therapy to different cur-off points for prednisolone testing in primary care. Between 9 to $16 \%$ of the COPD-population was classified as a responder, depending on criteria used. Responders according to the former ERS guideline ( $\mathrm{FEV}_{1}$ increase of $10 \%$ predicted) experienced a significant effect of inhaled thuticasone on health status ( 0.29 points/yr, $\mathrm{p}=0.05$ ) during three years of treatment. A similar, but not significant effect on health status $(0.26$ points $/ y r, p=0.06)$ was seen using the former BTS criteria, while ATs-responders showed less effect ( 0.20 points/yr). Possible clinically relevant reductions in exacerbacion rare (rate-ratio 0.67 ) and $\mathrm{FEV}_{\mathrm{I}}$ decline $(39 \mathrm{ml} / \mathrm{yr})$ occurred in responders according to BTS, but did not reach statistical significance. Quite similar results were seen in the ERS-group (rate-ratio 0.68 and $+30 \mathrm{ml}$ respectively) but much less so when applying the ATS-criteria (rate-ratio 0.77 and $+8 \mathrm{ml}$ respectively). By comparing different definitions of the prednisolone test on long-term disease outcomes, it seems that the 1995 ERS 
definition still has clinical value. Our suggestion would be, therefore, to reconsider the recent omission of the prednisolone test, as proposed in GOLD $^{1}$, NICE $^{29}$ and ATS/ERS ${ }^{16}$ Guidelines in light of this new evidence.

Interestingly, the only other longterm prospective study $y^{22}$ that assessed prednisolone testing on these outcomes, but not in a primary care population, concluded on the basis of using ATS-criteria that there was no relationship between the short term response to prednisolone and the rate of decline in $\mathrm{FEV}_{\mathrm{I}}$ or health status'. In fact, our results are in line with that widely cited study, since we only found possibly meaningful results using the ERS and BTS-criteria. In addition, the Isolde researchers looked at the so-called Callahan criteria ( $\mathrm{FEV}_{1}$ increase of $20 \%$ of baseline), which were derived from a meta-analysis ${ }^{12}$ looking at oral corticosteroid therapy, not prednisolone testing. In fact, this cut-off indeed also showed a significant effect, but this was deemed by the researchers to be the result of confounding. Thus, it seems to matter what criteria to use, and indeed when doing prednisolone trials we cannot recommend to use the former ATS-criteria, based on our results and on those of the Isolde researchers.

In our study, the proportion of primary care COPD-patients meaningfully labeled as responder differs from $9 \%$ (ERS) to I $\%$ (BTS), which is considerably lower than expecred. We therefore fear that our study probably has been underpowered, since estimates in literature ranged from $20-30 \%$ responders. However, it is possible that we underestimate the number of potential responders in the population, since for ethical reasons our study design provided a 3 -month wash-out period to exclude all patients that experienced $>2$ exacerbations when taken of inhaled steroids in the three months preceding entry to the study. In our population, this means that 'steroid-depending' patients were not allowed to enter the study.

Contrary to the Isolde researchers, we found a significant gender difference in prednisolone responsiveness across all criteria groups. Women appear particularly prone to COPD when exposed to similar amounts of tobacco ${ }^{27}$ and interestingly, the proportion of female COP D-patients responding to prednisolone was consistently higher than among non-responders at baseline. No other significant differences were seen between responders and non-responders in terms of age, lungfunction, current smoking and pack years of smoking. This apparent gender difference in prednisolone response therefore deserves further studying, since earlier studies probably did not include sufficient numbers of fermales with COPD, whose' prevalence has been rising only in recent years. 
In this study, a clear history of asthma, allergic rhinitis or aropic eczema was an exclusion criterion, while reversibility to bronchodilators was not. However, we found no relationship between prednisolone response and bronchodilator reversibility, which was very similar across all criteria groups. We consider it highly relevant to clinical practice that reversibility to bronchodilator apparenty does not correspond to prednisolone responsibility, since these terms are sometimes interchangingly used as parameters of the same phenomenon. These study data indeed suggest that the response to oral steroids describes a different underlying inflammatory process than the response to bronchodilation, which is of a fundamentally different origin.

Our results show a significant effect on health status in ERS-responders, but is it clinically meaningful? Strictly spoken, the cut-off point for clinical relevance on the CRQ is 0.5 points, which is higher than the 0.29 points in our study. However, the rate-ratio for exacerbations ( $32 \%$ less than placebo) and even the $\mathrm{FEV}_{\mathrm{r}}$-decline (goml/year less than placebo) point in the same direction in both the ERS and BTS-groups (33\% less exacerbations and $39 \mathrm{~mL} /$ year less FEV -decline respectively), which seems of certain clinical relevance. The systematical difference in effects on all three ourcomes compared to the non-responders (and indeed the total group of COPD-patients) suggests that this rather small group of responders to prednisolone in fact is a distinct subgroup in primary care, which would need different medical treatment. Since the number of responders (using the ERS or BTs criteria) now can be expected to be around 10\% in a primary care population like ours, we think these results probably need replication in a larger primary care study. This small but possibly relevant proportion is identical to the 10\% that was found in the exarlier meta-analysis on the benefits of oral corticosteroid therapy for COPD-patients ${ }^{12}$. Further discussion is needed on the use of ATS-criteria versus the BTS and ERS, especially since the last recently have joined the first in a joint guideline ${ }^{16}$. As has been stated before ${ }^{28}$, it is important to keep an open mind about the possibility that there may be responder and nonresponder subgroups and to continue to seek ways to identify and characterise them, especially in primary care where heterogeneity is common ${ }^{21}$.

\section{Conclusions}

In primary care, prednisolone testing may distinguish COPD patients that benefit from inhaled steroid treatment in terms of health status. Test tesponders may also exhibit possible relevant effects on exacerbation rate and lung function decline. 


\section{References}

(n) in persons with mild chronic obstrucrive pulmonary disease who continue smoking. European Respiratory Society Study on Chronic Obstructive Pulnonary Disease. N Engl/ Med 1999; 340: 1948.1953.

4 Herland K, Akselsen JP, Skjonsberg OH, Bjerner L. How representative are dinical study patients with asthma or COP D for a larger "real life" population of patients with obstructive lung disease? Respir Med 2005; 99(1): 11-9.

5 The Lung Health Study Research Group. Effecrs of inthaled triancinolone on the decline in pulmonary function in chronic obstructive pulmonary disease. $N$ Engl/ Med 2000; 343: 1902-1909.

6 Vestbo J, Sorensen T, Lange $P_{w}$ et al., Long-term effecr of inhaled budesonide in mild and moderare chronic obstructive pulmonary disease: A randomised controlled trial.

Lancet 1999: 353: 1819-1823.

7 Calverley PMA. Inhaled corticosteroids are beneficial in chronic obstructive pulmonary disease. Am J Resp Crit Care Med 2000; 161: 341-342.

8 Nisar M, Walshaw M, Earis JE, Pearson MG, Calverley PM. Assessment of reversibility of airways obstruction in patients with chronic obstructive airways disease. 73 orrax $1990 ; 45: 190-94$.

9 Barnes PJ. Inhaled corticosteroids are not beneficial in churonic obstructive pulmonary disease. Am J Resp Crit Care Med 2000; 161: 342-344.

ro Chanez P, Vignola AM, O' Shaugnessy T, Enander I, Li D, Jeffery PK, Bousquet ]. Corticosteroid reversibility in COPD is related to features of asthma. Am / Resp Crit Care Med 1997; 155: 1529-1534.

II Schayck CP van, Grunsven PM, Dekhuijzen PNR. Do patients with CoP D benefit from treatment with inhaled corticosteroids? Eur Resp J 1996" 9: 1969-72.

12 Callahan CM, Dittus RS, Katz BP. Oral corticosreroid therapy for patients with stable chronic obstructive pulmonary disease: a meta-analysis. Anna Intern Med 1991; 114: 216223 .

13. Siafakas NM, Vermeire P, Pride NB, Paoletri P, Gibson J, Howard P, et al. Optimal assessment and management of chronic obstructive pulmonary disease (COPD). ERS consensus statement. Eur Resp J 1995; 8: 1398-420.

14 American "Thoracic Sociery. Standards for the diagnosis and care of parients with chronic obstructive pulmonary disease. Am J Respir Crit CaRE Med n995; 152: S77-120.

15. The COPD Guidelines Group of the Standards of Care Committee of the BTS; BTS Guidelines for the management of chronic obstructive pulmonary disease. Thorax 1997; 52(S5): 5I-28.

16 Celli BR, MacNee W, Agusti A, Anzueto A, Berg B, Buiss AS, Calverley PMA, Chawannes N, Dillard T, Fahy B, Fein A, Heffner J, Lareau S, Meek P, Martinez F, McNicholas W. Muris J, Austegard E, Pauwels R, Rennard S, Rossi A, Siafakas N, Tiep $B$, Vestbo J, Wouters E, ZuWallack R. Standards for the diagnosis and treatment of parients with COPD: a summary of the ATS/ERS position paper. Eur Respir/2004; $23(6): 932-46$. 
17 Weir DC, Grove RI, Robertson AS, Butge PS. Corticosteroid trials in non-asthmantic chronic airfow obstraction: a comparison of oral prednison and inhaled beclomethasone dipropionate. Thorox 1990; $45: 112-117$.

18 Koyama $H_{i}$ Nishimtira $K_{\text {, Mio }} \mathrm{T}_{\mathrm{y}}$ Izumi T. Response to oral corticosteroid in patients with chronic obstructive pul thonary disease. Intem Med 1992; 31: 1179-1184-

19 Weiner $P$, Weiner $M$, Rabner $M$, Waizman I, Magadle $R$, Zamir $D$. The response to intualed and oral steroids in patients with srable chronic obstrucrive airway disease. J hatern Med 1999; 245:83-89.

20 Dawies L, Nisar M, Pearson MG, Costello RW, Earis JE, Calverley BMA. Oral corticosteroid arials in the management of stable chronic obstructive pulmonary disease. Q Med 1999; 92: \$95-400.

21 Chavanes NH, Schermer TR], on behalf of the COOPT Study Group. Long-term inhaled steroid response testing should be done in heterogeneous COP D-population Iletrer. Thorax 2003:58: 648 .

22 Burge PS, Calverley IMA, Jones PW, Spencer 5 , Anderson JA, on behalf of the Isolde Study Group. Prednisolone response in patients with chronic obstructive pulmonary disease: results from the $150 \mathrm{LDE}$ study. Thorax 2003:58:654-658.

23 Chawanes $\mathrm{NH}$, Schermer TR], Wouters EF, Van Weel C, Van Schayck. CP. Treatment of COPD in general practice the COOPT atudy. Eur Respir I 2001;8 (Suppl 33):348S.

24 Guyar GH, Berman LB, Townsend M, Pugsley SO, Chambers LW. A measure of quality of life for clinical trials in chronic lung disease. Thor $\alpha x 198 ; 42: 773-8$.

25 Diggle PJ, Liang KY, Leger SL. Analysis of longirudinal data. Oxford (UK): Oxford Uniwersity Press, 1994.

26 Twisk JWR Applied longitudinal data analysis for epidemiology. Cambridge (Uk): Cambridge University Bress, 2003.

27 Prescott E, Bjerg AM, Andersen PK, et al. Gender difference in smoking effects on lang function and ristk of thospitalization for COPD: results from a Danish longirudinal population study. Eur Repoir /1997; no: $822-7$

28 Gross ND. Responses to steroids and bronchodilators in COPD in the ISOLD Ecrial: the far lady sings on [editorial]. Thorax $2003 ; 58: 647^{-648}$.

29. Warional Institute for Clinical Excellence (N ICE). Chronic obstractive pulmonary discase: national clinical guideline for mamagenent of chronic obstucrive pulmonary discase in adults in primary and secondary care. Thom $2004 ; 59$ (Suppl 1 ). 
Chapter 6

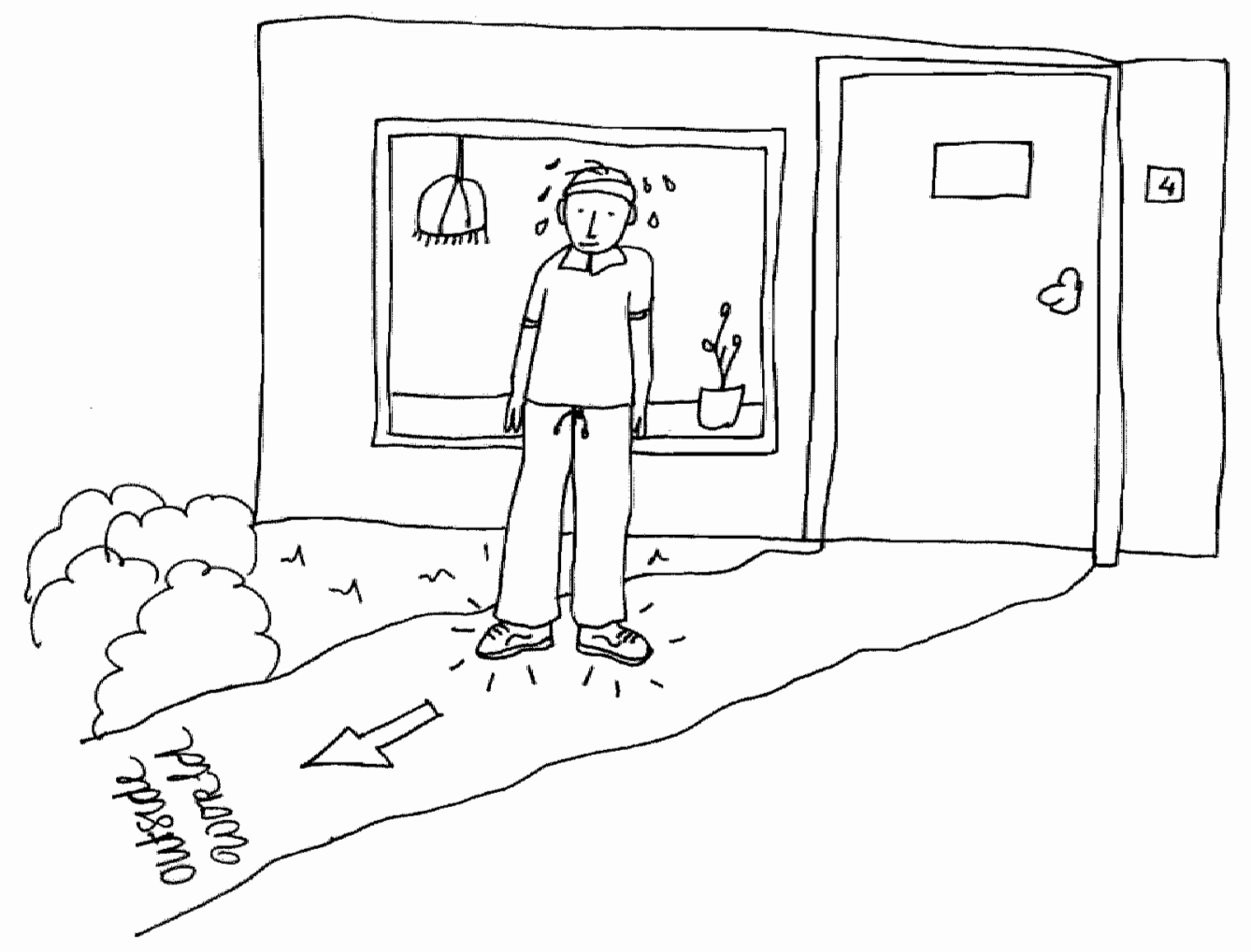




\section{Associations of Depressive Symptoms with Gender, Body Mass-Index and Dyspnea in Primary Care COPD-Patients}

NH Chavannes, MJH Huibers, TRJ Schermer, A Hendriks, C van Weel, EFM Wouters, CP van Schayck

Published in Family Practice; Advance Access July rs, 2005 Abstract published in European Respiratory Journal 2003; 22 (suppl 45): 375s 


\section{Abstract}

Aim

It has been suggested that severe COP $\mathrm{D}$ is associated with depressive symptoms, possibly linked to exacerbations, dyspnea and hospitalisation. Scarce data are available in primary care where most patients suffer from mild or moderare disease. We aimed to reveal associations of depressive symptoms with demographic and clinical characteristics in mild to moderate COPD.

\section{Methods}

Cross-sectional data on lung function measurements, exacerbation frequency, dyspnea, comorbidity, smoking behaviour, body mass index (BMI), age, gender and depressive symptoms (Beck Depression Inventory) of 147 primary care patients were assessed in multiple logistic regression anallyses.

\section{Results}

Patients suffered from mild to moderate obstruction ( $\mathrm{FEV}_{\mathrm{n}} 63.6 \%$ pred, range $45.1 \%$ to $82.1 \%$ ). Female gender ( $O R 4.8 \mathrm{CI}$ 2. I to 10.8 ), B $\mathrm{MI}>25$ (OR 0.4 . CI 0.2 to 0.8 ) and current smoking (OR $2.3 \mathrm{CI}$ I.OI to 5.3) were univariately associated with depressive symptoms, while in a multivariate logistic model only female gender (OR 4.0 CI 1.6 to 9.9), B MI>25 (OR 0.3 CI 0.1 to 0.7 ) and dyspnea (OR $1.8 \mathrm{CI}$ I.I to 2.9) were independently associated with depressive symptoms.

\section{Conclusion}

These data suggest that in primary care, depressive symptoms in COPD seem to be related with female gender, B MI and dyspnea. In this study, lung function, exacerbation rate, smoking behaviour, age and comorbidity are not independently associated with depressive symptoms in COPD of mild to moderate severity. 


\section{Background}

Several studies have assessed the occurrence of depressive symptoms in COPD-patients, reporting prevalences of up to $42 \%$ in moderate to severe COPD ${ }^{I-3}$. Depression was found to be the strongest independent predictor of mortality of COPD patients admitted to hospital for an acute exacerbation ${ }^{4}$. Depression and anxiety predict health related quality of life in COPD better than traditional lung function parameters ${ }^{I}$, while the dow main mental health of HRQL is scored worse than in patients with hypertension, diabetes, heart failure, arthritis and chronic low back pain.

However, few studies assessing prewalence of depression have been of sufficient methodological quality', and even less have investigated the primary care patient population, where most COPD is of mild to moderate severity. Underdiagnosis is a common finding, which is caused by both doctor- and patient related factors ${ }^{6}$. Recent studies found a relationship between depression and emergency visits and postulated that exacerbations may play an important role in the prevalence of depression? ${ }^{7}$, while severely impaired lung function was reported to be another key factor ${ }^{8}$ as well as living alone, reversibility of $\mathrm{FEV}_{I} \%$ predicted, respiratory symptoms and physical impairment ${ }^{9}$. However, despite reported findings the role of depression in COPD is still poorly understood.

Recently, mortality from COPD is reported to rise strongly, mainly because of increasing numbers of female patients, now surpassing death rates of male COPD in the United States ${ }^{10}$. But also in Europe this epidemiological shift starts to occurrin, ${ }^{\mathrm{II}}$. Research in COPD has focused on malles, since these were the most common subjects available, but contains very little data on femalle patients. Moreover, in primary care, most patients suffer from mild to intermediate disease, do not attend pulmonary clinics and as a result have not been studied thoroughly. The aim of this study was to reveal associations of depression with demographic and clinical characteristics of COPD patients who are attended in primary care.

\section{Method}

We conducted a cross-sectional study to investigate possible relations between depressive symptoms and lung function indices, exacerbation rate, smoking behaviour, dyspnea, age, body mass index (BMI), gender and comorbidity. Subjects were primary care patients with physician-diagnosed mild to moderate COPD, who participated in the coopr Study, a three year randomized clinical trial conducted between 1998 and 2003 in 46 Dutch general practices ${ }^{13}$. In this study, reversibility was not an exclusion criterion, but a history of asthma, allergic rhinitis or atopy was. $147 \mathrm{pa-}$ tients who were measured at the Academic Hospital Maastricht were cur- 
rent or past smokers between 30 and 75 years of age and fulfilled the Eutopean Respirarory Society criteria for a clinical diagnosis of COPD ${ }^{14}$. Patients with an FEV, below $40 \%$ of predicted were excluded.

Depressive symptoms were measured with the Beck Depression Inventory (BDI $)^{15}$. A score $>10$ on the $\mathrm{BDI}$ indicates an elevated risk for mood disturbances. Several independent variables were investigated for their association with depressive symptoms. Exacerbation rate was defined as number of registered physician contacts per year for increased respirarory symptoms, necessitating a medical intervention. Dyspnea was measured by the Medical Research Council (M RC) Dyspnea Index ${ }^{16}$. BMI was considered aberrant below 21 or above 25 . Comorbidity as defined as the number of co-morbid chronic conditions as registered by the primary care physician. All participants were current or former smokers with at least five packyears smoking history. Lung function measurements included flow-volume before and after bronchodilatation, using Micromedical Microloop II spirometers and Spirare software. Associations between variables were first investigated univariately, after which all significant variables were tested in an adjusted backward regression model. All analyses were performed using SPSS ro.o software.

\section{Resullts}

Table I summarizes the characteristics of the subgroups with and without depressive symptoms and the total study population. Patients expressed mild to moderate obstruction ( $\mathrm{FEV}_{10} 63.6 \%$ pred, range $45.1 \%$ to $82.1 \%$ ), with an average of 26.5 packyears smoked. Female gender ( $O R 4.8 \mathrm{CI} 2 . \mathrm{r}$ to I0.8), BMI>25 (OR $0.4 \mathrm{CI} 0.2$ to 0.8 ) and current smoking (OR $2.3 \mathrm{CI}$ 1.OI to 5.3) were univariately associated with depressive symptoms (Table 2). In a multivariate logistic model only female gender (OR $4.0 \mathrm{CI} 1.6 \mathrm{~g}$ to .6 ), BMI>25 (OR 0.3.CI O.I to 0.7) and dyspnea (OR I.8 CI I.I to 2.9) were independently associated with depressive symptoms.

\section{Discussion}

This study was aimed at exposing possible associations between clinical characteristics of COPD and depressive symptoms. In mild to moderate COPD we cannot confirm an association with exacerbations or comorbidity, probably because of a low exacerbation frequency and less impaired lung function. We did, however, find a quite strong association with female gender, and to a lesser extent with elevated BMI and dyspnea. Current smoking behaviour did not remain associated with depressive 


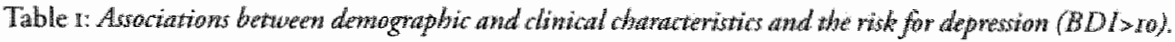
Figwes are means (SD) waless stated otherwide.

\begin{tabular}{|c|c|c|c|c|c|c|c|c|}
\hline & $\begin{array}{l}\text { Total } \\
(n=147)\end{array}$ & $\begin{array}{l}\text { Depressive } \\
\text { symptomis } \\
(0 \times 40)\end{array}$ & $\begin{array}{l}\text { No depressive } \\
\text { symproms } \\
(\mathrm{n}=107)\end{array}$ & $O R$ & $95 \% \mathrm{CI}$ & $\begin{array}{l}\text { OR } \\
\text { adj }\end{array}$ & $95 \% \mathrm{CI}$ & p-value \\
\hline $\mathrm{BDI}$ & $7.17 .0)$ & $16.1(6.8)$ & $3.7(28)$ & & & & & \\
\hline Gender $(\mathrm{l} / \mathrm{m})$ & $36 / \mathrm{dm}$ & $19 / 21$ & $17 / 90$ & 48 & $2.1-10.8$ & 40 & $1,6+9.9$ & 0.00 \\
\hline Age (yrs) & $58.6(10.2)$ & $57.2(0.9)$ & $59.2(10.4)$ & 1.0 & $0.95-1.02$ & & & \\
\hline $\mathrm{BMI}$ & $26.2(4.1)$ & $25.1(4-3)$ & $26.6(3.9)$ & 0.9 & $0.8-1.00$ & & & \\
\hline $\mathrm{BM} \mathbb{L}<2 \mathrm{~L}\left(\mathrm{no}_{0}\right)$ & 14 & 5 & 9 & 1.6 & $0.5-5.0$ & & & \\
\hline $\mathrm{BMI}>25(\mathrm{no})$ & 88 & 17 & 71 & 0,4 & $0.2-0.8$ & 0.3 & $0.1-0.7$ & 0.007 \\
\hline FEV (\%pred) & $63.6(18.5)$ & $63.9(15.2)$ & $63.4(19.7)$ & 1.9 & $0.98-1.02$ & & & \\
\hline $\mathrm{EEV} / \mathrm{FVC}$ & $61.5(14.3)$ & $62.0(16.0)$ & $61.4(13.6)$ & 1.0 & $0.98-1.02$ & & & \\
\hline Reversibility (\%) & $6.7(6.2)$ & $7 \cdot x(5.3)$ & $6.6(6.5)$ & 1.0 & $0.96-1.08$ & & & \\
\hline Packyears (yrs) & $26.5(4.1)$ & $29.4(16.6)$ & $25.4(14.9)$ & 1.0 & $0.99-1.04$ & & & \\
\hline $\begin{array}{l}\text { Smoking } \\
\text { (currend/former) }\end{array}$ & $95 / 52$ & 3119 & $64 / 43$ & 2,3 & $1.0 \mathrm{r} \times 5.3$ & 2.2 & $0.8-5.9$ & 0.106 \\
\hline $\begin{array}{l}\text { Exacerbation frequency } \\
\left.\text { (no. } / \mathrm{yr}^{\mathrm{f}}\right)\end{array}$ & $0.8(0.7)$ & $0.9(0.7)$ & $0.8(0.8)$ & 1.2 & $0.73-11.9$ & & & \\
\hline Comorbidity (no./pt) & $0.6(1.1)$ & $0.7(\mathrm{r} .3)$ & $0.6(1.0)$ & li.I & $0.78-1.5$ & & & \\
\hline MRC Dyspnea Index & $2.0(0.9)$ & $2.3(0.7)$ & $1.9(0.9)$ & 1.5 & $0.99-2.3$ & 1.8 & II.I -2.9 & 0.016 \\
\hline
\end{tabular}

symptoms in the multivariate model. Interestingly, we found less depressive symptoms in patients with an elevated BMI $(>25)$, while the inverse relation with $\mathrm{B}$ MI $<2$ I did not reach significance, probably due to low patient numbers. The importance of BMI and dyspnea has been recognized in recent guidelines ${ }^{17}$, but not the role of female gender. From previous epidemiological studies we learn that females are almost twice as likely to suffer from major depressive episodes as men ${ }^{18}$. However, considering the magnitude of the association we found, could it be that females in our study expressed a different pattern of emotional coping than our male COPD-patients? A small Finnish community based study ${ }^{\text {IS }}$ reported earlier that female COPD patients experienced more feelings of dissatisfaction with life than controls, and had more mental health problems than male patients. In an Italian study female gender was associated with a greater impact of COPD on health status ${ }^{20}$. Norwegian females reported more symptoms and lower self-rated health compared with males with similar smoking burden $^{2 r}$. However, we realize that measuring depressive symptoms can be influenced by gender in itself. From a comparative study on depression measurement instruments, it follows that mean BDI scores were indeed 
borderline higher in females than in males, as a result of possibly genderbiased items ${ }^{22}$. Major depression in the elderly presents with partially different symptoms in men compared to women. This suggests that gender infuences perception and expression of depressive syndromes ${ }^{23}$. Higher levels of catastrophic withdrawal coping strategy and lower levels of self-efficacy of symptom management are associated with higher levels of depression, anxiety and quality of life ${ }^{24}$. It is therefore important to investigate this possible association between gender and depressive symptoms further, since female parients with COPD are a rapidly increasing parient category, and this will likely require more attention from the primary care provider. At present, there seems to be a great disparity between prevalence of anxiety and depression symptoms in COPD patients and the recognition and treatment of these symptoms by primary care providers ${ }^{25}$. Indeed, there is an inverse relationship between the patients' perceived access to health care and depressive symptoms in chronic pulmonary disease ${ }^{26}$.

Can we achieve better results? Especially in primary care, the answer must be sought in integrated care models when taking care of these complex patients ${ }^{27}$. Compared with control groups, decline in depressive symptoms and increased exercise capacity occurred in patients with COPD after a brief rehabilitation of 3 weeks ${ }^{2}$. Moreover, treating depression in primary care setting can prevent unnecessary hospiralizarions and reduce health care costs ${ }^{29}$.

\section{Conclusions}

These data suggest that in primary care, depressive symptoms in COPD seem to be related to female gender and the presence of dyspneic complaints, while patients with an elevated B MI report less depressive symptoms. Based on our findings and previous reports in the literature we hypothesize that females with COPD may express a different disease coping pattern, including more depressive symptoms, which deserves further research. In this study, lung function, exacerbation rate, smoking behaviour, age and comorbidity are not independently associated with depressive symptoms in COPD of mild to moderate severity.

\section{References}

I. Curtis JR, Deyo RA, Hudson LD. Pulmonary rehabilitation in chronic respitatory insufficiency: 7 . Healuh-related qualiry of life among patients with chronic obstrucrive pulmonary disease. Thorax $1994 ; 492: 162-70$.

2. Lighe RW, Merrill EJ, Despars JA, Gordon GH, Mutalipassi LR. Prevalence of depression and anxiety in patients with $C O P D$. Relationship to functional capacity. Chest $1985: 87: 35-38$. 
3. Yohannis AM, Baldwin RC, Conolly M]. Depression and anxiety in elderly outpatients with chronic obstructive pulmonary disease: prevalence, and validation of the BASDEC sicreening questionnaire. Int I Ger Psyeh 2000; 15: v090-96.

4 Almagro P, Calbo E, Ochoa de Echaguen $A$, Barreiro B, Quintana $S$, Heredia JL, Garau J. Mortality after hospitalization for COPD. Chest 2002; 121: 1441-1448.

5 Ede L, Yzermans C], Brouwer HJ. Prevalence of depression in patients with chronic abstructive pulmonary disease: a systematic review. Thorax 1999:54:688-692.

6 Schayck van CP, Chavannes NH. Detection of astma and chronic obstructive pulmonary disease in primary care. Eur Resp / 2003; 21: Suppl 39: 16s-22s.

7 Dahlen I, Janson C. Anxiery and depression are related to the outcome of emergency trearment in patients with obstructive pulmonary disease. Chest 2002; 122: 1633-37.

8 Lacasse $Y$, Rousseau L, Malrais F. Prevalence of depressive symptoms and depression in patients with severe oxygen-dependent chronic obstructive pulmonary disease. J Cardiopulw Rehabil 2001; $24(2): 80-6$.

9 Manen JG, Bindels PJE, Dekker FW, Yzermans CJ, Zee van der JS, Schade E. Risk of depression in patients with chronic obstructive pulmonary disease and its determinants. Thorax 2002; 57" 412-416.

Io Mannino DM, Homa DM, Akinbami LJ, Ford ES, Redd SC. Chronic obstructive pulmonary disease surveillance - United States, 1971-2000. MMWR 2002; 5x(SS-6): I-IG.

II Houston M. Cancer figures for lreland show increase in lung cancer in womem. BMf 2003; 326:570.

I2 Bonueux LGA, Looman CWN, Coebergh JW. Mortality due to smoking in the Netherlands: 1.2 million tobacco-relared deaths between 1950 and 2015. Ned Tijdschr Geneeskd 2003;147(19): 917-2I.

Ij) Chavannes $\mathrm{NH}$, Schermer TR], Wouters EFM, Weel van C, Schayck van CP. Treatment of COPD in general practice: the COOPT study. Eur Resp J 2001 (18); Suppl 33: 348s.

${ }_{4}$ Siafakas NM, Vermeire P, Pride NB, Paoletti P, Gibson J, Howard P; et al. Optimal atssessmenr and management of chronic obstructive pulmonary disease (COPD). Eur Respir/1995: 8: 1398-1420.

15 Beck AT, Steer RA, Garbin MG. Psychometric properties of the beck depression inventory: twenty-five years of evaluation. Clinical Pyychology Review 1988; 8: 77-100.

16 Fletcher $\mathrm{CM}$, Elmes PC, Wood $\mathrm{CH}$. The significance of respiratory symptoms and the diagnosis of chronic bronchiris in a working population. BMJ 1959; 1:257-266.

17 Celli BR, MacNee W, and committee members. Standrads for the diagnosis and treatment of patients with COPD: a summary of the ATS/ERS position paper. Eur Resp J 2004; 23: $932-946$.

I8 Andrade L, Caraveo-Anduaga J], Berglund P, Bijl RV, De Graaf R, Vollebergh W, wet al. The epidemiology of major depressive episodes: results from the International Consortium of Psychiatric Epidemiology (ICPE) Surveys. Int/ Methods Psychiatr Res. $2003 ; 12(3): 165$.

19) Isoaho R, Keistinen T, Laippala P, Kuivela SL. Chronic obstructive pulmonary disease and symproms relate to depression in elderly persons. Psychol Rep 1995; 76(I):287-97.

20 Antonelli-Incalzi $\mathrm{R}_{x}$ Imperiale $\mathrm{C}$, Bellia $\mathrm{V}_{x}$ Catalano F, Scichilone N, Pistelli $\mathrm{R}_{*}$ Rengo $F$, and the SaRA invesrigators. Do GOLD stages of COPD severity really correspond to differences in health status? Eut Resp J 2003; 22: 444-449.

2. Langhammer $A$, johnsen $R$, Gulswik A, Holmen TI., Bjermer $L$. Sex differences in lung vulnerabiliry to tobacco smoking. Eur Resp J 2003; 21: 1017-1023. 
22 Salokongas RKR, Vaahtera K, Pacriev S, Sohthan B, Lehtinen V. Gender differences in depressive symptons. An arrefact caused by measurentent instruments? / Af Dis 2002; 68: $215-220$.

23 Kockler $M$, Heun R. Gender differences of depressive sumptoms in depressed and nondepressed elderly persons. Int / Ger Psych 2002;17: 6\$-72.

24 MeCathie HC, Spence SH, Tate RL. Adjustment to chronic obstructive pulmonary disease: the importance of psychological factors. Est Respir/ 2002 ; 19 (1): $47-53$.

25 Kim SHF, Kunik ME, Molinari VA, Hillman SL, Lalani S, er al. Functional impair. ment in COPD patiens. The impact of araxery and depression. Pychowatias 2000; 41: $465,-\mathrm{m}$.

26 Curtis JR, Borson S. Examining the link berween sarcoidosis an depression. Am J Resp Crit Care Med 2001; 163: 306-8.

27 Chawanes NH. A Palliative approach for COPD and heare failure? Eury / Pall Cart 2001: 8(6): $225-227$.

28 Kozora $\mathbb{E}$, Tran $Z$ V, Make B. Neurobehavioral improvement after brief rehabilitarion in patients with chronic obstructive pulmonary disease / Cardiopulm Rehabil 2002; 22 : 426-30.

29 Campbell TL, Franks P, Fiscella K, McDaniel SH, Zwanziger J, Mooncy C, Sorbero M. Do physicians who diagnose more mental health disorders generate lower health carc costs? J Fam Pract 2000; 49: 305-310. 
Tht

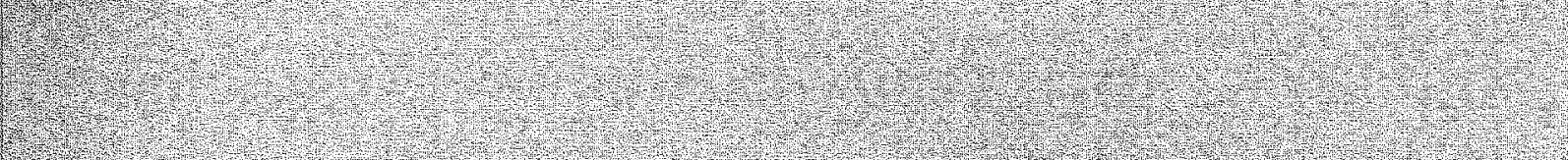

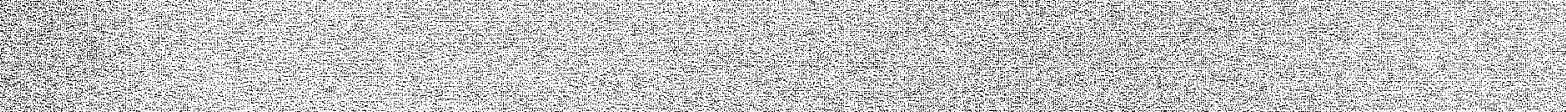

W.

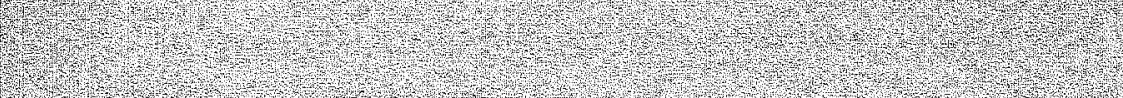

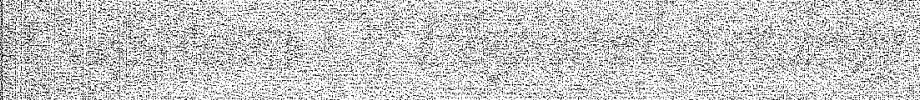

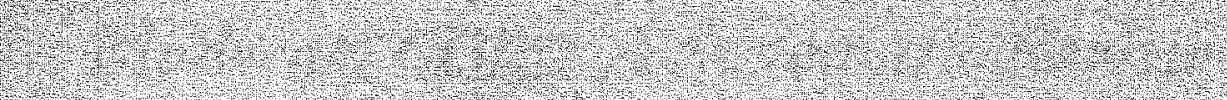

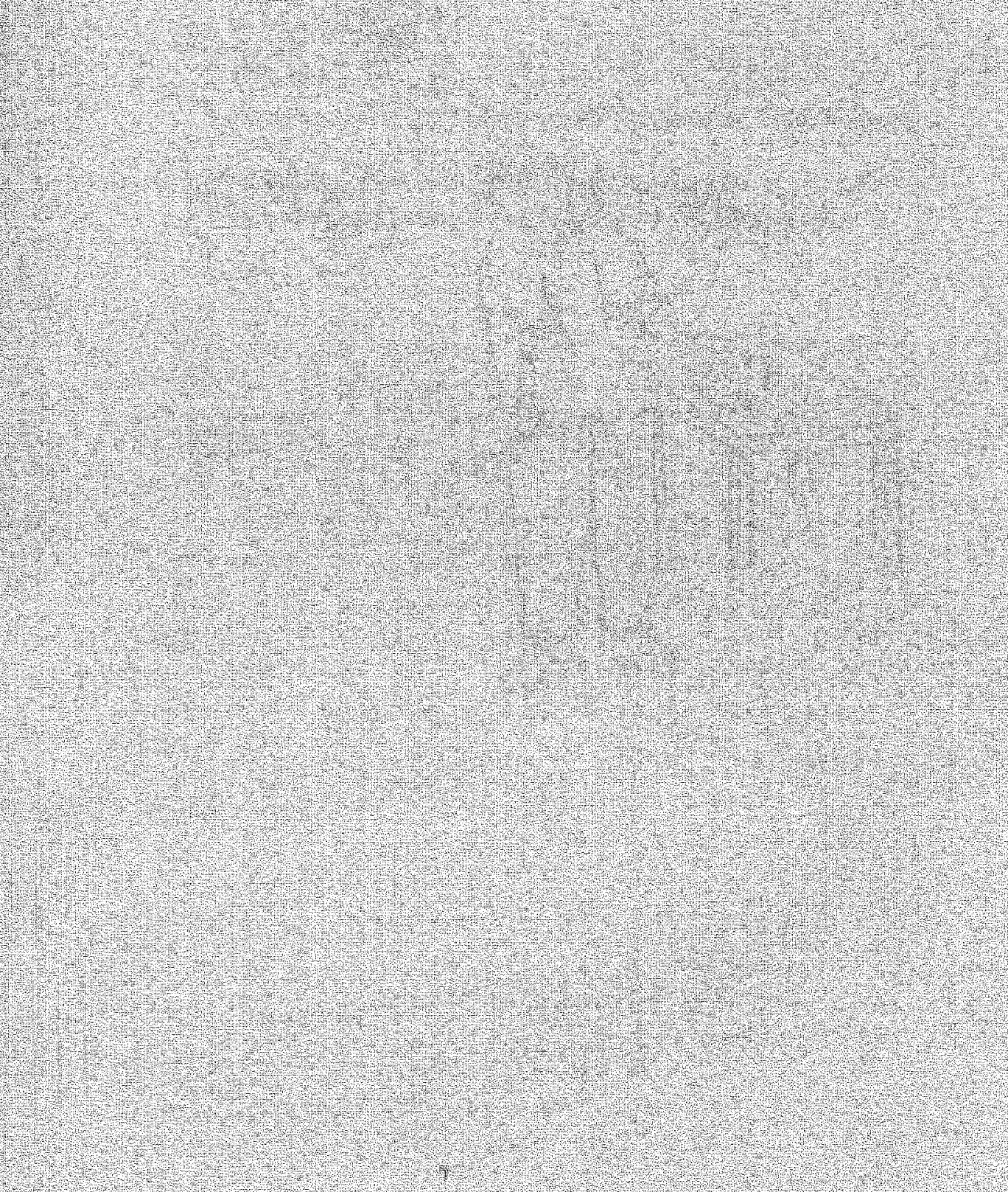


Chapter 7

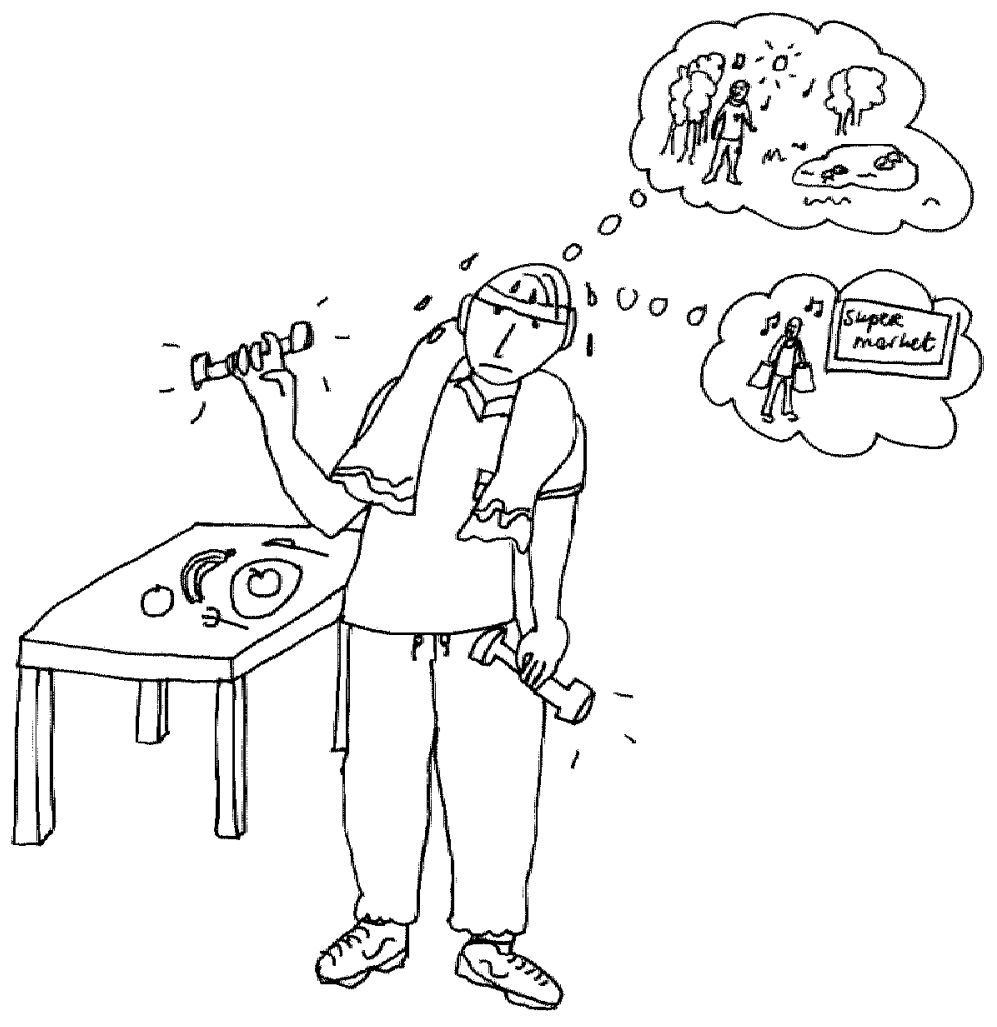




\section{Effects Of Physical Activity in Mild to Moderate COPD. A Systematic Review}

NH Chavannes, JJH Vollenberg, CP van Schayck, EFM Wouters

Published in British Journal of General Practice 2002; 52: 574-578

Translated adaptation published in Huisarts Nu 2003; 32(3): 130-137 


\section{Abstract}

\section{Background}

Pulmonary rehabilitation has become an evidence-based treatment in patients with severe COPD. In contrast, large numbers of patients suffer from mild to moderate COPD, receiving treatment from their GPs.

Advising in general practice should be clear, practical and attractive to patients, in order to advance compliance. This doesn't apply to pulmonary rehabilitation programmes, but does hold true for the GPS advice to improve the physical condition by walking, cycling or swimming, as recommended by the Dutch College of General Practitioners' Guideline for the Treatment of COPD. We performed a literarure search on the effects of physical activity in patients with mild to moderate COPD on exercise tolerance, dyspnea and quality of life ( $Q O L$ ). In addition, we looked for number of hospitalisation days and number of exacerbations, expressed, as oral prednisolone courses.

\section{Method}

The literature search included Medline (1983-1999), Embase (19842000), and the Cochrane Library (2000). All hits were screened on subject and language; abstracts were selected on the basis of a protocol including disease severity, hypothesis, outcome parameters and control group. Review articles on physical exercise and COPD were examined and reference lists of selected articles were screened for relevant studies.

\section{Results}

The broad literature search generated 4968 articles; after exclusion on tithe and abstract 35 original studies and 27 review arricles were analysed. of these, 5 original studies fited the criteria, and none of the review articles was selected. A positive influence of physical activity on exercise tolerance in mild to moderate COPD was reported in 4 out of 5 studies. There was no clear effect on dyspnea or QOL, probably because of low numbers of subjects. No studies were included addressing number of hospitalisation days or prednisolone courses as outcomes.

\section{Conclusion}

Physical exercise training (usually as part of a package of rehabilitation) can improve the fitmess of patients with mild or moderate COPD, but has not been shown to significantly benefit QOL or dyspnoea (or long term disease progression). 


\section{Background}

The Dutch College of General Practitioners' Guideline for the Trearment of COPD promoves a pro-active autitude of the $\mathrm{GP}^{1}$. In The Netherlands, patients with COPD are advised by their GP to improve their physical condition, for example by walking, cycling or swimming. In patients with severe COPD however, a pulmonary rehabilitation program is considered. While the efficacy of pulmonary rehabilitation programmes has been proven extensively, the recommended GPS advice is not evidence based at present $^{2,3,4}$. Pulmonary rehabilitation usually consists of a prolonged period of in- or outpatient revalidation, including intense specific exercises, breathing techniques and education, supervised by specialised rehabilitation staff. Exercise tolerance, dyspnea and quality of life (QOL) usually improve, while number of inpatient days in hospital decrease ${ }^{45}$. Effects on lung function parameters are not consistent. The true prevalence of COPD is hard to determine (estimates range from 5-15\% in the mature population), but it is acknowledged that the GP treats most patients with mild to moderate COPD ${ }^{1,6}$. In general practice it is important that the advice given is clear, practical and attractive to patients, which isn't applicable to the complex, intensive and exhaustive nature of pulmonary rehabilitation programmes. We therefore questioned what evidence is available in literature regarding the efficacy of physical activity in patients with mild to moderate COPD on functional status and prognosis. In this study 'physical activity' was operationalised as 'general physical condition enhancement (for example walking, cycling or swimming) and/or training of (most) large muscle groups". We performed a literature search with the following hypotheses: Is there an influence of physical activity on exercise tolerance, QOL and dyspnea in patients with mild to moderate COPD? Is there an influence of physical activity on number of hospitalisation days and number of exacerbarions, expressed as oral courses of prednisolone?

\section{Method}

The literarure search was performed in Medline ${ }^{5}$ Advanced (version WinSPIRS 4.0, 1983 until november 1999), Embase Excerpta Medica (version WinSPIRS 44.0, 1984 until 1989 edition 1990, 1989 until april 2000 edition 2000) and the Cochrane Library (2000, issue I) and included the search terms "COPD", "chronic obstructive pulmonary disease", "chronic bronchitis' and 'emphysema', combined with 'physical activity', 'exercise", "sports", and 'training'.

The 4968 electronically generated titles were selected on the basis of English or Dutch language and screened on relevance for the research questions: excluding articles not dealing with the relationship berween 
physical activity and COPD; only dealing with the raining of highly spe. cific muscle groups; only induding severe COPD; studies comparing two training programmes without control.

The next srep was judgment on the basis of the abstract. Excluded were articles: not including at least one of the relevant parameters (exercise tolerance, dyspnea, QOL, number of exacerbations or prednisolone courses); only including severe COPD or Intensive Care patients; not including an abstract; language not English or Dutch; or clearly not covering any of the hypotheses. The remaining studies, including one or more of the rellevant outcome parameters in mild to moderately severe COPD, or in unclear sewerity, were examined in full text, after removing double hits. In case of doubt, consultation between two researchers (RV and NC) took place until full consensus was reached. If severe COPD was included in the population as well, the results had to be reported separately (mild/moderate/sewere). The patients classified as 'severe' were consequently excluded. If severity wasn't reported in these terms, an $\mathrm{FEV}_{1}$ of $50 \%$ of predicted was determined as the lower threshold for inclusion, in accordance with the Dutch definition of patients with mild to moderate COPD'. If $\mathrm{FEV}_{\mathrm{I}}$ could not be elucidated, the study was excluded. Finally, a control group without intervention (of physical activity) had to be present, allowing inclusion for RCTS and CCTs only.

Review articles on the relationship between physical activity and COPD in non-severe COPD (or not mentioned severity) and covering one or more of the outcome parameters were also examined. "These had to fulfill the following criteria: $x$ Reviews on the influence of physical activity (as described before) in patients with mild to moderate COPD, or in which these patients were described separately; 2 At least one of the outcome parameters had to be examined; 3 There had to be al systematical approach of the literature search; 4 English or Dutch language.

Reference lists of selected studies were screened for relevant articles, applying the same methodology as used in the broad literature search.

\section{Results}

\section{Literature}

The broad لiterature search generated 4968 hits. After subsequent selection on title and abstract 35 original studies and 27 review articles were examined. No review article fitted the criteria, while seven original studies did. One study turned out to be a double publication; the Dutch article was excluded 7 . One study contained (as a result of bad compliance) a control group of one subject. This study will not be discussed further ${ }^{8}$. The key aspects and results of the remaining five studies ${ }^{9-13}$ are summarised in table $\mathrm{I}$. 
Table 1: Chatracteristics and results of studies fitting criteria

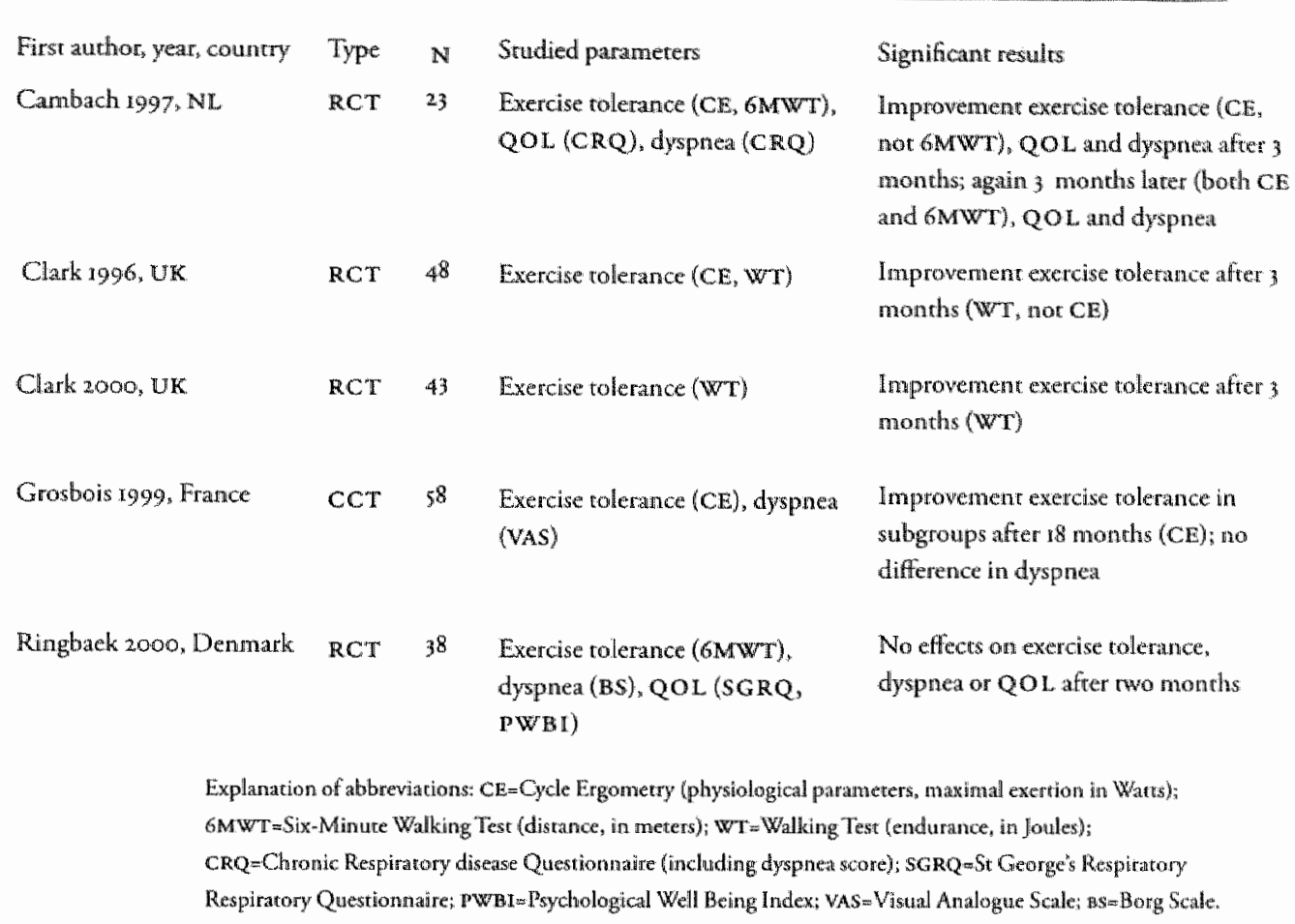

\section{Patients}

The most important characteristics of the population and interventions are presented in table 2. Only Ringbaek mentions the number of smokers. Only Grosbois gives information on symptom patterns; all patients experienced dyspnea on exertion and were less active. This is the only $\mathrm{CCT}$ included; patients could choose in which programme they would participate. In the study by Ringbaek there were significant differences between the control and intervention groups at the beginning of the study. Grosbois reported no significantly worse test results at baseline in the controlgroup. Drop outs were reported by Cambach (number unclear), Grosbois $(n=13)$ and Ringbaek $(n=7)$. No differences were found between participants and drop outs. The study aim was to exclude any patients suffering from severe COPD, to ensure that only data on mild to moderate disease were described. Applying the term 'mild to moderate COPD' resulted in patients with a $\mathrm{FEV}_{1}$, between $47 \%$ and $77 \%$ of predicted, in line with the original study aim. 
Table 2. Characteristics study populations and interventions

\begin{tabular}{|c|c|c|c|c|c|c|c|}
\hline Srudy & $\begin{array}{l}\text { Malel } \\
\text { fermale }\end{array}$ & $\begin{array}{l}\text { Meam } \\
\text { age }\end{array}$ & Exclusion when: & $\begin{array}{l}\text { FEV \% } \\
\text { predicted }\end{array}$ & Intervention & Frequency & Duracion \\
\hline Combach & $13 / 10$ & 62 & $\begin{array}{l}\text { Hear complaints, loco- } \\
\text { motor disabilinies }\end{array}$ & 59 & $\begin{array}{l}\text { Prinary care physiothera- } \\
\text { pist, giving both general } \\
\text { and specific muscle train- } \\
\text { ing, cducarion and recrea- } \\
\text { ron }\end{array}$ & $3 x /$ week & 12 weck \\
\hline Clark 1996 & - & 57 & - & 61 & $\begin{array}{l}\text { Home raining of large } \\
\text { muscle groups at low in- } \\
\text { rensiry }\end{array}$ & $7 \mathrm{x} /$ weel & I2 weeks \\
\hline Clark 2000 & $2 \zeta / 18$ & 49 & $\begin{array}{l}\text { Hearr complainis, anthri- } \\
\text { tis, daily oral steroids }\end{array}$ & 77 & $\begin{array}{l}\text { Hospital based general and } \\
\text { specific muscle raining }\end{array}$ & $2 x /$ wreek & II weeks \\
\hline Grosbois & $47 / 4$ & 62 & $\begin{array}{l}\text { Heart complaints, loco- } \\
\text { moror disabiliries }\end{array}$ & 49 & $\begin{array}{l}\text { Outparienc chinic thome } \\
\text { based generat and specific } \\
\text { muscle training and edu- } \\
\text { cation }\end{array}$ & $7 \mathrm{x} /$ week & If monts \\
\hline Ringbaek & $7 / 38$ & 63 & $\begin{array}{l}\text { Other pathology, domicili- } \\
\text { ary oxygen, psychiatric } \\
\text { disorders }\end{array}$ & 47 & $\begin{array}{l}\text { Hospital based general and } \\
\text { specific muscle raining } \\
\text { education and muscle } \\
\text { stretching }\end{array}$ & 2x/wreek & 9 weeks \\
\hline
\end{tabular}

\section{Methods and measurements}

Only Clark (1996) chose solely physical activity to be the study intervention, as part of a physiotherapist supervised programme, which could be carried out at home. The other studies also used specific training, education and recreation. Cambach applied a crossover design, in which each. group experienced an intervention period and a control period. This study included both asthma and COPD patients, but the tesults were specified; only the data on COPD are presented. Furthermore, only the first arm data were included in the meta-analysis, to avoid any risk of carry-over due to the design. Grosbois studied the period during follow-up after a rehabilitation program. During 18 months one group received no maintenance exercises, and three groups received different types of exercise. The measurements carried out in the separate studies are summarised in table $\mathrm{x}$.

\section{Results}

Most studies found significant differences between intervention and control groups with regard to exercise toletance. In figure 1 , a random effects meta analysis aims to summarise the effects on exercise tolerance. However, numbers were small and different outcomes had to be integrated to produce the figure. Effect and standard error of the effect were calculared 
from the means and standard deviations per group. Pooling of these different outcomes used to describe exercise tolerance (walking distance, endurance, etc.) is impossible. Therefore a standardized effect is calculated per study by dividing the effect by the pooled standard deviation. These standardised effecr values are summarized using a random effects meta-analysis according to a method which has been described in detail by DerSimonian et al $^{31}$.

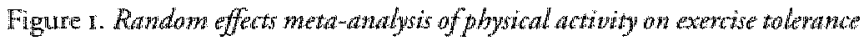

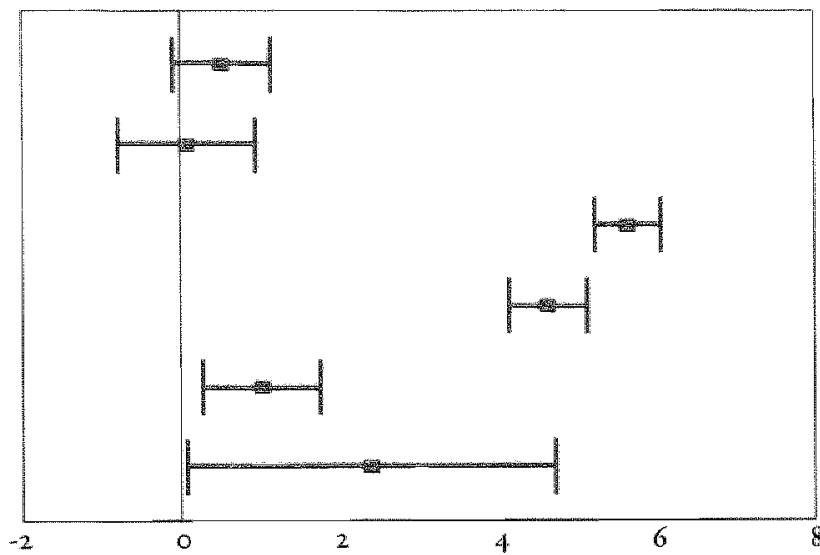

\begin{tabular}{|c|c|c|c|}
\hline Srudy & Measure & Effect & SE \\
\hline Rirugbaek a. an, zoo0 & GM W T, Meters & 29 & 17.38 \\
\hline Cambach c.a., 1997 & $6 \mathrm{MWT}$, Meters & $s$ & 23.13 \\
\hline Clark e.a.s 1996 & Walking Test, Joules & 5942 & 223,0 \\
\hline Clark e.a., 2000 & Walking Test, Joules & 3861 & 210.1 \\
\hline Grosboiscan, Igng & Cycle Ergonerer, Warrs & 2.44 .7 & 9.035 \\
\hline
\end{tabular}

A contradictory effect of physical activity on $Q O L$ was found in patients with mild to moderate COPD. The two studies involved used different instruments to assess QOL. Cambach found a significant positive effect during intervention and 3 months later, in concordance with other studies ${ }^{15,56}$. Ringbaek found no significant effects, possibly caused by a shorter intervention period and less frequent training. Although there are indirect signs for positive effects of physical activity on QOL in mild to moderate COPD, data is inconclusive at present.

No consistent effect was found on dyspnea either. Only Cambach found a significant improvement during the intervention, and after 3 months. The instrument used to measure dyspnea was part of the QOL questionnaire. Other measures of dyspnea were a VAS-scale and the Borg-scale, all reflecting the subjective nature of dyspnea. 
None of the studies used number of hospitalisation days or prednisolone courses as outcome measurements.

\section{Discussion}

In figure 1 , an attempt has been made to summarise the results in a randomised effects meta-analysis, after calculation of a standardised effect per study. Although interpretation is hampered by the fact that pooling is impossible an overall positive effect of physical activity seems to perpetuate. Four out of five researchers describe a positive influence of physical activity on exercise tolerance in parients with mild to moderate COPD. However, in the study by Cambach, improvement at 3 months was only $5 \mathrm{~m}$ compared to the control group. Although this difference increased up to $47 \mathrm{~m}$ at 6 months, we have chosen to include the initial figure only, so as not to overestimate the effect and to avoid any carry-over effect due to the crossover design. Ringbaek only found a non-significant improvement of the walking test. However, the duration of intervention was only two months and the frequency of training activity was just twice weetly. This brings Ringback to the conclusion that the low frequency is the cause of absence of effects in his study. Clark (2000) however, did find effects at the same training frequency but applying the intervention for three months. In addition, it is noteworthy that in Ringbaeks study there were significant differences between intervention and control group at baseline: the control group existing of more women, more smokers and a better 6 minute walking test. It is not unthinkable that especially the last difference has contributed to the observed absence of effects in this study. A frequency of twice weekly seems possibly effective to enhance exercise tolerance, if applied for at least three months. To illustrate, in pulmonary rehabilitation three to five times weekly is usual ${ }^{14}$.

Effects on both dyspnea and QOL were inconclusive (table $\mathrm{r}$ ). This might partly be a result of the subjective nature of these outcome measures, in contrast with objective measures of exercise tolerance.

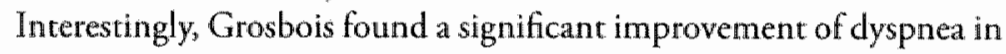
all patients during the intervention lasting 18 months, but observed no difference between the intervention and control groups. He therefore points out the motivation to perform exercises as a possible important factor for the effect on dyspnea. No effect on dyspnea was found by Ringbaek either. The long-term effects of physical activity on dyspnea remain controversial in this light, as in other studies ${ }^{17,18}$.

No studies were included examining the effects of physical activity on number of hospitalisation days or number of exacerbations, expressed as courses of prednisolone. As few studies have evaluated the long-term effects of pulmonary rehabilitation, information on this topic is scarce. 
Ries ${ }^{18}$ did not find a significant effect of pulmonary rehabilitation on hospitalisation days, while other investigators reported improvements in different patient categories ${ }^{19-22}$. However, none of these studies fitted our criteria.

One of the most important drawbacks of this review is the small number of articles and patients included, especially with regard to the parameters dyspnea and QOL. This is partly a result of the choice of definition of physical activiry and the exclusion criteria. All studies were designed as rehabilitation programmes. Only Clark (1996) applied the interwention in the home setting, while being weekly supervised by a hospital physiotherapist. To our knowledge, physical activity with little or no guidance, after recommendation of the $\mathrm{GP}$, has not been studied. Furthermore, few studies have been aimed at the patient with mild to moderate COPD. Ries described that patients in an early stage of COPD do not recognise the disease or do not consider it as disabling to necessitate rehabilitation ${ }^{4}$ "This might be a reason why dyspnea and Quality of Life are not shown to improve. It is therefore of importance for the GP to advise a means of physical activity that is attractive enough to be maintained for longer periods, and clear enough to be performed independently.

Different interventions and measurements have been applied, a fact that frustrates direct comparison in the random effects meta-analysis. Most programs offered specific exercises, education and sometimes psychosocial support in addition to physical activity. The controls usually received no program. That makes it difficult to determine what part of the intervention has contributed most to the effect. On the other hand, education and support usually are an integral part of the package the GP offers.

The duration of interventions varied from 8 weeks to 18 months. Only Cambach followed up for 12 weeks after the intervention. There is no consensus on the optimal duration of pulmonary rehabilitation. Effects have been described starting from two week $s^{23}{ }^{23}$ while others recommend several months ${ }^{24-26}$.

Respiratory rehabilitation in an early stage of COPD could become a treatment of preference in the future $4,5,27,28$. Rehabilitation in primary care or at home seems appropriate and effective ${ }^{9,10,22,29}$. However, too little research has been done in this patient group to draw firm conclusions on this matter. We conclude that physical exercise training (usually as part of a package of rehabilitation) can improve the fitness of patients with mild or moderare COPD, but has nor been shown to significantly benefit QOL or dyspnea (or long term disease progression).

The GP treats many patients with COPD. To which extent these patients are stimulated to undertake physical activity remains unknown. We expect 
however, that the dyspnea spiral (dyspnea $\rightarrow$ less exercise tolerance $\rightarrow$ increased dyspnea) is a prevalent problem, especially in rapidly worsening disease. Although it is unclear to what measture guidance is needed, more atrention for the aspect of physical activity could mean higher work demands on the already overloaded GP $\mathrm{P}$-practice. COPD represents however a chronic and progressive disease with a heavy burden on daily life, and constitutes an important cause of death. The intensive symptomatical treatment is costly and causes numerous side effects. Recommending guided physical activity twice weekly for at least three months could be a clear and important extension of current therapy.

Concerning costs little is known. We only found indirect signs that the number of hospitalisation days could decrease by physical activity. If this would be confirmed in a formal study, costs would likely be influenced positively. Haas already wrote in 1969 that the longer rehabilitation is postponed, the more expensive it will be for patient, family and sociery ${ }^{30}$. Therefore, we recommend to deliver more artention in general practice to the patterns of physicall activity in patients with mild to moderate COPD. More research, aimed at the long-term (cost) effectiveness in this patient category is justified and desirable.

\section{Acknowledgements}

We are grateful to dr. Arnold Kester and Ms Anne-Marie Korsten for their valuable contribution in constructing the figure.

\section{References}

1. Geijer RMM, Van Schayck CP, Van Weel C, et al. Dutch College of General

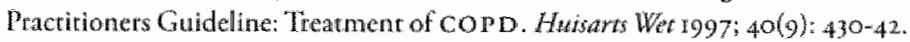

2 Lacasse $Y_{2}$ Wong E, Guyatt GH, et al. Meta-analysis of respiratory rehalyilitation in chronic obstructive pulmomary disease. Lameet 19,9; 3.48: 1115-9.

1 Lacasse Y, Guyatr GH, Goldstein RS. The components of a respuratory rehabilication program. A systematic overvicw. Chest 1997, Irr: $1077 \times 88$.

4 Ries AL. Position paper of the American association of cardiovascular and pulmonary rehabilitation. Scuicentific basis of pulmonary rehabilitation. / Cardiopulmonary Rehabil $1990 ; 10: 418-41$.

5 Lenzman MM, Chemiack RM. Rehabilitation of patients with chronic obstructive pulmonary discase. Am / Respir Dis 1976; 14: 1.145-65.

6 Van Schayck CP, Tirimanna PRS, Van den Boom G, et al. Acrual increase of rhe prevalence of astma and COFD in the Netherlands. Neth/ Med $1998 ; 142(43): 2352-5$.

7 Cambach W, Chadwick Straver RVM, Wagenar RC, Van Keimpema ARJ. Effectiviteit van een revalidatieprogramma woor patiënten met astma en COPD uitgevoerd in de cerstijinsgezondheidszong. Neth / Pbys 1998; 4: $26 \% 36$.

8 Lin MC, Liaw MY, Huang CC, Tsai YH. A mulnidisciplinary pulmonary rehabilitation progam for parients with noderately severe chronic obstructive pulmonary disease. J Fornos Med Assoc 1907; 96:869-73. 
9 Cambach W, Chadwick-Straver RWM, Wagenar RC, ex al. The effects of a community based pulmonary rehabilitation programme on exercise tolerance and quality of life: a randomized controlled trial. Ext Respir/ 1997 ; 10 : 104-13.

to Clark CJ, Cochrane L, Mackay E. Low intensity peripheral muscle conditioning improves exercise rolerance and breathlessness in COPD. Eur Respir/1996:9:2590-6.

I Clark CI, Cochrane LM, Mackay E, Paton B. Skeletal muscle strength and endurance in patients with mild COPD and the effects of weight training Ear Respir/2000; 15: $92-7$.

12 Grosbois JM, Lamblin C, Lemaire B, et al. Long-term benefits of exercise maintenance after outpatient rehabilination program in patiencs with chronic obstructive pulmonary disease. J Cardiopulom Rehabil 1999: 19: 216-25.

13 Ringbaek TJ, Broendum E, Hemmingsen L, et al. Rehabilitation of patients wich chronic obstructive pulmonary disease. Exercise twice a week is not suffichent! Respir Med 2000; $94: 150-4$.

I4 Decraner M, Donner CF, Schols AMWJ, Rehabilicarion. Exay Rexpir.Mon 1998;7: 21534.

15 Goldstein RS, Gort EH, Stubbing D, Avendano MA, Guyatt GM. Raundomised controlled trial of respiratory rehabilitation. Lancet 1994; 344: 1394-7.

I6 Gosselink HAAM, Wagenaar RC, Van Keimpema ARJ, Chadwick-Straver RYM. Het effect van een reactiveringsprogramma bij pariènten met CARA. Neth/ PHys 1950; 7/8: 193-9.

17 Ketelaars CAJ, Abu-Sad HH, Schlösser MAG, et al Long-term outcome of pulmonary rehabilitation in patients with COPD. Chest 1997; 112: 363-9.

18 Ries AL, Kaplan RM, Limberg TM, Prewitt LM. Effects of pulmonary rehabilitation on physiologic and psychosocial outcomes in parients with chronic obstrictive pulmonary disease. Awn Intern Med $1995 ; 122: 823-32$.

I9 Cox NJM, Hendricks $J C$, Binkhorst RA, et al. A pulmonary rehabilication program for parients with asthma and mild chronic obstructive pulmonary diseases (COPD). Lung $1993 ; 17: 235-244$.

20 Foglio $K$, Bianchi $L$, Bruletti $G$, et all. Long-term effectiveness of pulmonary rehalilitation in patients with chronic airway obstruction. Eur Respor/1999; 13: 125-32.

2.I Parker L, Walker J. Effects of a pulmonary rehabilitation program on physiologic measures, quality of life, and resource urilization in a health maintenance organization setting. Respir Care $1998: 43(3): 177-82$.

22 Wright RW, Larsen DE, Monie RG, Aldred RA. Benefte of a community-hospital pulmonary rehabilitation program. Respir Cara $1983 ; 28: 1474-9$.

23 Carter $R_{\text {, Coast J }}$, Idell $S$. Exercise training in parients with chronic obstructive pulmonary disense Med Sci Sport Exerc 1992; $24: 28$ r-9\%.

24 Belman MJ. Exercise in chronic obstrucrive pulmonary diseasc. Clinis in Chest Med $1986 ; 7: 5,85-97$.

25 Carter $\mathrm{R}$, Nicotra $\mathrm{B}$. The effect of exencise training and rehabilication on functional status in patients with chronic obstructive pulmonary disease (COPD). Int J Robabl Health 1996; 2: 143-67.

26 Geul-Klaren GA. Reactiveringsprogramma voor CARA-patiënten. Een nadere vitwerking van cen integrale behandelingswijze. Noth / Phys 1994; $9: 190-5$.

27 Bruinings AL, Bauer $H$, Mensen EAM, Willems LNA. Goede resultaten wan poliklinische longrevalidatie: 2 jaar ervaring in het Rijnlands Zeehospitium te Karwijk. Neth JMed 1996; 140:1504-8.

28 Kumar S. Pulmonary tehabilitation in chronic obstructive pulmonary disease: is someone too well or too sick to benefit from it: Phys Singapore 1999; 2: 105-9. 
29 Cambach W, Chadwick-Srawer RVM, Wagenaar RC, et al. Feasibility of a pumomary rehabilitation purogramme in communiry based physiotherapy practices. I Rehabit Sc 1994: $7: 104-12$.

30 Haas $\mathrm{A}$, Cardon $\mathrm{H}$. Rehabilitation in chronic obstructive pulmonary disease. Medical clinics of Nowb America 1969;53:593-606.

3I Dersimonian $\mathrm{R}$, Liard N. Meta analysis in dinical trials. Contr CLin Trials 1986; 7* $177-188$ 


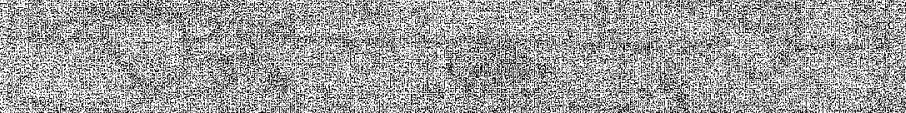
12
3 \begin{tabular}{ll}
1 \\
\hline
\end{tabular} 


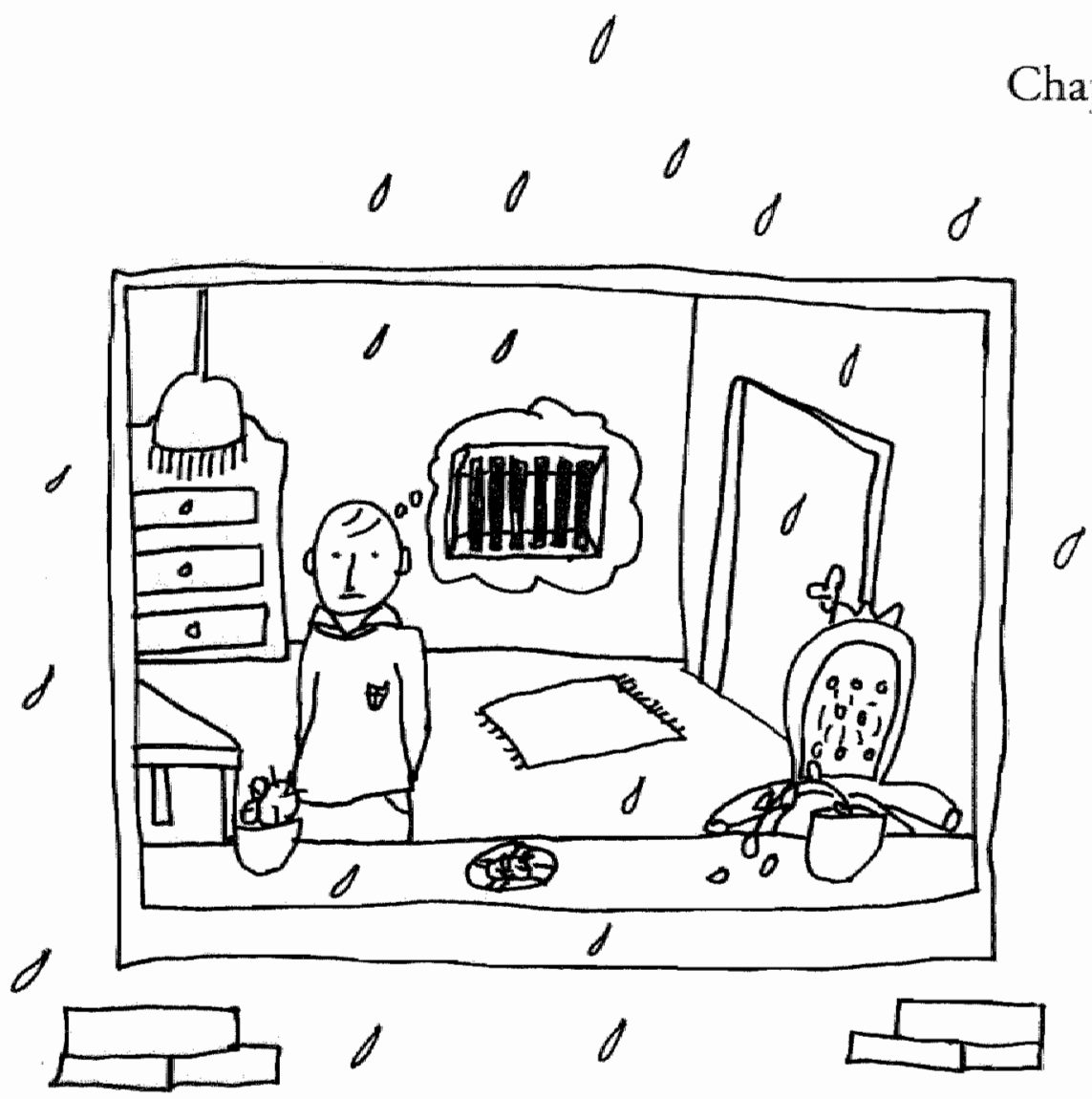




\section{Randomised, double blind, placebo- controlled trial of $\mathrm{N}$-acetylcysteine and fluticasone propionate in general practice patients with chronic bronchitis or chronic obstructive pulmonary disease (COPD)}

TRJ Schermer, NH Chavannes, PNR Dekhuijzen, EFM Wouters,

IWM Muris, RP Akkermans, CP van Schayck, C wan Weel

Submitted for publication

Presented at ERS 2005 Copenhagen 


\section{Abstract}

\section{Background}

Increased oxidative stress and bronchial inflammation are important mechanisms in the pathophysiology of chronic obstructive pulmonary disease (COPD). Inhaled corticosteroids and the anti-oxidative agent $N$-aceryloysteine are both considered to be pharmacotherapeutic options that may ameliorate the course of COPD. We investigated whether treatment with $N$-acetylcysteine or the inhaled corticosteroid futicasone propionate would improve respiratory health status or reduce the yearly exacerbation rate in (eX-)smokers with chronic bronchitis or COPD in general practice.

\section{Methods}

A randomised double dummy placebo controlled clinical rrial in 44 general practices in the Netherlands. The trial was preceded by a 3 -month washout period for the effects of withdrawal of inhaled conticosteroids and/or $\mathrm{N}$-acetylcysteine treatment and/or smoking cessation, and a subsequent 2-week 30 milligrams oral prednisolone pre-treatment. 286 patients with chronic bronchitis or COPD were randomly allocated to receive 600 milligrams oral $\mathbb{N}$-acetylcysteine once daily, inhaled futicasone propionate 500 micrograms twice daily, or placebo. Patients were followed for 3 years. Primary outcomes were the respiratory health status measured with the Chronic Respiratory Questionnaire (CRQ), and the yearly rate of exacerbations. Secondary outcomes were the yearly decline in forced expiratory volume in IS ( $\mathrm{FEV}_{\mathrm{I}}$ ) and forced vital capacity (FVC), respiratory symptoms and time to study dropout. Analysis was on the basis of intention to treat.

\section{Finding:}

The overall drop-out rate was $43 \%$. No differences berween the treatment groups existed in terms of rates or causes of dropout. The course of the CRQ total score did not differ between $N$-acerylcysteine $(p=0.306)$ or futicasone propionate $(\mathrm{p}=0.58 \mathrm{I})$ compared with placebo. The exacerbation rate was 1.35 times higher for $N$-acetylcysteine $(p=0.054)$ and 1.30 times higher for fluticasone propionate $(p=0.095)$ compared with placebo. The yearly post-bronchodilator $\mathrm{FEV}_{\mathrm{I}}$ decline was $64 \mathrm{~mL}$ [SD 5.4 ] for $N$-acetylcysteine $[\mathrm{p}=0.569$ versus $\mathrm{placebo}], 59 \mathrm{~mL}$ [SD 5.7,$]$ for Huticasone propionate $[\mathrm{p}=0.935]$, and $60 \mathrm{~mL}[\mathrm{SD} 5.4$,$] for placebo. No treatment effects on respi-$ ratory symptoms were observed.

\section{Interpretation}

We could not establish beneficial treatment effects for eirher oral $N$-acetylcysteine or high-dosed inhaled Auticasone propionate in adult patients 
with chronic bronchitis or mild to modesate COPD secruited in general practice. Subgroup analysis of our heterogeneous patient population may reveal differential treatment effects for $N$-acetylcysteine or Huticasone prom pionate.

\section{Introduction}

Chronic obstructive pulmonary disease (COPD) is a major cause of morbidity and mortality worldwide. The burden of COPD on sociery is expected to increase substantially in forthcoming years ${ }^{1,2}$. Bronchial inflammation and oxidative stress due to cigarette smoke exposure are important factors in the pathophysiology of $\operatorname{COPD} \mathrm{O}^{3} . \mathrm{N}$-acetylcysteine is a compound with anti-oxidative properties that is believed to reduce oxidative stress in the lung tissue by replenishing glutathione level $s^{4,5}$. Thus, treatment with $\mathrm{N}$-acetylcysteine may alter lung oxidant/antioxidant imbalance and, consequently, reduce respiratory symptoms, exacerbations and decline of lung function in patients with COPD. Published meta-analyses of clinical studies have pointed to a protective effect of $\mathrm{N}$-acetylcysteine on the risk of exacerbations $s^{6-8}$. However, the studies included in these meta-analyses generally did not last beyond six months of follow-up and used the proportion of patients suffering from an exacerbation rather than the actual rate of exacerbations as an endpoint. The long-term effects of $N$-acerylcysteine on clinical outcomes and disease progression have recently been reported in a placebo controlled trial in patients with moderate to severe COPD, the so-called 'Broncus' study'. In this study $N$-acetylcysteine was ineffective in preventing the accelerated lung function decline that is typical for COPD, nor did it prevent the occurrence of exacerbations or improve health starus. However, the subgroup of patients who were not on concomitant inhaled corticosteroid treatment showed some benefit of $\mathrm{N}$ acetylcysteine in terms of reduced exacerbation rate?

Compared with $N$ acerylcysteine, the long-term effects of inhaled corticosteroids in COPD have been investigated more extensively. Inhaled corticosteroids do not seem to be able to suppress the appropriate type of inflammation in the airways of patients with COPD ${ }^{10,11}$. The inflammation in COPD, in marked contrast to asthma, may even be resistant to inhaled corricosteroids due to an inhibitory effect of cigarette smoke exposure ${ }^{22}$. Three recent meta-analyses of published efficacy studies have indicated that there may be a small effect of regular inhaled corticosteroid treatment on lung function decline of 5 to $8 \mathrm{~mL}$ per year ${ }^{13-15}$. The clinical relevance of an effect this size remains questionable. One of the meta-analyses concluded that inhaled corticosteroid treatment reduces exacerbations by 30 percent in patients with COPD ${ }^{15}$.

The aim of the study reported in this paper was to determine the long- 
term clinical effectiveness of regular treatment with $\mathrm{N}$-acerylcysteine or futicasone propionate in the heterogeneous group of current or former smokers with chronic bronchiris or mild to moderate COPD that is typically treated in general practice. Over the past few years, changes in health status and occurrence of exacerbations have gained importance as study outcomes in clinical COR $D$ research ${ }^{16,17}$. The current study was designed to investigate effects on these outcomes instead of the conventional primary outcome, rate of lung function decline.

\section{Methods}

\section{Study population}

Patients were recruited from 44 general practices - also referred to as 'study centres' - in the southeastern part of the Nethetlands. The 108 general practitioners (GPs) in the study centres identified subjects with a diagnosis of COPD using existing diagnostic labels, drug prescription records, and call-up lists for the annual influenza vaccination campaign. Incident cases (i.e., parients being diagnosed during the accrual period in a study centre) were also eligible for inclusion. Subjects identified as being diagnosed with chronic bronchitis or COPD were invited for a screening visit to their generall practice to assess their eligibility for trial participation. Trial inclusion criteria were: age 35-75 years; current or ex-smoker; chronic dyspnea, sputum production and cough for at least three consecutive months per year during the previous two years ${ }^{\mathrm{r} 8}$; postbronchodilaton: forced expiratory volume in one second $\left(\mathrm{FEV}_{1}\right)<90 \%$ of the predicted value and/or postbronchodilator $\mathrm{FEV}_{\mathbf{I}} / \mathrm{FVC}$ (forced vital capacity) of the predicted value $<88 \%$ for men and $<89 \%$ for women. Subjects with a postbronchodilator $\mathrm{FEV}<40 \%$ of predicted were excluded, as were subjects with a history of asthma, allergic rhinitis, or allergic eczema; history of intolerance for $N$-acetylcysteine or inhaled corticosteroids; alpha-I-antitrypsin deficiency; cystic fibrosis; bronchiectasis; history of infection or active infection due to Mycobacterium tuberculosis; history of active peptic ulcer disease or intestinal malabsorption; severe congestive heart failure; reduced life expectancy because of other disease; evidence of illicit drug use or alcohol abuse; pregnancy; and anticipated non-compliance in taking study medication (i.e., tablets or inhalations). Trial eligibility as established by the GP was verified in one of the four involved certified pulmonary function laboratories. Indusion of patients tan from December 1998 to January 2001. The trial was completed on $\mathbb{I}$ January 2004 . The study was approved by the medical ethics review boards of the four hospitals involved. All study subjects gave written informed consent. 


\section{Trial design}

The study was designed as a randomised, double blind, double dummy placebo controlled phase iv trial with two active treatment groups, $N$-acerylcysteine and fluticasone propionate. Patients were followed for three years, with 3-monthly visits to their GP and yearly visits to the lung function laboratory of the nearest of the four involved hospitals. The study was done under double blind conditions - i.e., neither the investigator nor the patient were aware of che group assignment of patients. Patients who were current smokers were strongly advised to quit smoking before the trial. The trial was preceded by (in chronological order): an optional smoking. cessation attempt supported by the GP in trial candidates who were current smokers; a washout phase to eliminate possible carry-over effects of a successful smoking cessation attempt or the withdrawal of prior treatment with $N$-acetylcysteine and/or inhaled corticosteroids; and a run-in phase with $30 \mathrm{mg}$ oral prednisolone in order to attain the highest possible baseline condition. Primary outcomes of the study were the disease-specific quality of life as assessed with the Chronic Respiratory Questionnaire $(C R Q)^{19}$ and the occurrence rate of exacerbations. Secondary outcomes were the yearly decline in forced expiratory volume in I $(\mathrm{FEV}$ ) and forced vital capaciry (FVC), respiratory symptoms (dyspnea, phlegm, cough), and time to dropout.

Calculation of the sample size needed to detect a significant effect of $\mathrm{N}$ acerylcysteine or fluticasone propionate relative to placebo was based on the presumptive effects of these drugs on health-related quality of life (CRQ score) and exacerbation rate. Based on the number of patients needed to detect a. 0.5 point difference in the total CRQ score a power calculation was performed. A change of 0.5 point on the CRQ was considered the minimally important difference for this health status measure ${ }^{19,20}$. The standard deviation of the difference in total CRQ score for this study population was estimated to be $0.7^{21}$. With alpha $=0.05,1-b e t a=0.80$ and a $30 \%$ dropout rate the required number of patients was $270(90$ per treatment arm).

An additional power calculation was performed for exacerbations. Based on previous studies in patients with COPD the average number of exacerbations in a three year time frame was estimated to be three (1 per year) ${ }^{21-}$ 25. We considered a reduction of one exacerbation in three years time as a clinically relevant treatment effect. Assuming a Poisson distribution, the standard deviation was $\sqrt{3}=1.73$. A pha was set on $0.05, \mathrm{r}$ - beta on 0.80 . With the anticipated drop out rate of $30 \%$ the required number of patients was 207 ( 69 per treatment arm) to detect a significant difference in terms of exacerbations.

Trial medication consisted of either oral $N$-acetylcysteine (trade name Fluimicil ${ }^{\text {ras }}$, provided by Zambon BV, Amersfoort, the Netherlands) ad- 
ministered as 600 milligrams effervescent tablets dissolved in a glass of tap water taken once daily in the morning, fluticasone propionate (trade name Flixotide ${ }^{\text {tu }}$, provided by GlaxoSmith Kline BV, Zeist, the Netherlands) 500 $\mu \mathrm{g}$ twice daily administered as dry powder inhalation by Diskus ${ }^{\text {Th }}$ inhaler, or placebo treatment. The dosages of $\mathrm{N}$-acetylcysteine and fluticasone propionate were chosen on the basis of reported efficacy data from previous research ${ }^{8,26,27}$. $N$-acerylcysteine and placebo tablets and Aluticasone propionate and placebo inhalers had identical external appearances and expiration dates, and were packaged and labelled in exacrly the same way to prevent recognition by GPs, patients, and investigators. Patients were instructed to bring their tablets and inhalers with them in every visit to their general practice. Compliance was assessed after every scheduled 3-monthly visit by counting of the returned tablet blister strips and the doses remaining in the inhalers. The numbers of returned tablets and puffs were recorded by the GP on a drug accountability form. Patients were considered compliant with regard to the trial medication if they had taken $80 \%$ or more of both their effervescent tablets and inhalations. Concomitant use of other drugs was documented by the GPs. Nasal and ophthalmic corticosteroids and all bronchodilators (including theophylline) were allowed, but GP were instructed to prescribe the same bronchodilator throughout the study as much as possible for a particular patient. GP $s$ were informed that single inhaler combined treatment with fenoterol and ipratropium bromide was the preferred bronchodilator treatment.

For the allocation to treatment arms a predetermined computer generated randomisation list based on a block size of three was generated by an independent statistician. The block size was chosen to balance the three treatment arms by study centre. The independent statistician sent the randomisation list ditectly to the Department of Clinical Pharmacy of the Radboud University Nijmegen Medical Centre where the trial medication was packed and stored until transportation to a study centre was required. Sealed copies of the randomisation list were stored on three locations: in the offices of the independent statistician and the chief pharmacist of the Department of Clinical Pharmacy, and in the office of the duty pulmonologist of the University Lung Centre Dekkerwald. Storage of the latter copy was to guarantee 24 -hr accessibility of randomisation codes in the case of a life-threatening adverse event. General practices were provided with uniquely numbered cardboard boxes containing a set of effervescent tablets and inhalers to be assigned to a patient. One set of study medication was sufficient for roo days of treatment. A study centre received a number of blocks that matched with the anticipated number of eligible parients for that particular centre. Each mutation in the location of a set of trial medication was recorded by the investigators. Supplies of tablets and inhalers for every patient were identified by a unique three-digit randomisation 
number. Study centres were instructed to always assign the lowest randomisation number availlable first. The randomisation code was broken after the data cleaning and final analyses had been concluded, which was verified by the same independent statistician who had generated the randomisation list. Also, a time stamped copy of the final dataser was sent by recorded delivery to the funding source, the Dutch Council for Health. Insurances, before the blinded group allocation was disclosed in the presence of the independent statistician.

\section{Measurements}

Patients were first screened in their general practice to assess inclusion and exclusion criteria and to obtain baseline characteristics (i.e., spirometry; smoking status and history; relevant co-morbidity; number of exacerbations in the previous two years; current use of respiratory medication). If the patient complied with the inclusion criteria, he or she received the informed consent information and was asked to sign the consent form. Patients requiring a washout period were scheduled for a visit to a lung function laboratory three months after screening, patients without a washout after one to three weeks. The laboratory staff verified the inclusion criteria by repeating spirometry and medical and smoking history taking. After the prednisolone run-in phase, the patient was randomly allocated to a treatment group by the GP and received the first box of trial medication. Next, a house visint by a tesearch nurse was scheduled to instruct the patient in how to use the effervescent tablets and inhalers, and how to complere an exacerbation study calendar. After that, patients visited their general practice every 3 months and the lung function laboratory every 12 months untill the end of the three year trial period. At each visit, the following were recorded: lung function; smoking habits; adverse events; level of respiratory symptoms; use of health care resources and number of days with restricted activities in the past three months).

Health status was assessed during the annual visits to the lung function laboratory using the interviewer administered version of the Chronic Respiratory Questionnaire ( $\mathrm{CRQ}$ ), a disease-specific instrument ${ }^{\mathrm{r}}$. "The CRQ is a 20 -item instrument which measures four domains: activity related dyspnoea; fatigue; emotional function; and mastery (i.e., the patient's perception of control over the disease). Answers are scored on a seven point scale ranging from I (maximum impairment) to 7 (no impairment). The CRQ dyspnea domain is made up of five activities selected by the patient to cause the grearest shortness of breath. The patient rated the level of dyspnea on these self-selected activities during subsequent administrations of the CRQ as a part of the yearly visits to the lung function laboratory. Results are expressed as the mean overall score and mean scores for each of the four domains separately. The CRQ has shown to be a reliable and valid 
instrument in COPD research ${ }^{2 \mathrm{n}, 28}$. To standardise measurement conditions, the questionnaire was completed after the salbutamol for the postbronchodilator lung function test had been inhaled. Lung function technicians were trained in administering the questionnaires and were instructed not to assist patients with the interpretation of the questionnaire. Respiratory symptoms (i.e., dyspnea, cough, phlegm) were measured on a 7-point Likert scale during the 3 -monthly visits to the general practice. A higher score on this scale indicates less serious symptoms.

Patients were instructed to contact or visit their GP in case of worsening of their respiratory symptoms. An exacerbation was defined as an episode with one or more subsequent unscheduled contacts with either a GP or a pulmonologist due to worsening of respiratory symptoms. In case no course of prednisolone and/or antibiotics was prescribed, the exacerbation was labelled as 'mild'; exacerbations treated with prednisolone and/or antibiotics were labelled as 'moderate', exacerbations leading to an emergency room visit or hospitalisation as 'severe'. The definition and severity classifcation used during the trial was also used to assess the occurrence of exacerbations in the two years before the trial from patients' medical records. During the trial data on exacerbations were recorded by the GPs. Additional information about exacerbations from pulmonologists or, in case of emergency room visit or hospitalization, from hospitals were inquired by the GP if applicable and forwarded to the investigators.

Completeness of exacerbation reporting was verified in the patients' medical record by a research nurse after the patients final trial visit. The date of the first contact with the physician was considered as the onset of the exacerbation. No attempt was made to establish the duration of an exacerbation. For every exacerbation-related contact GPs indicated whether it belonged to a previous exacerbation or not. When this judgement was absent, an interval of $>30$ days since a previous contact was used to decide for the onset of a new exacerbation ${ }^{29}$. Apart from the data on exacerbations recorded by the GPS, patients themselves kept a study calendar to report episodes with aggravated respiratory symptoms (dyspnea, cough, phlegm) andior increased use of bronchodilator puffs. An episode was defined as $\geq 3$ consecutive days with aggravated symptoms with an interval of $>7$ days since the previous episode. An episode ended when symproms had returned to their normal level and no additional bronchodilator puffs were used anymore.

Study centres and laboratories were all equipped with the same electronic spirometer (Microloop I I ${ }^{\text {rm }}$; MicroMedical Lid, Rochester, UK) and spirometry sofware (Spirare ${ }^{\mathrm{Ta}}$; Diagnostica Ltd, Oslo, Norway). The durability of the Microloop turbine flow sensor has proved to be acceptable ${ }^{30}$. Spirometry was performed according to European Respiratory Society standards ${ }^{31}$ at all scheduled visits of trial participants to the general practice 
or the lung function laboratory. General practice staffs (GPS and practice assistants) were trained in spirometry before the start of the study. We have previously reported that spirometric indices measured by trained general practice staff are valid but cannot be used interchangeably with a laboratory test ${ }^{32}$. Both in the laboratories and the study centres spirometry was conducted before and 15 minutes after administration of 400 micrograms salbutamol by metered-dose inhaler and a Volumatic spacer. Patients were asked to refrain from using bronchodilators and cigarette smoking a specified number of hours before every scheduled trial visit, depending on the type of bronchodilator used. For each test at least three acceptable forced expiratory manoeuvres were required. The spirometric indices (including $\mathrm{FEV}_{1}$ and FVC) of the manoeuvre with the highest sum of FEV, and FVC were stored and used for analysis. Spirometers were checked for errors in readings by a research nurse every 3 months using a 3 litre syringe and by means of 'biological control" - i.e., a manoeuwre performed by the research nurse herself. In case of a deviation of $>3 \%$ in the volume reading or a divergent outcome of the biological control manoeuvre the spirometer was replaced. Based on the spirometric test results the ratio of $F E V_{\text {If }}$ to $F V C$ and the FEV $\%$ predicted (using ECCS reference equations ${ }^{3}$ ) were calculated, and patients were posthoc classified according to GOLD stages ${ }^{33}$. Reversibility after bronchodilator was expressed as the percentage change of the predicted $F E V_{\mathbf{r}}$.

\section{Statistical analysis:}

The primary analyses were done on an intention to treat basis - i.e., all randomised patients were included in the analyses. Additional per protocol analyses were done on patients with a trial medication compliance rate $>80 \%$. Hypothesis testing was two-sided; $p=0.05$ was defined as statistically significant. The Statistical Analysis System (SAS, Version 8.2 for UNIX, SAS Institute Inc., Cary, NC, USA) was used. In all statistical models used $N$-acetylcysteine and Auticasone propionate treatment were each tested with placebo as the reference group. For the descriptive analysis of exacerbations the mean and median yearly exacerbation rates were calculated. Statistical testing of differences in exacerbation rates during the study between $N$-acetylcysteine or fluticasone propionate and placebo was done in a correlated time-event mode ${ }^{134}$ using the GENMOD-procedure in SAS, with Poisson distribucion and assuming a compound symmetry correlarion structure. Results are reported as rate ratios for an exacerbation in the $N$-acetylcysteine or the fluticasone propionate group versus placebo. A rate ratio < indicates a prophylactic effect of $N$-acerylcysteine or fluticasone propionate. Because the two data sources on exacerbations - GP reports and patient study calendars - overlapped, data from these two sources were analysed separately. Effects on health status were analysed using repeated 
measurements regression analysis ${ }^{35}$ (MIXED-procedure in SAS) on the CRQ total and domain scores, in order to adjust for correlation between successive measurements. Covariates included in the regression models were study centre; baseline postbronchodilator $\mathrm{FEV}_{1} \%$ predicted; age; gender; smoking status; and pack years. Repeated measurements regression models with the same covariates were also used to analyse differences in the yearly decline of lung function indices (pre- and postbronchodilator $\mathrm{FEV}_{\mathrm{I}}$ and FVC) and respiratory symptoms. Only the spirometric tests from the general practices were used for the analysis of lung function decline. All patients with at least one repeated spirometry were included in these analyses. Spirometric tests with a reproducibility $\geq 5 \%$ and tests performed within a 6-week period after the onset of an exacerbation were discarded. In case a patient had used a bronchodilator within the allowed time frame for that particular drug the prebronchodilator spirometric values were discarded as well.

A dropour was defined as a patient in whom the blinded trial medication was withdrawn by the $\mathrm{GP}$, either for medical reasons or due a patients" lack of motivation to continue its use. A maximum effort was made to complement the collection of outcome data in all patients, including those who dropped out of the trial. Comparison of the proportion of dropouts was done by Cochran-Mantel-Haenszel test. Time to dropout was calculated as the number of days from the beginning of the trial to the date of a documented withdrawal of trial medication and compared between the groups using analysis of variance. For patients who finished the study, the final visit to the lung function laboratory terminated their follow-up period; for those who also withdrew from follow-up the dropout date was the last follow-up date, except for exacerbations which continued to be reported by the GP in these cases. Missing data were assumed to be missing at random. Following our original hypothesis regarding differential effects of $N$-acetylcysteine and inhaled corricosteroids in COPD ${ }^{36}$, a priori defined subgroup analyses were done for a number of parient characteristics (i.e., age, gender, smoking, severity of obstruction, reversibility). These subgroup analyses will be reported in a separate paper.

\section{Role of the funding source}

The funding source (Dutch Council for Health Insurances) had no role in the collection, management, analysis, or interpretation of the data; writing of the report; or the decision where the study results would be submitted for publication. "The investigators were allowed to submit a paper for publication three months after the approval of the final study report. The corresponding author had full access to all the data in the study and had final responsibility for submitting this paper for publication. 


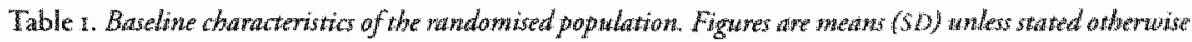

\begin{tabular}{|c|c|c|c|}
\hline & Nwaceryloysteine & Placebo & Fluticasone proplonate \\
\hline \multicolumn{4}{|l|}{ Gemeral } \\
\hline $\mathbb{N}$ & 96 & 96 & 94 \\
\hline Gender, malles $(\%)$ & $75(78)$ & $65(68)$ & $69(73)$ \\
\hline Age, years & $59.2(9.2)$ & $59.6(10.1)$ & $58.4(9.9)$ \\
\hline Weighr, kg & $98.8(16.0)$ & $77.2(14.5)$ & $77.5(5.5)$ \\
\hline Body mass index, $\mathrm{kg}_{\mathrm{m}} \mathrm{m}^{2}$ & $26.5(4.0)$ & $2.6 .0(4.6)$ & $26.5(4.6)$ \\
\hline \multicolumn{4}{|l|}{ Smoking } \\
\hline Smoking history, pack years & $280(17.5)$ & $26.5(16.7)$ & $30.2(18.2)$ \\
\hline Smoking starus, current smokers ( $\%$ ) & $54(56)$ & $49(51)$ & $58(62)$ \\
\hline Cigarettes, current number per day* & $8.6(10.1)$ & $8.1(10.7)$ & $10.4(12,0)$ \\
\hline \multicolumn{4}{|l|}{ Phamacotherapy } \\
\hline \multicolumn{4}{|l|}{ Bronchodilators, number (\%) } \\
\hline No bronchodilator & $22(23)$ & $23(24)$ & $24(26)$ \\
\hline Short-acting ${ }^{*}$ & $\$ 6(58)$ & $53(55)$ & $5:(54)$ \\
\hline Long-acring or theophylline & $18(19)$ & $20(21)$ & 19) $(20)$ \\
\hline \multicolumn{4}{|l|}{ Prophylactic medication ${ }^{8}$, number (\%) } \\
\hline Inlaaled corticosteroids & $43(45)$ & sin $(53)$ & $37(39)$ \\
\hline$N$-acerylcysteine & $5(5)$ & $2(2)$ & $5(5)$ \\
\hline \multicolumn{4}{|l|}{ Pulmonary function } \\
\hline \multicolumn{4}{|l|}{ Prebroncbodilator } \\
\hline $\mathbb{F E V}(\mathrm{mL})$ & $1929(624)$ & $2010(717)$ & $1919(608)$ \\
\hline as $\%$ predicted & $61.7(14.5)$ & $65.7(17.7)$ & $63.2(17.1)$ \\
\hline PVC $(\mathrm{mL})$ & $3135(922)$ & $31911(996)$ & $3154(950)$ \\
\hline $\begin{array}{c}\text { FEV } / \mathrm{v} \\
\text { Postbroncbodilator }\end{array}$ & $61.7(11.2)$ & $63.11(12.4)$ & $61.8(12.2)$ \\
\hline $\mathrm{FEV}_{\mathrm{l}}(\mathrm{mL})$ & $2 \mathrm{~J} 36(644)$ & $2179(715)$ & $2087(604)$ \\
\hline as oredicted & $68.1(93.9)$ & $71.4(17.1)$ & $68.7(15.7)$ \\
\hline FWC (mL) & $347 \times(974)$ & $3.427(972)$ & $3398(876)$ \\
\hline $\mathbb{E V} / \mathrm{FVC}$ & $61.7(11.0)$ & $63.9(12.6)$ & $62.1(11.8)$ \\
\hline Reversibilicy, as \% predicted FEV & $6.8(5.4)$ & $6.1(4.5)$ & $5.9(5.3)$ \\
\hline Reversibility, as baseline FEW, & $12.5(11.7)$ & $10.4(8.5)$ & $11.0(11,1)$ \\
\hline \multicolumn{4}{|l|}{ Response on prednisolone test } \\
\hline \multicolumn{4}{|l|}{ Prebroncbodilator } \\
\hline $\mathrm{FEV}_{\mathrm{g}}(\mathrm{mL})$ & $87(251)$ & $62(220)$ & $31(218)$ \\
\hline as $\%$ predicted & $3.0(8.7)$ & $2.3(7 \cdot 4)$ & $1 . .2(7+5)$ \\
\hline \multicolumn{4}{|l|}{ Postbronchodilator } \\
\hline $\mathrm{FEV}_{1}(\mathrm{~mL})$ & $97(195)$ & $84(2: 14)$ & $50(192)$ \\
\hline as predicted & $3.2(6.7)$ & $3.0(7.0)$ & $1.9(6.7)$ \\
\hline \multicolumn{4}{|l|}{ Exacerbation history } \\
\hline \multicolumn{4}{|l|}{ Yearly exacerbarion tate } \\
\hline noean (SD) number/year & $0.87(0.75)$ & $0.90(0.81)$ & $0.86(0.80)$ \\
\hline median $(\mathbb{Q Q R})$ number/year & $0.5(1.0)$ & $0.5(1.0)$ & $0.5(1.5)$ \\
\hline
\end{tabular}




\section{Health stratus}

\begin{tabular}{|c|c|c|c|}
\hline CRQ-Tond score & $4.8 ;(1.04)$ & $4.84(1.11)$ & $4.73(1.00)$ \\
\hline CRQ-Dyspnoca & $4.55(1.32)$ & $4.59(1.48)$ & $4.59(1.48)$ \\
\hline CAQ - Iratigue & $4.54(1.10)$ & $4.66(1.24)$ & $4.31(1.22)$ \\
\hline CAQ-Emotional funcrion & $4.82(1 ., 1)$ & $4.83(1.24)$ & $4.72(1.05)$ \\
\hline CRQ-Mastery & $5.47(1.27)$ & $5.33(1.32)$ & $5.33(1.26)$ \\
\hline \multicolumn{4}{|c|}{ 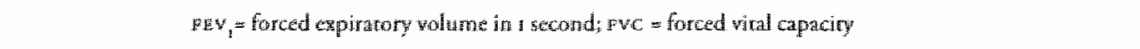 } \\
\hline \multicolumn{4}{|c|}{ 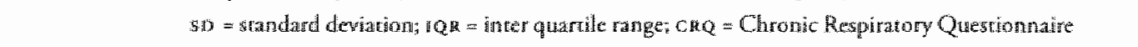 } \\
\hline \multicolumn{4}{|c|}{ "indading patients who reported to be noty-smoker at the eine of trial entry } \\
\hline \multicolumn{4}{|c|}{ Aat the start of the washour phiatse } \\
\hline \multicolumn{4}{|c|}{ * shortacting - $z^{-a g o n i s t, ~ s h o r t-a c t i n g ~ a n t i c h o l i n e r g i c e ~ o n ~ c o m b i n a t i o n ~ o f ~ b o r h ~}$} \\
\hline \multicolumn{4}{|c|}{ "long-acring - - -agonist and/or theophylline, with or withour addirional short-acring bronchodilato } \\
\hline \multicolumn{4}{|c|}{ 3. an the time of the screening wisit to the general practice } \\
\hline
\end{tabular}

Table 2. Characteristico of study dropouts and completers

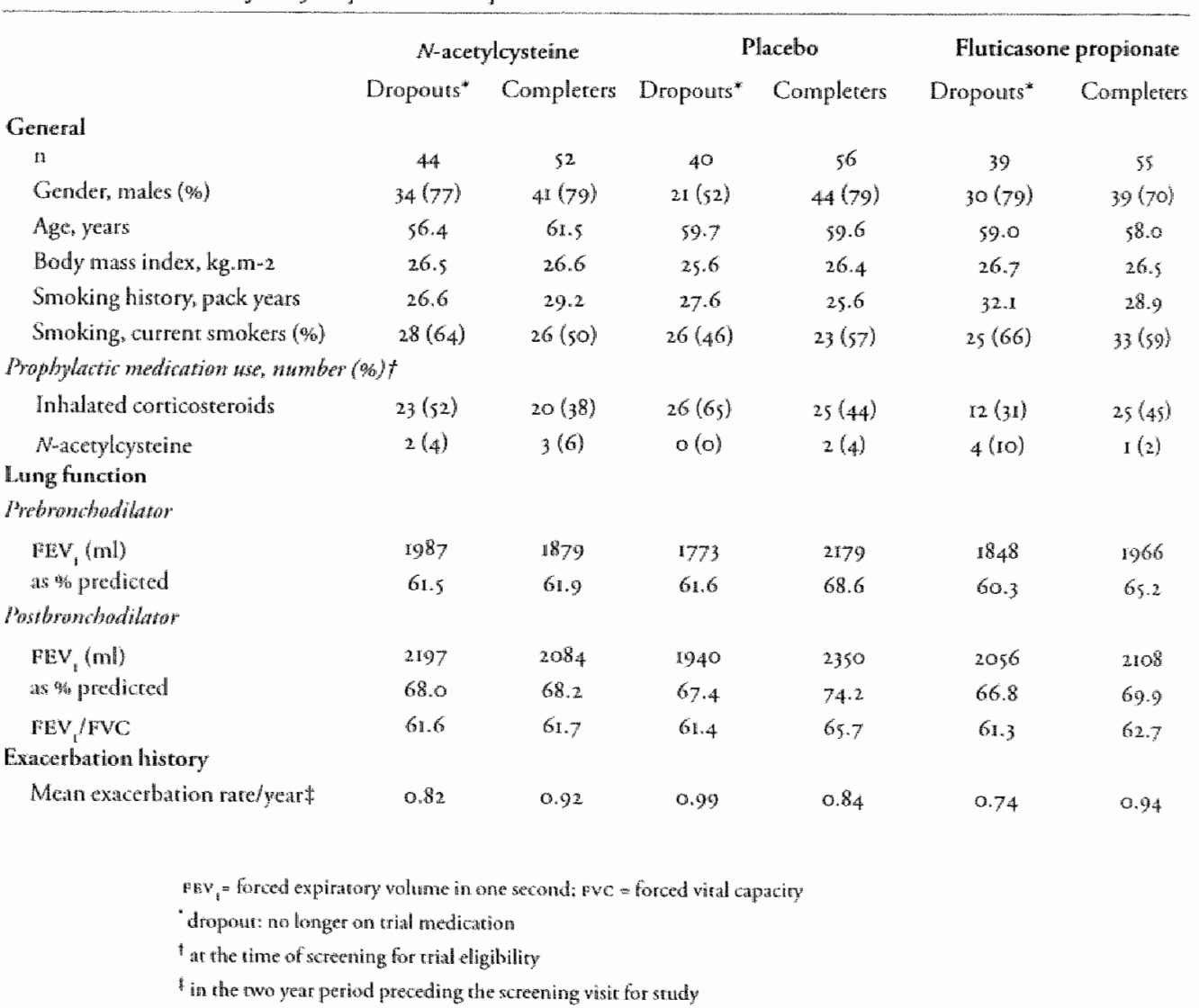


Figure 1. Profle of number of patients and dropout during each phase of study

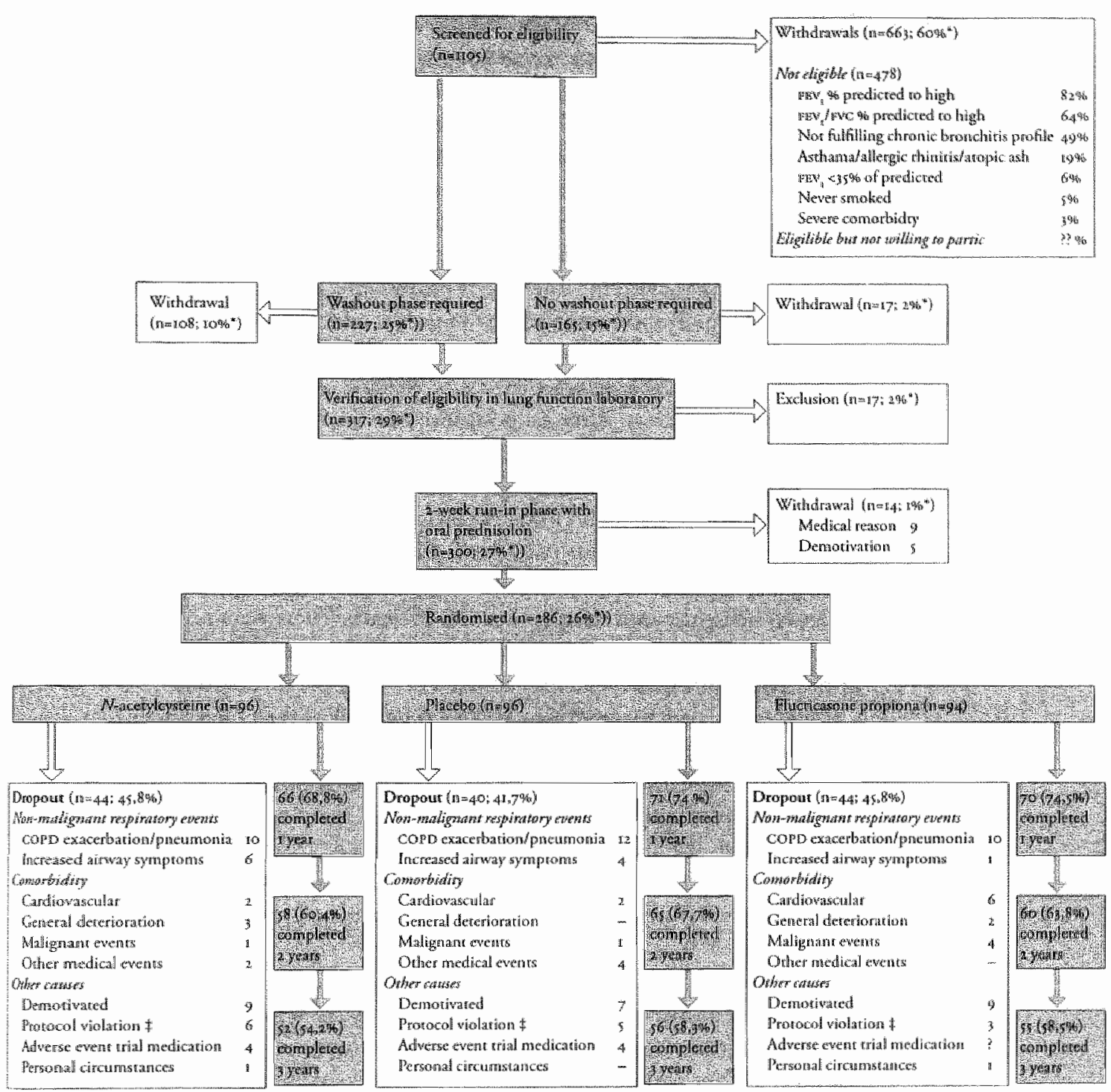

* proporrion of the total screened

t trial candidates could be incligible for mone than one reason

* either due use of an inhaled corticosteroid or $\mathrm{N}$-acenylcysteine duting the trial, or not being able to properly use the rrial medication 


\section{Results}

\section{Patient demographics, dropout and treatment compliance}

Table I shows the baselinte characteristics of the patients in the three treatment groups. Following the GOLD classification, 62 patients [22\%] suffered from chronic bronchitis without obstruction, 40 [14\%] from mild COPD, $138[48 \%]$ from moderate COPD, and $46[16 \%]$ from severe COPD. Details on the dropout of study candidates during the pre-trial phase have been described in details elsewhere (37) and are summarised in figure $\mathrm{I}$. The overall dropout rate during the trial was $43 \%$ and was not different for $N$-acetylcysteine, fluticasone propionate, or placebo $(p=0.790)$. Average time to dropout was 318 [SD 3I4] days and was also similar for the three groups $(p=0.828)$. Figure 2 shows the course of the respiratory related dropout, whereas table 2 shows the characteristics of study dropouts compared with completers. After dropout from the trial, 10 [10.4\% of all] patients originally assigned $N$-acetylcysteine, 15 [15.1\%] patients assigned placebo, and 1o [10.6\%] patients assigned futicasone propionate received one or more prescriptions for an inhaled corticosteroid from their GP or pulmonologist. Twelve patients ( 8 in the futicasone propionate group) died during the trial, myocardial infarctions (4 patients) and lung carcinoma (3 patients) being the most frequent causes of death. There were no statistically significant differences in the self-reported changes in smoking status or the daily number of cigarettes smoked between the three groups.

On average, parients used 64.I [SD 38.5] percent of their effervescence tablets and 6I.9 [SD 37.7] of their dry powder inhalations. There were no significant differences in the use of tablets or inhalations between the treatment groups. $4 \mathrm{I}[43 \%]$ of patients assigned to $N$-acetylcysteine were compliant rowards the use of their trial medication (i.e., used $80 \%$ or more of the dispensed number of doses); corresponding figures for the Huticasone propionate and placebo groups were $48[51 \%]$ and $45[47 \%]$, respectively.

\section{Clinical effects}

The total number of exacerbations reported by the GPs was 751. Most exacerbations [ $84.3 \%$ ] were of moderate severity (i.e., were treated with prednisolone and/or antibiotics). Especially in the $N$-acetylcysteine and fluticasone propionate groups the distribution of exacerbation rate was skewed due to a small number of distinct outliers (figure 3 ). Table 3 shows the mean and median yearly exacerbation rates in the three groups and the rate ratios for $\mathrm{N}$-acetylcysteine and Huticasone propionate compared to placebo. With a mean rate of 0.73 [95\% CI $0.58 ; 0.89]$ exacerbations per year the lowest rate was observed in the placebo group. $N$-acetylcysteine treated patients showed I.35 times higher exacerbation rates than placebo treated patients $(p=0.054)$. The corresponding figure for fluticasone propionate was 
$I_{3} 30(p=0.095)$. Median exacerbation rates were very similar for the three treatment groups (table 3), which illustrates the influence of the outliers in the $N$-acetylcysteine and fluticasone propionate groups on the overall results. $77 \%$ of all patients produced valid study calendar registrations for at least one month of follow-up. The mean number of calendar months registered was 23.I [SD 14.0] for $N$-acerylcysteine, 24.7 [SD 12.1] for fluticasone propionate, and 24.9 [SD [2.3] for placebo. The number of episodes with aggravared symptoms extracted from the calendar data was 3.5 [SD 4.6] per year for $N$-acetylcysteine, 3.I [SD 3.9] for fluticasone propionate, and 3.3 [SD 3.9] for placebo $(\mathrm{p}=0.768)$.

Figure 2. Coume of pespinatory related drop-owt in whe for the three study groups.

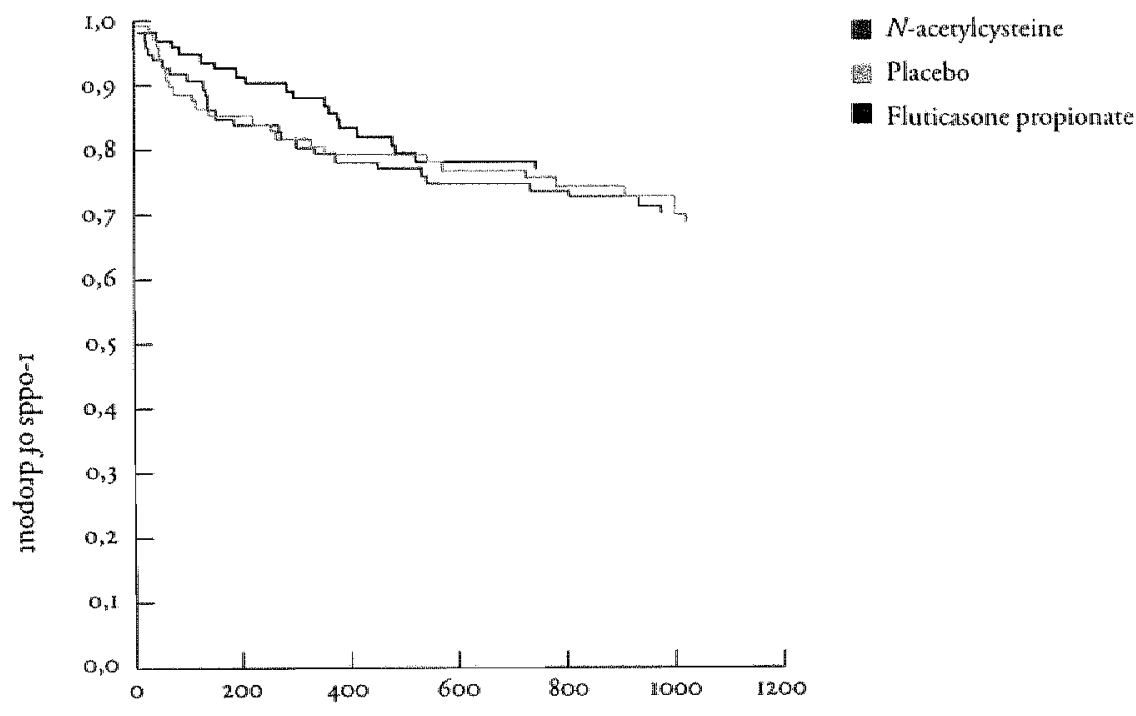


Table 3. Yearly exacerbation rates and rate watios for $N$-acetylysteine and faticasone propionate relative to placebo

\begin{tabular}{|c|c|c|c|c|c|c|c|c|}
\hline & \multicolumn{2}{|c|}{$N$-acetylcysteine } & \multicolumn{2}{|c|}{$\begin{array}{l}\text { Placebo } \\
(n=96)\end{array}$} & \multicolumn{2}{|c|}{$\begin{array}{l}\text { Fluticasone propionare } \\
\qquad(\mathrm{n}=94)\end{array}$} & \multicolumn{2}{|c|}{$\begin{array}{l}\text { Rate Ratio: } \\
\text { (p-value) }\end{array}$} \\
\hline & $\begin{array}{c}\text { Mean } \\
\left.(05)^{\circ} \mathrm{Cl}\right)\end{array}$ & Median: & $\begin{array}{c}\text { Mean } \\
(9 y \% \mathrm{Cr})\end{array}$ & Median & $\begin{array}{c}\text { Mean } \\
(95 \% \mathrm{CD})\end{array}$ & Median & $\begin{array}{c}\text { Nacetyloysteine } \\
\text { persus placebo }\end{array}$ & $\begin{array}{l}\text { Fluticasone propion } \\
\text { nate verug placebo }\end{array}$ \\
\hline Intencion to treat & $\begin{array}{c}1.00 \\
(0.8 .61: 14)\end{array}$ & 0.67 & $\begin{array}{c}0.73 \\
(0.58: 0.89)\end{array}$ & 0.69 & $\begin{array}{c}0.98 \\
(0.75 ; 1.20)\end{array}$ & 0.67 & $\begin{array}{c}1.35 \\
(0.054)\end{array}$ & $\begin{array}{c}1.30 \\
(0.095)\end{array}$ \\
\hline Per protocolt & $\begin{array}{c}0.82 \\
(0.46 ; 1.19)\end{array}$ & 0.38 & $\begin{array}{c}0.52 \\
(0.33 ; 0.71)\end{array}$ & 0.32 & $\begin{array}{c}0.75 \\
(0.46: \ldots 05)\end{array}$ & 0.35 & $\begin{array}{c}x .28 \\
(0.036)\end{array}$ & $\begin{array}{c}\text { T.2.7 } \\
(0.046)\end{array}$ \\
\hline & $\begin{array}{l}\ln \\
\mathrm{F}\end{array}$ & $\begin{array}{l}\text { rprekanom: } \\
\text { cetylcystei } \\
\text { example: }\end{array}$ & $\begin{array}{l}\text { urnber of tim } \\
\text { e, fluticasone } \\
\text { eyearly exacert }\end{array}$ & $\begin{array}{l}\text { per year } t \\
\text { opionate) } \\
\text { arion rate f }\end{array}$ & $\begin{array}{l}\text { at patients in a } \\
\text { xacerbated no } \\
\text { r. N-acerylcyse }\end{array}$ & $\begin{array}{l}\text { active creatm } \\
\text { often than } P \\
\text { de treated par }\end{array}$ & $\begin{array}{l}\text { nt group } \\
\text { rients in the placebo } \\
\text { ents was } 1.35 \text { cimes his }\end{array}$ & $\begin{array}{l}\text { roup. } \\
\text { uer than for placebo }\end{array}$ \\
\hline
\end{tabular}

Table 4. Mean (SE) effect of three years" treatwent on lung function in the three treatment arms

\begin{tabular}{|c|c|c|c|c|c|c|c|c|c|c|c|}
\hline & \multicolumn{3}{|c|}{$N$-acetyllcysteine } & \multicolumn{3}{|c|}{ Placebo } & \multicolumn{3}{|c|}{ Fluticasione propionate } & \multicolumn{2}{|c|}{$p$ values } \\
\hline & $\begin{array}{l}\text { Crude } \\
(n * 96)\end{array}$ & $\begin{array}{c}\text { Mdjusted } \\
(n=96)\end{array}$ & $\begin{array}{c}\text { Per } \\
\text { protocolt } \\
(\mathrm{n}=4 \mathrm{I})\end{array}$ & $\begin{array}{l}\text { Crude } \\
(n=96)\end{array}$ & $\begin{array}{c}\text { Adjusted } \\
(n=96)\end{array}$ & $\begin{array}{c}\text { Per proco- } \\
\text { colt } \\
(n=45)\end{array}$ & $\begin{array}{l}\text { Crude } \\
(n=94)\end{array}$ & $\begin{array}{c}\text { Adjusted } \\
(n=94)\end{array}$ & $\begin{array}{c}\text { Per } \\
\text { prorocol } \\
(n=48)\end{array}$ & $\mathbb{I}$ & II \\
\hline \multirow[t]{2}{*}{$\mathrm{PEV}_{\sharp}(\mathrm{ml})$} & $-53(6.0)$ & $-5,2(6.0)$ & $-544(8.0)$ & $-53(6.0)$ & $-53(6.0)$ & $-56(7.5)$ & $-47(6.2)$ & $-47(6.2)$ & $-43(7.5)$ & 0.954 & $a_{0}, g_{1}$ \\
\hline & $-64(5.4)$ & $-64(5 \cdot 4)$ & $-60(7.5)$ & $-60(5.4)$ & $-60(5.4)$ & $-62(7.1)$ & $-59(5.7)$ & $-59(5.7)$ & $-59(7.1)$ & 0.569 & 0.985 \\
\hline \multirow[t]{3}{*}{ FVC $\left(\mathrm{mL}^{\prime}\right)$} & $-54(10.5)$ & $-54(10.5)$ & $-26(14.8)$ & $-5 \pi(10.4)$ & $-51(10.4)$ & $-45(14.0)$ & $-24(10.8)$ & $-23(10.8)$ & $-16(14 x)$ & 0.881 & 0.06 \\
\hline & $-79(9.5)$ & $-79(9.5)$ & $-51(13.9)$ & $-65(9.4)$ & $-65(9.4)$ & $-57(13.1)$ & $-46(9.9)$ & $-46(9.9)$ & $-42(13.2)$ & 0.312 & 0.146 \\
\hline & \multicolumn{11}{|c|}{ 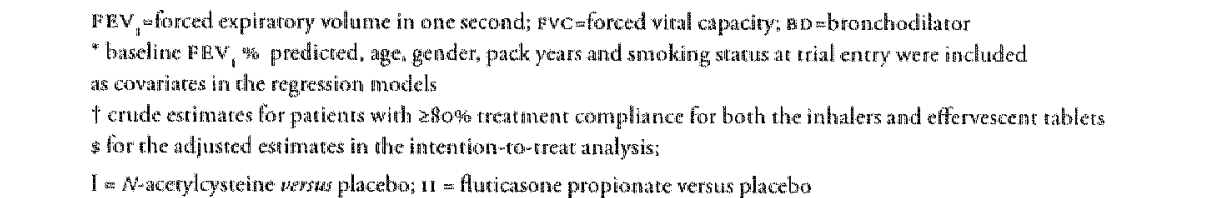 } \\
\hline
\end{tabular}


Figure 3. Distribution of exacerbation rates by treatment group

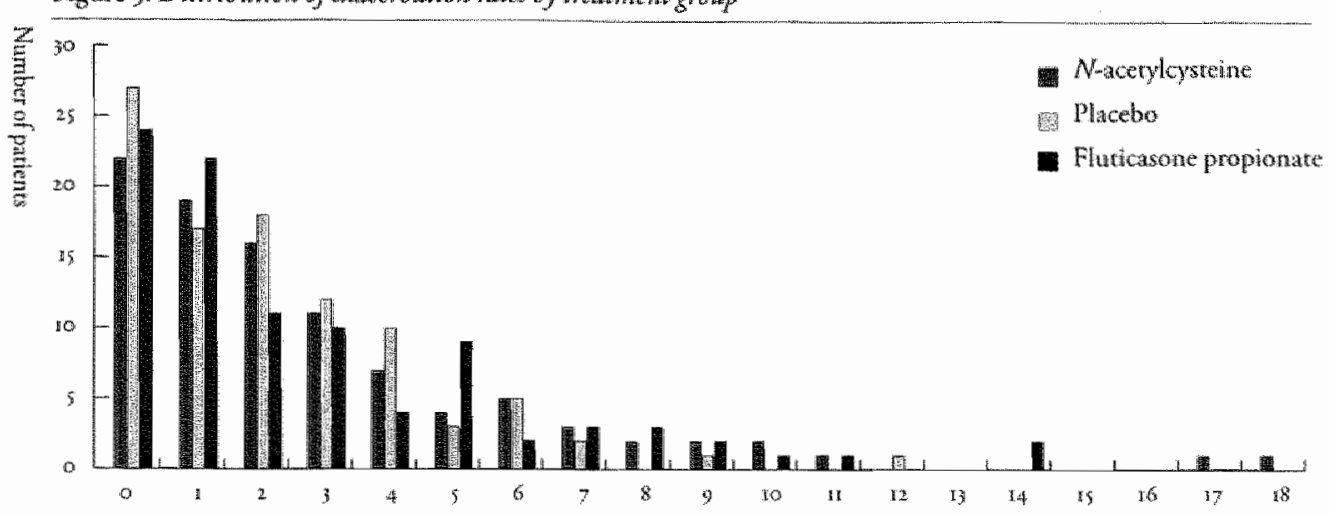

Nunter of exacerbations during the rrial

The analysis of the changes in health status showed improvements of the total CRQ score in all three trearment groups, especially in the first year of the study (figure 4). No statistically significant differences for either $N$-acetylcysteine or fluticasone propionate relative to placebo was observed $(p=0.306$ and $p=0.58 r$, respectively). Mean $C R Q$ scores never exceeded the 0.5 units' threshold for the minimum clinically important difference.

None of the four CRQ domain scores showed statistically significant improvements in favour of $N$-acetylcysteine or futicasone propionate.

Figure 5 shows that the course of the pre-and postbronchodilator FEV, in the $N$-acetylcysteine and Aluticasone propionate groups paralleled the course in the placebo group, except for the (expected) initial increase in the Aluticasone propionate group in the first three months after randomisation. Table 4 shows the crude and adjusted yearly decline in the $F \mathbb{E V}$ for the total trial period. For the postbronchodilaror $\mathrm{EV}$, the decline which was lowest in the fluricasone propionate group $(47 \mathrm{~mL}$ [SE 6]), followed by the $N$-acetylcysteine and placebo groups ( $52 \mathrm{~mL}[\mathrm{SE} 6]$ and $53 \mathrm{~mL}[\mathrm{SE} 6]$, respectively). No statistically significant differences in favour of either $\mathrm{N}$-acetylcysteine or Aluticasone propionate were observed for the pre- or postbronchodilator $\mathrm{FEV}$. A similar pattern was recorded for the decline of the FVC (table 4), the Auticasone propionate group showing the lowest decline for the prebronchodilator as well as the postbronchodilator FVC values. For the prebronchodilator FVC decline the difference between fluticasone propionate and placebo treatment approximated the level of staristical significance $(p=0.061$ ). Although the symptoms scores for phlegm and cough (but not the dyspnoea scores) seemed to improve in the fluticasone propionate group during the first 6 months, no statistically significant differences in symptom scores between the study groups were found for the rotal trial period (figure 6). 


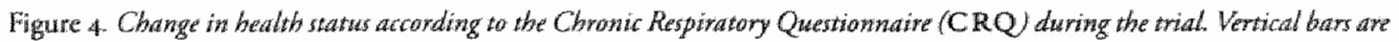
stawdand errors.

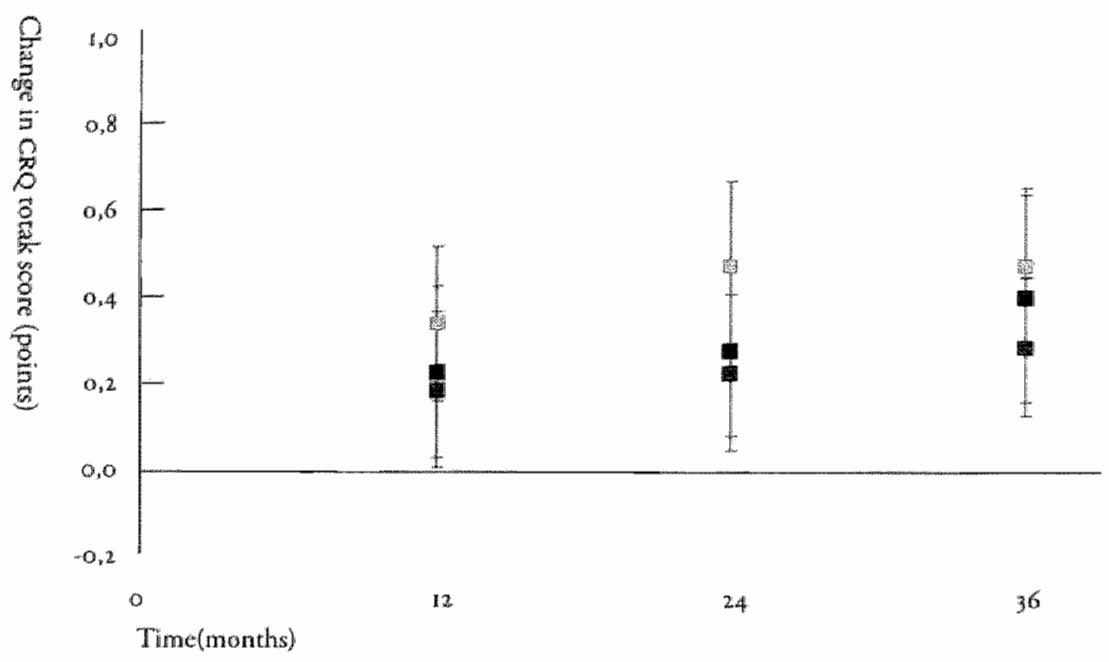

Figure S. Delline of FEV in the three treatment groups

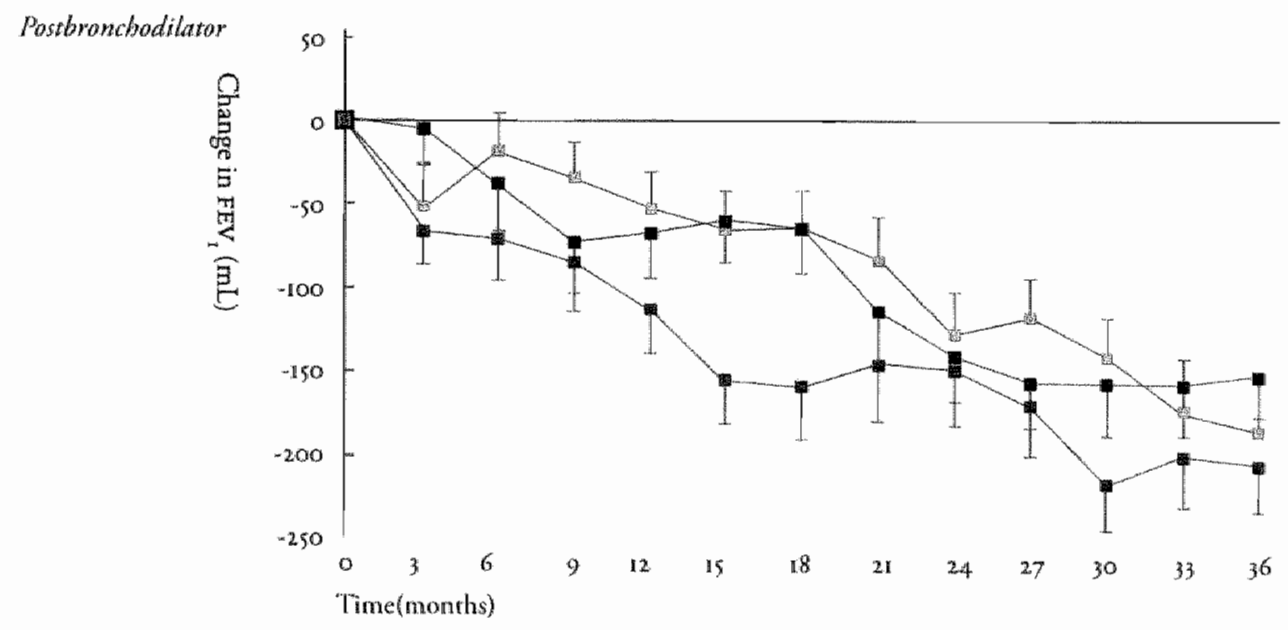

N-acetyloysteine Placebo a Furicasone propionate 
Figure 6. Meata change ins symptom scores * for phlegn and couth during the 3 year observation period "measured on a y-point Likert scale
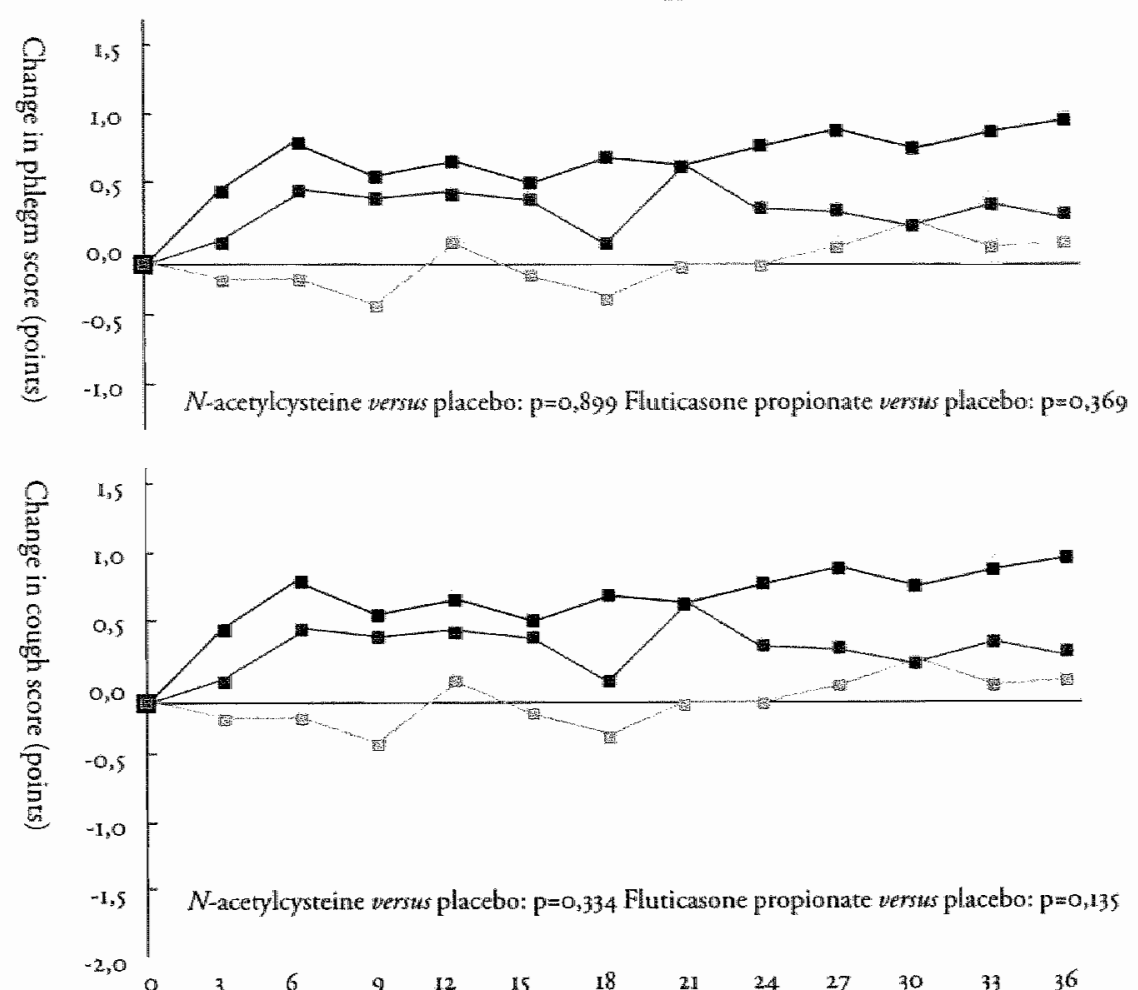

Time(months) 


\section{Discussion}

In this general practice based study we found that neither regular treatment with 600 milligrams of oral $\mathrm{N}$-acetylcysteine nor 1000 micrograms of inhaled Auticasone propionate per day affected the long term course of respiratory health stanus or the rate of exacerbations in a heterogeneous population of (ex-) smokers with chronic bronchitis or mild to moderate COPD. Although the higher exacerbation rates in the $\mathrm{N}$-acetylcysteine or fluticasone propionate groups may be misinterpreted as 'deleterious' effects of these treatments, this finding is explained by the fact that a small number of distinct outliers in the two active treatment groups - but not in the placebo group - experienced very frequent exacerbations. Analysis of the secondary outcomes showed no differences in the decline of the $\mathrm{FEV}$, and $\mathrm{FVC}$, respiratory symptoms, or time to dropout for either $\mathrm{N}$-acetylcysteine or futicasone propionate.

With the current insights in the pathophysiology of COPD ${ }^{38}$ our trial population can be characterized as a heterogeneous group of middle-aged (ex-) smokers with chronic bronchitis, who either showed incipient airflow obstruction or had established mild to moderate obstruction. We deliberately did not exclude patients with teversibility of airflow obstruction from the trial, because we considered bronchodilator responsiweness to be a continuous variable in COPD. In the mean time, the rightness of this presumption has been demonstrated by other investigarors ${ }^{39}$. As a consequence, the composition of our study population was rather different from previous long-term follow-up studies on the effects of $\mathrm{N}$-acetylcysteine" and inhaled corticosteroids ${ }^{26,27,40,4 \mathrm{~T}}$.

Assessment of respiratory health status is increasingly recognised as an important additional measurement in patients with $\operatorname{COPD}^{16}$ and is a berter predictor of furure admission to hospital and death than $F E_{I}$ is, at least in patients with severe COPD ${ }^{42}$. Compared with previous studies in patients with more severe COP ${ }^{43}{ }^{47}$, the baseline CRQ scores in our study showed a rather low level of baseline health status impairment. Obviously, this limits the room for a relevant therapeutic effect on health starus for both active treatment groups. This argumentation also applies to the room for improvement on exacerbations: the average exacerbation rate in the two years preceding the trial was 0.9 exacerbarions per year, which is lower than the rates reported from studies in secondary care COPD patients from our country $4^{8,49}$ and elsewhere ${ }^{40,50}$.

A substanrial number of patients were treated with an inhaled corticosteroid and/or $N$-acetylcysteine by their GP or pulmonologist at the time of enrolment in the study. In order to establish their eligibility for the trial, these patients had to withstand a washout period of at least three months. It cannot be ruled out that patients with a good treatment response on ei- 
ther $N$-acetylcysteine or inhaled corticosteroids withdrew wheir involvement before or during the washout phase that preceded the trial because of worsening of their respiratory condition. Previous reports on withdrawal of inhaled corticosteroid treatment in COPD ${ }^{8,51-53}$ imply that this has probably played a role in our study. If this selective dropout of patients with a good treatment response has indeed occurred, this may have produced an underestimation of the actual treatment effects of $N$-acetylcysteine and fluticasone propionate.

Our findings do not support the conclusions of the published metaanalyses ${ }^{6-8}$ and a recent observational study ${ }^{54}$ that $N$-acetylcysteine reduces the risk of exacerbation in COPD. Although the Broncus study showed no beneficial effect of $N$-acetylcysteine on exacerbations in the main analysis, subgroup analysis on the parients who were not on concomitant inhaled corticosteroids treatment ( $-30 \%$ of the total study population) suggests that there may be such a prophylactic effect in the absence of this anti-inflammatory treatment 9 . In our study concomitant use of inhaled corticosteroids was not permitted unless a patients had dropped out, in which case the GP could introduce (or reintroduce) this trearment. Although eventually this occurred in only $13 \%$ of the patients in the $N$-acetylcysteine group and $17 \%$ in the placebo group, we did not observe a similar treatment effect in favour of $\mathrm{N}$-acetylcysteine as the Broncus investigators did.

In contrast with the findings from the Broncus trial ${ }^{9}$ no effect of $N$-acetylcysteine on the (forced) vital capacity was seen, nor were we able to confirm the finding from Broncus that $N$-acetyllcysteine improves functional residual capacity (FRC): although measurement of $\mathrm{FRC}$ was part of the baseline assessment in the lung function laboratory, this measurement was not repeated in the subsequent yearly visits to the laboratory. It should be noted dhat the effects on these secondary outcomes in Broncus was predominandy in patients with severe COPD (GOLD stage III) ${ }^{38}$, a group that comprises only $25 \%$ of all diagnosed COPD patients ${ }^{55}$ and $16 \%$ of our trial population.

We did not find a treatment effect of fluticasone propionate in our study population that predominantly existed of patients with mild to moderate disease. In our view, this further supports the standpoint of current COPD guidelines that inhaled corticosteroids should be reserved for patients with severe COPD - i.e., patients with an $\mathrm{FEV}$, below $50 \%$ of the predicted value and frequent exacerbations $39.56,57$.

The consistent increase of the health status (CRQ) scores over time in all three treatment groups was salient and unexpected. Our explanation for this observation is that it was caused by an 'in-study effect' - i.e., was the consequence of the rather intense periodic monitoring of patients as a necessary part of their trial participarion. Although previous placebo controlled studies have shown beneficial effects of fluticasone propionate treat- 
ment on health status measurements ${ }^{40.50}$, we did not observe this in the current study. Again, this may have been caused by the limited room for improvement in this particular study population.

The size of our trial population was not sufficient to establish effects on lung function decline by $\mathrm{N}$-acetylcysteine or Huticasone propionate treatment with an acceptable level of statistical power. Nonetheless, several spirometric indices ( $\mathrm{FEV}_{\mathrm{v}}$ and $\mathrm{FVC}$ being the most important ones) were repeatedly measured and studied as secondary outcomes. The results showed that apart from the initial increase of the $\mathrm{FEV}$ in the fluticasone propionate group during the first months after randomisation that has also been reported for several other inhaled corticosteroid trials ${ }^{40,4 x}$, the further decline of $\mathrm{FEV}_{\mathrm{t}}$ did not significantly differ between the treatment groups. The obserwed small difference in favour of fluticasone propionate treatment was of the same magnitude $(6 \mathrm{~mL})$ that has been reported in recent meta-analyses on inhaled corticosteroid treatment in $C O P D^{13-15}$.

As expected, and in line with previous long-term studies in patients with $\operatorname{COPD}^{27,40}$, dropout during the trial was substantial ( $43 \%$ overall).

Although the number of dropouts, time to dropout, and reasons for dropout did not differ between the study groups, there was a salient difference in the number deaths during the trial: one for $N$-acetylcysteine, three for placebo, and eight for futicasone propionate treatment. Closer examination of the causes of death in these patients did not give cause for a suspected association between fluticasone propionate treatment and a higher mortality risk.

In conclusion, in this study we could not establish beneficial treatment effects for either oral $N$-acerylcysteine or high-dosed inhaled fluticasone propionate in adult patients with chronic bronchitis or mild to moderate COPD. Subgroup analysis of our heterogeneous patient population may reveal differential treatment effects for $\mathrm{N}$-acetylcysteine or fluticasone propionate.

\section{References}

1 Murray CJ, Lopez AD. Alternative projections of mortalicy and disability by cause 1990-2020: Global Burden of Disease Sudy. Lancet 1997; 349(9064): 1498-504.

2 Feenstra TL, van Genugten ML, Hoogenveen RT, Wourers EF, Rurten-van Molken MP: The impact of aging and smoking on the future burden of chronic obstructive pulmonary disease: a model analysis in the Netherlands. Am J Respir Crit Care Med 2001: $164(4): 590-6$

3 Barnes PJ, Shapiro SD, Pauwels RA. Chronic obstructive pulmonary disease: molecular and cellular mechanisms. Eur Respir/ 2003; 22(4):672-88. 
4 Dekhuijzen PN. Antioxidant properties of N-acetylcysteine: therr relevance in relation to chronic obstructiwe pallmonary disease. Evr Respir / 2004; $23(4) \div 629-36$.

5 Repine JE, Bast A, Lankhorst I. Oxidative stress in chronic obstructive pulmonary dig ease. Oxidative Stress Study Group. Am J Respir Chit Caw Med 1997: 156 (2 Pt 1): 341-57.

6 Stey $C$, Steurer J, Bachmann $S$, Medici TC, TRAMER MR. The effect of oral $N$-acerycysteine in chronic bronchitis: a quantitative systematic review. Eur Respir/2000; 16 : $253-62$.

7 Poole PJ, Black PN. Oral mucolytic drugs for exacerbations of chronic obstructiwe pulmonary disease: systenaric review. $B M$ J $2001 ; 322: 1-6$.

8 Grandiean EM, Berthet P, Ruggieri MP Leuenberger P. Efficacy of oral longuterm $N$ acetylcysteine in chronic broncho-putmonary disease: a meta-analysis of published double-blind, placebo-controlled clinical trialls. Clin 7 her $2000,22(2): 209-21$.

9 Decramer M, Rutten-wan Molken M, Dekhuijzen PN, Troosters T, van Herwaanden $\mathrm{C}$, Pellegrino $\mathrm{R}$ er al. Exfects of $\mathrm{N}$-acetylcysteine on outcomes in chronic obstructive pulmonary disease (Bronchitis Randomized on NAC Cost-Urility Study, BRONCUS): a randomised placebo-controlled trial. Lancet 2005; $365(9470): 1552-60$.

Io Gizycki MJ, Hattoruwa KL, Barnes N, Jeftery PK. Effects of fluticasone propionate on inflammatory cells in COP D: an ultrastructural examination of endobronchial biopsy tissue 7horax 2002; $57(9): 799-803$.

II Hatrotuwa HI, Gizycki M], Ansari TW, Jeffery BK, Barnes NC. The effects of inhaled Auticasone on airway infammation in chronic obstructive pulmonary disease: a double-blind, placebo-controlled biopsy study. Am I Respir Crit Cure Med 2002; 165: 1579\% 8 o.

12 Barnes PJ, Ito K, Adcock LM. Corticosteroid resistance in chronic obstructive pulmonary disease: inactivation of histone deacetylase. Lanct 2004; $363(9410): 731-3$.

13. Highland $\mathrm{KB}$, Strange $\mathrm{C}$, Heffner JE. Longuterm effects of in haled corticosteroids on FEV in patients with chronic obstruccive pulmonary disease. A meta-analysis $A$ Ann Intern Med 2003; 138(12): 969-73.

14 Sutherland ER, Allmers $H$, Ayas NT, Venn AI, Martin R]. Inhaled corticosteroids reduce the progression of airflow limitation in chronic obstructive pulmonary disease: a meta-analysis. Thorax 2003; 58(11): $937 * 41$.

15 Alsaeedi A, Sin DD, McAlister FA. The effecrs of inhaled corticosteroids in chronic obstructive pullmonary disease: aystematic review of randomized placebo-concrolled trials. Am/Med. 2002; 1.13 $3(1): 59-65$.

16 van Schayck C.P. Is lung function really good paramerer in evaluating the long-term effects of inhaled corticosteroids in COPD? Etw Respir/2000; $15(2): 23.8 \mathrm{~m}$.

17 Pauwels R, Calverley I Buist AS, Rennard S, Fukuchi Y, Stahl E et al. Cop p exacerbations: the importance of a standard definition. Respir Med 2004:98(2): 99-107.

18 Siafakas NM, Vermeire P, Pride NB, Paoletri P, Gibson ], Howard P et al, Optimal assessment and management of chronic obstructive pulmonary disease (COPD). The European Respiratory Society Task Force [see comments]. Eur Respir/ 199 5; 8 (8): 1398420.

I9 Guyatr GH, Berman LB, Townsend M, Pugsley 50 , Chambers LW. A measure of quality of life for clinical trials in chronic lung disease. 7 orax $1987 ; 42(10): 773-8$,

20 Redelmeier DA, Guyatt GH, Goldtein RS. Assessing the minimall important differ* ence in symproms: a comparison of two techniques. J Clin Ephidemio/ 1996; $49(1)$ : $1215-9$. 
21 Rurten-van Molken M, Roos B, Van Noord. J A. An empirical comparison of the St George's Respiratory Questionnaire (SGRQ) and the Chronic Respiratory Disease Questionnaire (CRO) in a elinical trial setting. Thorax 1999; 54 (n): 995-roo3.

22. Dompeling $E_{\text {, van }}$ Schayck CP, Molema J, Follgering $H$, van Grunswen PM, van Weel C. Inhaled beclomethasone improves the course of asthma and COPD [see commentsl. Eur Respir J 1992; 5:945-52.

23 Renkema TEJ, Schouren PJ, Koeter GH, Postma DS. Effects of long-term treatment with corticosteroids in COPD. Chest 1996; 109: 1156-62.

24 Burrows $B, B$, oom JW, Traver GA, Cline MG. The course and prognosis of different forms of chronic airways obstruction in a sample from the general population. N EnglJ Med 1987; 317(21):1309-14.

25 Brocard H., Charpin J, Germoury J. [Multicenter, double-blind study of oral acerylcysteine vs. placebo] Erude multi-centrique en double aveugle avec acerylcysteine oral ws. placebo. Eur / Respir Dis Suppl 1980; 111: 65-9.

26 Pauwels RA, Lofdahl CG, Laitinen LA, Schouten JP, Postma DS, Pride NB et all. Longterm treatment with inhaled budesonide in persons with mild chronic obstructive pulmonary disease who continue smoking. $N$ Engl/ Med 1999; 340: 1948-53.

27 Vestbo J Sorensen T, Lange P, Brix A, Torre P, Viskum K. Long-term effect of inhaled budesonide in mild and moderate chronic obstructive pulmonary disease: a randomised controlled trial. Larcet 1999; 353: 1819-23.

28 Harper R, Brazier JE, Waterhouse JC, Walters SJ, Jones NMB, Howard P. Comparison. of outcome measures for patients with chronic obstructive pulmonary disease (COPD) in an outpatient setting. Thordix $1997 ; 52: 879-87$.

29. Seemungal TA, Donaldson GC, Bhowmik A, Jeffries DJ, Wedzicha JA. Time course and recovery of exacerbations in patients with chronic obstructive pulmonary disease. An J Respir Crit Care Med 2000; 161(5): 1608-13.

30 Dirksen A, Madsen F, Pedersen OF, Vedel AM, Kok-Jensen A. Long term performance of a hand held spirometer. Thorax 1996; 51: 973-6.

31 Quanjer PH, Tammeling GJ, Coces JE, Pedersen OF, Peslin R, Yernault JC. Lung volumes and forced ventilatory flows. Report Working Party Standardization of Lung Function Tests, European Community for Steel and Coal. Official Statement of the European Respixarory Sociery [see comnents]. Eur Respir / Suppl I993; 16(s): 5-40.

32 Schermer TR, Jacobs JE, Chavannes NH, Harman J, Folgering HT, Bottema BJ er al. Walidicy of spirometric testing in a general practice population of patients with chronic obstructive pulmonary disease (COPD). 7homx 2003:58(10):861-6.

3) Global Iniriative for Chronic Obstructive Lung Disease (GOLD). www.Gol. DCorp. com. Dare accessed: Auguss 9, 2005.

34. Diggle P], l.iang KY, Zeger SL. Analysis of longitudinal data. Oxford (UK): Oxford University Press; 1994 .

35 Twisk JWR Applied longitudinal data analysis for epidemiology. First Editioned. Cambridge, UK: Cambridge University Press; 2003.

36 wan Schayck CP, Dekhuijzen PN, Gorgels WJ, van Grunsven PM, Molema J, van Herwarden CL, and van Weel C. Are anti-oxidant and anti-inflammatory treaments effecrive in different subgroups of COPD? A hyparhesis. Respir Med r998; 92, 12591264.

$\$ 7$ Schermer TRI, Hendriks AJC, Chavannes NH, Dekhuijzen PNR, Wouters EFM, van den Hoogen HJ et al. Probability and determinants of relapse after discontinuation of inhaled corticosteroids in parients with COPD treated in general practice. Prim Care Respiry 2004:13:48-55 
38 Pauwels R, Anthonisen N, Bailey WC, Barnes PJ, Buist AS, Calwerley P, ClarkT), Fabbri LM, Fukuchi Y, Grouse L. Hogg JC, Jenkins C, Postma DS, Rabe KF, Ramsey SD, Rennard SI, Rodriguez-Roisin R, Siafakas NM, Sullivan SD, and Tan W. Global Initiative for Chronic Obstructive Pulmonary Disease (GOLD - executive stimmary) (updared 2004). 2701A. 2004. Bethesda "Narional Institutes of Health.

39 Calverley PM, Burge PS, Spencer S, Anderson JA, Jones PW. Bronchodilator reversibility resting in chronic obstructive pulmonary disease. Thorax 2003; 5818: $659-64$.

40 Burge PS, Calverley PMA, Jones PW, Spencer S, Anderson IA, Maslen TK. Randomised, double blind placebo controlled study of fluticasone propionate in patiens with moderate to severe chronic obstructive pulmonary disease: the ISOLDE trial. BMJ 2000; 320: 1297-303.

$4^{\mathrm{I}}$ Wise MD, Canner J, Weinmann $\mathrm{G}$, Scanlon. P, Skeans M. Effect of inhaled triamcinolone on the decline in pulmonary function in chronic obstructive pulmonary disease. N Engl/ M Med 2000; 343: 1902-9.

42 Osman LM, Godden DJ. Friend JAR, Legge JS, Douglas JG. Quality of life and hospital re-admission in patients with chronic obstructive pulmonary disease. 7horax 1997: 52: 67-7I.

43 Schunemann HJ, Griffith L, Jaeschke R, Goldstein R, Srubbing d, Austin Pet al. A comparison of the original chronic respiratory questionnaire with a standardized version. Chest 2003; 124(4): 1.421-9.

44 Schunemann HJ, Guyatr GH, Griffith R, Stubbing d, Goldstein R. A randomized controlled trial ro evaluate the effect of informing patients about their pretreatment responses to two respiratory questionnaires. Chest 2002; $122: 1701-8$.

45 Ward IA, Akers G, Ward DG, Pinnuck M, Williams S, Trotr ] er al. Feasibility and effectiveness of a pulmonary rehabilitation programme in a community hospiral setring. Br. . Gen.Pract. 2002; $52(480): 539-42$.

46 de Torres JP, Pinto-Plata V, Ingeniro E, Bagley P, Gray A, Berger R er al. Power of outcome measurements to detect clinically significant changes in pulmonary rehabilitation of patients with COPD. Chest 2002; 121: 1092-8.

47 Rurten-van Mölken M, Roos B, Noord vJA. An empirical comparison of the St George's Respiratory Questionnaire ( $S G R Q$ ) and the Chronic Respiratory Disease Questionnaire ( $C R Q$ ) in a clinical trial setting. Thorax r999: 54:995-1003.

48 van der Valk P, Monninkhof E, van der Palen I, Zielhuis $\mathrm{G}$, wan Herwaarden $\mathrm{C}$. Effect of discontinuation of inhaled corticosteroids in patienses with chronic obstructive pulmonary disease: the COPE study. Am / Respir Crit Care Med 2002; 166(ro): 1358-63.

49 Oostenbrink \B, Rurten-van Molken MP, AI M], Van Noord JA, Vincken W. One-year cost-effectiveness of tiotropium xersus ipratropium to treat chronic obstructive pulmomary disease. Eur Respir J 2004; 23(2): 2411-9.

go Calverley P, Pauwels R, Vestbo J, Jones P, Pride N, Gulswik A et al. Combincd salmerer-" ol and fluticasone in the treatment of chronic abstructiwe pulmonary disease: at randomised controlled risal. Lancet 200; 361(9356): 449-56.

51 O'Brien A, Russo-Magno P. Kark A, Hiranniramol S, Hardin M, Kaszuba M et al. Effects of withdrawal of in haled steroids in men with severe irreversible airflow obstruction. Am f Respir Crit Care Med 2001; 164: 365-71.

52 Wouters EF, Postma DS, Fokkens B, Hop WC, Prins J, Kuipers AF et al. Withdrawal of Auticasone propionate from combined salmeterol/fluticasone treatment in patients with COPD causes immediate and sustained disease deteriorations; a tandomised controlled trial. Thorax $2005 ; 60(6): 480-7$. 
53 Jarad NA, Wedzicha \A, Burge PS, Calverley PM. An observational seudy of inhaled corticostreroid withdrawal in stable chronic obstructive pulmonary disease. Respir Med $1999 ; 93(3): 161-6$.

54 Gerrits CMJM, Herings RMC, Leufkens HGM, Lammers J-W]. N-aceryloysteine reduces the risk of re-hospitalisation among parients with chronic obstructive pulmonary disease. Eur Respir /2003; 21: 795-8.

59 Lips EJI, Feenstra TL, Schermer TRJ, Rutten-van Molken MP. Severity distribution of physician-diagnosed COPD in the Netherlands. Eur RespirJ 2003;22 suppl 45:67s.

56 National Institute for Clínical Excellence (NICE). Chronic obstructive pulmonary disease: national clinical guideline for management of claronic obstructive pulmonary disease in adults in primary and secondlary care. Thorax zo04; 59 (Suppl I).

57 Celli BR, MacNee W, Agusti A, Anzueto A, Berg B, Buist AS, Calverley PMA, Chavannes $N$, Dillard I', Fahy B, Fein A, Heffner I, Lareau S, Meek P, Marrinez F, McNicholas W, Muris J, Austegard E, Pauwels R, Rennard S, Rossi A, Siafakas $N$, Tiep B, Westbo J, Wourers E, ZuW Wallack R. Standards for the diagnosis and treatment of patients with COPD: a surumary of the ATS/ERS position paper. Eur Respir $J$ 2004; $23(6): 932-46$. 


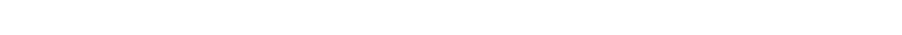

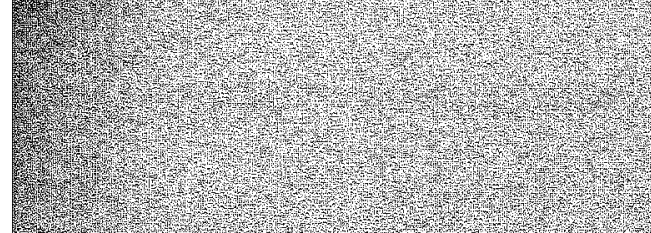

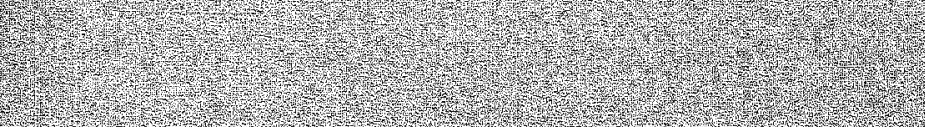

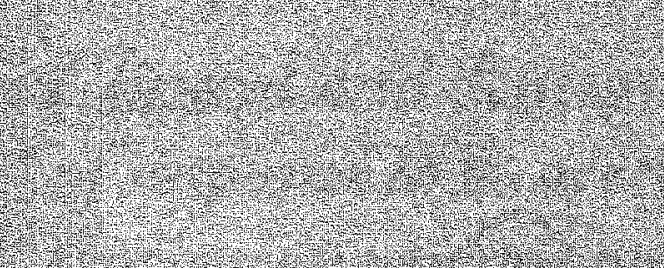

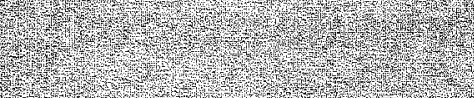

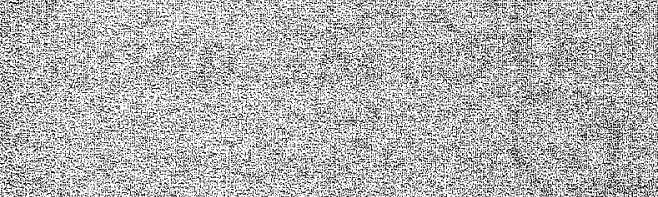

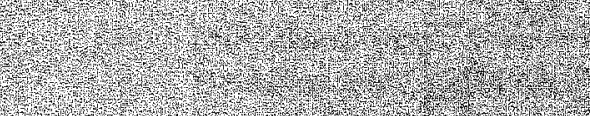

7.

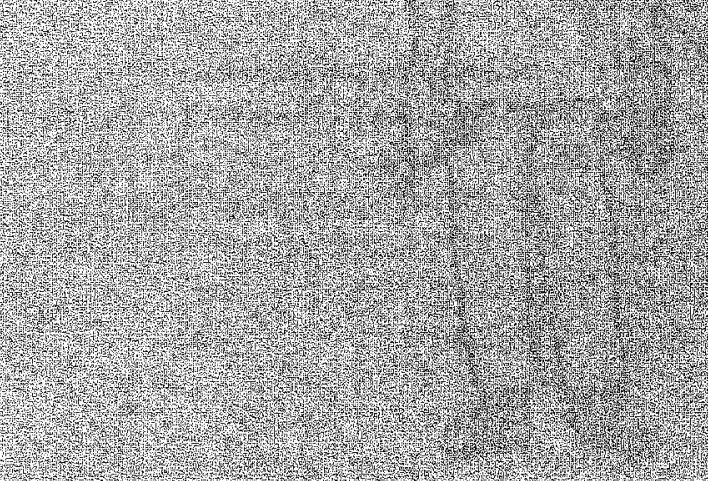


Chapter 9

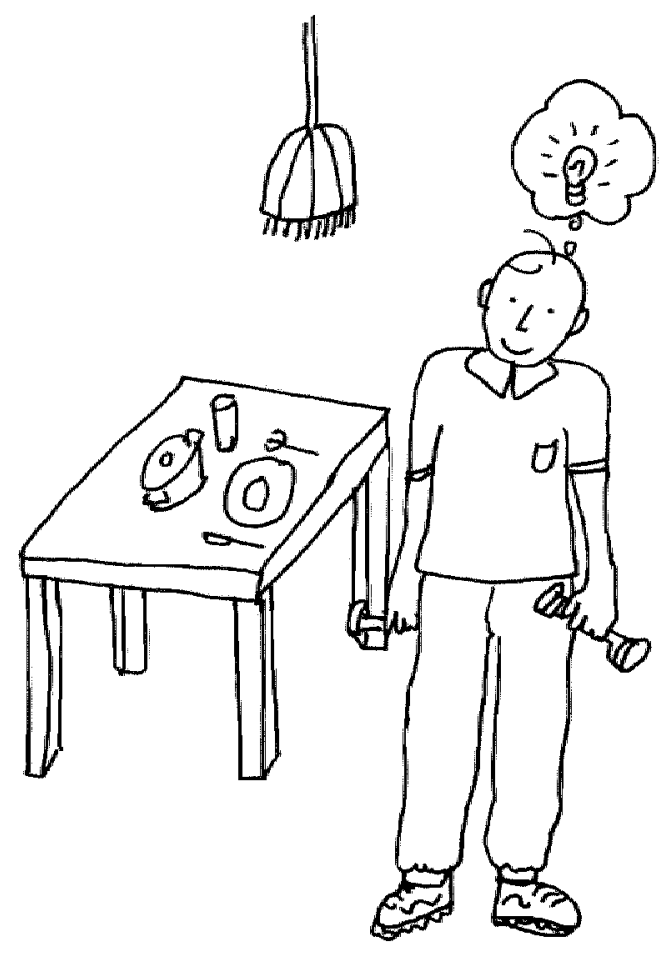




\section{Clinical and demographic determinants of response to $\mathrm{N}$-acetylcysteine and fluticasone propionate in primary care COPD: The COOPT Study}

NH Chavannes, TRJ Schermer, EFM Wouters, HT Folgering

RP Akkermans, JWM Muris, C van Weel, CP van Schayck

Submitted for publication

Presented at ERS 2005 Copenhagen 


\section{Abstract}

Aim

There is a great need to identify subgroups within the large primary care COPD-population that may benefit from inhaled steroid or anti-oxidant therapy: Studies so far have shown some benefits in patients with severe COPD and frequent exacerbations, but these represent a minority in primary care. We postulated relevant subgroups based on exacerbations, lungfunction, reversibility, smoking behaviour and gender.

\section{Method}

The COOPT-study randomised 286 primary care COPD patients (mean FEV, postBD $66 \%$ ) to receive inhaled fluticasone (FLU), oral $N$-acetylcysteine (NAC) or placebo (Pla) during three years. Main outcomes were exacerbations, health status (CRDQ) and post-BD FEV. Repeated measurements analysis was performed.

\section{Results}

NAC showed a prophylactic effect ( $-15 \%$, relative ratio 0.43 ) on exacerbations in the highest quartile of packyears, but negative effects on heal th status $\left(-0.23\right.$ points/yr) in patients with reversibility, and on $\mathrm{FEV}_{\mathrm{I}}$ in former smokers $(-3 \mathrm{rml} / \mathrm{yr})$. FLU showed a positive effect on health status ( +0.27 points/yr) in moderate versus severe COPD, but a negative effect on FEV in females versus males $(-37 \mathrm{ml} / \mathrm{yr})$.

\section{Conclusions}

Within the heterogeneous primary care COPD population we identified clinically relevant characteristics. For treatment with FLU or NAC it is important that some patients may benefit while others might not, apparently depending on determinants of lungfunction including reversibility, smoking behawiour and gender. 


\section{Background}

COPD is a large and growing health problem worldwide, both for parients and their healthcare providers ${ }^{\mathrm{y}-4}$. In past few years the scope of COPD as a major disease has received increasing international attention ${ }^{x}, C O P D$ is a worldwide cause of morbidity and mortality, leading to substantial and increasing economic and social burden of disease ${ }^{2}$. From long-term prospective registrations the increasing importance of COPD relative to other major causes of death like coronary heart disease and cancer is clear: while these are leveling of in prevalence, COPD continues on a rising slope ${ }^{3,4}$. It is expected that COPD will have become the global third cause of death by $2020^{2}$. The increase in prevalence and disease burden is largely attributable to the number of females with COPD; this group started smoking at a historically later stage then men'. Possibly, fernales express a larger vulnerability to the harmful effects of smoking ${ }^{6}$, resulting in a progressive decline of lung funcrion and worsening of health status. "This gender specific transition with regard to COPD has occurred earlier in the United States and the United Kingdom than in Western Europe, and is still taking place in the rest of the world 4 . Female gender seems to be related to depressive symptoms 7 , long-term benefit of exercise therapy ${ }^{8}$ and development of severe COPD 9 . Importantly, women with COPD may have different responses to medical rreatment and smoking cessation interventions ${ }^{10}$. Smoking cessation is still the only intervention that has convincingly proven to slow down the progression of COPD ${ }^{\mathrm{Ir}}$, but it seems to have an even clearer advantage for women than it does for men ${ }^{12}$.

Within the heterogeneous COPD-population there is a great need to identify determinants of treatment success or failure ${ }^{13}$. In previous studies $^{14-16}$, severe COPD and having frequent exacerbations have been pointed out to be predictive factors for a positive effect of inhaled fluticason. However, the studied population was not representative of primary cart COPD, where most patients receive treatment for mild to moderate obstruction ${ }^{17} . N$-acetylcysteine has been associated with better health status in COPD-parients with frequent exacerbations ${ }^{18-21}$, but this has not been studied in long-term RCTs. In the large EUROSCOP-trial ${ }^{22}$ it was observed that the beneficial effect of inhaled corticosteroid drugs was greater in subjects with a history of fewer packyears of smoking. In an earlien study a favourable response to inhaled corticosteroids was found in COPD-patients with a fast decline in lung function, a high degree of reversibility and few packyears $^{23}$. It has therefore been hypothesised that antioxidants might be most effective in the subgroup of COPD-patients who smoke heavily and respond insufficiently to inhaled corticosteroid drugs ${ }^{24}$. These are the patients with a largely irreversible airway obstruction, most likely caused by an oxidative rather than an inflammatory process ${ }^{25}$ (see Figure 1). 
Figure $\mathrm{x}$. Hypoibetical efficacy of the N-acetylcysteine (NAC) versus inhaled corticostenaids in different subgroups of

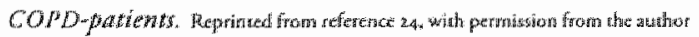

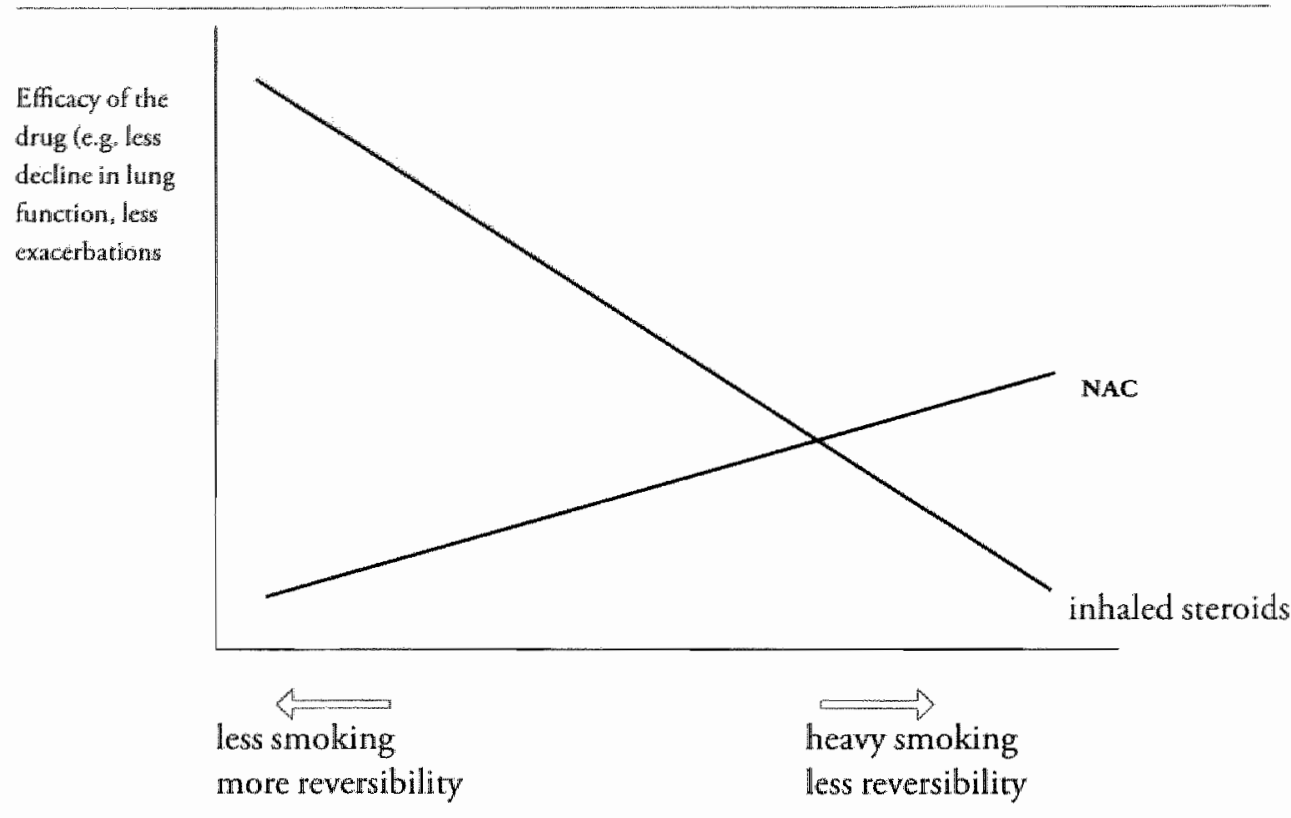

COPD represents a heterogeneous group of patients with chronic respiratory symptoms, usually in combination with progressive lungfunction decline that is not fully reversible. The degree of obstruction can vary from mild to very severe, with widely ranging prognosis and complaints. Reversibility is the acure effect of a bronchodilator on the Forced Expiratory Volume in one second ( $\mathrm{FEV}_{\mathrm{r}}$ ), a sign that usually is associated with more asthmatic inflammation. It is estimated that 10-30\% of COPDpatient show a significant degree of reversibility, depending on clinical setting ${ }^{14,26,27}$. The infuence of nutritional starus, expressed as Body Mass Index (BMI) has been acknowledged in past few years, a BMI $<21$ representing a negative prognostic factor for mortality ${ }^{28}$. The experienced degree of dyspnea is an imporant factor infuencing health status, while lung function indices are of less importance ${ }^{29}$. COPD often leads to a diminished quality of life, especially in severe obstruction ${ }^{30}$, while co-morbidity is relatively common ${ }^{31,32}$. All these factors occur in differing degrees in COPD-patients, illustrating the hererogeneicy of the disease, implicating more than lung function decline ${ }^{33}$. Because of this heterogeneity it is plausible that pharmacologic interventions will be differentially effective across subgroups of COPD-parients. Applying evidence-based indications for pharmacotherapy in individual parients with COPD therefore explicitly deserves attention. Results of the main study analyses presented recently ${ }^{34}$ 
indicate that on the total group level neither $N$-acetylcysteine nor futicasone showed significant effects on exacerbations, health status or lungfunction during three years of treatment. For that reason we studied what determinants could be identified for a long-term trearment success or fallure of $N$-acetylcysteine respectively inhaled fluticasone propionate in patients with mild to moderate COPD treated in primary care.

\section{Method}

\section{Population and determinants}

This study was a three-year follow-up, double-blind, randomised, placebo-controlled, double-dummy experiment, with three study arms. Preceding the study, a three-months wash-our period took places", allowing for effects of stopping with inhaled steroids, $N$-acetylcysteine, or smoking to subside, followed by a two-week course of $30 \mathrm{mg}$ prednisolone per day. The study population was recruited in 44 general practices in the Southeastern part of The Netherlands. Inclusion crireria were: 30-75 year old (ex-) smokers with a diagnosed chronic bronchitis or mild to moderately-severe COPD. Exclusion criteria were: severe COPD (FEV $<40 \%$ of predicted); history of asthma, allergic thinitis and/or atopic eczema; severe comorbidity. Interventions consisted of $(\mathrm{r})$ oral $\mathrm{N}$-acetylcysteine $600 \mathrm{mg}$ I dd I $(n=96)$; (II) fluticasone propionate $500 \mu g 2$ dd 1 powderinhaler ( $n=94)$; (IIr) oral placebo tablet and powderinhaler $(n=96)$. Primary outcome measures were exacerbation frequency and disease-specific quality of life (CRQ-questionnaire ${ }^{36}$ ). Secondary outcomes were post-bronchodilator $\mathrm{FEV}_{\mathrm{r}}$, other lungfunction parameters and respiratory symptoms. On clinical grounds and based on international literature number of parient characteristics were selected for potential relevance in differentiating treatment effects. For the following variables subgroup analyses were conducted: severity of airway obstruction, expressed as post-bronchodilator $\mathrm{FEV}$, (mild, moderate, severe according to GOLD-classification ${ }^{37}$ ); smoking history (highest versus lowest quartile) and current smoking status; exacerbation history ( $>2$ exacerbations in the year preceding study); bronchodilator reversibility ( $\geq 12 \%$ increase FEV ${ }_{1}$ predicted according to E RS ${ }^{38}$ ); Body Mass Index (BMI $<2 \mathrm{I})^{33}$; gender; degree of dyspnea $(M R C \geq 239$ ).

\section{Statistical Analysis}

Differences in longitudinal scores on primary outcomes health status and exacerbation frequency, and secondary outcome postbronchodilator $\mathrm{FEV}_{\mathrm{I}}$ were tested by using statistical techniques for repeated measurements; for further analysis of prognostic variables, statistical differences were judged on clinical relevance. The placebo group has been taken as representing the natural course, relative to the intervention groups. For 
statistical testing of differences in exacerbation frequency between placebo and intervention groups during the study period we used a correlared time-event model' ${ }^{\circ}$ (GENMOD-procedure in SAS; Poisson distribution, compound symmetry correlation structure). In analysing the effects on health status a longitudinal analysis was performed on the CRQ-totalscore, while for the statistical testing of differences in annual lungfunction decline analyses for repeated $\mathrm{FEV}$ measurements were used. The regression model for these outcomes accounted for correlation berween repeated measurements ${ }^{4}$ (PROC MIXED in SAS, compound symmetry correlation structure). Subgroup analyses for the relevant dinical variables were analysed by adding an interaction term in the model of each variable with the intervention term. Besides testing for the course of effects in time of the three outcome variables, the exacerbation frequency during three years follow-up has been analysed.

\section{Results}

In Table I the distribution of the population over the different subgroups is shown, as well as the number of exacerbations per year, and the course of exacerbations, health status and lungfunction. In general, health status seems to increase within all subgroups, in contrast with lungfuncrion, which is on the decline in more or less all subgroups. A less consistent pattern is observed with regard to number and course of exacerbations.

Noteworthy is the small number of people that exacerbated frequently $(>2 / y r)$ in the two years preceding study $(15 / 286 ; 5 \%)$, as well as the low number of people with a BMI $<2$ I $(29 / 286 ; 10 \%)$.

In Table 2 the significant treatment effects of $N$-acetylcysteine (NAC) and futicasone (FLU) on exacerbations, health status and post-bronchodilator $\mathbb{F E V}$, within relevant subgroups are shown. In the highest quartile of packyears the exacerbation rate-ratio of NAC vs pllacebo is 0.85 , compared to 1.97 in the lowest quartile. The ratio between highest/lowest quartile equals $0.43(p=0.049 .95 \% \mathrm{CI}[0.20,0.95])$; which means that the exacerbation rate-ratio is $57 \%$ less in the highest quartile compared to the lowest quartile of packyears. With regard to health status FLU shows a small but significant positive effect of +0.12 points $/$ year $(\mathrm{p}=0.043,95 \% \mathrm{CI}[0.02$, $0.231)$ in moderate COPD compared to placebo, but not in severe COPD. The significant difference between moderace and severe $C O P D$ reaches 0.27 points/yr $(p=0.029,95 \%$ CI [0.029, 0.519$])$. 


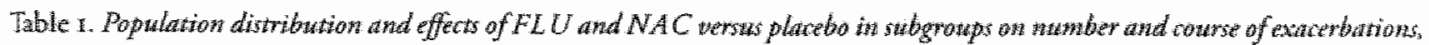
keallob statw and hang function.

\begin{tabular}{|c|c|c|c|c|c|c|c|c|c|c|c|c|c|c|c|c|}
\hline \multirow{2}{*}{\multicolumn{2}{|c|}{ Determinanss }} & \multicolumn{3}{|c|}{$\begin{array}{l}\text { Number of patients } \\
\text { per subgroup }\end{array}$} & \multicolumn{3}{|c|}{$\begin{array}{l}\text { Number of } \\
\text { exacerbations/yt }\end{array}$} & \multicolumn{3}{|c|}{$\begin{array}{l}\text { Course of } \\
\text { exacebations/yt }\end{array}$} & \multicolumn{3}{|c|}{$\begin{array}{l}\text { Health status (CRQ) } \\
\text { points/yr }\end{array}$} & \multicolumn{3}{|c|}{ 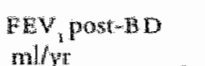 } \\
\hline & & $\mathbb{F} L U$ & NAC & Pla & FLU & $\mathrm{NAC}$ & $\mathrm{Pla}$ & FLU & NAC & Pla & FLU & $\mathrm{NAC}$ & Pli & FLU & NAC & $\mathrm{Pa}$ \\
\hline \multirow{3}{*}{$\begin{array}{l}\text { HEV } \text { in post- } \\
\text { BD (uspred) }\end{array}$} & Mild & 25 & 18 & 39 & 0.97 & 0.65 & 0.56 & +0.08 & -0.22 & -0.22 & +0.15 & +0.14 & +0.19 & -87 & -78 & -71 \\
\hline & Moder. & 55 & 65 & 4 & 0.82 & 0.99 & 0.74 & -0.18 & -0.02 & -0.05 & +0.20 & +0.07 & +0.08 & -48 & -98 & -4 \\
\hline & Severe & 4 & n & 16 & 3.21 & 4.45 & 1,08 & +0.43 & -0.45 & -0.13 & $-0 . x 0$ & +0.04 & 40.06 & $-5 x$ & -73 & -73 \\
\hline Frequent & $>2 / j x$ & 4 & 5 & 6 & 1.33 & 2.73 & 0.78 & +0.50 & -0.80 & -0.16 & 40.28 & +0.20 & $+0.1 y$ & -34 & -71 & -34 \\
\hline $\begin{array}{l}\text { exacerbin- } \\
\text { mans }\end{array}$ & $\leq 2 / / r$ & 90 & 91 & 90 & 0.90 & 0.89 & 0.72 & -0.09 & -0.09 & -0.13 & +0.15 & +0.07 & +0.12 & -99 & -64 & $-6 \mathrm{x}$ \\
\hline Packyears & High & 22 & 25 & 25 & 0.76 & 0.81 & 1.00 & 0.00 & +0.16 & -0.08 & +0.18 & +0.12 & 40.08 & -63 & -75 & -59 \\
\hline (quartiles) & Lowe & 23 & 24 & 24 & 1.03 & I. 2.1 & 0.60 & -0.09 & -0.42 & +0.04 & +0.13 & +0.09 & 40.15 & -94 & -59 & $-7 x$ \\
\hline \multirow{2}{*}{$\begin{array}{l}\text { Smoking } \\
\text { bethaviour }\end{array}$} & Current & 58 & 54 & 49 & 0.91 & 0.86 & 0.70 & -0.12 & $* 0, \mathbf{M}$ & -0.10 & +0.16 & +0.04 & 80.10 & .66 & $\infty 61$ & $-7 / 3$ \\
\hline & Sropped & 36 & 42 & 47 & 0.94 & $x+13$ & 0.75 & +0.14 & -0.14 & -0.17 & +0.15 & +0.12 & +0.14 & -48 & -67 & $-48^{\circ}$ \\
\hline \multirow{2}{*}{$\begin{array}{l}\text { BD- } \\
\text { reversillbility }\end{array}$} & $\geq \mathrm{rr}_{2}$ & 12 & 17 & 9 & 0.78 & 1.08 & 0.67 & -0.58 & -0.65 & -0.44 & 40,12 & +0.02 & +0.26 & -52 & -35 & -37 \\
\hline & $<12 \%$ & 82 & 79 & 87 & 0.94 & 0.96 & 0.73 & 40.06 & $-\mathrm{O} . \mathrm{OH}$ & -0.111 & +0.16 & +0.09 & +0.10 & -60 & -69 & -62 \\
\hline \multirow[t]{2}{*}{ MII } & $\geq y_{I}$ & 8, & 89 & 83 & 0.87 & 0.96 & $0.7^{1}$ & +0.07 & -0.17 & -0.17 & 40,17 & +0.08 & +0.111 & -56 & -62 & -57 \\
\hline & $<2 I$ & 9 & 7 & 13 & L. 33 & 3.24 & 0.79 & -0.89 & +0.43 & +0.08 & 4.0 .03 & -0.12 & +0.18 & 85 & -106 & -79 \\
\hline \multirow[t]{2}{*}{ Gender } & Female & 25 & 21 & $3 I$ & 0.96 & 113 & 1.05 & -0.04 & -0.24 & -0.42 & +0.25 & +0.06 & $\$ 0.10$ & -68 & -67 & -42 \\
\hline & Male & 69 & 75 & 65 & 0.90 & 0.94 & 0.57 & -0.01 & -0.09 & 0.00 & +0.11 & +0.08 & +0.12 & -55 & -64 & -66 \\
\hline$M R C$ & $\geq 2$ & 23 & 21 & ar & 1.32 & $x_{1} 30$ & 0.97 & -0.13 & -0.72 & 0.00 & +0.18 & +0.06 & +0.06 & -79 & -43 & -55 \\
\hline $\begin{array}{l}\text { Dyspnea } \\
\text { Sale }\end{array}$ & $<2$ & 69 & 75 & 74 & 0.80 & 0.89 & 0.64 & 40.04 & +0.04 & -0.14 & +0.14 & +0.08 & wo.14 & -55 & -68 & -61 \\
\hline
\end{tabular}

Table 2. Stummary of significant effects of FLU (in italics) and NAC (in bold) versus placebo on exacerbations, bealth stathes and lang fusction during three years follow-up in primaty care COPD.

\begin{tabular}{|c|c|c|c|c|c|c|c|}
\hline \multirow[t]{2}{*}{ Dererminants } & & \multicolumn{2}{|c|}{ Total number of exacerbarions: } & \multicolumn{2}{|c|}{ Health stanus (CRQ) } & \multicolumn{2}{|c|}{$\mathbb{E B W}, \mathbb{P O s t}-\mathrm{BD}$} \\
\hline & & Rate ratios & Relative Ratio & Poinuts/yr & Effect/yr & $\mathrm{mll} / \mathrm{yr}_{\mathrm{r}}$ & Effectyr \\
\hline \multirow{3}{*}{$\begin{array}{l}\text { Few: post-BD } \\
\text { (orpoped) }\end{array}$} & Mild & & & -0.04 & & & \\
\hline & Moderate & & & +0.12 & +0.27 & & \\
\hline & Severe & & & $-a, d s$ & $p=0.029$ & & \\
\hline \multirow[t]{2}{*}{ Packyears (quartilles) } & High & 0.85 & 0.43 & & & & \\
\hline & Low & 1.97 & $p=0.049$ & & & & \\
\hline \multirow{2}{*}{$\begin{array}{l}\text { Smoking } \\
\text { behawiour }\end{array}$} & Current & & & & & +12 & $-3 \mathrm{mal}$ \\
\hline & Sropped & & & & & -19 & $p=0.035$ \\
\hline \multirow{2}{*}{$\begin{array}{l}\text { Rewersibulity to } \\
\text { brondhodilator }\end{array}$} & $212 \%$ & & & -0.24 & -0.23 & & \\
\hline & $<12 \%$ & & & -0.01 & $p=0.038$ & & \\
\hline \multirow[t]{2}{*}{ Gender } & Fermale & & & & & -26 & $-3,7+n=1$ \\
\hline & Male & & & & & $+J \pi$ & $p=0.03 \pi$ \\
\hline
\end{tabular}


There is a statistically significant negative effect of $\mathbb{N} A C$ on health status in the subgroup with reversibility $\geq 12 \%$ : the rreatment effect is -0.23 points/ year lower then in the $<2 \%$ reversibility group $(\mathrm{p}=0.038,95 \% \mathrm{~B}$ I $[-0.45$, -

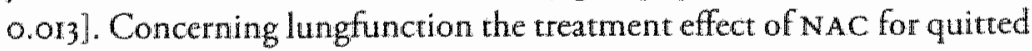
smokers is $19 \mathrm{ml} /$ year worse than in the placebo group, while in current smokers a positive effect of $12 \mathrm{ml} /$ year is observed. The overall treatment effect of NAC in quitted smokers thus equals -3.ml/year, which is significantly lower than in the current smokers group ( $\mathrm{p}=0.035,95 \% \mathrm{CI}[2.0$, $60.0]$ ). Lungfunction is also influenced by gender, since FLU has a positive effect in males ( $+\mathrm{mm} /$ year compared to placebo) but a negative effect in females $(-26 \mathrm{~m} /$ year compared to placebo). This results in a significant gender difference of $37 \mathrm{ml} /$ year $(p=0.035 .95 \% \mathrm{Cr}[0.002,0.072])$.

\section{Discussion}

This study demonstrates the differential effects that treatments can have in a primary care population of COPD-patienes. Even when total group results show no difference, determining factors can cause significant treatment effects in subgroups. In this study, $\mathrm{N}$-acetylcysteine (NAC) showed a protective effect $(-15 \%$, relative ratio $0.43, \mathrm{p}=0.049)$ on exacerbations in the highest quartile of packyears, but negative effects on health status $(-0.23$ points $/ y r, p=0.038$ ) in patients with reversibility, and on $F E V_{1}$ in former smokers $(-3 \mathrm{~mm} / \mathrm{yr}, \mathrm{p}=0.035)$. Fluticasone on the other hand, showed a small positive effect on health status (+0.12 points/yr, $\mathrm{p}=0.043$ ) in moderate $C O P D$, which was significantly favourable to the surprisingly negative effect ( -0.15 points/yr) in severe COPD (difference 0.27 points/yr, $\mathrm{p}=0.029)$. Also, fluticasone showed an unexpected significant negative effect on $\mathrm{FEV}_{1}$ in females compared to males $(-37 \mathrm{ml} / \mathrm{yr})$. To our knowledge, it is the first time that such differentiated effects during a follow-up of three years have been reported. Moreover, the tools to measure these determinants are generally available in primary care, and illustrate once more the necessity for spirometry including reversibility testing: not only for sound diagnosis, but also to determine possible treatment effectiveness. Careful assessment of packyears seems not only important for risk stratification, but also to decide on treatment strategy. "The possible prognostic role of gender thas potential implications for disease management: female COPD-patients seem to react differently to inhaled steroids, and this clearly warrants further research into gender differences in COPD.

In the past years few new study results have appeared on effectiveness of long-term treatment with $\mathrm{N}$-acetylcysteine in COPD. A recent retrospective analysis of medication records observed that treatment with $\mathrm{N}$-acetylcysteinne was associated with 30\% fewer re-hospitalisations after an initial 
admission due to a COPD exacerbation ${ }^{42}$ "Indication bias could however not be ruled out in this study, and follow-up was limited: on average 276 days with a maximum of $\mathrm{y}$ year. Three meta-analyses have been published in which all known studies since the eighties have been aggregated ${ }^{18-20}$. Although study quality differed considerably, all three meta-analyses concludied that $\mathrm{N}$-acetylcysteine was moderately effective in reducing the number of exacerbations in COPD, between $23-29 \%^{18,19}$ or, expressed as proportion of patients free of exacerbation during 3-6 months, $48 \%$ when treated with $\mathrm{N}$-acetylcysteine versus $3 \mathrm{I} \%$ in the placebo group (relative gain $1,56,95 \% \mathrm{CI} 1,37 ; 1,77)^{20}$. The reduction in exacerbation frequency was larger in studies up to three months of treatment $(0,13$ per patient) than in studies with more than three months' follow-up $(0,06 \text { per patient })^{18}$. From this it can be concluded that treatment with $\mathrm{N}$-acetylcysteine has a shortterm preventive effect on exacerbations in COPD. However, long-term efficacy and effects on lungfunction and health status were lacking until recently.

The current study shows that in the highest quartile of packyears a prophylactic effect of NAC in the order of a $15 \%$ reduction in exacerbations compared to placebo takes place. Compared to the lowest quartile of packyears. the relative effect of $\mathrm{NAC}$ is $0.43(57 \%$ reduction). This treatment effect could be of clinical relevance. Recent results from the BRONCUS-study ${ }^{4}$ show that in the group of patients only using NAC a $22 \%$ reduction of number of exacerbations occurred, which seems in line with the effect we observed in the highest quartile of packyears, but not in the whole group. Interestingly, both in our inhaled steroids study leg and in the largest part of the BRONCUS population that was using inhaled steroids, no effects on exacerbations appeared. In addition, the prescriprion of NAC with the aim of improving health status or preserving lungfunction has not proven effective: no positive effects on these outcomes have been observed in any of the subgroups. The significant negative effect sizes compared to placebo amounted to -0.23 points/year on health status in the group with $\geq 12 \%$ reversibility and $-3 \mathrm{mml} /$ year lungfunction decline in quitted smokers, compared to current smokers.

A number of large clinical trials have been conducted in recent years on the longterm efficacy of treatment with inhaled steroids in COPD. In mild. COPD, the results of low-dose inhaled steroids have been disappointing. In the American Lung Health Study three years of triamcinolon reduced $\mathrm{FEV}_{1}$-decline with only $2.8 \mathrm{ml} /$ year compared to placebo 44 . The Euroscop Study only described a short-term effect of budesonide in continuous smokers, but no long-term effect on lungfuncrion dedine ${ }^{22}$. In a population-based cohort, no effects of three years low-dose budesonide on lung- 
function or exacerbations were found either"s. In newly found primary care COPD-patients, again only short-term effects of low-dose fluticasone on $F_{E V}$, were reported ${ }^{46}$. The long-term efficacy of high-dose inhalied steroids has been studied in a pooled anallysis and in three RCTs. The pooled analysis included 197 COPD-patients from three earlier RCTS, excluding all patients with asthmatic features 47 . No improvement occurred in postbronchodilator $\mathrm{FEV}_{\mathrm{I}}$-decline or exacerbation frequency. A two-year study in 78 patients with moderate to severe COPD found no effect of high-dose on pre-or post-bronchodilator $\mathrm{FEV}_{1}$-decline ${ }^{4}$. However, the very large TRISTAN-study, a single-year placebo-controlled study treating $1465 \mathrm{pa-}$ tients with moderate to severe COPD with high-dose fluticasone, the longacting $B_{2}$-agonist salmeterol or the combination of these, showed for both pre- and post-bronchodilator $\mathrm{FEV}_{1}$-level an increase of circa $40 \mathrm{ml}$ in the fluticasone group compared to placebo ${ }^{49}$. Because the study only lasted twelve months, no long-term annual lungfunction decline could be determined. The mean number of exacerbations per year was 1.05 for fluticasone and 1.30 for placebo $(\mathrm{p}=0.003)$, which equals a $19 \%$ reduction ${ }^{49}$. The ISOLDE-study, a placebo-controlled study treating 75I patients with moderate to severe COPD for three years with high-dose fluticasone, showed no effect on post-bronchodilator $\mathrm{FEV}_{1}$-decline ${ }^{\mathrm{Is}}$. The number of exacerbations however, was $25 \%$ lower in the fluticasone group $(0,99$ versus 1,32 exacerbations per year, difference $-0.3,95 \% \mathrm{CI}-0.4 ; 0.0$ ) and a clinically relevant decrease in health status was delayed by nine months $(p=0,004)$.

In this three-year primary care study with 286 mild to moderate COPD patients, no effects of high-dose fluticason on exacerbation frequency or course of exacerbations could be shown. We observed a small but significant effect of fluticason on health status in the group with moderate COPD (GOLD 2), amounting to 0.12 points/year compared to placebo. This does not reach the minimal clinically important difference of 0.5 points/year of the $\mathrm{CRQ}^{36}$, and thus does not warrant use of inhalled steroids in the whole group. Interestingly, the effect is opposite in the severe COPD group, where it would have been expected based on current literature ${ }^{16}$. The significant difference between the moderate and severe groups amounts up to 0.27 points; the difference between the mild and moderate groups was 0.16 points, which did not reach significance. Possibly, the distribution of patients in our population, the larger part being GOLD 2, has influenced these statistically significant but clinically less relevant results. Finally, gender does seem to play a role in the effects of inhaled steroids in COPD. In femalles, Auticasone had an outspoken negative effect compared to men, amounting to a significant $-37 \mathrm{ml} /$ year difference in lungfunction decline. Clinically this can be considered relevant, and reminds us of the fact that few COPD-studies have included enough females to analyse differentiated 
treatment effects. It is hitherto unclear whether this apparent difference is caused by pharmaco-biological mechanisms or by psychosocial behaviour patterns. Epidemiologically, it could also be the case that a distinct group of females with COPD has emerged first, not necessarily representing all future females with COPD. The reason why this separate group would present itself to the primary care clinician frst would be explained by a mote active disease pattern with more sympromatic distress. It remains to be seen if this picture

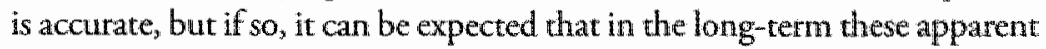
gender differences in disease expression would diminish. In ongoing and future studies this finding should be tested with high priority, given the implications it may bear.

Previous therapeutical studies have employed much stricter in- and exclusion criteria, leading to study populations hardly representing the large group of patients treated in primary care ${ }^{50}$. We have attempted to entance external validity by allowing a heterogeneous group of mild to moderate COPD to be included, leading to much more differentiated treatment effecrs. The group that we studied encompassed clearly more mild COPDpatients than previous long-term studies using high-dose inhaled steroids. Also, we allowed for a degree of reversibility, but ruled out any history of asthma, rhinitis or atopic allergy. The number of exacerbations preceding the study was recorded, but was not an inclusion criterion. Interestingly the group of patients with frequent exacerbations ( $>2 /$ year) seems to amount to only $5 \%$ in primary care, and as a consequence this factor does not appear to be a determinant in mild to moderate COPD. In daily practice, it remains difficult to measure this factor, since underreporting is common, especially when afterwards asking for exacerbations. In addition, the proportion of patients with a $\mathrm{BMI}<2 \mathrm{I}$ is around $10 \%$ and does not seem to predict significant treatment effects in a primary care population.

\section{Conclusions}

Within the heterogeneous primary care COPD population it is possible to distinguish clinically rellevant subgroups that seem to react differently to either fluticasone propionate or $N$-acerylcysteine. For treatment with these medications it is important to realise that some patients may benefit while others might nor, apparently depending on determinants of lung function including reversibility, smoking behaviour and gender which are measurable in primary care practice. 


\section{Acknowledgements}

We are grateful to all participating patients, their GPS and practice assistants, without whom this study could not have been performed.

\section{References}

Pauwels RA, Buist AS, Calverley PM, Jenkins CR, Hurd S.S. Global strategy for the diagnosis, management, and prevention of chronic obstructive pulmonary disease NHLBI/WHO Global Initiatiwe for Chronic Obstructiwe Lung Disease (GOLD) Workshop summary. Am J Respir Crit Carre Med 2001; 163:1256-76.

2. Murray CI. Lopez AD. Alternative projections of morralicy and disability by cause 1990-2020: Global Burden of Disease Study. Lancet 1997; 349: 1498-504.

3 Mannino DM, Homa DM, Akinbami LJ, Ford ES, Redd SC. Chronic obstructive pulmonary disease surveillance--United States, 1971-2000. MMWR Surveill Summ $2002 ; 51: 1-16$.

4 Murray CI, Lopez AD. Mortality by cause for eight regions of the world: Global Burden of Disease Study. Lancet 1997:349: 1269-76.

5 Feenstra TL, van Genugten ML, Hoogenveen RT, Wouters EF, Rutten-wan Molken. MP. The impact of aging and smoking on the furure burden of chronic obstructive pul-monary disease: a model analysis in the Netherlands. Am f Respir Crit Care Med 200\%: 164: $590-6$.

6 Langhammer A, Johnsen R, Gullswik A, Holmen 1 L, Bjermer L. Sex differences in lang vulnerability to tobacco smoking, Eur Respir J 2003: 21: 1017-23.

7 Chavannes $\mathbb{N H}$, Huibers MJH, Schermer TRI, et al. Associations of depressive symptoms with gender, body mass-index and dyspnea in primary care $\mathrm{CO} P \mathrm{D}$-parients. Fam Pract 2005; Advance Access lluly 15.

8 Foy CG, Rejeski WJ, Berry M], et al. Gender moderates the effects of exercise therapy on health-related quality of life among COPD patients. Chest 2001; 19:70-76.

9 Silverman EK, Weiss ST, Drazen JM, et al. Gender-related differences in severe, earlyonset chronic obstructive pulmonary disease. Am J Respur Crit Care Med 2000; 162: $2152-98$.

10 Varkey $\mathrm{AB}$. Chronic obstructive pulmonary disease in women: exploving gender differences. Curr Opin Pulm Med 2004; 10(2): $98-103$.

II Anthonisen NR, Connetr JE, Kiley JP, Altose MD, Bailey WC, Buise AS er al. Effects of smoking intervention and the use of an inhaled anticholinergic bronchodilator on the rate of decline of $\mathrm{FEV}_{1}$.JAMA 1994; 272: $1497-505$.

12 Connert JE, Murray RP, Buist AS, ex all. Changes in sunoking startus affect women more than men: results of the lung Healch Study. Am f Epidemiol 2003: 157:973-9.

13 Chavannes NH, Schemer TR], Wouters EF, Van Weel C, Van Schayck CT. Treament of COPD in general practice: the COOPT study. Eur Respir J 20or; r8 (Suppl 33): $348 \mathrm{~S}$.

14 Calverley PM. Inhaled corticosteroids are beneficial in chronic obstructive pulmonary disease. Ath / Respir Criv Care Med 2000; 16n: 341-2.

is Burge PS, Calverley PMA, Jones PW, Spencer S, Anderson JA, Maslen TK. Randomised, double blind placebo controlled situdy of fluticasone propionate in patiens with moderate to severe chronic obstructive pulmonary disease: the ISOLDE trial. $B M / 2000 ; 320: 1297-303$. 
16 Jones PW, Willits $\mathbb{L} R_{*}$ Burge PS, Calverley PM; Inhaled Steroids in Obstructive Lung Disease in Europe study investigators. Disease severity and the effect of fluticasone propionate on chronic abstructive pulmonary disease exacerbarions. Eur Respir I 2003; 21(1): 68-73.

17 Chavannes NH,.Schermer TRJ. Long-term inhaled steroid response testing should be done in heterogeneous COPD -population [letter]. Thonidx $2003 ; 58 ; 647.8$.

I8 Poole PJ, Black PN Oral mucolytic drugs for exacerbations of chronic obstructive putmonary disease: systematic review. BMJ zoor; $322: 1-6$.

19 Grandjean EM, Berther P, Ruggieri MP, Leuenberger P. Efficacy of oral Jong-serm $N$ acerylcysteine in chronic broncho- pulmonary disease; a meta-analysis of published double-blind, placebo-controlled clinical trials. Clin Ther 2000; 22: 209-21.

20. Stey C, Seeurer J, Bachmann S, Medici TC, Tramer MR. The effect of oral $N$-acetylcysteine in chronic bronchitis: a quantitative systematic review. Evtr Respir / $2000 ; 16$ : $253-62$.

2.1. Grandjean E. M., Berthet, $\mathbb{P}$, Ruffmann, R., and Leuenberger, P. Cosr-effectiveness analysis of oral $N$-acetylcysteine as a preventive treatment in chronic bronchiris. Pharm Res 2000; 42: 39-50.

22 Pauwels RA, Lofdalil CG, Laitinen LA, Schouren JP, Postma DS, Pride NB et all Longterm treatment with inhaled budesonide in persons with mild chronic obstructive pulmonary disease who continue smoking. N Engl/ Med 1999; 340: 1948×53.

23 Schayck CP van, Grunsven PM van, Dekhuijzen PN: Do patients with copo benefit from trearment with inhaled corticosteroids? Eur Respir J (1996) 9: 1969-1972,

24 Schayck CP van, Dekhuijzen PNR, Gorgells WJMJ, Grunsven PM van, Molema J. Herwaarden CLA wan, Weel $C$ van: Are anti-oxidant and ant-inflammatory treatment effective in different subgroups of COPD? A lyypothesis Resp Med (1998) 92: 1.259-1264.

25. Chavannes $\mathrm{NH}$, Schayck $\mathrm{CP}$ wan. Developments in the trearment of chronic obstructive pulmonary disease (COPD): the clinical picture. Curr Opin linest Drugs 2000; I(I): $75-78$.

26 Nisar M, Walshaw M, Earis JE, Pearson MG, Calverley PMA. Assessment of reversibility of airway obstruction in patients with chronic obstructive airways disease. Thorax 1990; $45: 190-4$.

27 Barnes PJ. Inhaled corricosteroids are not beneficial in chronic obstructive pul monary disease. An I Respin Crit Care Med 2000; 161: 342-4.

28 Schols AM, Slangen J, Volovics L, Wouters EF Weight loss is a veversible factor in the prognosis of chronic obsructive pulmonary disease. Am. J Respir Crit Care Med rog8: 157: 1791-7.

29 Nishimura $K$, Izumi $T$, Tsukino $M$, Oga T. Dyspnea is a better predictor of s-year supvival than airway obstruction in patients with COPD. Chest 2002; 12:1: 1.434-40.

30 Ferrer M, Alonso I, Morera J, Marrades $R_{*}{ }_{*}$ Khalaf $A_{x}$. Aguar MC et all. Chronic obstructive pulmonary disease stage and heal th-related quality of life. The Quality of Life of Chronic Obstructive Pulmonary Disease Study Group. Ann Intern Med 1997; 127: 1072-9.

3I van Manen JG, Bindels PJ, Dekker FW, Bottema BJ, wan der Zee JS, IJzermans CJ et al. The influence of COPD on health-related quality of life independent of the influence of comorbidity. / Clin Epidemiol 2003; 56: 1177-84.

32 van Mamen JG, Bindels PJ, IJzermans CJ, van der Zee JS, Bottema BJ, Schade E. Prevalence of comorbidity in patients with a chronic airway obstruction and controls over the age of $40 . /$ Clin Epridemiol zoor; $54: 287 \sim 93$.

33 Celli BR, Cote CG, Marin JM, Casanova $C$. Montes de Oca M., Mendez RA et al. The Body-Mass Index, Airflow Obstruction, Dyspnea, and Exercise Capaciry Index in Chronic Obstructive Pulmonary Disease. N EnglJ Med 2004; 350: 1005-12. 
Schermer IR], Chavannes NH, Wouters EFM, Akkermans RP, Dekhuijen, Schayck $C$ Pan, Weel $C$ wan. A double-blind placebo-controlled randomised dinical trial comparing the long-term effecriveness of $N$-acetylcysteine and Auticasone propionate in parients with COPD in general pracuice. Presentation ERS 2005. Schermer TRJ, Hendriks AlC, Chawannes NH, Dekhuizen PNR, Wouters EFM, yan den Hoogen H] et al. Probabiliny and determinants of relapse after discontinuarion of inhaled corticosteroids in patients with COPD treated in general practice. Prim Came Respir J 2004: 13:48:5\%.

36 Guyart $\mathrm{GH}$, Berman LB, Townsend M, Pugsley 50 , Chambers LW. A measure of quality of the for dinical trials in chronic lung disease. Thorax $1987 ; 42: 77 \%-8$.

37 Global Initiarive for Chronic Obstructiwe Lung Disease (GOLD). www goldcopd com. Dark accessed: August 15 2005.

38 Siafakas NM, Vermetre P. Pride NB, Paoletri P, Gibson J, Howard P et al. Optimal assessment and management of chronic obstructive pulmonary disease (COPD). Eur Respir/1995; 8: 1398-420.

39 Bestall JC, Paul e $\mathbb{A}^{\mathrm{A}}$, Garrod R, Garnharn R, Jones PW, Wedzicha JA. Usefulness of the Medicall Research Council (MRC) dyspnoea scale as a measure of disability in patients with chronic obstructive pumonary disease. Thorax $1999 ; 54(7) ; 581-6$.

Diggle Pl, Liang KY, Zeger 5L. Analysis of longitudinal dara. Oxford (UK): Oxford University Press; 199 .

4. Twisk JWR. Applied longitudinal data analysis for epidemiology. Cambridge (UK): Cambridge University Press, 2003.

42 Gerrits CMJM, Herings RMC, Leufkens HGM, Lammers J-WI. N-acerylcysteine reduces the risk of re-hospitalisarion among patients with chronic obstructive pulmonary disease. Eur Respur $/ 2003$; $21: 795$-8.

43 Decramer M, Rurten-wan Molken M. Dekhuijzen PN, Troosters T, wan Herwarden C. Pellegrino R, wan Schayck CP; Olivieri D, Del Donno M, De Backer W, Lankhorst 1, Ardia A. Effects of $N$-acerylcysteine on outcomes in chronic obstructive pulmonary disease (Bronchiris Randomized on NAC Cost-Utility Study, BRONCUS): a randomised placebo-controlled trial. Lance 2005; $365(9470): 1552-60$.

44 Wise MD, Connet J, Weinmann G, Scanlon P Skeans M. Effect of inhaded triancinolone on the dedine in pulmonary function in chronic obstructive pulmonary disease. N Engl/J Med 2000; 343: 1902-1909.

45 Vestbo J, Sorensen T, Lange P, Brix A, Torre P, Viskum Long-term effect of inhaled budesonide in mild and moderate chronic obstructive pulnonary disease: a ran. domised conkrolled rial. Lawer 1999; 353:1819-23.

46 van Grunswen $P$, Schermer T, Akkermans $\mathbb{R}$, Albers $M$, van den Boom $G_{3}$ van Schayck Oet al. Short-and long-term efficacy of Auticasone propionate in subfects with early signs and symptoms of chronic obstructive pulmonary disease. Resulss of the DIMCA study. Respir Med 2003; 97: 1303-12.

47 van Grunsven PM, van Schayck CP Derenne JP, Kerstjens HAM, Renkema TEJ, Postma DS et al. Long term effects of inhaled cotricosteroids in chronic obstructive pulmonary disease: a meta-analysis. Thowat $1999 ; 54: 7=17$.

48 Weir DC, Bale GA, Bright P. Burge PS. A double-blind placebo-controlled study of the effect of inhaled beclome thasone dipropionate for a years in patients with nonasthmatic chronic obstructive pulmonary discase. Clin Exp Allergy r999:29. Suppl 2: 125-128.

49 Calverley $P$, Pauwels $R$, Vestbo J. Jomes P, Pride N, Gulsvilk A et al. Combined salmeterol and fucicasone in the treatment of chronic obstructive pulmonary disease: a randomised controlled trial. Lancet 2003; 361: 449-56.

so Herland K. Akselsen JP Skjonsberg OH, Bjermer L. How representative are clinica]. study patients with astlima or COPD for a larger "real life" population of patients with obstructive lung disease? Respir Med 2005; 99(I): $11-9$. 
Chapter Io

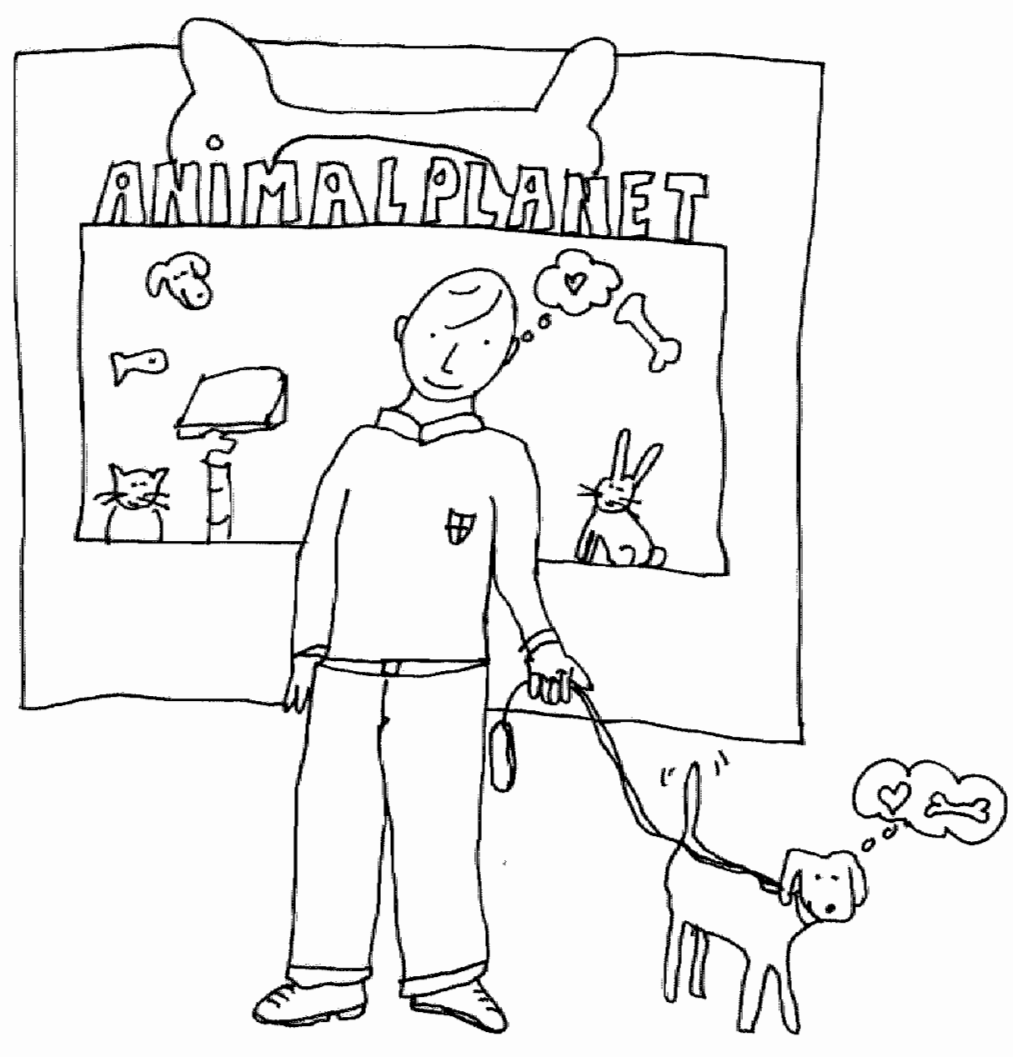


General Discussion 


\section{Activism versus nihilism}

In primary care, COPD has long been regarded as an irrewersibly deteriorating disease hard to treat, usually inflicted by ongoing nicotine-addiction even harder to cope with. The grim prognosis of COPD combined with this etiological and therapeutical pessimism may have led to a negative spiral of behaviour among healthcare providers, which bares resemblance to the vicious circle COPD-patients often find themselves trapped within. In practice, under- or misdiagnosis of COPD is common, and undertreatment is not an unusual result. To break through the mutually reinforcing processes of deconditioning and social deprivation which characterise the advance of $C O P D$, healthcare providers first must recognise the COPD-patient as such, and secondly activate a lasting counterforce involving medical treatment, non-pharmacological interventions, and lifestyle measures including patient education and selfmanagement skills. Ideally, this involves a tailot-made programme of interventions aimed at the specific problems and strengths of each patient, medical, conditional or psychosocial. This means that a multidisciplinary effort is required, and a team needs to be forged, bringing together all relevant disciplines, including the experience-based knowledge of patients. In fact, there is little reason to be nihilistic about this disease, since there's simply too much work to be done. The overwhelming need for a team effort becomes clear both in daily practice and from epidemiological studies, showing a sharply rising prevalence of COPD that will continue for the coming decades worldwide. This is in sharp contrast with other major causes of death and disability like heart disease and cancer, which show a leveling or slightly decreasing prevalence ${ }^{x}$.

\section{Integrated team}

In Chapter One the novel section of the recent electronic American Thoracic Society/European Respiratory Society Guidelines on COPD: Integrated Disease Management of $\mathrm{COPD}^{2,3}$ (www thoracicorg/coPD) is introduced. In this highly interactive section, primary care physicians, respiratory nurse specialists and rehabilitation physicians have worked together with respiratory specialists to integrate key elements of daily care with the most recent practical evidence available In contrast to many guidelines, the ATS/ERS task force has committed itself to produce a use- 
able tool for all health workers in the field of COPD. It is important to realise that up to $90 \%$ of care for COPD patients is already delivered in primary care, and that most patients prefer to be treated at home. Optimising the primary care interface thus offers a great chance to increase patient satisfaction", while posing quite a challenge in COPD. Therefore, this section specifically aims at streamlining cooperation berween primary care level physicians, nurses and assistants, who often go unmentioned in the average international guideline. Through active communication between the levels of health care delivery, it is believed this has been the first true effort to produce trans-disciplinary COPD-standards on an internarional level.

\section{Patient empowerment}

Most importantly, this section emphasizes the essential role of the parient in the whole heal th care organisation: we should realize that approximately $50 \%$ of exacerbations are not reported to health care givers ${ }^{6}$, for reasons that include: fear of admission, fear that nothing can be done, not wanting to bother the doctor, or just postponing decisions?. Explaining to patients that short courses of oral steroids are especially effective during the first 72 hours ${ }^{8}$ could mean an often overlooked but crucial intervention by primary care teams. Implementing daily activity programs to improve exercise tolerance ${ }^{9}$ may seem a modest intervention, but could change the downward spiral of inactivity and social deprivation that has overcome many COPD patients. The focus should be on adequate education and sharing of responsibilities. From recent data ${ }^{\text {to }}$, it becomes clear that use of self-medication is positively associated with shorter exacerbations, building an evidence-based case for Exacerbation Rapid Action Plans. Of course, such interwentions should be part of a continuously updated registration and feedback system. It is difficult to provide a blueprint of such a system, since local circumstances differ enormously on both sides of the Atlantic, and between countries. However, a number of key elements are offered, which could be part of a locally adjusted integrated disease management program, and the ATS/ERS task force sincerely welcomes future experiences from different setrings, since the document will be continuously updated. 
PART ONE: DIAGNOSIS

\section{Diagnosing COPD in primary care}

Any programme that aims for disease management of COPD in primary care starts with a valid diagnosis. However, in the past; doubrs have been expressed concerning the validity and quality of office spirometry. The results of a recent study ${ }^{[1}$ indicate that, on average, the validicy and quality of spirometric testing in Dutch general practices is satisfactory in comparison with the 'gold standard' procedure, a spirometric test performed in a pulmonary function laboratory. Reasons for this positive result can be sought in the elaborate training programme, which specifically emphasised elements of test performance which are often insufficient in general practice, the use of spirometers with display How-volume curves, and the fact that most of the testing was performed by practice assistants, not by practitioners. Practice assistants normally have more time available, or may be more able to encourage patients. The results of this study seem to support the already widespread practice of performing spirometric tests in primary care settings. Further encouragement of primary care physicians to implement spirometric tests therefore seems justifiable, provided the training of practice staff is sufficient. Another part of this study programme addressed the interpretative skills of primary care physicians regarding flow-volume curves. In Chapter Two it was investigated how able GPS actually are in recognising spirometric patterns, and how this abiliry may influence their clinical behaviour. This study ${ }^{12}$ demonstrared for the first time the reasonable diagnostic achievements of trained GPs with regard to commonly encountered spirometric patterns. Curves of obstructive airways disease as well as the physiological can be considered the more prevalent conditions, as opposed to patterns suggestive of restriction or fixed upper airways obstruction, which GPs can be expected to be less familiar with. Thus, the flow-volume curve seems to support establishing a diagnosis in patients with respiratory morbidity, bur probably leads to an increased use of additional diagnostic procedures or specialist care, at least initially.

\section{Flow-volume versus peak flow}

In a pro-conseries forming Chapter Three ${ }^{13,14}$ it is argued that a complete flow-volume loop is an important diagnostic element in the diagnosis of 
COPD, since incipient obstruction is primarily localised in the small airways and does not markedly affect the peak expiratory flow rate. In diagnosing COPD patients, peak flow (PEF) measurement seems too crude to differentiate the different degrees of obstruction, and is simply unable to detect any signs of restriction. COPD is a growing problem for society, which should not be underestimated. With sufficient funding, adequate training and motivated heal thcare workers, there is no good reason why spirometric testing cannot be widely implemented. It is argued that PEF can be of added value for unscheduled wisits, such as during a period of worsening symptoms. However, in case of an acute exacerbation of COPD, measurement of PEF (or for that matter spirometry) does not add much to the diagnosis; but it does wear the patient out. If a diagnostic test were to be clone at that moment, it should be an oxygen saturation measurement, which is non-invasive and quick, and does not pose a burden to the patient. This could provide additional information for referral if one suspects respiratory failure ${ }^{\mathrm{s}}$. It has been demonstrated in a diagnostic study of patients with acute COPD-exacerbations that the optimal cut-off point for oxygen saturation measurement is $92 \%$, with a sensitivity of $100 \%$ and a specificity of $86 \%^{16}$.

\section{Underlying inflammation}

Besides spirometry, clinicians establish diagnosis by careful history taking and considering risk factors. There has been some uncertainty on how well this clinical practice correlates with underlying inflammatory patterns, which have been shown to cause different respiratory diseases ${ }^{17}$. Especially when risk factors like smoking are present, the differential diagnosis can be broad, and this situation is explored in Chapter Four ${ }^{88}$. In this study it is investigated in what respect clinical diagnoses correlate with spurum inAammatory patterns of primary care patients with respiratory complaints: which inflammatory markers are linked to clinical disease categories in primary care, and what is the role of measuring bronchodilator reversibility. Although it is generally accepted that systemic inflammation contributes to the impaired health status in $C O P D$, little is known about the origin of the systemic inflammation. In an earlier study ${ }^{17}$, the possible relationship between the local and systemic inflammatory response was assessed. Patients with COPD had significantly higher percentages of neutrophils and increased levels of soluble tumor necrosis factor receptor $\mathrm{R}_{55}$ ( (STNF-R55) and the chemokine interleukine-8 ( $\mathrm{IL}-8)$ in their induced sputum samples compared to healthy smokers. Furthermore, the presence of ongoing inflammatory processes in the airways and circulation of patients with COPD was confirmed, despite smoking cessation. In the current study ${ }^{18}$, we demonstrate that clinical diagnoses are largely distinguishable on the basis of in Hamma- 
tory markers in blood plasma and sputum. In a multivariate analysis, a smaller set of variables remains significantly associated, which opens the possibility to test predictive values of these wariables in larger populations. COPD (GOLD 2) and so-called healthy smokers show consistent opposite associations with plasma lipopolysaccharide binding protein (LBP), while patients with chronic bronchitis (GOLD o) show relatively predominant lymphocytic inflammation compared to other diagnosis groups. In addition, sputum eosinophilia, a potential target for therapy, remains significantly associated with bronchodilator rewersibility across the spectrum of respiratory disease, while other clinical characteristics are not. It thus seems that different phenotypes are distinguished on the basis of relatively simple parameters, which are readily available in primary care. Current guidelines should continue to emphasise the importance of history taking including smoking behaviour, and performing spirometry including reversibility, since these contribute significantly to achieving a proper clinical diagnosis.

\section{To test or not to test?}

After a spirometrically objectified diagnosis has been established, several international guidelines suggest that a diagnostic prednisolone test can be done to predict treatment response to inhaled steroids. The influential earlier Isolde Study dismissed the prednisolone test however ${ }^{19}$, based on the former ATS-criteria, in a population not representing primary care COPDpatients, and after ruling out any reversibility. Since then, the literature has been inconclusive on the utility of the prednisolone test in primary care $\operatorname{COPD}^{20}$. This long-standing issue is therefore investigated in Chapter Five $^{2 \mathrm{r}}$, comparing the test-responders according to several international guidelines. The study reveals that, when applying the (former) criteria from ERS or BTS, possible clinically relevant differences berween responders and non-responders seem to occur regarding long-term effects of inhaled steroids. Interestingly, the former ATS-criteria apparently do not detect this responder-group, which is in line with the earlier mentioned study ${ }^{19}$. The prednisolone-response is present in $9-16 \%$ of the whole group of COPD patients, but when looking at gender, it turns out that it occurs in $6-9 \%$ of males and $16-23 \%$ of females. So, females seem $2-3$ times more likely to respond to oral steroid testing in this study. The relevance of these data is summed up in its potential modifying effect: according to the former ERS definition, responders show significant improvement in annual health status, and a possibly relevant but not significant exacerbation reduction and slowing of lung function decline appears when applying former ERS and BTS-criteria. It is now a matter of debate whether one considers a prednisolone test necessary to detect the clinically relevant 
9-12\% responders to inhaled steroids, also considering the drawbacks of two weeks of oral prednisolone. However, taking the increase in female COPD-patients in coming decades into account would likely mean higher response rates.

\section{Depressive symptoms}

The role of female gender in COPD disease expression has been studied insufficiently, probably due to the fact that COPD used to be a typical male disease. In the COOPT Study however, a considerable group of females was included, reflecting the shift towards female gender which occurs world wide among COPD-patients. Anorher disease feature recently deserving more atrention is the reported higher prevalence of depressive symptoms among COPD-patients. Especially in more severe COPD, several studies show that depression can be common ${ }^{22-24}$, but it is uncertain if depressive symptoms play a role in mild to moderate disease. Therefore, Chapter Six ${ }^{25}$ investigates possible clinical and demographic factors associated with depressive symptoms in primary care COPD. The results suggest that in primary care, depressive symptoms in COPD seem to be relared to female gender and the presence of dyspneic complaints. Interestingly, we found less depressive symptoms in patients with an elewated BMI ( $>25)$, while the inverse relation with $\mathrm{BM}<<21$ did not reach significance, probably due to low patient numbers. Based on these findings and previous reports in the literature it is hypothesized that females with COPD may express a different disease coping pattern, including more depressive symptoms, which cleserves further research. In this study of mild to moderate COPD-parients, Jung function, exacerbation rare, smoking behaviour, age and comorbidity are not independently associated with depressive symptoms in COPD of mild to moderate severity. 


\section{PART TWO: TREATMENT}

\section{Reactivation in Primary Care}

Recently, it has elegantly been demonstrated that the BODE-index, which integrates the body-mass index (B), the degree of airflow abstruction (O), dyspnea (D) and exercise capacity (E) is a berter predictor of mortality than FEV, in GOLD-3 and GOLD-4 COPD patients. ${ }^{26}$. This landmark. study provides good proof that COPD should be regarded as a multi-component disease, which consequently needs a multi-faceted approach. It remains the question howewer, how sensitive and relevant the $\mathrm{BODE}$-index will be in a primary care population, which usually consists of many more patients with GOLD-2 and GOLD-I stage disease. The proportion of nutritionally depleted individuals will probably be lower, as suggested in Chapter Six ${ }^{25}$, and the role of exercise capacity has not been assessed thoroughly in primary care. This aspect is covered in Chapter Seven', a systematic review of available evidence in mild to moderate COPD that reveals that reactivation does lead to improved exercise tolerance, although only few studies have been aimed at this patient category. It has been described before $^{27}$ that patients in the early stages of disease do not recognise the disease or do not consider it as disabling enough to necessitate rehabilitation. This may be a reason why dyspnea and health status do not appear to improve. Therefore it is important for the primary care physician to advise patients a method of physical activity that is acceptable enough to be maintained for longer periods and clear enough to be performed independently. It seems possible that a twice-weekly training frequency may be effective in enhancing exercise tolerance if applied for at least three months. It is concluded that physical exercise training (usually as part of a package of rehabilitation) can improve the fitness of patients with mild or moderate COPD, but that it has not yet been shown to significantly benefit health status or dyspnea, or long-term disease progression.

\section{Medical treatment}

Despite large efforts made to improve the wellbeing of patients with COPD, clinical results of current therapy are limited so far. Most notably, it can be concluded that the effectiveness of inhaled steroid therapy for asthma cannot be extrapolated to COPD ${ }^{28}$. This holds especially true for 
the earlier studies, which are solely aimed at reducing the decline in lung function in irreversible COPD. Subjective improvements in wellbeing were not accounted for in these large studies, although they might have been detected. When looked for, these effects can contribute significantly to the evidence based treatment of COPD ${ }^{29,30}$. In an earlier review ${ }^{31}$, the emergence of health status as an outcome parameter in COPD studies was discussed, and to what extent available drugs have proven to be efficacious in the long-term treatment of COPD. In addition, the medical treatment of smoking cessation is touched upon, an important topic which only recently has deserved more attention ${ }^{32}$. An early literature search ${ }^{33}$ exploring antidepressant therapy for smoking cessation, found that both the atypical antidepressant agent bupropion and the low-cost antidepressant nortriptyline seem to have clinically relevant effects on smoking cessation.

Possibly, the use of antidepressants enables quitters to sustain their selfefficacy and positive attitude with regard to smoking cessation, because antidepressants (used as smoking cessation stimulants) may suppress the symptoms of nicotine withdrawal, and prevent increases in poor mood. Thus, active psychological intervention in combination with pharmacotherapy is required ${ }^{34}$. In the treatment of COPD-patients, the possibilities to support smoking cessation clearly deserve further research. However, in the last two chapters of this thesis, long-term medical treatment of COPD with inhaled corticosteroids and $N$-acetylcysteine is focused upon, since these are therapies already quite commonly used in practice, while the question of their longterm efficacy in primary care has remained unanswered as yet.

\section{Neither ICS nor NAC?}

Chapter Eight reports the results of a randomised, double blind, placebo controlled trial of $N$-acetylcysteine and fluticasone propionate in general practice patients with chronic bronchitis or chronic obstructive pulmonary disease (COPD $)^{35}$. The aim of this study was to determine the longterm clinical effectiveness of $1 \mathrm{CS}$ versus NAC in mild to moderate $C O P D$ in terms of exacerbations, health status, lung function and symptoms. Compared with placebo the exacerbation rates for NAC and ICS were I.35 and 1.30 higher, although not significant, while the course of health sratus scores did not differ for NAC or ICS compared to placebo. The main conclusion of this large primary care randomized clinical trial is, that futicasone and $N$-acetylcysteine do not seem to influence disease progression for the whole group of primary care patients. Previously reported prophylactic effects of NAC and ICS on exacerbations were not confirmed in this heterogeneous group of (ex) smokers with chronic bronchitis and/or COPD. Explorative subgroup analyses are suggested that may reveal patients that 
do bereftr from NAC or inhated steroids. Recent resuls from the BaNCUS-study ${ }^{4}$ show that in the group of parients only using $\mathrm{NAC}$ (30\% of the study population) an annual an reduction of number of exacerbations occurred, which was not rephoted in our scudy. Interestingly, both in our inhaled steroids study leg and in the largest part of the BRONCUS population that was using inhaled sterolds alongside $\mathrm{NAC}_{3}$ no effects on exacerbations appeared. In addition, the prescription of NAC with the am of improving health status or preserving lungfunction has not proven effective: no positive effects on these outcomes have been observed in any of the subgroups.

\section{Targeting treatment}

In an earlier observational paper, it was examined what happens in a primary care COPD-population when taken of inhaled steroid reatment ${ }^{36}$. The results indicated that discontinuation of inhaled steroids may harm patients with COPD, since the overall probability of adverse respirarory ontcome after stopping ICS was $0.37(95 \% \mathrm{CI} 0.31,0.44)$. Furthermore, the probability of an adverse respirarory outcome may be higher in women, elderly patients, smokers and patients with higher bronchodilator reversibility while on inhaled steroid treatment. This observational study preceded the RCT reported in Chapter Eight ${ }^{35}$, and it is subsequently explored in Chapter Nine 37 if there are any determinants for treament success or failure in this RCT. Ultimately, the question whether it is possible to define subgroups within the heterogeneous primary care population that determine clinical outcomes, can now be addressed. All determinants and cut-off points analyzed in this study are based on earlier studies where they were considered modifiers of disease; by applying these variables in our prospective long-rerm study, we can assess their value as predictors of treatment effects of either NAC or ICS. In this study, NAC showed a prophylactic effect on exacerbations in the highest quartile of packyears, but negative effects on health status in patients with reversibility, and on $\mathrm{FEV}$-decline in former smokers. Thus, on the basis of these results, NAC seems wartanted only in currently smoking COPD-patients with considerable ( $>30)$ packyears, and who are lacking bronchodilator reversibility. ICS, on the other hand, showed a small positive effect on health status in moderate $C O P D$, while a negative effect was seen

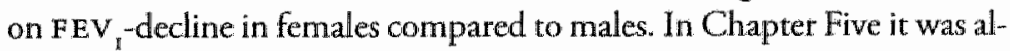
ready concluded that prednisolone testing according to the former $\mathrm{E}$ R $\mathrm{s}$ or BTS criteria can distinguish a group of 9-12\% of primary care COPD-patients who respond favourably to long-term $1 \mathrm{CS}$, but that the chances to detect female responders are 2-3 times higher. It seems therefore plausible that the prednisolone test detects a distinct group of responders to inhaled steroids, a distinction that seems especially sharp in female COPD-patients. Based on 
these results, , CS seem warranted in moderate COP D patients who respond to the diagnostic prednisolone test, since the whole group of primary care COPD does not seem to respond favourably to long-term ICS treatment. In the B RON CUS-study ${ }^{48}$ no differentiated treatment effects of smoking behaviour or disease severity were found, possibly because the BRONCUSpopulation consisted of $l$ ess heretogenic patients (with regard to severity of obstruction, degree of reversibility and smoking history) than the COOPTpopulation. For the practising healthcare provider it is important that within our heterogeneous primary care COPD population it seems possible to distinguish clinically relevant subgroups, based on packyears and current smoking behaviour, reversibility of airway obstruction, prednisolone testing and gender.

\section{Role of gender}

In all studies where we looked at gender as a dererminant ${ }^{21,25,36}$, it turns out to be a powerful outcome modifier: the probability of relapse after discontinuing inhaled steroids, the probability of response to oral steroids and the presence of depressive symptoms remain all firmly associated with female gender after adjusting for confounding. This is an unexpected and therefore even more important result of the studies in this thesis, and is likely related to the fact that few earlier studies have looked into the role of gender, often because females simply did not appear to have COPD yet. In recent years, other investigators have increasingly reported gender differences in symptoms, health status, lung vulnerability and hospitalisations due to COPD ${ }^{4953}$. An explanation why females appear to have a different disease pattern, could possibly be sought in pharmaco-biological mechanisms or psychosocial behaviour patterns, but that goes beyond the scope of this thesis. An alternative, more basic explanation is imaginable however. Based on the epidemiologic shift that has occurred in the past decades, it can be hypothesised that a distinct group of females with COPD has emerged first to the level of clinical detection, not necessarily representing all females with COPD. The reason. why this separate group would present itself to the primary care clinician first would be explained by features we identified in our studies and the literature: responding well to prednisolone and relapsing when taken of inhalled steroids, while expressing more (depressive) symptoms, possibly leading to more hospitalisations. In short: a patient group that will be noted first because of a more active disease and more symptomatic distress. It remains to be seen if this picture is accurate, but if so, it can be expected that in the long-term these gender differences in disease expression would diminish. 


\section{Reversibility and inflammation}

Reversibility to bronchodilator medication was not a significant predictor of treatment success of inhaled steroids, but it did predict a negarive effect of NAC, confirming an earlier hypothesis that anti-oxidants probably have an effect in the group without reversibility but with a more deleterious smoking behaviou ${ }^{37}$. It seems that bronchodilator reversibility is a separate test feature from reversibility to oral steroids, as it did not predict treatment success or failure from inhaled steroids in COP D. However, in the whole group of smoking related respiratory disease, including asthma, bronchitis and smokers without symptoms, a significant association was found berween sputum. eosinophilia and bronchodilator reversibility ${ }^{8}$. Possibly, the low number of COPD-patients expressing significant eosinophilia (6\%) in this study forms part of the explanation. Another part may be formed by the role of eosinophilia itself; a recent study ${ }^{38}$ did find a small improvement of post-bronchodilator FEV , due to short-term steroid treatment in eosinophilic COPDparients, but no effect on spurum eosinophilia itself. Here we may be dealing with the hitherto little understood phenomenon of steroid-resistance in COPD-patients, suggesting that other effect modifying factors in the inflammatory cascade still have to be unravelled before we can really target larger patient groups on the basis of intlammatory patterns. In addition, the clear difference in inflammatory patterns between GOLD o and COPD patients is an intriguing finding, which provides support for earlier findings from the longitudinal Copenhagen City Heart Study, in which a gradual development from GOLD o to GOLD I or higher levels of obstructive disease could not be demonstrated ${ }^{4}$. It seems likely that GoLD o patients represent a different phenotype, which does not necessarily lead to an earlier assumed gradual development of $C O P D^{1}$.

\section{Global scope}

COPD is a major public health problem with increasing prevalence worldwide, mainly because of an increasing global tobacco consumption. In the developing world, efforts of major tobacco companies to increase their markets have been enormous in the past few years, and this will most certainly lead to alarming smoking prevalences in the large populations of Asia, Africa and Latin America 39 . In China, with $20 \%$ of the world's population smoking $30 \%$ of the world's cigarertes, massive retrospective and prospective studies have been undertaken to predict the development of deaths attributable to tobacco use. On the basis of current smoking patterns, the number of tobacco deaths in China is estimated to rise from 0.6 million in 1990 to about 3 million deaths a year by the middle of the century ${ }^{40,4 r}$. These predictions of a large increase in tobacco-attributable mortal- 
ity are supported by case-controlled dara from Hong Kong, where cigarette consumption reached its peak 20 years carlier than in mainland China. In 1998, tobacco caused 33\% of all male deaths at ages 25-69 yrs in Hong Kongt2. What these studies are telling us is that the future focus should be worldwide. If curtent smoking parterns persist it has been estimated that by 2030 cigarettes will cause 3 million deaths a year in the western world, as opposed to 7 million dearhs yearly in the developing world ${ }^{4}$. What can possibly be done about these frightening numbers? One possibility is to assess local disease distributions, smoking behaviour and healthcare resources, and implement tailored interventions based on these local circumstances. From a WHO-sponsored diagnostic study ${ }^{44}$ performed within the Family Health Program of Northern Brazil, it can be concluded that having 'a smoking history of more than five pack years' and 'both symptoms of dyspnea and cough' were independent risk factors for having COPD. It required the testing of 2.6 smokers wirh $>5$ pack years to detect one at risk. Implementing spirometry in current North-Brazilian primary care pracrice improved case finding greater than fourfold. The long-term effectiveness of this case-finding intervention is currently under study.

\section{Future developments}

This complex and increasingly prevalent disease is in need of an integrated team effort ${ }^{3}$, a need that only becomes more urgent towards the end stages of the disease 45 . Communicating viewpoints across levels of care in an earlier stage can lead to useful results on both sides. In addition, the role of the patient as a critical factor in achieving success should be recognized, and emphasis should be laid on targeted education and shared responsibility. The reasons why COPD-patients do consult their health care providers are often unknown ${ }^{46}$, while not consulting in case of exacerbations is common 47 . Within the context of a primary care team, early treatment using patient-administered Exacerbation Rapid Action Plans could be initiated and monitored closely; the effectiveness of such plans is currently under study. Probably, the mainstay of primary care COPD-treatment will continue to be maximal bronchodilation, combined with multidisciplinary reactivation programs. Inhaled corticosteroids and antioxidant treatment for the whole group of mild to moderate COPD cannot be recommended. Smoking cessation and self-management are important but difficult to achieve lifestyle interwentions, which may benefit from the wholesome effects of the first two interventions, like a crowbar breaking into the vicious cycle of deconditioning and social deprivation. In practice, COPD-patients have become accustomed to a slow but unstoppable decline in health status; when reactivation puts a halt to that process, many patients express a sometimes long-forgotten enthusiasm. Seizing that moment of change is the challenge of the multidis- 
ciplinary team, and will largely determine the long-term effects of any programme. In addition, distinct parient groups that can readily be detected in primary care on the basis of history taking, lungfunction and response to prednisolone testing, may benefit from inlualed steroids or oral $N$-acetylcysteine. Different phenotypes can be distinguished on the basis of these relatively simple parameters, which are available in primary care. Current guidelines should therefore continue to emphasise the importance of these parameters, endorsing primary care providers to achieve a proper clinical diagnosis and enabling a tallored rreatment strategy. Future research into the effect modifying factors of treatment success in different phenotypes and their underlying inflammatory patterns is still needed in order to tailor treatment startegies further.

\section{References}

1. GOLD/NIH Pawels RA, Bust AS, Calverley PM, Jenkins CR, Hurd SS. Global strat: egy for the diagnosis, management, and prevention of chronic obstructive pulmonary disease. NHLBT/WHO Global Initiative for Chronic Obstructive Lung Disease (GOLD) Workshop summary. Am J Respir Crit Care Med zoot; 163: 2256-76.

2. Celli BR, MacNee W, Agusti A, Anzueto A, Berg B, Buist AS, Calverley PMA, Chavannes N, Dillard T, Fahy B, Fein A, Heffuer ], Lareau S, Meek B, Martinez F, McNicholas W, Muris ], Austegard E, Panwels $R$, Rennard S, Rossi A, Siafakas $N$, Ticp B, Vestbo I, Wouters E, ZuWallack R. Standards for the diagnosis and treatment of patients with COPD: a sumnary of the ATS/ERS position paper. Eur Respir / 2004 ; $23(6): 93: 2-46$.

3. Chavannes N. Joining forces with primary care: ATS/ERS guidelines on COPD. Frontiers Mag 2004: 1: 6-7"

4. Ojoo JC, Moon T, McGlone S, et al. Patients" and carers' preferences in rwo models of care for acute exacerbarions of $C O P D$ : results of a randomised controlled trial. 7 how 2002:57:167-169

5. Wilson A, Wynn A, Parker H. Patient and carer sutisfaction with "hospital at home": quantitarive and qualitative results from andomised controlled trial. Br/ Gem Prat $2002: 52: 9-13$.

6. Seemungal TA, Donaldson GC, Bhowmik A, Jeffries DI, Wedzicha JA. Time course and recovery of exacerbations in patients with chronic obstructive pulmonary disease. Am I Rexpir Crit Care Med 2000: 161: 1608-1613.

7. Parayil R, Jones $K$, Chavannes $N$, Hendriks $A_{3}$ Nonikov D, Price D, Ostergaard M, Molen T vara der, Espen $L$ wan, Zenmaro M. Patterns in patient experience of COPD exacerbations in the UK, Denmark and The Netherlands - a qualinative study. Eur Rop /2003:22, suppl 45: 67s.

8. Wood-Baker R, Walters EH, Gibson P. Oral corticosteroids for acute exacerbations of chronic obstructive pulmonary disease (Cochrane Rewiew). In: The Cochrane Libraph Issue 4 . Oxfond, Update Sofware, 2002.

9. Chavannes $\mathrm{NH}_{3}$ Vollenberg JJH, Schayck CP van, Wouters EFM. Effects of physical activity in mild ro moderate COPD: a systematic revilew. Br/ Ger Irac 2002: $52: 574$ 578 . 
10. Hurst JR, Wilkinson TMA, Donaldson GC, Wedzicha JA. Selfmedicarion at exacerbation of chronic obstructiwe pulmonary disease (COPD) is associared with faster recovery time. Eur Respir J 2003; 22, suppl 45:559s.

ir. Schermer TR, Jacobs JE, Chavannes NH, Hartman J, Folgering HT, Bortema BJ, Weel van C. Validity of spirometric testing in a general practice population of patients with chronic obstructive pulmonary disease (COPD). Thorax 2003; 58: 861-86.

12. Chavannes $N$, Schermer $T$, Akkermans $\mathbb{R}$, Jacobs $\$, Graaf $G$ van de, Bollen $R$, Schayck $O$ van, Bottema B. Impact of spirometry on GPs diagnostic differenciation and decision-making. Resp Med 2004; 98: 1124-1:130.

13. Chavannes $N$. The necessity for spirometry in the primary care management of $C O P D$. Prim Care Resp J 2004; 13: 11-14.

14. Chavanues N. Reply to: Spirometry and peak expiratory flow in the primary care management of COPD by Patrick White. Prim Care Resp/2004; 13: 9-10.

15. Chavannes $\mathbb{N}$. Pullse oximetry and respiratory disease in primary care. Prim Care Resp $J$ $2003 ; 12(1): 2-3$.

16. Kelly AM, McAlpine R, Kyle E. How accurate are pulse oximeters in patients with acute exacerbations of chronic obstructive airways disease? Respir Med 2001; 95(5): 33640.

17. Vernooy JH, Kucukaycan M, Jacobs JA, Chavannes NH, Buurman WA, Dentener MA, Wouters EF. Local and Systemic Inflammation in Parients with Chronic Obstructive Pulmonary Disease: Soluble Tumor Necrosis Facror Receprors Are Increased in Sputum. Am J Ruspir Crix Care Med 2002;166: 1218-1224.

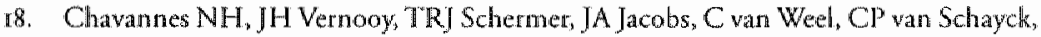
EFM Wourers. Patterns of inflammation and the use of reversibility testing in smokers with airway complaints: The COOPT spurum induction study. Eur Resp / 2003; 22: 69s.

19. Burge PS, Calverley PMA, Jones PW, et al. Prednisolone response in patients with chronic obstrucrive pulmonary discase: results from the 1sOLDE srudy. Thorax 2003:58: 654-8.

20. Chavannes N, Schermer TRJ, on behalf of the CoOPT Study Group. Long-term inhaled steroid response testing should be done in heterogeneous COPDpopulation [letter]. Thomax 2003; $58: 647$.

21. Chavamnes NH. Schermer TRJ, Wouters EFM, Van den Bosch W, Dekhuijzen R, Muris.JWM, van Weel $C_{y}$ wan Schayck CP. Predictive value and urility of oral steroid testing for treament of COPD in primary care: The COOPT Study. ERS 2005.

22. Curtis JR, Deyo RA, Hudson LD. Pulmonary rehabilitation in chronic respiratory insufficiency. 7. Health-related quality of life among panients with chronic obstructive pulmonary disease. Thorat 1994; 49: 162-70.

23. Light RW, Merrill EJ, Despars JA, Gordon GH, Mutalipassi LR. Prevalence of depression and anxiety in patients with COPD. Relationship to funcrional capacity. Chest $1985 ; 87 ; 35-38$.

24. Yohannis AM, Baldwin RC. Conolly MJ. Depression and anxiety in elderly outpatients with chronic obstructive pulmonary disease: prevalence, and validarion of the BASDEC screening questionnaire. Int/ Ger Pych 2000; 15: 1090-96.

25. Chavannes $\mathrm{NH}, \mathrm{MJH}$ Huibers, TRJ Schermer, A Hendriks, C van Weel, EFM Wouters, $C P$ van Schayck. Associations of depressive symptoms with gender, body mass-index and dyspnea in primary care COPD-patients. Fam Practice 2005; July 15 Advance Access. 
26. Celli BR, Cote CG, Marin JM, Casanova C, Montes de OCa M, Mendez RA, Pinto Plara V, Cabral HJ. The body-mass index, airfow obstruction, dyspnea, and exercise capacity index in chronic obstrucrive pultionary disease. NEngl/ Med 2004; 350(10): roos- 12.

27. Ries AL. Position paper of the American Association of Cardiowascular and Putmonary Rehabilitation. Scientific basis of pulmonary rehabilitation. J Cardiopulm Rehabil 1990; 10: 418-44.1.

28. Chavannes NH, Schayck van CP. Developments in the treatment of chronic obstructive pulmonary disease (COPD): The clinical picture. Cwrr Opin Invest Drugs 2000; I(1): $75-78$.

29. Burge PS, Calverley PMA, Jones PW, Spencer S, Anderson JA, Maslen TK. Randomised, double-blind, placebo-controlled study of fiuricasone propionate in patients with moderate to severe COPD: the ISOLDE trial. BMJ 2000; 320: 1297-1303.

30. Spencer S, Anie K, Calverley PMA, Jones $P$ PW. Rate of health status decline is reduced in COPD patients treated with futicasone compared to placebo. Am/ Respir Crit Care Med 1999; 159: As22.

31. Chavannes $\mathrm{NH}$, Schayck van CP. Qualicy of bife in patients with chronic obstruccive. pulmonary disease (COPD): Which drugs help most? BioDrugs 2000; 13 (2): 1274133.

32. Hughes JR, Stead L, Lancaster T. Antidepressants for smoking cessation (Cochrane Review). The Coctirane Library, Issue 2, 2003.

33. Huibers $\mathrm{MJH}$, Chavannes $\mathrm{NH}$, Whena EJ, Schayck van $\mathrm{CP}$. Antïdepressants for smoking cessation: a promising new approach? Eur Resp J 2000; 16:379-380.

34. Decramer M, Gosselink R, Bartsch P, Lofdahl CG, Vincken W, Dekhuijzen R, Vestbo J, Pauwelis R, Naeije R, Troosters T. Effecti of treatments on the progression of COPD: report of a workshop held in Leuven, II-12 March 2004. Thomax zoos; 60(4): 343-9.

35. Schermer TRJ, Chavannes NH, Dekhuijzen R, Wouters EFM, Muris IWM, Akkermans R, van Schayck CP, van Weel C. Randomised, double blind, placebo conrrolled trial of $N$-acetylcysteine and fluticasone propionate in general practice patienrs with chronic bronchiris or chronic obstructive pulmonary disease (COPD). ERS 2005.

36. Schermer TRJ, Hendriks AJC, Chavannes NH, Dekhuijzen PNR, Wouters EFM, Hoogen $H$ van den, Schayck CP van, Weel $C$ van. Probability and dererminants of relapse after discontinuation of inhaled corticosteroids in patients with COPD treated in general practice Prim Care Resp J $2004: 13: 48$-55.

37. Chavannes NH, Schermer TRJ, Wouters EFM, Folgering H, Akkermans R, Muris JWM, van Weel C, van Sehayck CP. Demographic and clinical determinants of tresponse to $\mathrm{N}$-acecylcysteine versus fluticason in mild to moderate COPD in primary care: "The COOPT Study. ERS 2005.

38. Brighting $C E$, McKenna $S$, Hargadon B, Birring S, Green R, Siva R, Berry M, Parker D, Monteiro W, Pavord ID, Bradding P. Spurum eosinophilia and the short term response to inhaled mometasone in chironic abstructiwe pullmonary disease. Thorax 2005;60(3): 193-8.

39. Schayck van $C_{\text {, }}$ Chavannes NH. Detection of asthma and COPD in primary carc. Enur Resp /2003; 39: 16s-22s.

40. Liu $B Q$, Peto $R$, Chen ZM, et al. Emerging tobacco hazards in China: 1. Rerrospective proportionall martality study of one million deaths. BMJ $1998 ; 317: 1411-1422$.

4r. Niu SR, Yang GH, Chen ZM, et al. Emerging tobacco hazards in China: 2. Early mortality results from a prospective study: $B M J \times 998 ; 317: 1423-1424$. 
42. Lam TH, Ho Y, Hedley AJ, Mak KH, Pero R. Mortality and smoking in Hong Kong: case-control study of all ad ult deaths in 1998 . BMJ 2001; 323; 361-367.

43. Lopez AD. Counting the dead in China. BM/1998; 317\%: 1399-1400.

44. Hamers RL, Bontemps ST, Akker M van den, Soura RG, Penaforre JC, Chavannes NH. Diagnostic achievement and case finding of chronic obstructive pulmonary disease in Brazilian primary care. Trop Med Int Health 2005; IO(2): A5.

45. Chavannes NH. A palliative approach for COPD and heart failure? Eur / Pall Care 2001: 8(6): $225-227$.

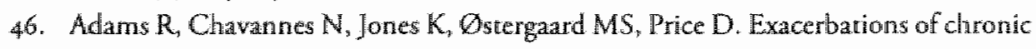
obstructive pulmonary disease - A patients' perspective. Prim Care Resp /, accepred 2005, pending minor revision.

47. Seemungal TA, Donaldson GC, Bhow mik $A$, Jeffries DJ, Wedzicha JA. Time course and recovery of exacerbations in parients wich chronic obstructive pulmonary disease. Am J Respir Crit Care Med 2000;161(5): 1608-13.

48. Decramer M, Rutten-wan Molken M, Delkhuijzen PN, Troosters T, van Herwaarden C, Pellegrino R, wan Schayck CP, Olivieri D, Del Donno M, De Backer W, Lankhorst 1. Ardia A. Effects of $N$-acetylcysteine on outcomes in chronic obstructive pulmonary disease (Bronchitis Randomized on NAC Cost-Utility Study, B RONCUS): a randomised placebo-controlled trial. Lancet 2005:365(9.470): 1552-60.

49. Isoaho R, Keistinen T, Laippala P, Kivela SL. Chronic obstructive pulmonary disease and symproms relate to depression in elderly persons. Psychol Rep 1995; 76(1): $287-97$.

so. Prescott E, Bjerg AM, Andersen PK, Lange P, Vestbo J. Gender difference in smoking effects on lung function and risk of hospitalization for COPD: results from a Danish longitudinal population study. Eur Resp J I997; $10(4): 822-7$.

51. Antonelli-Incalzi R, Imperiale C, Bellia V, Catalano F, Scichilone N, Pistelli R, Rengo $F$, and the SARA invesrigators. Do GOLD stages of COPD severity really correspond to differences in health status? Exur Resp / 2003; 22: 444-449.

52. Langhammer A, Johnsen R, Gulswik A, Holmen TI, Bjermer L. Sex differences in lung vulinerability to tobacco smoking. Eur Resp J 2003; 21: 1017-1023.

53. Watson L, Vestbo I, Postma DS, Decramer M, Rennard S, Kiri VA, Vermeire PA, Soriano JB. Gender differences in the management and experience of Chronic Obstructive Pulmonary Disease. Respir Med 2004; 98(12): 1207-13.

54. Vestbo J, Lange P. Can GOLD stage o provide information of prognostic wallue in chronic olstrnctive pul monary disease? Am / Respir Crit Care Med 2002; 166: 329-332. 


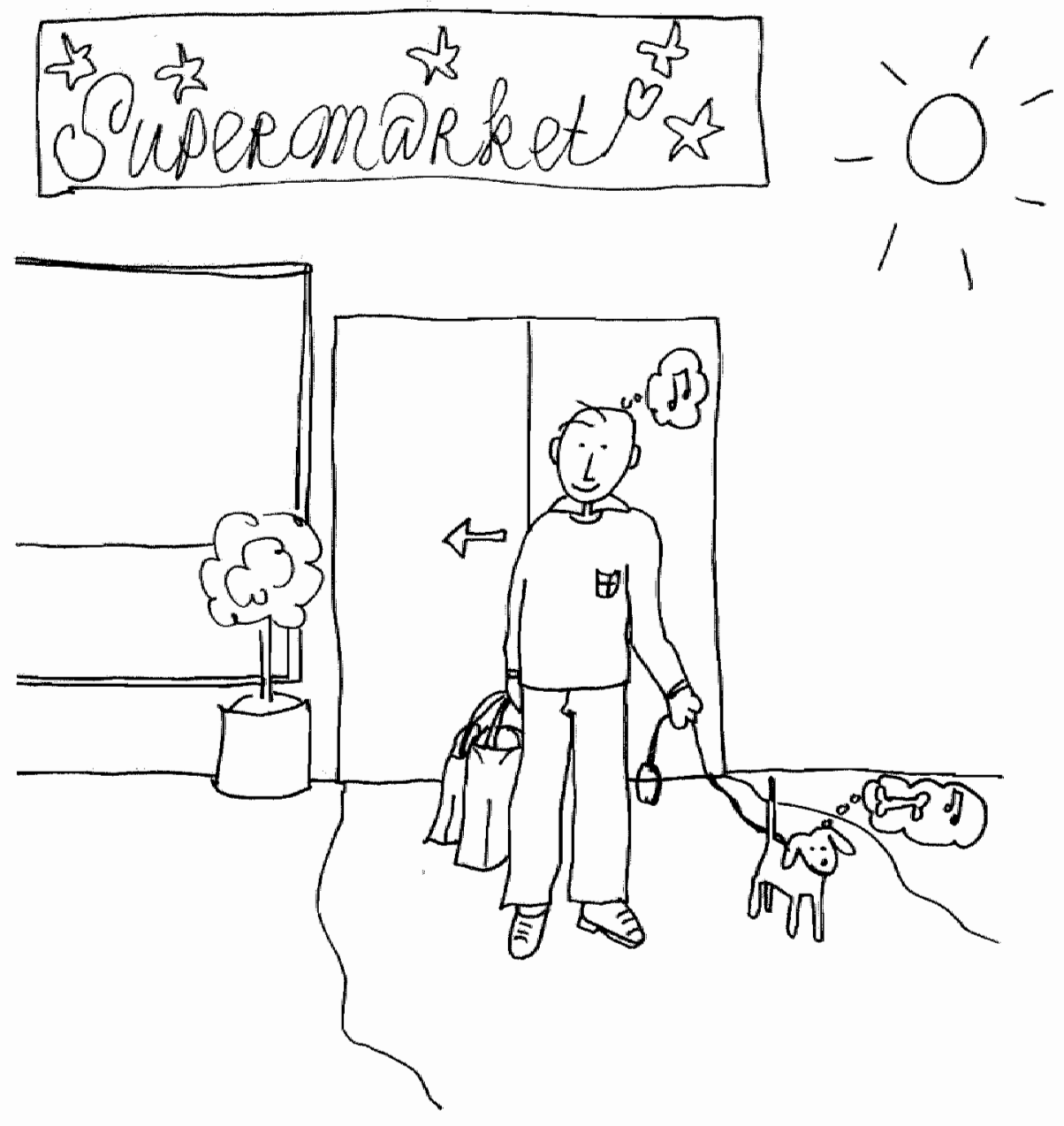


Summary 


\section{Chapter I: Introduction}

The introduction gives an overview of integrated care for chronic obstructive pulmonary disease (COPD), which involves the patient and a team of clinical professionals cooperating with secondary care and rehabilitation services. Optimal disease management involves redesigning standard medical care to integrate rehabilitative elements into a system of patient selfmanagement and regular exercise. Case finding is a simple and effective means of enhancing the diagnosis of COPD in primary care, while the use of spirometry by primary care providers is recommended to detect airways obstruction and facilitate smoking cessation. A diagnosis of COPD is confirmed by spiromerry, which can be performed in a primary care setting if personnel are specifically trained and quality assurance is maintained.

Deconditioning, comorbid illnesses and symptoms of depression often accompany COPD. Even in patients with mild disease, health status can be substantially compromised. The majority of COPD exacerbations are managed at home by the patient or the primary care team. Approximately 50\% of exacerbations are not reported to clinicians. Patients with COPD should be made more aware of the symptoms of an exacerbation and be encouraged to report these early to clinicians. Conversely, physicians should make use of the experience of the individual pacient and ask for early signs of an exacerbation. In most cases, short courses of oral corticosteroids should be initiated at first signs of an exacerbation. Primary care teams give most of the professional care provided to patients reaching end of life. A disease management flow diagram for integrated care of COPD is introduced. This chapter was published electronically as part of the 2004 ATS/ERS Guideline on Diagnosis and Treatment of COPD.

\section{PART ONE: DIAGNOSIS}

\section{Chapter 2}

This chapter aims to compare the achievements of trained GPs in reaching a spirometric diagnosis with an expert consensus panel (r) and to assess the influence of spirometry on the GPS decision-making (2). Spirometry is increasingly implemented in general practice, while the ability of general practitioners ( $G$ Ps) ro interpret How-volume curves ( $F-V$ curves) has been 
questioned. Furthermore, the role of spiromery in the GPs" decision-making process has barely been studied. Twelwe cases including a wide range of F-V curves were interpreted by 39 GPs as well as by the expert panel. Diagnostic test chanacteristics were calculated using multi-level analysis and summarised by diagnostic odds ratios (DOR). Differences in decisionmaking indicators were expressed as odds ratios and $95 \%$ confidence intervals. The results show that normal F-Y curves (DOR 65.0) and obstructive F-V curves (DOR 48.9) were reasonably well diagnosed, while rate and mixed pathological patterns achieved considerably lower scores ( $D O R$ 3.8). Intermediate scores wete obtained in the recognition of incorrect test manoeuvres (DOR 24.4). Spirometry influenced the GPS decision-making in reducing the number of alternative diagnoses (OR $0.27[0.20,0.35])$, but also increased referral rates (OR $7.26[4.7 \mathrm{H}, 11.2]$ ) and the use of diagnostic prednisolone courses ( $\mathrm{OR} 4.55[3.12,6.64]$ ) substantially. It is concluded that trained GPS were able to differentiate berween normal and obstructive disease patterns, while F-V curves suggestive of rare and mixed pathology were often missed. Spirometry seems to infuence the decision-making process of the GP; whether this represents an initial or a more sustained effect remains to be evaluated in studies of daily primary care practice.

\section{Chapter 3}

In this chapter a pro-con series is presented, regarding the use of spirometry versus peak expiratory flow in the management of COPD. On the pro-side it is argued that spiromerry allows a unique non-invasive look into the functioning of the lungs, which can be both medically informative and of practical value. Respiratory complaints are among the most prevalent in primary care, whille smoking rates remain globally high, illustrating the need for proper tools to investigate the possible causes of chronic pulmonary symptoms. Smoking cessation programs and disease management programs are the preferred treatment strategies for $C O P D$; these rely on a vallid spirometric diagnosis, as promoted by international COPD guidelines. In addition, involving the patient in treatment plans and explaining the detrimental effects of smoking can be greatly facilitated by the visual impact of a flow-volume curve. Evidence suggests that spirometry is a valid, feasible and interpretable diagnostic tool in a primary care setting, provided that quality standards of performance and training are sufficiently mer. COPD is a growing problem for sociery, which should not be underestimated. If sufficient funding, adequate training and motivated healthcare workers are available, there is no good reason why spirometric testing cannot be widely implemented. On the con-side it is argued that peak expiratory How (PEF) has been dismissed by national and international guidelines as an inappropriate test for the assessment of the impact of 
COPD, bur with poor evidence in support of this position. This seems shortsighted since PEF is a reliable and reproducible test and could contribute to the management of COPD in the short term and in support of spirometry. As a result of infection or in response to treatment there may be changes in airway calibre in COPD which could be captured in the consultation by PEF. In a primary care setting spirometry is too time consuming and complex to be provided in the context of normal acute consulting. Furthermore there is no evidence that spirometry provides more information than PEF in the day-to-day management of a patient already diagnosed with COPD using forced expiratory volume in the first second/ forced vital capacity (FEV/FVC).

Primary care teams should ensure that their patients have adequate access to high quality spirometry. This can be provided in primary care or in local centres or in hospitals depending on the interest, motivation and resources of primary care teams. In support of spirometry general practitioners ( $G \mathbb{P}^{\prime}$ s) could then consider using PEF in the day-to-day management of COPD. In addition, the application of non-invasive oxygen saturation measurement deserves further research.

\section{Chapter 4}

The aim of the study presented in Chapter 4 is to reveal what inflammatory patterns prevail in clinically established diagnosis groups, and what factors are associated with sputum eosinophilia, the most probable target for treatment. Although both smoking and respiratory complaints are very common, tools to improve diagnostic accuracy are scarce in primary care. Induced sputum and blood plasma of 59 primary care patients with COPD $(n=17)$, asthma $(n=11)$, chronic bronchiris $(\mathrm{CB}, \mathrm{n}=14)$ and smokers with no respiratory complaints ('healthy smokers', $n=17$ ) were collected, as well as lung function, smoking history and clinical work-up. Patterns of inflammatory markers per clinical diagnosis and factors associated with eosinophilia were analyzed by multiple regression analyses; the differences expressed in odds ratios (OR) with $95 \%$ confidence intervals. The results immply that COPD was univariately associated with sputum neurrophilia, raised levels of the chemokine interleukin- $8(I L-8)$ and the soluble tumor necrosis factorteceptors R55 and R75 ( $5 T$ NF-R55 and STNF-R75) in sputum and plasma, while lipopolysaccharide binding protein (LB P) was only raised in plasma. Healthy smokers (HS) showed a relatively lowered LBP in plasma, but no other significant relations. Asthmatics showed a posirive association with sputum eosinophilia, and inversely with neutrophils in sputum, while patients with chronic bronchitis showed raised levels of sputum lymphocytes and lower levels of ST NF-R55 and STN F-R75 in plasma. Multivariately, COPD remained significantly associated with taised 
plasma-LBP (OR 1.2 [1.04-1.37]) and STNF-R55 in sputum (OR I.Or [1.0or1.OI]), while HS expressed significantly lowered plasma-L B P (OR 0.8 [0.72-0.95]). Asthma was characterized by higher sputum eosinophilic counts (OR 1.3 [1.05-1.54]); while $C B$ showed significantly higher lymphocytic sputum counts (OR I.5 [1.12-1.9]). Clinically, sputum eosinophilia was significantly associated with reversibility after adjusting for smoking, lung function, age, gender and allergy. It is concluded that clinical diagnoses were largely distinguishable on the basis of a panel of inflammatory markers in sputum and blood plasma. Multivariately, a smaller set of potential biomarkers remained significantly associated, which opens the possibility to test predictive values of these markers in larger prospective populations. Sputum eosinophilia remained significantly associated with reversibility across the spectrum of respiratory disease, while other clinical characteristics were not.

\section{Chapter 5}

The study presented in Chapter 5 assesses the utility of the oral prednisolone test in predicting the effectiveness of inhaled fluticasone relative to placebo in terms of exacerbations, heallth status (CRQ) and post-bronchodilator forced expiratory wollume in one second $\left(\mathrm{FEV}_{\mathrm{f}}\right)$. The oral prednisolone test is widely used to distinguish COPD-patients who might benefit from inhaled steroid treatment. Previous studies used selected parient groups not representing the large COPD-population in primary care. The study included 286 primary care $C O P D$-patients who underwent prednisolone testing ( 14 days $30 \mathrm{mg}$ ) before randomisation in a 3-year follow-up randomised clinical trial (CoOPT-Study). Spirometry was performed before and after the test to international criteria. The results show that 9 to $16 \%$ of the COPD-population was classified as responder, depending on criteria used. Responders according to the former E RS-criteria experienced a significant effect of inhaled Auticasone on heal th status ( 0.29 points $\left./ y r_{,}, p=0,05\right)$. Possible clinically relevant reductions in exacerbation rate (rate-ratio 0.67 ) and FEV decline $(39 \mathrm{ml} / \mathrm{yr}$ ) occurred in both ERS and B'TS-responders, bur did not reach statistical significance. It is concluded that prednisolone testing may distinguish COPD patients that benefit from inhaled steroid treatment in terms of health status. Test responders may also exhibit possible relevant effects on exacerbation rate and lung function decline.

\section{Chapter 6}

In Chapter 6 we aim to reveal associations of depressive symptoms with demographic and clinical characteristics in mild to moderate COPD. It Jas 
been suggested that severe COPD is associated with depressive symptoms, possibly linked to exacerbations, dyspnea and hospitalisation. Scarce data are available in primary care where most parients suffer from mild or moderate disease. Cross-sectional data on lung function measurements, exacerbation frequency, dyspnea, comorbidity, smoking behaviour, body mass index (BMI), age, gender and depressive symptoms (Beck Depression Inventory) of 147 primary care patients were assessed in mulriple logistic regression analyses. Patients in this study suffered from mild to moderate obstruction ( $\mathrm{FEV}_{1} 63.6 \%$ pred, range $45.1 \%$ to $82 . \mathrm{r} \%$ ), which is typical for primary care. Results reveal that female gender ( $O R 4.8 \mathrm{CI} 2.1$ to 10.8 ), $\mathrm{BMI}>2.5$ (OR $0.4 \mathrm{CI} 0.2$ to 0.8 ) and current smoking (OR $2.3 \mathrm{CI}$ I.OI to 5.3) were univariately associated with depressive symptoms, while in a multivariate logistic model only female gender (OR $4.0 \mathrm{Cr} x .6$ to 9.9 ), BMI $>25$ (OR $0.3 \mathrm{CI}$ O.I to 0.7 ) and dyspnea (OR I.8 CI I.I to 2.9) remained independently associated with depressive symptoms. These data suggest that in primary care, depressive symptoms in COPD seem to be related with female gender, BMI and dyspnea. In this study, lung function, exacerbation rate, smoking behaviour, age and comorbidity are not independently associated with depressive symptoms in COPD of mild to moderate severity.

\section{PART TWO: TREATMENT}

\section{Chapter 7}

Chapter 7 presents the results of a meta-analysis on the effects of physical exercise training in mild to moderate COPD. Pulmonary rehabilitation has become an evidence-based treatment in patients with severe COPD. In primary care however, large numbers of patients suffer from mild to moderate COPD, receiwing treatment from their GPS. We performed a literature search on the effects of physical activity in patients with mild to moderate COPD on exercise tolerance, dyspnea and quality of life (QOL). In addition, we looked for number of hospitalisation days and number of exacerbations, expressed as oral prednisolone courses. The literature search included Medline, Embase, and the Cochrane Library. All hits were screened on subject and language; abstracts were selected on the basis of a protocol including disease severity, hypothesis, outcome parameters and control group. Review articles on physical exercise and COPD were examined and reference lists of selected articles were screened for relevant studies. The broad literature search generated 4968 articles" after exclusion on title and abstract 35 original studies and 27 review articles were analysed. Of these, 5 original studies fitred the criteria, and none of the review articles was selected. A positive influence of physical activity on exercise tolerance in 
mild to moderate COPD was reported in 4 out of 5 studies. There was no clear effect on dyspnea or QOL, probably because of low numbers of subjects. No studies were included addressing number of hospitalisation days. or prednisolone courses as outcomes. It is concluded that physical exercise training (usually as patt of a package of rehabilitation) can improwe the fitness of patients with mild or moderate COPD, but has not been shown to significantly benefit QOL or dyspnoea (or long term disease progression).

\section{Chapter 8}

In this Chapter, the results of a 3 -year randomised double dummy placebo controlled clinical trial in 44 general practices in the Netherlands are presented. Increased oxidarive stress and bronchial inflammation are important mechanisms in the pathophysiology of chronic obstructive pulmonary disease (COPD). Inhaled corticosteroids and the anti-oxidative agent $N$-acetylcysteine are both considered to be pharmacotherapeutic options that may ameliorate the course of COPD. We investigated whether treatment with $N$-acerylcysteine or the inhaled corticosteroid fluticasone propionate would improve respiratory health status or reduce the yearly exacerbation rate in $\left(\mathrm{ex}^{-}\right)$smokers with chronic bronchitis or COPD in general practice. The trial was preceded by a 3 -month washout period for the effects of withdrawal of inhaled corticosteroids and/or $N$-acetylcysteine treatment and/or smoking cessation, and a subsequent 2-week $30 \mathrm{milli}$ grams oral prednisolone pre-treatment. 286 patients with chronic bronchitis or COPD were randomly allocated to receive 600 milligrams oral $N$-acetylcysteine once daily, inhaled fluticasone propionate 500 micrograms twice daily, or placebo. Parients were followed for 3 years. Primary outcomes were the respiratory health status measured with the Chronic Respiratory Questionnaire (CRQ), and the yearly rate of exacerbations. Secondary outcomes were the yearly decline in forced expiratory wolume in $\mathrm{I} S(\mathrm{FEV}$ ) and forced vital capacity (FVC), respiratory symptoms and time to study dropout. Analysis was on the basis of intention to treat. The results showed that the overall drop-out rate was $43 \%$. No differences between the treatment groups existed in terms of rates or causes of dropout. The course of the CRQ total score did not differ between $N$-aceryll cysteine $(p=0.306)$ or fluticasone propionate $(p=0.58 \mathrm{r})$ compared with placebo. The exacerbation rate was 1.35 times higher for $N$-acetylcysteine $(p=0.054)$ and 1.30 times higher for Huticasone propionate $(p=0.095)$ compared with placebo. The yearly post-bronchodilator $\mathrm{FEV}$, decline was $64 \mathrm{~mL}$ [SD 5.4] for $N$-acetylcysteine $[\mathrm{p}=0.569$ versus placebo], $59 \mathrm{~mL}$ [SD 5.7, ] for fluticasone propionate $[p=0.935]$, and $60 \mathrm{~mL}[\mathrm{SD} 5.4$,] for placebo. No treatment effects on respitatory symptoms were observed. Therefore, we concluded that we could not establish beneficial treatment effects for either oral $N$ - 
acetylcysteine or high-dosed inhaled futicasone propionate in adult patients with chronic bronchiris or mild to moderate COPD recruited in general practice. Subgroup analysis of our hererogeneous patient population may reveal differential treatment effects for $N$-acetylcysteine or Auticasone propionate.

\section{Chapter 9}

There is a great need to identify subgroups within the large primary care COPD-population that may benefit from inhaled steroid or anti-oxidant therapy. Studies so far have shown some benefits in patients with severe COPD and frequent exacerbations, but these represent a minority in primary care. In Chapter 9 the results of an analysis of determinants of treatments success or failure in primuary care COPD-patients are presented. We postulated relevant subgroups based on exacerbations, lungfunction, reversibility, smoking behaviour and gender. The cOOPT-study randomised 286 primary care COPD patients (mean $\mathrm{FEV}_{1}$ postBD $66 \%$ ) to receive inhaled fluticasone propionate (FLU), oral $N$-acetylcysteine (NAC) or placebo (Pla) during three years. Main outcomes were exacerbations, health status (CRQ) and post-BD FEV . Repeated measurements analysis was performed. The results revealed that $\mathrm{NAC}$ showed a prophylactic effect $(-15 \%$ 。 relative ratio 0.43 ) on exacerbations in the highest quartile of packyears, but negative effects on health status $(-0.23$ points/yr) in patients with reversibility, and on $\mathrm{FEV}_{\mathrm{I}}$ in former smokers $(-3 \mathrm{rml} / \mathrm{yr})$. FLU showed a positive effect on health status ( +0.27 points/yr) in moderate versus severe COPD, but a negative effect on $\mathrm{FEV}_{1}$ in females versus males $(-37 \mathrm{ml} / \mathrm{yr})$. It is concluded that with in the heterogeneous primary care COPD population we identified clinically relevant characteristics. For treatment with FLU or NAC it is important that some patients may benefit while others might not, apparently depending on determinants of lungfunction including reversibility, smoking behaviour and gender.

\section{Chapter ro: General Discussion}

This complex and increasingly prevalent disease is in need of an integrated team effort, a need that only becomes more urgent towards the endstages of the disease. Communicaring viewpoints across levels of care in an carlier stage can lead to useful results on both sides. In addition, the role of the patient as a critical factor in achieving success should be recognized, and emphasis should be laid on targeted education and shared responsibility. The reasons why COPD patients do consult their heal th care providers are often unknown, while not consulting in case of exacerbations is common. Within the context of a primary care team, early treatment using patient- 
administered Exacerbation Rapid Action Plans could be initiated and monitored closely; the effectiveness of such plans is currenty under study. Probably, the mainstay of COPD-treatment will continue to be maximal bronchodilation, combined with mullidisciplinary reactivation programs. Inhaled corticosteroids and antioxidant treatment for the whole group of mild to moderate COPD cannot be recommended. Smoking cessation and self-management are important but difficult to achieve lifestyle interventions, which may benefit from the wholesome effects of the first two interventions, like a crowbar breaking into the vicious cycle of decondirioning and social deprivation. In practice, COPD-patients have become accustomed to a slow but unstoppable decline in health status; when reactivation puts a halt to that process, many patients express a sometimes long-forgotten enthusiasm. Seizing that moment of change is the challenge of the multidisciplinary team, and will largely determine the long-term effects of any programme. In addition, distinct patient groups that can readily be detected in primary care on the basis of history taking, lungfunction and response to prednisolone resting, may benefit from inhaled steroids or oral $N$-acetylcysteine. Different phenotypes can be distinguished on the basis of these relatively simple parameters, which are available in primary care. Current guidelines should therefore continue to emphasise the importance of these parameters, endorsing primary care providers to achieve a proper clinical diagnosis and enabling a tailored treatment strategy. Future research into the effect modifying factors of treatment success in different phenotypes and their underlying inflammatory patterns is still needed in order to tailor treatment strategies further. 
Samenvatting 
- 


\section{Hoofdstuk r: Inleiding}

In de inleiding wordt een overzicht van geïntegreetde zorg voor chronische obstructieve longziekte (COPD) gegeven, dat betrekking heeft op de patiënt en een team van eerstelijns klinische professionals, in samenwerking met de tweede lijn en de revalidatiezorg. Optimale geintegreerde zorg komt neer op het herinrichten van de standaard medische zorg, door elementen van revalidatie, patiënten-zelfmanagement en dagelijkse activiteit in het zorgplan in te bouwen. "Case finding" is een simpele en effectieve aanpak om de diagnose van COPD in de eerste lijn te vergemakkelijken, terwijl de toepassing van spirometrie in de huisartspraktijk wordt aanbevolen om luchrwegobstructic aan te tonen en stoproken-programma's te faciliteren. De diagnose 'COPD' wordt gesteld op basis van spiromerrie, wat kan worden uitgevoerd in de eerste lijn mits personeel specifiek wordt getraind en kwaliteitsborging wordt gehandhaaft. Verlies van condirie, bijkomende ziektes en tekenen wan depressie komen vaak woor bij cop D. Zelfs bij patiënten met mild COPD kan de kwaliteit van leven substantieel zijn aangetast. De meerderheid van de opHakkeringen van COPD wordt in de thuissituatie doorgemaakt door de patiënt of behandeld door de huisarts. Circa 50\% van de opflakkeringen van COPD wordt echter niet gemeld. Patiënten met COPD zouden zich daarom meer bewust moeten zijn van de eerste tekenen van een opflakkering, en worden aangemoedigd om deze te melden aan het eerstelijns team. Tegelijkertijd zouden behandelaars beter gebruik moeten maken van de ervaringen van de individuele patiënt en navraag moeten doen naar de eerste tekenen van opflakkeringen uit het verleden. In de meeste gevallen moeten korte stootkuren van oraal prednison worden gegeven bij de eerste tekenen van een opflakkering. Eerstelijns teams bieden de meeste professionele zorg aan patiënten die de laatste levensfase hebben bereikt. Een interactief stroomschema voor geïntegreerde COPD-zorg wordt geïntroduceerd. Dit hoofdstuk werd elektronisch gepubliceerd als onderdeel van de internationale ATS/ERS Richtijn voor Diagnose en Behandeling van COPD. 


\section{DEEL I: DIAGNOSE}

\section{Hoofdstuk 2}

Dit hoofdstuk handelt over de prestaties van getrainde huisartsen in het stellen van een spirometrische diagnose, vergeleken met een consensus panel van experts. Tevens wordt de invloed van spirometrie op de besluitvorming van de huisartsen gemeten. Spirometrie wordt in toenemende mate toegepast in de huisartspraktijk, terwijl een goede interpretatie van flowvolume $(\mathrm{F}-\mathrm{V})$ curves door huisartsen in twijfel wordt getrokken. Tevens is de rol van spirometrie in het besluitvormingsproces van de huisarts nauwelijks bestudeerd. Twaalf casus die een breed scala aan F-V curves besloegen, werden geïnterpreteerd door 39 huisartsen en door het consensus expertpanel. Diagnostische test-karakteristieken werden berekend door middel van multi-level analyse en samengevat in diagnostische odds ratio's ( $D O R$ ). Verschillen tussen besluitvormings-indicatoren werden uirgedrukt in odds ratio's en $95 \%$ betrouwbaarheidsintervallen. De resultaten laten zien dat de normale F-V curves (DOR 65.0) en obstructieve F-V curves (DOR 48.9) redelijk tor goed werden gediagnosticeerd door de huisartsen, terwijl de zeldzamere en gemengde pathologische patronen duidelijk slechter werden gescoord (DOR 3.8). Tussenliggende scores werden bereikt in de herkenning van onjuist geblazen curves (DOR 24.4). Spirometrie beïnloedde het besluitvormingsproces van de huisartsen door een vermindering van het antal alternatieve diagnoses (OR $0.27[0.20,0.35]$ ), maar ook een verhoogd aantal verwijzingen $(7.26[4.7 \mathrm{r}, 1 \mathrm{I} .2])$ en gebruik van diagnostische prednisonkuren $(4.55[3.12,6.64])$. Er wordt geconcludeerd dat getrainde huisartsen in staat zijn tot het differentiëren tussen normale en obstructieve ziekrepatronen, maar dat F-V curves suggestief voor zeldzamere of gemengde pathologie valk worden gemist. Spirometrie lijkt her besluirvormingsproces van de huisarts te beinvloeden; of dit een tijdelijk of blijwend effect is moet blijken uit studies in de dagelijkse praktijlk.

\section{Hoofdstuk 3}

In dit hoofdstuk wordt een pro-con serie gepresenteerd, met betrekking tot het gebruik van spirometrie versus peakflow in het disease management van COPD. Aan de pro-zijde wordt beargumenteerd dat spirometrie ons een unieke en niet-invasieve kijk gunt in het functioneren van de longen, wat zowel medisch informatief als praktisch nuttig kan zijn. Luchtwegklachten behoren tot de meest voorkomende klachten in de eerste lijn, terwijl roken wereldwijd nog steeds veel vóókomt, wat de noodzaak illustreer van goede instrumenten om de mogelijke oorzaken van chronische luchtwegklachten te achterhalen. Stoproken programma's en disease ma- 
nagement programma”s zijn de COPD-behandelings-strategieën van voorkeur; deze zijn gestoeld op een valide spirometrische diagnose, zoals wordt gepropageerd door internationale COPD richtlijnen. Daarnaast kan het berrekken wan de patiënt in het zorgplan en het geven van voorlichting ower de verwoestende effecten van roken uirstekend worden gefaciliteend door de visuelle indruk van een flow-volume curve. Bewijs is woorhanden dat spirometrie een valide, toepasbaar en interpreteerbaar diagnostisch instrument is in de eerstelijns setting, mits kwaliteitswaarborgen van uitvoering en training voldoende worden gehandhaafd. COPD vertegenwoordigt een groeiend maatschappelijk probleem, dat niet mag worden onderschat. Bij voldoende financiering, adekwate training en gemotiveerde hulpverleners, is er geen goede reden waarom spirometrie niet op brede schaal kan worden toegepast. Aan de con-zijde wordt beargumenteerd dat peak expiratory flow (PEF) ten onrechte is afgewezen door nationale en internationale richtlijnen, als zijnde een incorrecte rest woor de beoordeling van de ernst van COPD. Er zou echter slechts mager bewijs zijn voor deze stelling, want PEF is een betrouwbare en reproduceerbare test, en zou kunnen bijdragen aan het acute management van $C O P D$, ter ondersteuning van spirometrie. Door infectie of als reactie op behandeling kunnen er veranderingen optreden in het luchtweg kaliber bij COPD, wat zou kunnen worden gemeten met behulp van PEF. In de eerstelijns setting neemt spirometrie teveel tijd in beslag en is te complex om te worden toegepast in de acute situatie van een opflakkering van luchtwegklachten. Daarnaast is er geen bewijs dat spirometrie meer informatie verschaft dan PEF in her dagelijkse management van een COPD-patiënt die reeds gediagnosticeerd is door middel van geforceed expiratoir volume in de eerste seconde/ geforceerde vitale capaciteit ( $\mathrm{FEV}_{\mathrm{I}} / \mathrm{FVC}$ ).

Eerstelijns teams zouden moeten warborgen dat hun patiënten daadwerkelijk toegang hebben tot hoge kwaliteits spirometrie. Dit kan worden geleverd in de eerste lijn, in lokale diagnostische centra of in ziekenhuizen, afhankelijk van het gestelde belang, de motivarie en de middelen van eerstelijns teams. Ter ondersteuning van spirometrie zouden huisartsen PEF kunnen overwegen in her dagelijks management van COPD. Daarnaast verdient de eerstelijns toepassing van de non-invasieve perifere zuurstofsaturatie-meting verder onderzoek.

\section{Hoofdstuk 4}

Het doel van de studie in Hoofdstuk 4 is duidelijkheid te scheppen in welke onderliggende ontstekingsprocessen samenhangen met veclvoorkomende klinische diagnosegroepen, en welke factoren samenhangen met eosinofiele inflammatie, het meest waarschijnlijke therapeutisch aangrijpingspunt. Ondanks het frequent voorkomen van zowel roken als lucht- 
wegklachten, zijn er in de eerste lijn maar weinig instrumenten beschikbaat om een juiste diagnose bij respiratoire klachten te stellen. Geïnduceerd sputum en bloedplasma van 59 eerstelijns pariënten mer COPD $(n=17)$, astma $(n=11)$, chronische bronchitis $(C B, n=14)$ en rokers zonder luch wegklachten ('gezonde rokers', $n=17$ ) werden werzameld, naast de longfunctie, rookhistorie en anamnese. Patronen van inflammatoire markers, uitgesplitst naar klinische diagnose en factoren die geassocieerd waren met eosinofilie werden geanalyseerd met behulp wan multipele logistiche regressie; de verschillen werden uitgedrukt in odds ratio's (OR) met $95 \%$ betrouwbaarheidsinterwallen. De resultaten impliceren dat COPD univariaat is geassocieerd met neutrofielen in het sputum, verhoogde niveaus van de chemokine interleukine-8 (IL-8) en de oplosbare tumor necrose factor receptoren R55 en $\mathbb{R} 75$ ( $S T$ TNF-R 55 en ST NF-R75) in sputum en bloedplasma, terwijl het lipopolysaccharide bindend eiwit (LBP) slechts werhoogd was in bloedplasma. 'Gezonde rokers' vertoonden een relatief verlaagd LBP in bloedplasma, maar geen andere significante relaties. Astmatici vertoonden een positieve associatie met eosinofielen in sputum, en een negatieve associatie met neutrofielen in sputum. Patienten met chronische bronchitis onderscheidden zich door verhoogde niveaus van lymfocyten in her sputum, en verlaagde niveaus van STNF-R55 en STNF-R75 in bloedplasma. Multivariaar bleef COPD significant geassocieerd met een verhoogd LBP in bloedplasma (OR 1.2 [1.04-1.37]) en STNF-R55 in sputum (OR I.OI [I.OOr-1.or]), terwijl 'gezonde rokers" significant lagere LB P-waarden in bloedplasma vertoonden (OR 0.8 [0.72-0.95]). Astma werd gekarakteriseerd door hogere eosinofielen in sputum (OR I.3 [1.05-I.54]); rerwijl $C B$-patienten significant hogere lymfocyten in sputum vertoonden (OR 1.5 [1.12-1.9]). Eosinofilie in sputum bleef significant geassocieerd met reversibiliteit, na correctie voor roken, longfunctie, leeftijd, geslacht en allergie. Er wordt geconcludeerd dat klinische diagnoses grotendeels terug zijn te voeren op een set van ontstekingsmarkers in sputum en bloed plasma. Multivariaat blijft een kleinere set van potentiële biomarkers significant geassocieerd met klinische diagnoses, hetgeen mogelijkheden biedt om voorspellende waardes te testen in een grotere prospectieve populatie. Sputum eosinofilie blijft significant geassocieerd met bronchodilatoire reversibiliteit over het spectrum van luchtwegobstructie, terwijl dit niet voor de andere klinische karakteristieken geldt.

\section{Hoofdstuk s}

De studie die wordt gepresenteerd in Hoofdstuk 5 behandelt de toepassing van de orale prednisontest als voorspeller van de effectiviteit van geïhaleerd Aluticason ten opzichte van placebo, uitgedrukt in opflakkeringen, kwaliteit van leven (gemeten met de CRQ-vragenlijst) en longfunctie 
$\left(\mathrm{FEV}_{\mathrm{i}}\right)$. De orale prednisontest wordt veel gebruikt om COPD-patienten te detecteren die baat zouden hebben bij behandeling met inhalatiesteroïden. De test is echter nooit gevalideerd in de eerste lijn. Eerdere studies hebben gebruik gemaakt wan sterk geselecteerde patiëntenpopulaties die niet de grote eerstelijns COPD-populatie representeerden. Deze studie includeerde 286 eerstelijns COPD-patiēnten die vóór randomisatie de prednisontest ondergingen ( $\mathrm{I}_{4}$ dagen $30 \mathrm{mg}$ ), waarna deelname wolgde aan een driejarige gerandomiseerde klinische trial (COOPT-Studie). Spirometrie werd voor en na de prednisontest verricht; responders en non-responders werden geclassificeerd volgens internationale criteria. De resultaten laten zien dat 9 tot $16 \%$ van de COPD-populatie werd geclassificeerd als responder, afhankelijk van de gebruikte criteria. Responders volgens de voormalige ERS-criteria ervoeren significante effecten van geünhaleerd Auticason op kwaliteit van leven ( 0.29 punten/jaar, $\mathrm{p}=0.05)$. Mogelijk klinisch. relevante verminderingen in exacerbatie-frequentie (rare-rario 0.67 ) en

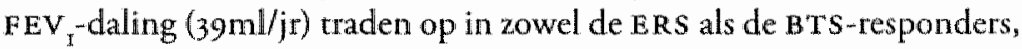
maar bereikten geen statistische significantie. Er wordt geconcludeerd dat de prednisontest COPD-patiënten zou kunnen onderscheiden die baat hebben bij inhalatiesteroïden wat betreft de kwaliteit van leven. Prednisontest-responders zouden tevens mogelijk rellevante effecten op exacerbatiefrequentie en longfunctieverlies kunnen ervaren.

\section{Hoofdstuk 6}

In Hoofdstuk 6 richten we ons op de mogelijke associaties van depressieve symptomen met demografische en klinische kenmerken van eerstelijns COPD-patiënten. In de literatuur wordt gesuggereerd dat ernstig COPD is geassocieerd met depressie, mogelijk in samenhang met opflakkeringen, kortademigheid en ziekenhuisopnamen. Spaarzame gegevens zijin beschikbaar in de eerste lijn, waar de meeste patiënten eerder mild tot matig COPD hebben. Cross-sectionele gegevens over de longfuncrie, optakkeringen, kortademigheid, bijkomende ziekten, rookhistorie, body mass index (BMI), leefrijd, geslacht en depressieve symptomen (Beck Depression Inventory (BDI)) van 147 eerstelijns COPD-patiënten werden geanalyseerd met behulp van multipele logistische regressie en uiggedrukt in odds ratio's (OR) met betrouwbaarheidsintervallen (BI). Patienten in deze studie hadden milde tor matig-ernstige obstructie ( $\mathrm{FEV}_{\mathrm{x}} 63.6 \%$ voorspeld, range $45.1 \%$ tot $82.1 \%$ ), wat representatief is voor de ecrste lijn. De resultaten laten zien dat vrouwelijk geslacht (OR $4.8, \mathrm{BI}$ 2.I tot 10.8 ), B MI $>25$ (OR $0.4 \times$ BI 0.2 tot 0.8 ) en huidig roken (OR 2.3, BI 1.Or tot 5.3) een univariate associatie vertoonden met depressieve symptomen, terwijl in een mulcivariaat logistisch model vrouwelijk geslacht (OR 4.0, BI I.6 tot 9.9), BMI $>25$ (OR 0.3 BI 0.1 tot 0.7) en kortademigheid (OR 1.8, CI 1.1 to 2.9) 
onathankellik geassocieerd waren met depressieve symptomen. Interessant is dat cen verhoogde B MI juist geassocieerd lijkt te zijn met minder depressieve symptomen. Deze data suggereren dat depressieve symptomen bij eerstelijns COPD-patiënten lijken samen te hangen met vrouwelijk geslacht, B MI en kortademigheid. In deze studie waren longfunctie, opflakkeringen, rookgedrag, leeftijd en bijkomende ziekten niet onafhankelijk geassocieerd met depressieve symptomen bij mild tot matig COPD.

\section{DEEL 2: BEHANDELING}

\section{Hoofdstuk 7}

In Hoofdstuk 7 worden de resultaten gepresenteerd van een meta-analyse naar de effecten van inspanningstraining bij mild tot matig COPD. Longrevalidatie is inmiddels een evidence-based behandeling bij ernstig COPD, maar in de eerste lijn hebben grote aantallen patiënten juist last van mild tot matig COPD, en worden daar door hun huisarts voor behandeld. We verrichtten een literatuuronderzoek naar de effecten van lichamelijke inspanning bij patiënten met mild tot matig COPD op de inspanningstolerantie, kortademigheid en kwaliteit van leven. Daarnaast keken we naar aantallen ziekenhuisopnamen en exacerbaties (opHakkeringen), uitgedrukt in aantallen prednisonkuren. Het literatuuronderzoek besloeg de databanken van Medline, Embase, en The Cochrane Library. De resultaten werden gescreend op taal en onderwerp; samenvattingen werden gesellecteerd op basis van een protocol waarin de ernst van de aandoening, hypothese, uitkomstmaten en controlegroep werden omschreven. Overzichtsartikelen met betrekking tot inspanningstraining en referentielijsten van geselecteerde artikelen werden nagezocht om alle relevante studies te traceren. De brede zoekopdracht genereerde 4968 artikelen; na exclusie op titel en samenvatting bleven 35 originele studies en 27 overzichrsartikelen over voor analyse. Van deze selectie voldeden slechts 5 originele studies aan de criteria, en geen van de overzichtsartikelen. De resultaten lieten zien dat in 4 van de 5 studies een positief effect van inspanningstraining op inspanningstolerantie bij mild tot matig COPD werd beschreven. Er was echter geen duidelijk effect op kortademigheid of kwaliteit van leven, mogelijk door de lage aantallen deelnemers. Er werden geen studies geïncludeerd die het aantal ziekenhuisopnamen of prednisonkuren als uitkomstmaat hanteerden. Er word geconludeerd dar inspanningstraining (meestal als onderdeel van revalidatie) de fitheid van patiënten met mild tot matig COPD kan verbeteren. Er wordt echter nog geen bewijs gevonden voor effecten op kwaliteit van leven of kortademigheid (of langetermijns ziektebeloop). 


\section{Hoofdstuk 8}

In dit hoofdstuk worden de resultaten van een 3 -jarige gerandomiseerde dubbel-dummy, placebo-gecontroleerde, klinische trial in 44 Nederlandse huisartspraktijken gepresenteerd. Toegenomen oxidatieve stress en bronchiale inflammatie zijn belangrijke mechanismen in de pathofysiologie van chronisch obstructieve longziekte (COPD). Inhalatiesteroiden en het antioxidant $N$-acetylcysteine worden beschouwd als farmacotherapeutische opties die het beloop van COPD gunstig zouden kunnen beïnloeden. We onderzochten of behandeling met $N$-acetylcysteine of het in halaticcorticosteroïd futicason propionaat de kwaliteit van leven of de jaarlijkse exacerbatiefrequentie verbeterden onder (ex) rokers met chronische bronchitis of COPD in de huisartspraktijk. De studie werd voorafgegaan door een drie maanden durende uitwas-periode om te kunnen stoppen met enige bestaande behandeling mer inhalatiesteroïden of $N$-acetylcysteine, of te stoppen met roken. Daaropvolgend werd bij alle deehnemers de orale prednisontest uitegvoerd ( 2 weken 30 milligram). Her lot bepaalde vervolgens in welke behandelgroep de 286 patienten met chronische bronchitis of COPD terecht kwamen: 600 milligram oraal $N$-acetylcysteïne eenmaal daags, 500 microgram geïnhaleerd fluticason propionaat tweemaal daags, of placebo. Patiënten werden gedurende 3 jaar behandeld. Primaire uitkomsten waren de COPD-specifieke kwaliteit van leven, zoals gemeten met de Chronic Respiratory Questionnaire (CRQ), en de jaarlijkse frequentie van exacerbaties (opllakkeringen). Secundaire uitkomsten waren de jaarlijkse achteruitgang van het geforceerde expiratoire volume in $\mathbf{I}$ seconde $\left(\mathrm{FEV}_{\mathrm{I}}\right.$ ) en de geforceerde vitale capaciteit (FVC), luch twegsymptomen en de tijd tot studie-uitval. De analyse vond plaats op basis van het principe van "intention to treat". De resultaten lieten zien dat de totale studie-uitval $43 \%$ bedroeg. Er traden geen verschillen tussen de behandelingsgroepen op met betrekking tot vórkomen of oorzak van uirval. Hev beloop van de CRQ-totaalscore verschilde niet tussen $N$-acerylcysteine $(p=0.306)$ of fluticason propionaat $(p=0.581)$ vergeleken met placebo. De exacerbatiefrequentie was 1.35 maal hoger bij $N$-acetyloysteine $(p=0.054$ ) en 1.30 maal hoger bij futicason propionat $(p=0.095)$ vergeleken met placebo. De jaarlijkse post-bronchodilatoire $\mathrm{FEV}_{\mathbb{\pi}}$-daling bedroeg $64 \mathrm{~mL}$ [SD $5.4]$ bij $N$-acerylcysteïne $[\mathrm{p}=0.569$ versus placebo]. $59 \mathrm{~mL}[\mathrm{SD} 5.7$. ] bij fluticason propionat $[\mathrm{p}=0.935]$, en $60 \mathrm{~mL}[\mathrm{SD} 5.4$,$] bij placebo. Er werden$ geen effecten op luchrwegsymptomen gexien. We concluderen dat we niet een gunstig effect hebben kunnen vaststellen wan behandeling met oraal $N$-acetylcysteine of hooggedoseerd geïnhaleerd Auticason propionaat bij volwassen patiënten met chronische bronchitis of mill tor matig COPD, die werden gerecruteerd in de huisartspraktijk. Subgroep-analyses in onze heterogenene patiënten-populatie zijn aangewezen om mogelijke differen- 
viele behandelingseffecten van $N$-acetylcysteine of fluticason propionaat aan te tomen.

\section{Hoofdstuk 9}

Binnen de grote eerstelijns COPD-populatie is er behoefte aan de identifcatie van subgroepen, die baat zouden kunnen hebben bij inhalatiesteroiden of anti-oxidatieve therapie. Wetenschappelijke studies hebben tot zower aangetoond dat er effecten kunnen optreden bij patiënten met ernstig COPD en frequente exacerbaties (opflakkeringen), maar deze groep vormt slechts een minderheid in de eerstelijn. In Hoofdstuk 9 worden de resultaten gepresenteerd wan een determinanten-analyse van behandelings-succes of-falen bij eerstelijns COPD-patiënten. Vooraf postuleerden we relevante subgroepen, gebaseerd op exacerbaties, longfunctie, reversibiliteit op luchtwegverwijders, rookgedrag en geslacht. De COOPT-studie randomiseerde 286 cerstelijns COPD-patiënten (gemiddelde post-bronchodilatoire $\mathrm{FEV}_{1} 66 \%$ ) om gedurende drie jaar te worden behandeld met geïnhaleerd Aluticason propionaat (FLU), orale $N$-acetylcysteine (NAC) of placebo (Pla). De belangrijkste uitkomstmaten waren exacerbaties, de kwaliteit van

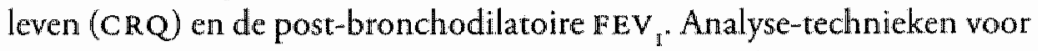
herhaalde metingen werden toegepast. De resultaten lieten zien dat NAC een beschermend effect had ( $-15 \%$, relatieve ratio 0.43 ) op exacerbaties in het hoogste kwartiel van packyears, maar negatieve effecten op kwaliteit van leven ( -0.23 punten/jr) bij patiënten met reversibiliteit, en op $\mathrm{FEV}$, bij voormalige rokers $(-3 \mathrm{mml} / \mathrm{jr})$. FLU vertoonde een positief effiect op kwaliteit van leven $(+0.27$ punten/jr) bij matig versus ernstig COPD, maar een negatief effect op FEV bij vrouwen versus mannen $(-37 \mathrm{ml} / \mathrm{jr})$. We concluderen dat er binnen de heterogene eerstelijns COPD-populatie klinisch relevante kenmerken kunnen worden onderscheiden. Voor de behandeling met FLU of NAC is het van belang dat sommige patiẻnten wel en anderen niet baat zouden kunnen hebben bij medicatie, afhankelijk van determinanten van de longfunctie inclusief de reversibilieit, rookgedrag en geslacht.

\section{Hoofdstuk 10: Algemene Discussie}

Bij de behandeling van deze complexe en toenemend voorkomende ziekte is er behoefie aan een geintegreerde ream-aanpak, een behoefte die alleen groter wordt naarmate de eindfase van de ziekte in beeld komt. Het communiceren van standpunten over de schotten in de zorg kan leiden tot nuttige resultaten aan beide zijden. Bovendien zou de rol van de patiënt als bepalende succesfactor moeten worden erkend, en de nadruk zou meer moeten worden gelegd op specifieke voorlichting en gedeelde veranowoorde- 
lijkheid. De beweegredenen waarom COPD-patiënten hun hulpverleners consulteren zijn vaak onbekend, terwijl het niet zoeken van hulp bij opflakkeringen algemeen voorkomt. Binnen de context van het eerstelijns team zou vroege behandeling door middel van patiënt-afhankelijke Exacerbatie Actie Plannen kunnen worden opgestart en gemonitord; de effectiviteit van dergelijke plannen word momenteel onderzocht. Waarschijnlijk blijfr de hoeksteen van COPD-behandeling maximale bronchodilatatie, gecombineerd met multidisciplinaire reactivatie programma's. Geinhaleerde corticosteroïden en anti-oxidanten kunnen niet worden aanbevolen woor de gehele groep van mild tot matig COPD. Stoproken programma’s en zelfmanagement zijn belangrijke maar lastig te bereiken lifestyle veranderingen, die baat zouden kunnen hebben bij de resultaten van bovengenoemde twee interventies; door als een breekijzer de vicieuze cirkel van deconditionering en sociale deprivatie te doorbreken. In de praktijk zijn weel COPD-patiënten gewend geraakt aan een langzame maar onvermijdelijke achreruitgang van de kwaliteit van leven; als reactivatie dat proces tor staan brengt, overvalt menige patiënt een soms lang-vergeten enthousiasme. Dat moment van verandering vormt de kans voor het multidisciplinaire beliandelteam, en zal grotendeels de langetermijns effecten van het programma bepalen. Daarnaast zijn er beperkte patiëntengroepen die afgrensbaar zijn in de eerstelijn op basis van anamnese, longfunctie en respons op de prednisontest, die mogelijk baat hebben bij inhalatiesteroiden of oraal $\mathrm{N}$-acetylcysteïne. Verschillende fenotypen kunnen worden onderscheiden op basis van deze relatief simpele kenmerken, die beschikbaar zijn in de eerste lijn. Huidige richtlijnen zouden daarom het belang van deze kenmerken moeten bijven benadrukken, en hulpverleners ondersteunen bij het stellen van de juiste klinische diagnose en opstellen van een op maat gresneden behandelstrategie. Toekomstig onderzoek naar de effect-modiferende factoren van behandelsucces in verschillende fenotypes en onderliggende inflammatoire patronen is noodzakelijk om behandelstragieën verder aan te scherpen. 



\section{Dankwoord}

Exact zeven jaar geleden besloor ik - koud terug uit Brazilië - na enig wikken, wegen en ruggespraak met de achterban, de sprong in het diepe te wagen: voortaan zou ik door het leven gaan als arts in opleiding tot huisartsonderzoeker (AIOTHO). Afgezien van deze afko die opvallend vaak werd aangezien voor een oost-aziatisch merk laagverbruik-boodschappenwagen, verwachtre ik niet al te veel problemen; een glanzende toekomst in onderzoeksland lag te lonken. Maar zoals dat gaat met de echte keuze's in het leven: je weet niet waarvoor je kiest, dat merk je toch pas onderweg, proefondervindelijk, zeg maar. Zeven jaar van toch vrij hard werken, zelfs stug doorploeteren in periodes, onzekerheid over uitkomsten en financiering, conflicten over samenwerking en afstemming waren mijn deel, gelardeerd met een onverwacht sausje van erkenning, enkele internationale onderzoeksvrienden en zelfs enig inzicht in de materie. Het is maar waar je voor kiest. Ik ben bang dat al mijn collega's, vrienden, familie en vooral mijn vriendin voorgaande omschrijving op onderdelen zullen herkennen: dank zij hun gewillig luisterend oor, vaak tot vervel(l)ens aan toe, kon ik mij telkens weer losmaken van gedane zaken, en me vol goede moed richten op de noodzakelijke voortgang binnen de vreemde wereld die onderzoek nu eenmaal schept.

De tandem met de opleiding tot huisarts was daarom ook een welkome afwisseling: zat het tegen bij de onderzoekspoot, dan kon er weer afleiding worden gezocht bij probleemoplossing in de opleidingspraktijk, en vice versa. Her feit dat de opleiding daardoor over langere tijd werd uitgesmeerd betekende dat ik meerdere opleidingsgroepen heb mogen lastig vallen met ongeremd onderzoekersenthousiasme. Mijn dank aan al deze collega's is groot, en ook vol verbazing, dat de omgang met zo'n vreemde eend in de bijt eigenlijk altijd soepel is blijven verlopen. Niet in de laatste plaats heeft dat gelegen aan de flexibele houding van mijn begeleiders Henk Goetsch, Gerard Benthem, Maria Mulder en Gerrie Wagenaar, en de ruimhartige verantwoordelijken bij de huisartsopleiding Ywonne van Leeuwen en Paul Ram: her belang van die ietwat hypomane AIOTHO's stond bij jullie altijd buiten kijf, en dat was goed te voelen.

Huisartsgeneeskunde daarentegen is een niet minder vreemde wereld: het merendeel van de bevolking doet er zaken mee en ziet er ook het belang 
van in, maar de onderlinge diversiteit in aanpak en organisatie is enorm, de professionalisering vaak nog gaande, en vele vakbroeders hebben nog altijd het gevoel niet woor vol te worden aangezien. Onderzoek is daarom het vehikel bij uitstek om her vak blijvend op de kaart te zetten, en werkelijk serieus genomen te worden. Daarom ben ik de ruim honderd huisartsen die, ondanks de dagelijkse praktijk-hektiek, lange jaren aan zoiets abstracts als onderzoek hebben durwen meedoen, enorm erkentelijk. Het feir dat zij de grote impact van COPD inzagen en het ook aan wilden pakken, heeft ze denk ik veel waardering opgeleverd bij de vele patiënten die middels het onderzoek werden opgespoord. Maar wellicht ben ik hun assistenten en praktijkondersteuners nog meer erkentelijk, want ondanks hun vreselijk drukke dagindeling zijn zij meestal degenen geweest die de longfuncriemetingen uitwoerden, die bijhielden welke onderzoeksdeelnemers moesten worden opgeroepen, en welke al waren langs geweest. Voor de huisartsen en praktijkondersteuners die er nog mee door willen gaan: we starten vanuit de huisartsopleiding een geintegreerd COPD-programma warin vele geleerde lessen uit het onderzoek in de prakrijk zullen worden toegepast.

In één adem volgen de onmisbare collega's wan het onderzoeksteam, zowel in Nijmegen als Maastricht, die jarenlang de trein gaande hielden, ook als ik zonodig weer eens een stukje huisartsopleiding aan het woltooien was. Veel dank aan Annie Hendriks, Riet Cretier, Gita Siebers, Joke Grootens en Lea Peters. Ook mijn collega-onderzoeker Tjard Schermer, die al langer met de COOPT-studie bezig was en ook eerder dit jaar is gepromoveerd, ben ik veel dank verschuldigd. Zonder dit professionele team was mijn promotie werkelijk nooit mogelijk geweest.

Mijn promotores Onno van Schayck en Miel Wourers: dank voor de grote kansen en nieuwe inzichten die ik door jullie heb gekregen in de afgelopen jaren. Vaak enerverend, soms confronterend, is er toch een praktisch hybride resultaat unit voortgekomen: huisartsgeneeskunde met een respiratoire onderbouwing. Het is nu al te merken dat het een gat in de markt is.

Mijn co-promoton Jean Muris: voor rustig en zelfgevraagd advies kon ik altijd bij je terecht, en nog leuker was eigenlijk het samenwerken aan de ATs/E Rs Guidelines in Parijs, en het samen opzetten van diverse COP Dcursussen. Moeten we wooral blijwen doen!

Veel dank gaat uit nar mijn mede-AIOTHO's Marjolein de Vries, Parrick van Limpt, Katinka Prince, Loes van Bokhoven, Rogier Hopstaken, Roelf Norg, Annemiek Nijholt, Paul Houben en Wemke Veldhuizen: doordat we vooral in de begintijd veel leed met elkaar deelden was een en ander draaglijk, en over het algemeen erg leuk om op te reflecteren. I $\mathrm{k}$ ben eens 
benieuwd hoe onze 'eerste generatie' zich zal ontwikkelen in de komende jaren.

De andere collega's op de vakgroep en daarbuiten, met name de groep die bekend stond als "Thembi-gangers" was net zozeer onmisbaar, al was thet maar vanwege de eindeloze stof tot discussie over onderlinge verschillen en overeenkomsten, die naarmate de aantallen Belgische biertjes, bitterballen en single malts zich vermenigvuldigden, steeds meer gingen overlappen. IJmert, Tanja, Marjan, Marcus, Ludovic, Paul, Pierer, Mark, Lisette, Ute, Babette, Sjoerd, Raymond, Andy, en vele anderen bewijzen: inspiratie moet je laten borrelen!

Mijn nieuwe collega's en alle medewerkers van Gezondheidscentrum Zuiderkroon te Rotterdam; met name Michiel van Heel, Sandra Edixhoven, Robert Odekerken en Suzanne Jongerius, Petra van der Jagt en Alexandra Tigges, die zich telkens weer hebben moeten realiseren dat "niet op de praktijk' niet automatisch "vrij" betekent.. dank voor dat voorstellingsvermogen. Maar vooral: dank voor de geweldige prestatie om met z"n allen binnen zo'n korte tijd een prachtig en vooruitstrevend centrum neer te zetten in zo'n intensieve wijk. Ik denk dat we daar trots op mogen zijn, en het is een voorrecht om van zo'n fris en toch hecht ream deel uit te mogen maken.

Stichting Boog, in de persoon van directeur Rob Hartings, die als overkoepelende stichting drie gezondheidscentra in Rotterdam beheert, en innovatie van de eerste lijn hoog in het vaandel heeft staan. Het feit dat Boog onderzoek in de huisartspraktijk actief ondersteunt maakt mooie dingen mogelijk, en smaakt naar meer.

Mijn cerste opleidingsprakrijk te Beek, met name Herman van Rens, dic me enorm veel wertrouwen schonk en al doende vertrouwen genereerde, en nog steeds demonstreert hoe jarenlang enchousiasme kan leiden tot weer nieuwe motiwatie en blijvende interesse.

Mijn tweede opleidingspraktijk in Bocholtz, en dan vooral her gehele COPD-team, waar ik nog regelmatig bij aanschuif: dank voor jullie tomeloze inzet voor de Geintegreerd CoPD Management Studie. Ik kijk uit naar de eerste resultaten van volgend jaar!

Het Kroonluchterteam in Rotterdam: een lichtend voorbeeld in COPDland. 
Met dank aan Geert-Jan Dinant, opdat we nog veel lagdrempelig international onderzock en onderwijs mogen aanpakken.

Dank aan Samira Guerrouj en Paul de Vries: opdat we nog vele innovatieve nascholings-programma's mogen opzetten.

Veel dank aan Miriam Reeders en Saskia van Rheeden: war een gestroomlijnde samenwerking al niet toe kan leiden!

Dank aan Ine Siegelaer en Annemie Capellen, die op cruciaal-logistieke momenten altijd de helpende hand bieden.

Dank aan Ruud Vollenberg, Gabriëlle van de Graafen Ralf Bollen, voor de prettige samenwerking, destijds als haio-onderzoekers.

Veel dank aan Reinier Akkermans, voor de vele inzichtgevende momenten gedurende complexe analyses.

Veel dank aan Marjan van de Akker, voor de uiterst flexibele en effektieve manier van co-begeleiding van wetenschapsstages.

Dank aan Geertjan Wesseling en Juanita Vernooy, voor de transmurale sam menwerking op het gebied van inflammatie en geïntegreerde zorg.

Dank aan Wil van den Bosch en Bart Thoonen, woor hun progressieve enthousiasme voor het huisartsenvak, en opdat de differentiatie in de eerste lijn verder om zich heen moge grijpen.

Dank ook aan de (voormalige) wetenschapsstudenten Raph, Sander, Maaike en Marlous, die prachtig oorspronkelijk onderzoek werricht(t)en onder tropische onstandigheden.

My Brazilian and Chilean colleagues: Henrique Sá, Julio Penaforte, Ruben Gamboa and Ruy Souza, thanks for your relentless enthusiasm, and let's keep up the good work!

My colleagues from the $U K \mathrm{~K}$ and Scandinavia: Elise Austegard, Rachel Adams, Kevin Jones, Marianne Ostergaard, David Price, Mark Levy and Patrick White, let"s continue to put primary care research on the international agenda.

My American colleagues Brian Tiep, Suzanne Lareau, John Heffner and Antonio Anzueto: I'm looking forward to continue our fruitful cooperati- 
on in COPD disease management, ethical issues and exacerbations on both sides of the Arlantic.

My colleagues at wHo: Salah Ottmani and Robert Scherpbier, your determination inspired and enabled our Brazilian studies. Many thanks for that.

Many thanks to Bill MacNee and Bart Celli, for letting me participate in the ATS/ERS COPD Guideline Committee, which has beet an unforgettable experience, and will continue to be.

Mijn broers Ivar en Ole, wie weet kunnen we nou eindelijk weer eens een broederlijke vakantie plannen nat Odessa of Kamcharka. De grote stress is nu in ieder geval over.

Mijn ouders Ingebjørg en Arnour, jullie steun is altijd enorm geweest, en dankzij jullie niet-aflatende aandacht was ik altijd weer beter in staat om besluiten te nemen. Het begrip actief ontspannen komt denk ik ook uit jullie opvoedkundige koker, dus ga ik me naar jullie voorbeeld weer meer richten op sporten, muziek maken en reizen.

Ineke mijn lief, je was altijd de eerste die weer eens mocht vernemen van problemen of conflicten, en degene die het meest mocht meegenieten van brainstormen of luchtkastelen. Je oprechte aanwezigheid en reflectievermogen, maar ook het trekken van grenzen $z i j n$ voor mij onmisbaar geweest om dit werk te kunnen voltooien, en er tevens de grap van in te blijven zien. 



\section{Publications}

\section{Articles}

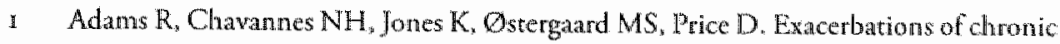
obstructive pulmonary disease - A patients" perspective. Prim Care Rerp/2005; in ptess.

2. Chavannes NH, Huibers MJH, Schermer TRJ, Hendriks A, Weel wan C, Wouters EFM, Schayck wan CP. Associations of depressive symproms with gender, body-mass index and dyspnea in primary care COPD-patients. Fam Praction 2005: Adwance Access July I5.

3 Bosch W wan den, Schermer TR,. Chavannes NH. Urilicy of pulse-oximetry in gencal practice. Huisarts Wiet $2005 ; 48(9): 467-9$.

4 Orbon K, Schermer T, Gulden J van der, Chavannes N, Schayck O van. Weel C van " Folgering H. Employment status and quality of life in patients with chronic

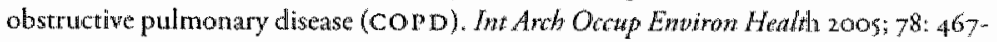
474 .

5 Schermer "TRJ, Folgering HTM, Jacobs JE, Chavannes NH, Hartman J, Weel C van, Botrema BJAM. Spiromeric investigation in patients with COPD in general practices and lungfunction laboratories just as reliable, but not interchangable. Ned Tijdschr $G$ en $2004: 148(46) ; 2280-5$.

6 Chavannes $N$, Schermer T, Akkermans $\mathbb{R}$, Jacols I, Graaf $G$ vain de, Bollen $R$, Schaych $O$ van, Bottema B. Impact of spirometry on GP' diagnostic differentiation and decision-making. Resp Med 2004; 98: 1124-1130.

7 ATS/ERS TASK FORCE REPORT: BR Celli, W MacNee, A Agusti, A Anzueto B Berg, AS Buist, PMA Calyerley, N Chavannes, T Dillad, B Faty, A Fein, J Heflnar, SLarcau, P Meck, Hartinez, MeNicholas J Muris, E Austegard, R Pauwds. S Remard, A Rossi, N Siafakas, B Tiep, J Vestbo, E Wourers, and R ZuWallack. Standards for the diagnosis and trearment of patients with COPD: summary of the ATS/ERS position paper. Eur Respir/2004: 23:932-946.

8. Chavannes N. Joining forces with primary care: ATs/ Eus guidelines on COPD. Frontien Mag 2004; I: 6-7

9 Schermer ITR. Hendriks AJC, Chavannes NH, Dekhuijzen PNR, Wourers EFM, Hoogen $H$ van den, Schayck CP van, Weel C wan. Probability and decerminants of islapse afrer discontinuarion of inhaled corricosteroids in parients with COPD crated in general practice. Prim Care Resp / $2004 ; 13: 48-55$.

10 Chavannes $\mathrm{N}$. The necessity for spirometry in the primary care management of $\mathrm{CO} D \mathrm{D}$. Prim Care Resp/2004: 13: 11-14.

n Chavanes N. Reply ro: Spirometry and peak expiratory How in the primary care management of COPD by Parick Whire. Prim Care Resp/zoo4; 13: 9-10.

12 Chavanes N, Schayck CP van. Diagnostiek COP D in de huisarrspraterigle: pronctief aan de slag! DLMS 2003; 44: 7 8. 
13 Chavannes $N$, Schermer TRJ, on behallif of the COOPT Study Group. Long-rerm inhaled steroid response testing should be done in heterogeneous copD-population lletter]. Tharaze 2003; 58:647.

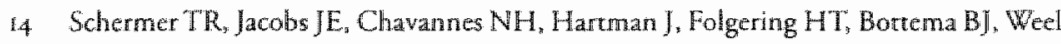
van C. Validity of spiromerric testing in a general practice population of patients with chronic obstructive pulmonary disease (COPD). Thorax 2003:58: 861-86.

15 Chavannes $\mathbb{N}$, Vollenberg R, Schayck C van, Wourers E. Effecten van lichamelijke activiteit bij lichte tot matige COPD. Huisarts $\mathrm{Nu} 2003 ; 32(3): 130-137$.

16 Chavannes $\mathbb{N}$. Pulse oximerry and respiratory disease in primary care [edironial]. Prim Care Resp J 2003; 12(1): 2-3.

17 Schayck van CP, Chavannes NH. Detection of asthma and COPD in primary care. Euer Resp J 2003: 39: 16s-22s.

18 Chavannes. NH, Vollenberg JJH, Schayck wan CP, Wouters EFM. Effects of physical activity in mild to moderate COPD: a systematic review. Br J Gen Prac 2002: 52: 574$57^{8 .}$

19 Vernooy $] H$, Kucukaycan $M$, Jacobs $\rrbracket A_{\text {, Chavanes }} N H$, Buurman WA, Dentener MA, Wouters EF Local and Systemic Inflammation in Patients with Chronic Obscructive Pulmonary Disease: Soluble Tumor Necrosis Factor Receptors Are Increased in Spurtum. Am / Respir Crit Care Med 2002;166: 1218-1224.

20 Chavannes NH. A palliative approach for COPD and heart failure? Eur I Pall Care 2001; 8(6):225-2:27.

21 Wagena EJ, Graaf de L, Chavannes NH, Grootheest van AC, Schayck van Cl? Unrest abour safery of bupropion as an aid to smoking cessation unwarranted. Ned Tijdschr Geneesh 2001;145(31): 1489-1492.

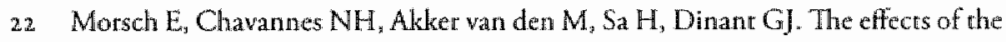
Family Health Program on child heal th in Ceara state, northeastern Brazil. Arch Public Health 2001; 59: 151-165.

23 Wagena E, Zeegers MPA, Huibers MJH, Chawannes NH, Schayck van $O$. Bupropion: A new effective aid in smoking sensation [letrer]. Ned Tijdschr Geneesk 2001; 145: 103-104.

24 Chavannes $\mathrm{NH}$, Schayck van CP. Developments in the trearment of chronic obstructive pulmonary disease (Cornd): The clinical picture. Curr Opin Invest Drugs zooo; $(1): 75-78$

25 Huibers MJH, Chawannes NH, Wagena EI, Schayck van CP. Antidepressants for smoking cessation: a promising new approach?? [editorial]. Eur Resp / 2000; 16: 379380.

26 Schayck wan CP. Chavannes NH. Primary Care Asthma Management in "The Netherlands. Prim Care Resp J 2000; 9(2) Suppl: Siz-Siz.

27 Chavannes $\mathrm{NH}$, Schayck van CP. Quality of life in patients with chronic obstructive pulmonary disease (COPD): Which drugs luelp most? BioDrugs 2000; 13 (2): 127-133.

28 Peters MCE, Geelen JLMC, Hekking JWM, Chavannes NH, Geraedts JPM, Straten van HWM. Reduced glucose consumption in the Curly Tail Mouse does not initiate the parthogenesis leading to spinal neural tube defects. J Nutr 1998; 128: 18:9-1828.

\section{Book Contributions}

I Chavannes NH, Dekhuijzen PNR, Tober FMI. CoPD meer dan FEV: Management. Obstructieve longziekten, module 3. Houten/Diegem zoos; Bohn Stafleu van Loghum. 
2 Chavannes NH, Dekhuijzen PNR, Toben FMJ COPD meer dan FEV, Behandeling. Obstrucrieve longziekrern, module 2. Houten/Diegem 2005: Bohn Stafteu van Loghum.

3. Schermer T, Chavannes NH. Spirometrie. In: Het verschil tussen astma en CoPD. Houten/Diegem 2004; Bohrn Srafleu van Loghum.

4 Chavannes NH, Dekhuijzen PNR, Toben FMJ. COPD meer dan FE⿰氵 $v_{1}$. Diagnostick. Obstructieve longziekren, module 1. Houten/Diegem 2005: Bohn Stafleu van Loghum.

5 Chavannes NH, Schayck wan CP. Epidemiology of asthma and COPD. Chapter I in: Treatment strategies in asthma. Houten/Diegem 1999; Bohn Stafleu van Loghum.

6 Schermer T", Chavannes NH. Spitometrie. In: Bijblijven 1999:15 (9).

\section{Abstracts}

I Chavannes $\mathrm{N}$, Schermer $\mathrm{T}$, Wouters E, Folgering H, Akkermans R, Metsemakers ], Weel $C$ van, Schayck $O$ van. Demographic and clinical determinants of response to $\mathrm{N}$ acetylcysteine versus fluticason in mild to moderate COPD in primary care: The COOPT Study. Presented at ERS 2005.

2 Chavannes N, Schermer T, Wourers Ex Bosch W, Dekduijzen R, Muris , Weel C van, Schayck $\mathrm{O}$ van. Predictive value and utility of oral steroid testing for treatment of COPD in primary care: The COOP'T Study. Presented at ERS zoos.

3 Schermer T, Chavannes $N$, Wouters E, Akkermans R. Dekhuijzen R, Schayck O van, Weel $\mathrm{C}$ wan. Eftectiveness of $\mathrm{N}$-acerylcysteine and Aluticasone propionate in patients with COPD in general pracrice. Presented at ERS 2005.

4 Hamers RL, Bontemps ST, Akker M van den, Souza RG, Penaforte JC, Chavannes NH. Chronic obstuctive pulmonary disease in Brazilian primary care: Diagnostic achievement and case-finding. Trop. Med Int Heath zoos; 10 (2): A5.

5 Chavannes $N$, Vernooy JH, Schermer TR], Jacobs JA, Weel C van, Schayck CP wan, Wouters EF. Patterns of inflammation and the use of reversibility testing in smokerss with airway complaints: the COOPT spunum induction study. Eur Resp J 2003; 22: 69s.

6 Paxayil R, Jones $K$, Chavannes $N_{n}$ Hendriks $A_{*}$ Nonikow D, Price D, Ostergaard M, Molen T van der, Espen L van, Zennaro M. Patterns in patient experience of COPD exacerbations in the UK, Denmark \& Nerherlands - a qualitative study. Fur Resp. I 2003i:2: $67 \mathrm{~s}$.

7 Chavannes $\mathrm{NH}$, Huibers MHH, Schermer TRU, Hendriks A, Wed van C, Wouters EF, Schayck wan CP. Association of depressive symproms with gender in primary care COPD patients: results from the COOPT study. Eur Resp/ $/ 2003 ; 22: 375 \%$

8 Parayil $R$, Jones $K$, Chavannes $N$, Hendriks $A$, Nonikov $D$, price $D$, Ostergaard M, Molen T van der, Espen L varn, Zennaro M. Multi-centre research: The Experience of a UK, Danish \& Durch qualitative study exploring the meaning of COPD \& its exacer* barions to pacients. Eur Resp / 2003; 22:66s.

9 Chavannes N, Schermer T, Akkermans R, Jacobs A, Graaf G van de, Bollen R, Schayck $O$ van, Bottema $B$. Interpretation of spirometry in general practice: partern recogrnition and decision-making. Eur Resp/ 2002; suppl 38: 414s.

Io Schermer $T$, Chavannes $N$, Saris $C$, Akkermans $R$, Schayck $O$ van, Weel $C$ van. Exacerbations and associated health-care costs in paticnts with chronic obstructive pulmonary disease (COPD) in general practice. Results from the COOPT trial. Etor Rexp/ 2002; suppl 38: $398 \mathrm{~s}$.

If Chavannes $\mathrm{NH}_{3}$, Schermer TRJ, Wouters EF Van Weel C, Van Schayck CP. Treatment of COPD in general practice: the COOPT study. Eur Respir/2001; 8 (Suppl 33): 3485 . 



\section{About the author}

Niels Chavannes was born in Apeldoorn, The Netherlands, on the gth of June 1972. He grew up in Soest, where he complered his secondary education at the Griftland College in 1991. Attracted by the hilly surroundings of the south - scarce in Holland - he chose to study Medicine at Maastricht University, a pursuit diversified by racebiking and playing bass-guitar in several bands. During his studies he was gripped by the possibilities of, and global need for primary health care, especially when working in Brazil at the end of rotationships in 1998 . In that same year he graduated and started to work as a researcher at the Department of General Practice, combining $\mathrm{PhD}$-research with the vocational training in General Practice at Maastricht University from 1999 onward. The studies contained in this thesis were prepared and conducted during these years, and allowed for many inspiring opportunities and experiences in the international field of respiratory research and primary care education. In 2003 he became a general practitioner and started living together with his girlfriend in the city of Rotterdam, where many challenges in primary care can still be met. Since 2004 he has been working as a GP at the newbuilt Health Center Zuiderkroon in Rotterdam, an integrated primary health care facility serving a multi-ethnic population. At the same time, he continues working as a researcher and teacher at several COPD-related projects at Maastricht University. In addition, he coordinates research projects on integrated COPD management in the town of Bocholtz, and case-finding strategies in the Amazonian city of Boa Vista, Brazil. He is the Chairman of the Integrated Disease Management section of the ATS/ERS COPD Standards. 